Final Report

FHWA/IN/JTRP-2004/6

\title{
EVALUATION OF SURFACE (TOP DOWN) LONGITUDINAL WHEEL PATH CRACKING
}

\author{
By \\ Terhi K. Pellinen \\ Professor of Civil Engineering \\ School of Civil Engineering \\ Purdue University \\ Geoff Rowe \\ President \\ Abatech, Inc. \\ and \\ Kalapi Biswas \\ Graduate Research Assistant \\ School of Civil Engineering \\ Purdue University \\ Joint Transportation Research Program \\ Project No. C-36-31P \\ File No. 2-11-16 \\ SPR-2788 \\ Conducted in Cooperation with the \\ Indiana Department of Transportation \\ and the U.S. Department of Transportation \\ Federal Highway Administration
}

The contents of this report reflect the views of the authors who are responsible for the facts and accuracy of the data presented herein. The contents do not necessarily reflect the official views or policies of the Indiana Department of Transportation and Federal Highway Administration. This report does not constitute a standard, specification, or regulation.

Purdue University

West Lafayette, Indiana

September 2004 
TECHNICAL REPORT STANDARD TITLE PAGE

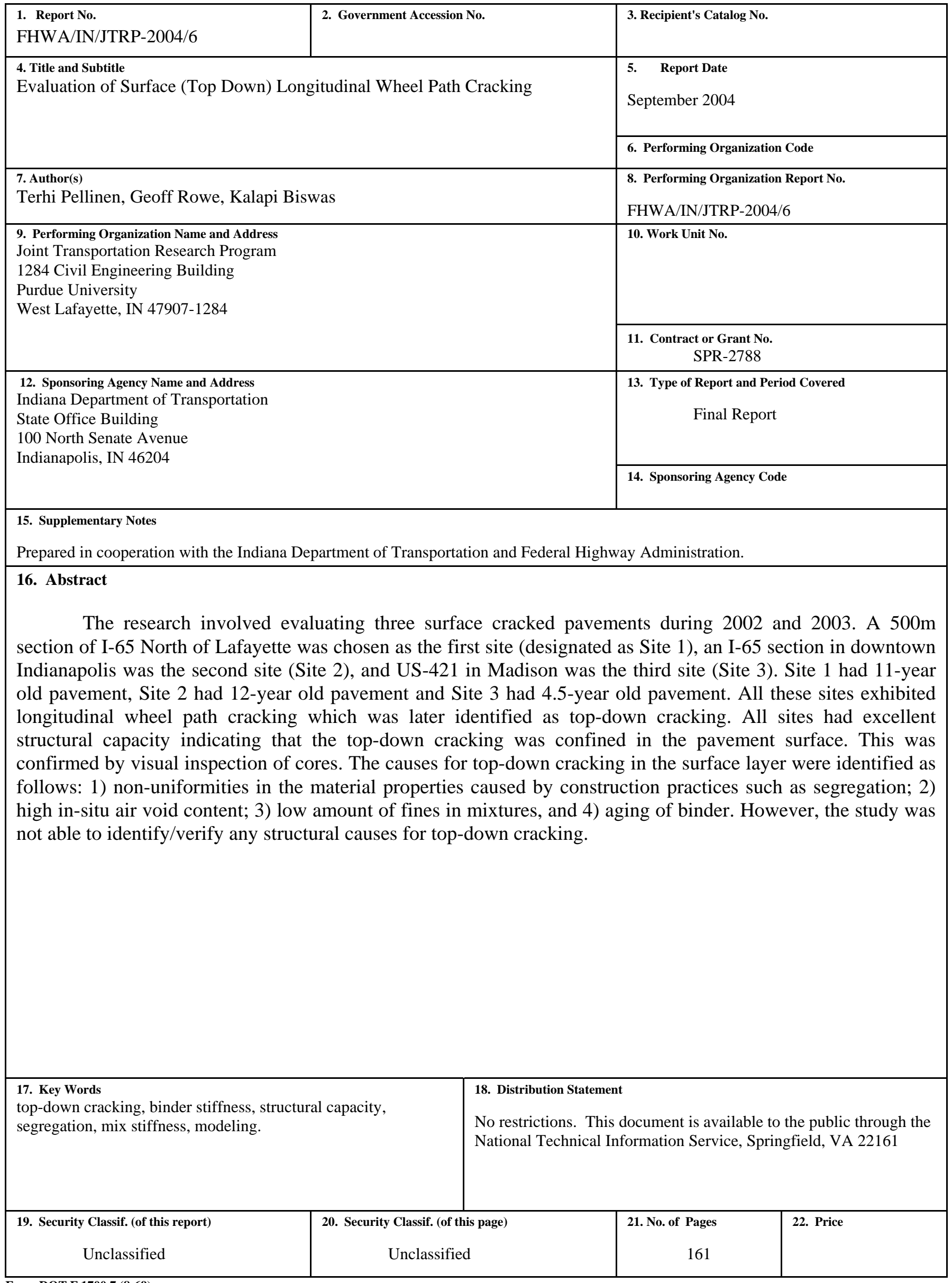

Form DOT F 1700.7 (8-69) 


\section{TECHNICAL Summary}

INDOT Research

Technology Transfer and Project Implementation Information

TRB Subject Code: 24-3 Pavement Distress and Performance

Publication No.: FHWA/IN/JTRP-2004/6, SPR-2788

September 2004

Final Report

\section{Evaluation of Surface (Top-Down) Longitudinal Wheel Path Cracking}

\section{Introduction}

The objective of the study was to evaluate topdown cracked pavements and assess their structural capacity as well as study in-place materials to propose the best identification of distress type, material selection, and rehabilitation methods to be used in Indiana.

Research involved evaluating three surface cracked pavements during 2002 and 2003. A $500 \mathrm{~m}$ section of I-65 North of Lafayette was chosen as the first site (designated as Site 1), an I-65 section in downtown Indianapolis was the second site (Site 2), and

US-421 in Madison was the third site (Site 3). Site 1 had 11 year old pavement, Site 2 had 12 year old pavement and Site 3 had 4.5 year old pavement. All these sites exhibited longitudinal wheel path cracking which was later identified as top-down cracking.

The research was carried out by conducting visual surveys, Falling Weight Deflectometer (FWD) testing, and coring the cracked and non cracked pavement areas. Cores were first inspected and then subjected to a full laboratory-testing program to measure rheology and fracture properties of the binders used in the surface mixtures. Then, the measured material properties were utilized in a Layered Elastic analysis program to investigate stresses and strains in the top of the pavement surface.

\section{Findings}

The cores obtained from cracked areas were examined visually and also using $\mathrm{x}$-ray tomography. The visual inspection and $\mathrm{x}$-ray tomography indicated that the cracks were confined in the thin surface mix and did not penetrate deeper into the pavement in any of the sites. This confirms that the observed surface cracking is a top-down cracking.

Based on the visual survey, none of the sites seem to exhibit load-end segregation. However, this finding was not verified by laboratory testing. The systematical pattern in the longitudinal surface cracking in all sites may indicate some longitudinal mix segregation caused by screed extensions in the paver.

The FWD testing indicated that all sites had excellent structural capacity and computed effective structural numbers $\mathrm{SN}_{\text {eff }}$ were 8.5, 10.2, and 6.1 for Sites 1, 2, and 3, respectively. The thickness of the full depth asphalt pavement was $368 \mathrm{~mm}, 530 \mathrm{~mm}$ and $203 \mathrm{~mm}$ for the sites 1, 2, and 3, respectively. Therefore, at least for Sites 1 and 2 the pavement thickness and structural capacity indicate "perpetual" pavement and, therefore, they will not exhibit bottom-up cracking. Site 3 in Madison is also structurally very strong due to the layer of rubblized concrete underneath the asphalt layers. To sum up, it is not expected that bottom-up cracking develops in these pavements.

Binder testing was done only for the binder extracted from the 1.5-2 mm thick surface mix. The original binder grade for Site 3 was PG 70-22 and the other sites had PG 64-22 binder. Based on Dynamic Shear Rheometer (DSR) testing it was estimated that the high temperature performance grade for Site 1 binder was PG 82, for Site 2 PG 76, and for Site 3 PG 82. Thus, Site 1 had aged three PG grades while Site 2 and 3 had aged two PG grades. Therefore, Site 2 binder was aged least and Site 3 binder was aged relatively the most. Compared to binder properties found in the literature, the binder stiffness data does not seem 
to differ significantly from the "normally" aged binder stiffness values.

The mixture properties were also measured from the thin surface mix layer. The Site 3 had highest air void content average being $10.1 \%$, while Site 1 and 2 had $8.1 \%$ and $7.4 \%$, respectively. It can be speculated that the high air void content in Site 3 has accelerated the binder aging compared to the other sites, although it had the highest binder content of $6.3 \%$ while Site 1 and 2 had $5.4 \%$ and $5.9 \%$, respectively.

All mixtures were fine $9.5 \mathrm{~mm}$ surface mixtures and the amount of fines passing $0.075 \mathrm{~mm}$ sieve was 2.5 to $2.9 \%$ for Sites 1 and 3, while Site 2 had 5.8. The studied mixtures had effective binder volume between 8 to $10 \%$, and voids filled with asphalt ranging from 50 to $55 \%$. Literature suggests that a better mix cracking performance may be obtained by increasing mix density by compaction.
In addition, mixtures with more fines may be more crack resistant than mixtures with low amount of fines.

The crack propagation in all sites was confined to the surface layers. Research suggests that when the thickness of the pavement is above $200 \mathrm{~mm}$ the topdown cracks are not likely to propagate through the entire pavement layers.

Based on ranking of sites, none of them seem to have properties far better than the others. The binder in Site 2 is softest but does not have good low temperature cracking properties. Site 3 hard binder has aged significantly compared to the other sites. The air void content in the mixes seems to point in the direction that the binder aging is accelerated when the air void content exceeds $7.5 \%$. The higher amount of fines in the mix may prevent binder and mix aging as Site 2 properties suggest.

\section{Implementation}

The implementation of this research can be divided into the short, medium and long term goals. The short and medium term implementation issues are related to the INDOT's current construction practices and possible changes in them. The medium and long term implementation goals are related to the pavement design issues and therefore to the future research in the local and possibly in the national level (Federal Highway Administration (FHWA) and National Cooperative Research Program (NHCRP)). The short and medium term local implementation issues include:

- $\quad$ Training of contractor and state personnel to enhance construction and QC/QA work (high priority)

- Development of top-down identification, prevention, and rehabilitation guide based on research findings (high priority)

- Modify current construction specifications to reduce segregation (high priority)

- Modify current pavement design practices (low priority)

- Research of tendency of asphalt mix to segregate (low priority)

A short description of items listed above is presented as follows. Training of personnel must be organized in cooperation with INDOT and Asphalt Pavement Association of Indiana. This way the issues hindering good quality can be identified and hopefully remedied. Issues that are needed to be included in the training are mixture compaction, lay down operations, and prevention of segregation.
A guide to identify top-down cracking and select rehabilitation strategy needs to address the following listed items. Not all of these items can be addressed with great detail and this guide must develop over time to incorporate any future research or empirical findings of pavement performance in Indiana.

- Identification of top-down cracking (visual survey and coring)

- Verification of pavement structural capacity using FWD

- Verification of bonding between layers with coring and with possible laboratory test

- Identification of segregation (visual survey, coring and laboratory measurements)

- Material Selection (stiffer or softer binder/mix compared to the replaced material and existing structure)

- Structural issues (surface layer thickness same as before or thicker?)

- Construction practices (the need for tack coat, type of tack coat, type of rollers such as steel wheel or vibratory)

To implement the needs to modify current construction specifications related to the in-situ density and amount of fines in the mixture, a research plan to establish the relationship between mix design and achievable in-situ mixture density must be developed. Some ideas how the research can be conducted are listed below:

- Use Superpave Gyratory Compactor (SGC) to establish a laboratory compaction curve for standard surface and base mixtures in Indiana. 
Select the standard mixture such that it represents typical aggregates and binder grade used.

- The compaction curve must be developed for different compaction temperatures by each temperature compacting mixture to the refusal density (zero percent air void content if possible).

- The laboratory gyratory compaction must be correlated to the field compaction by using field test strips. Densification using different roller types must be examined at various temperatures. This will establish equivalency of mix densification between field and laboratory compaction.

- As a part of the mix design process, require SGC compaction test for each designed mix to verify the mix compactability. If possible, use gyratory that can measure shear force during the compaction.

- Measure stiffness of the standard mixtures by SST Shear Frequency Sweep Test and axial dynamic modulus test and Indirect Tensile strength of the standard mixtures and correlate this to the JTRP SPR 2644 study findings.

- Correlate standard mixture material properties to pavement performance

- Modify standard mixtures by changing binder stiffness and/or the amount and type (round or crushed) of fines in the mix.

- To verify boundary conditions (i.e., simulation of real life pavement performance) possible Pur-Wheel tests can be performed.

Pavement structure, i.e., layer thicknesses, number of layers, and type of layers (rigid or flexible) all affect pavement performance, in addition to the type of materials used. Literature suggests that differential stiffness differences affect the stress distribution and thus crack formation in the pavements. In this study two sites had rubblized base underneath the flexible pavement. How this contributes to the top-down cracks was not studied. The combined stress distribution in the pavement structure is affected by the environment and type and magnitude of loading, as we know. What we do not know is what is the worst (or best) possible pavement structure to prevent particular pavement distress and how distresses interact with each other.

To implement changes to the current pavement design practices and verify items related to the structural aspects and construction practices in the developed rehabilitation guide a research plan to study shear stresses and friction between tire and pavement must be developed.
Some ideas how the research can be conducted are listed below:

- Construct trial pavement in the INDOT APT pit to study the role of bonding between surface and base layer. The bonding is also related to the friction between the tire and the surface mixture. The high shear stresses that can be developed in the APT by applying high wheel loading without wander provide a means to conducting accelerated pavement surface failure experiments. Testing can be conducted in varying pavement temperatures to separate the cracking and rutting phenomenon. The things related to the bonding of surface layer, the use of tack coat, type of tack coat and compaction are some of the variables.

- In a similar manner, the APT pit can be used to study the role of surface layer thickness for the formation of surface cracks and rutting. Also, the effect of stiff layer (rubberlized concrete) underneath the asphalt layers can be studied.

- This type of research would allow investigation of the issue of using stiff or soft binder in the overlay to replace topdown cracked surface mix (stiffness differentials, layer thickness and rutting versus cracking).

As mentioned above cracks find their way through the least resistance and the coarse portion of segregated mixture typically have high air voids content, low binder content and low amount of fines compared to the job mix formula (Pellinen, 1985). All these properties contribute to the mixture's vulnerability to fracture.

Segregation may be caused by poor mixing or poor lay down of the mix and the degree of segregation is dependent on the mixture's tendency to segregate. The segregation tendency increases when mix has low amount of fines passing $0.075 \mathrm{~mm}$, low binder content, and large aggregate top size (Pellinen, 1985).

The segregation tendency of the mixtures should be considered in the mix design. It would be desirable to develop a quick laboratory method to measure segregation tendency. In the 70's Swedish researchers Hillgren and Sjöblom (1979) developed a method to measure segregation tendency of asphalt mixtures in the field and in the laboratory. Unfortunately testing requires binder extraction and gradation testing of $11 \mathrm{~kg}$ of asphalt mix which makes it less practical for frequent use. The method is based on dropping asphalt mix through a funnel and 
measuring binder content and gradation of fine and coarse portion of segregated mixture.

The segregation caused by paving operations and paver can be prevented to some extent by first understanding when the mix is segregated and then adjusting paver to reduce the segregation. Mixture transfer vehicles have been successful in reducing the load-end segregation but "machine" segregation caused by the paver is still not well understood. Field studies have shown that a thermal camera is an effective way to reveal the segregated spots by measuring temperature differentials in the hot mix asphalt.

\section{Contacts}

For more information:

Prof. Terhi K. Pellinen

Principal Investigator

School of Civil Engineering

Purdue University

West Lafayette IN 47907

Phone: (765) 496-2513

Fax: (765) 496-1364

E-mail: pellinen@ecn.purdue.edu

\section{Indiana Department of Transportation}

Division of Research

1205 Montgomery Street

P.O. Box 2279

West Lafayette, IN 47906

Phone: (765) 463-1521

Fax: (765) 497-1665

\section{Purdue University}

Joint Transportation Research Program

School of Civil Engineering

West Lafayette, IN 47907-1284

Phone: (765) 494-9310

Fax: (765) 496-7996 


\section{AKNOWLEDGEMENTS}

The authors wish to acknowledge Ms. Haleh Azari at Federal Highway Turner Fairbank Research Center for her help in scanning the cracked cores using X-ray tomography. The authors also wish to acknowledge the computation work conducted by Mr. Mark Sharrock for the development of the routines and software used to produce these results and Dr. Ayesha Shah for the laboratory testing conducted at the North Central Superpave Center and Dr. Khaled Galal at Indiana Department of Transportation, Research Division. Also, the Study Advisory Committee members, Mr. Lee Gallivan, Federal Highway Administration, Mr. David Andrewski, Indiana Department of Transportation, Materials and Tests, Mr. Gerry Huber, Heritage Research Group, and Dr. Khaled Galal, Indiana Department of Transportation, Research Division for their valuable advice during the course of the research. 


\section{TABLE OF CONTENTS}

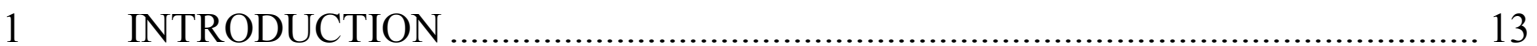

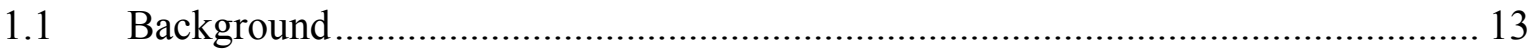

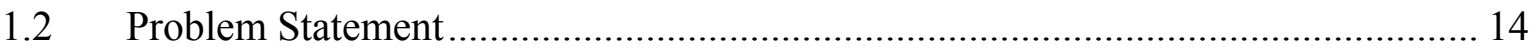

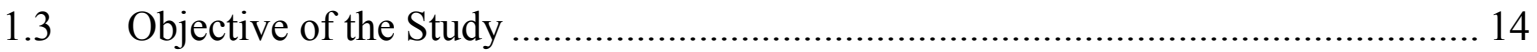

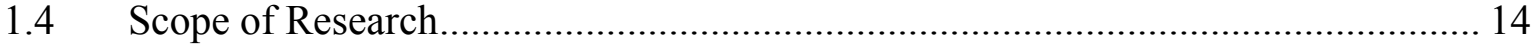

2 LITERATURE REVIEW OF TOP-DOWN CRACKING ................................... 16

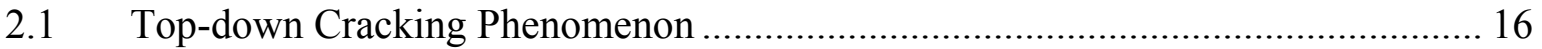

2.2 Pavement Loading and Tire Effects............................................................ 17

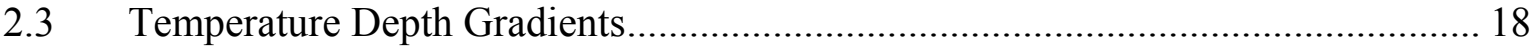

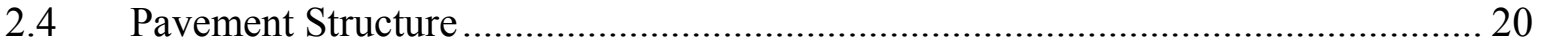

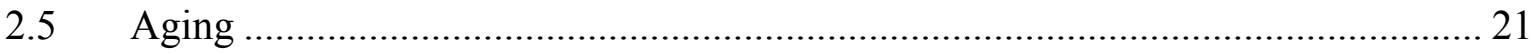

2.6 Mix Composition and Raw Materials ............................................................ 21

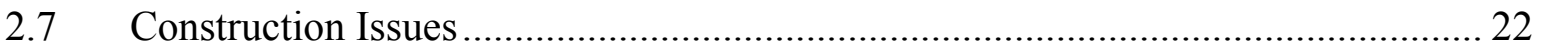

3 COLLECTION AND ANALYSIS OF SITE DATA …....................................... 24

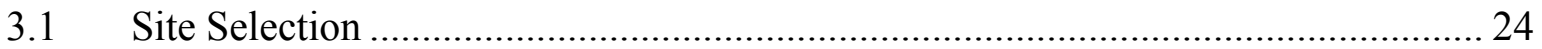

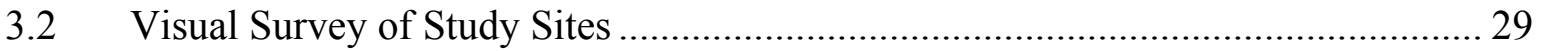

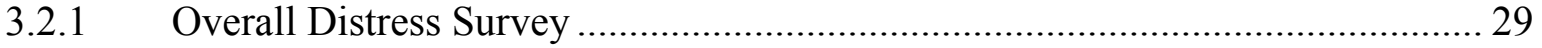

3.2.2 Location of Longitudinal Surface Cracks.................................................... 33

3.3 Distress Data Collection from INDOT PMS .................................................. 38 
3.4 Falling Weight Deflectometer (FWD) Testing ........................................... 39

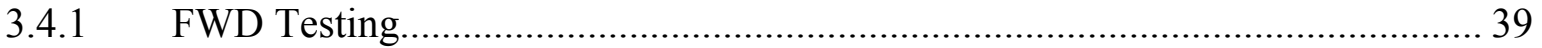

3.4.2 Back-calculation of Stiffness Moduli ......................................................... 44

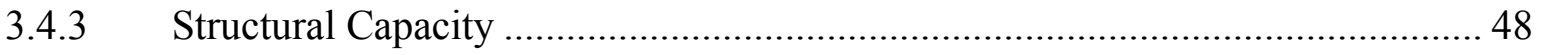

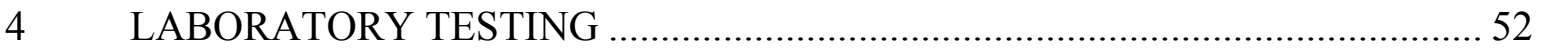

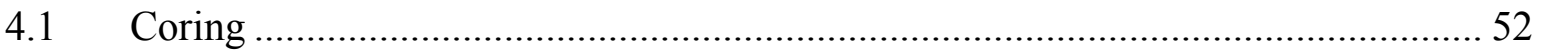

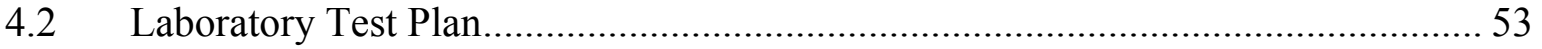

4.3 Measured Layer Thicknesses.......................................................................... 55

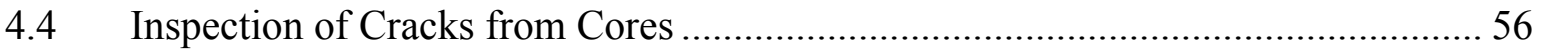

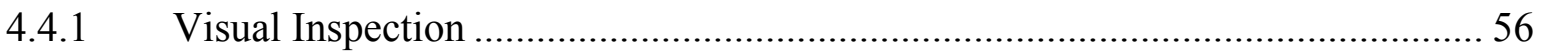

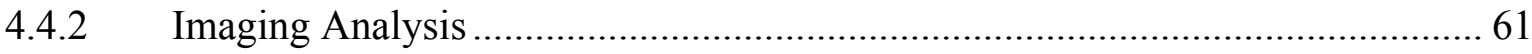

4.5 Test Results for Conventional Asphalt Binder Properties ................................... 64

4.6 Test Results for Asphalt Mixture Composition ................................................ 65

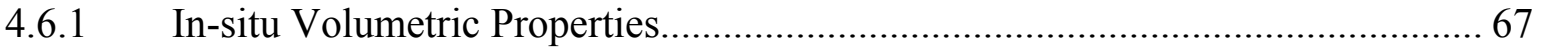

5 ANALYSIS OF RHEOLOGICAL AND MECHANICAL TEST DATA .............. 68

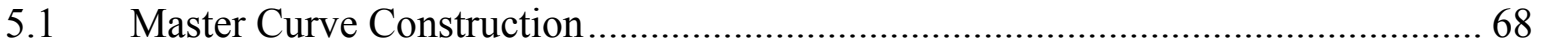

5.2 Asphalt Binder Testing and Analysis ............................................................ 69

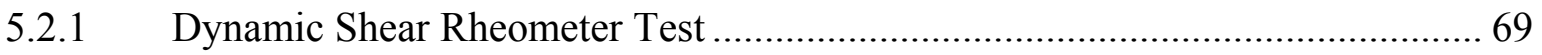

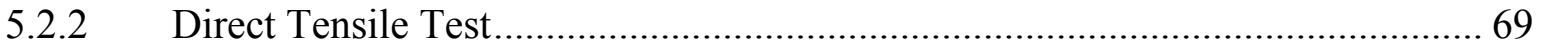

5.2.3 Determination of Critical Cracking Temperature(CCT) .............................. 76

5.2.4 Combined Binder Master Curves ................................................................ 78 


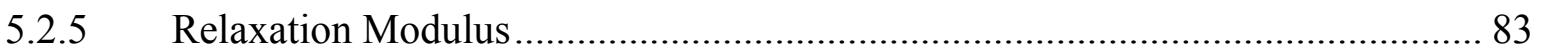

5.3 Asphalt Mixture Testing and Analysis ................................................................. 84

5.3.1 SST Shear Frequency Sweep Test .............................................................. 84

5.3.2 Creep Compliance $\mathrm{D}(\mathrm{t})$ and Indirect Tensile Strength Tests.............................. 85

6 VISCO-ELASTIC 3-D FINITE ELEMENT MODELING ……………………..... 90

6.1 Development of Material Models for FE Analysis................................................. 91

6.1.1 Base Binder Model .................................................................................... 91

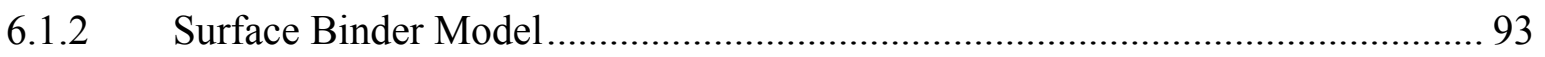

6.1.3 Selected Mix Stiffness Approach ………………........................................ 95

6.1.4 Visco-elastic Model Development for FE Analysis ............................................. 97

6.2 Mesh Design and Gaussian Quadrature................................................................ 98

6.2.1 Pavement Depths at Gauss Points............................................................... 98

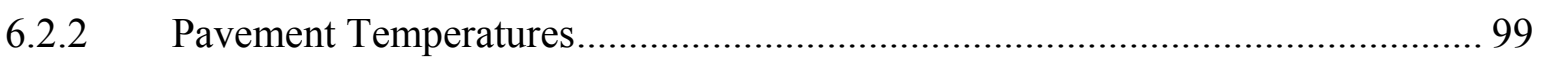

6.2.3 Loading Time/ Frequency ............................................................................... 104

6.3 Wheel Load Modeling …………………………….................................... 105

6.4 Pavement Modeling ……………………………......................................... 107

6.5 Elastic Layered Analysis System................................................................... 108

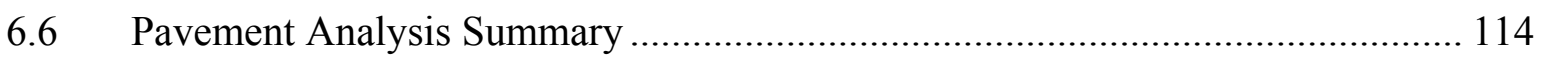

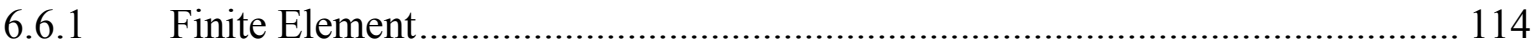

6.6.2 Elastic Layer Analysis .......................................................................... 115

7 SUMMARY, CONCLUSIONS AND RECOMMENDATIONS ......................... 117 


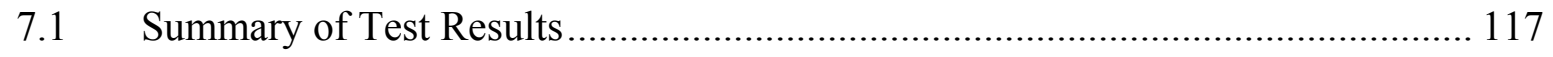

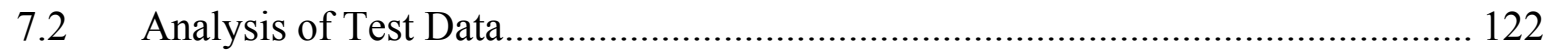

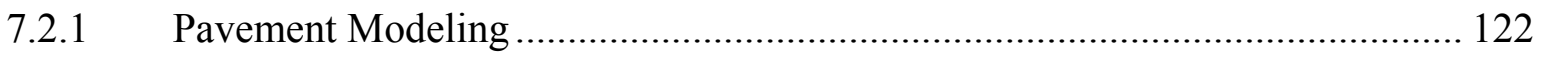

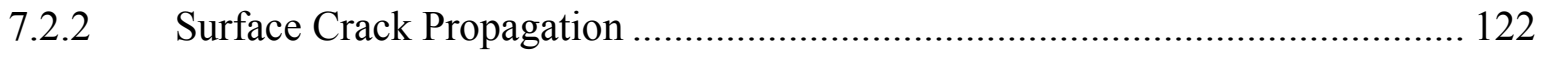

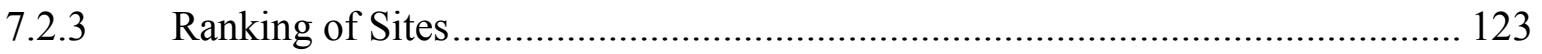

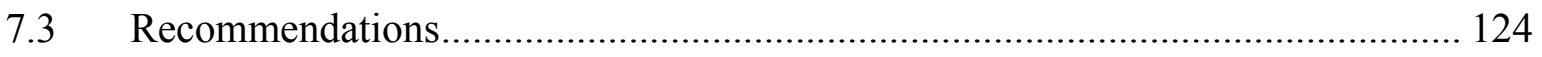

7.3.1 Prevention of Top-down Cracking …................................................. 124

7.3.2 Rehabilitation of Top-down Cracked Pavements ....................................... 127

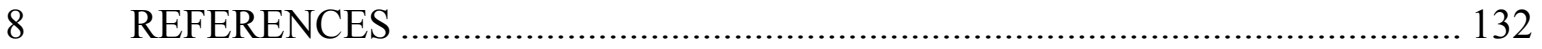




\section{LIST OF TABLES}

Table 1: Design thicknesses for the study sites ........................................................ 26

Table 2: Report of distress data of study sites ..................................................... 34

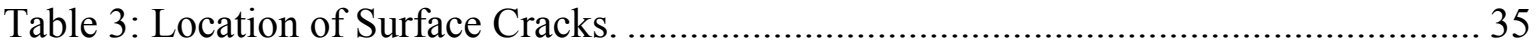

Table 4: Pavement Condition Parameters........................................................................ 39

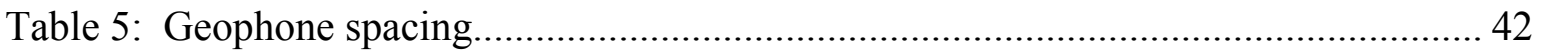

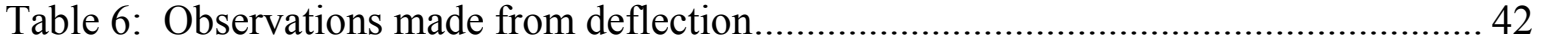

Table 7: Statistical Analysis of FWD data................................................................ 47

Table 8: Air and pavement temperatures for FWD back-calculation.............................. 48

Table 9: $\mathrm{SN}_{\text {eff }}$ based on assigned layer coefficient values............................................ 49

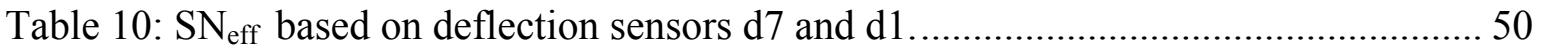

Table 11: Average Effective Structural Number and traffic carrying capacity................. 51

Table 12: Measured parameters and test procedures ............................................... 54

Table 13: Measured layer thicknesses. ................................................................... 55

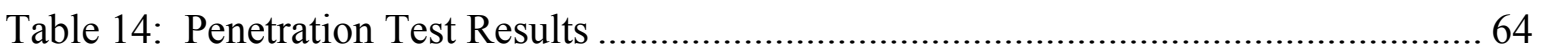

Table 15: ASTM requirements for penetration graded asphalt cements ......................... 64

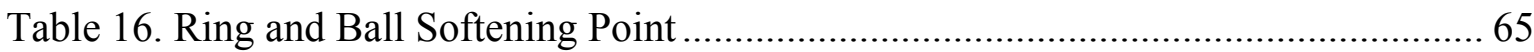

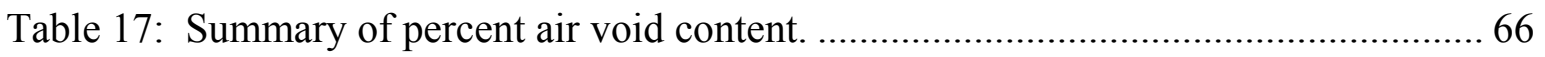

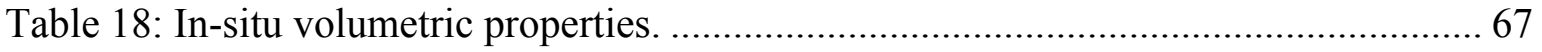

Table 19. Typical test report generated by eVDTT software ...................................... 70

Table 20. Measured failure stress and strain from DTT test. ...................................... 71 
Table 21. Summary of Estimated Critical Cracking Temperatures for Site 1 to 3

Table 22: Analysis parameters using CAM model .................................................... 83

Table 23: Summary of Indirect Tensile Strength Test Results.................................... 89

Table 24: Parameters for CA model for base binder ................................................. 92

Table 25: Parameters for CA model for surface binder.............................................. 95

Table 26: Pavement Depths corresponding to Gauss Points for FE analysis ................... 99

Table 27: Maximum and Minimum pavement temperature-depth values...................... 102

Table 28: Temperature at gauss points for FE analysis ............................................ 104

Table 29: Magnitude of octohedral shear strains $(\mu \varepsilon)$ for each site/condition................ 115

Table 30. Summary of Material Properties and Pavement Performance........................ 118

Table 31: Crack depth \% of layer thickness......................................................... 122

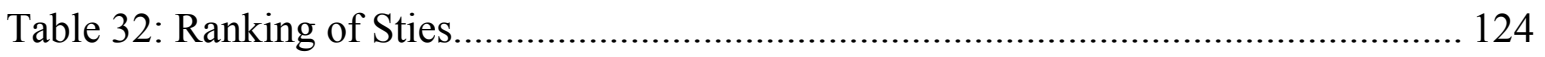




\section{LIST OF FIGURES}

Figure 1: Surface cracked major interstate highway (I-65 North) in Indiana................... 13

Figure 2: Flow Chart of Research Approach and Literature Review ............................ 15

Figure 3: Map of Indiana with selected study sites .................................................. 27

Figure 4: SITE 1 I-65 North of Lafayette ............................................................... 27

Figure 5: SITE 2 I-65 Near Indianapolis ............................................................ 28

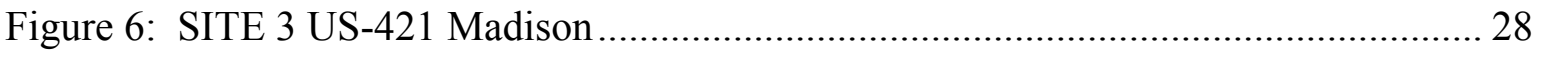

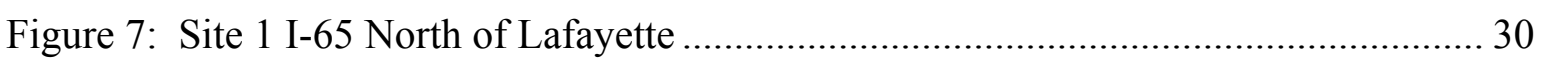

Figure 8: Site 2 I-65 near Indianapolis ............................................................... 31

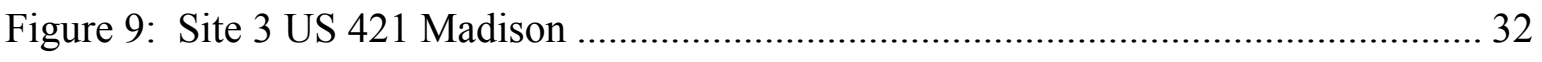

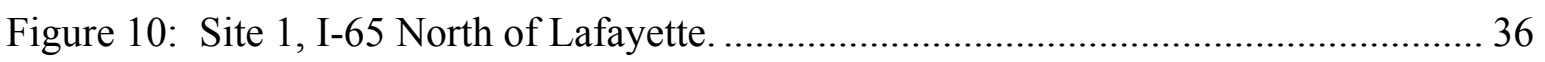

Figure 11: Site 2, I-65 Loop and Site 3, US-421 Madison........................................... 37

Figure 12: Schematic of standard loading configuration and deflection basin................. 40

Figure 13: FWD testing on Site 1 (I-65 North of Lafayette)....................................... 41

Figure 14: Illustration of the locations for FWD measurements ................................. 41

Figure 15: Inspection of Deflection Profile, Site 1 I-65 North ...................................... 43

Figure 16: Inspection of Deflection Profile, Site 2 I-65 Loop...................................... 43

Figure 17: Inspection of Deflection Profile, Site 3 US 421 Madison.............................. 44

Figure 18: Definition of Rigid Half-Space and Subgrade Stiffness Model....................... 45

Figure 19: Example of fitted and measured FWD bowls, Site 3 US-421 Madison........... 46

Figure 20: Coring locations in the pavement, Site 1................................................ 52 
Figure 21: Laboratory testing plan for cores

Figure 22: Surface cracked cores obtained from the studied pavement sites. 57

Figure 23: Inspection of Cracks, Site 1, I-65 North.................................................. 58

Figure 24: Inspection of Cracks, Site 2, I-65 Loop. ............................................... 59

Figure 25: Inspection of Cracks, Site 3, US-421 Madison. ............................................. 60

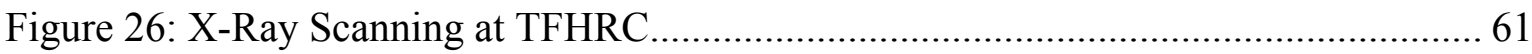

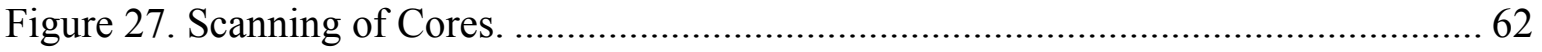

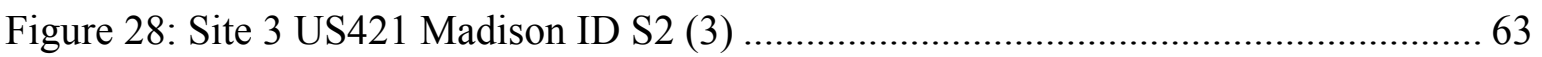

Figure 29. Determination of the relaxation modulus from the DTT. .............................. 73

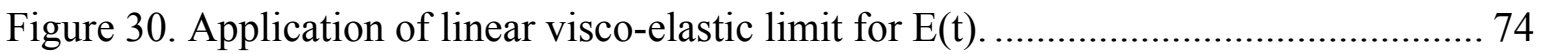

Figure 31 . Isotherms of $\mathrm{E}(\mathrm{t})$ developed from the DTT............................................... 75

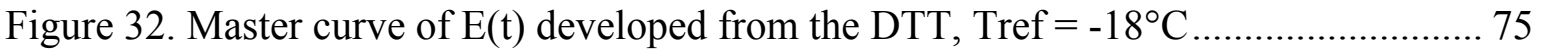

Figure 33. Linearized Arrhenius shift factors developed from the DTT.......................... 76

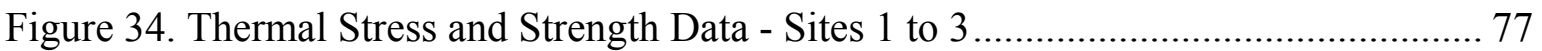

Figure 35: Master curve for shear complex modulus $\left|\mathrm{G}^{*}\right|$, Site1................................. 79

Figure 36: Master curve for shear complex modulus $\left|\mathrm{G}^{*}\right|$, Site2 ................................. 80

Figure 37: Master curve for shear complex modulus $\left|\mathrm{G}^{*}\right|$, Site 3. ................................. 81

Figure 38: Comparison of binder shear stiffness $\left|\mathrm{G}^{*}\right|$ master curves. ............................. 82

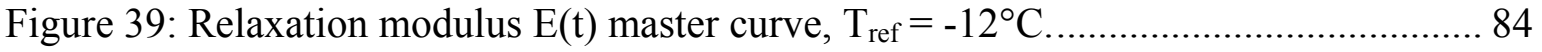

Figure 40: Master curves for Site 1 I-65 North of Lafayette ......................................... 86

Figure 41: Master curves for Site 2 I-65 Near Indianapolis ....................................... 87 
Figure 42: Master curves for Site 3 US 421 Madison ............................................ 88

Figure 43: Summary of SST mix shear stiffness master curves.................................... 89

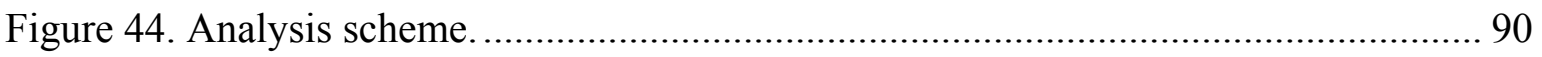

Figure 45: CA fit for binder $\left|\mathrm{G}^{*}\right|$ and phase angle for all site for base binder.................. 92

Figure 46: C-A fit for $\mathrm{G}^{*}$ and phase angle for Site 1 surface binder............................. 93

Figure 47: C-A fit for $\mathrm{G}^{*}$ and phase angle for Site 2 surface binder............................. 94

Figure 48: CA fit for binder $\left|\mathrm{G}^{*}\right|$ and phase angle for Site 3 surface binder. ................... 94

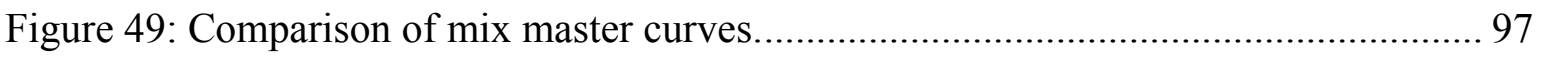

Figure 50: Pavement Representation for Site 1 I-65 North ..................................... 100

Figure 51: Site 1 Annual temperature-depth variation ............................................. 103

Figure 52: Mesh used to represent complex wheel loading on 3-D analysis. ................ 106

Figure 53: Displacements for site 1 using existing FE Code....................................... 108

Figure 54: Representation of wheel load in elastic layer analysis .............................. 109

Figure 55: Relative magnitude of loads on each contact patch, MN ............................ 110

Figure 56: Variation of octahedral shear strain across transverse profile of pavement

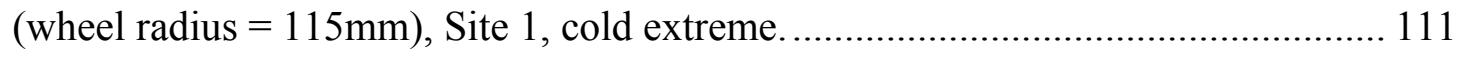

Figure 57: Variation of octahedral shear strain across transverse profile of pavement

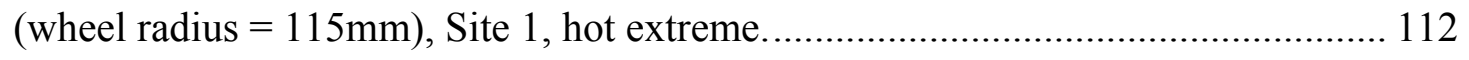

Figure 58: Variation of octahedral shear strain across transverse profile of pavement

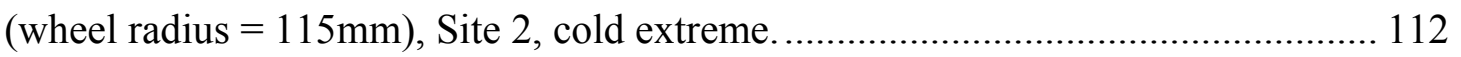

Figure 59: Variation of octahedral shear strain across transverse profile of pavement 


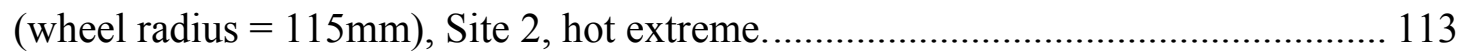

Figure 60: Variation of octahedral shear strain across transverse profile of pavement

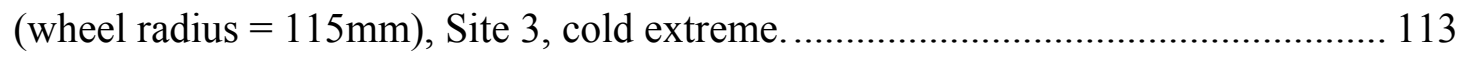

Figure 61: Variation of octahedral shear strain across transverse profile of pavement

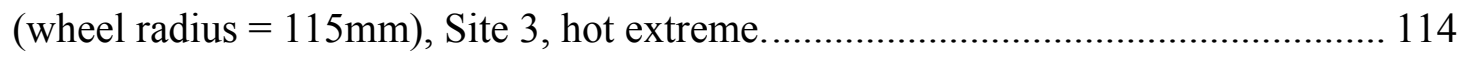

Figure 62: Measured crack depth as function of asphalt layer thickness. ..................... 123 


\section{INTRODUCTION}

\subsection{Background}

Surface-initiated longitudinal wheel path cracking in asphalt pavements, Figure 1, has been reported as a widespread mode of failure in asphalt concrete pavements. It is a phenomenon that has recently attracted a large amount of interest and very few theories have been presented so far that fully explain the phenomenon of the top-down cracking mechanism. Studies performed by various researchers have shown that the existing design and evaluation methods that use average conditions are inadequate for predicting this type of surface cracking. The mechanisms controlling surface cracking are related to the fracture properties of the asphalt mixture loaded by traffic and climate. Work in recent years has suggested several theories for understanding these mechanisms. However, additional studies of in-situ pavements are needed to develop a complete understanding of the topdown cracking phenomenon to develop better rehabilitation guides for these pavements.

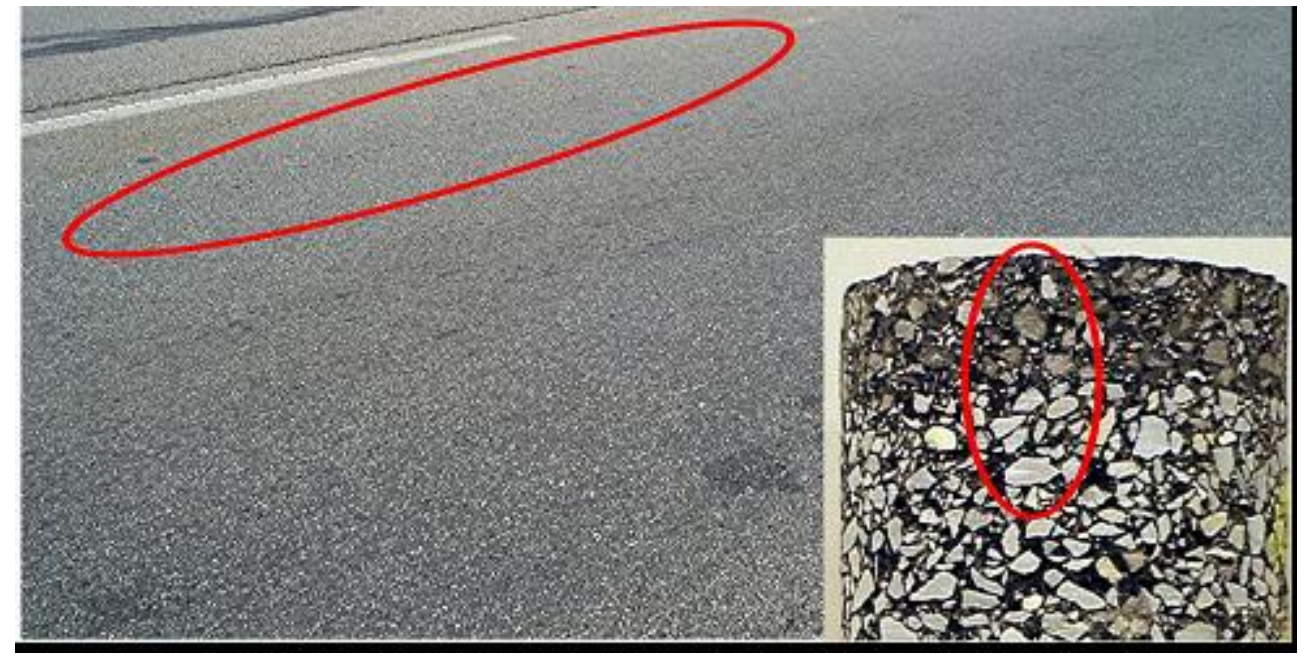

Figure 1: Surface cracked major interstate highway (I-65 North) in Indiana. 


\subsection{Problem Statement}

The maintenance need of cracked highway structures has relied upon bottom-up mechanistic design models for asphalt pavements. A badly cracked pavement will normally require a major maintenance program involving the removal and reconstruction of the highway. However, the repair of top-down cracked pavements can generally be confined to the replacement of the upper portion of the pavement structure with new materials. The correct identification of the type of cracking that is occurring in pavements will consequently make a significant impact upon the cost of rehabilitation of pavement sections. In addition, the selection of materials for the top-down cracked pavement is likely to be significantly different from those considered for deep, thick asphalt pavement sections.

\subsection{Objective of the Study}

The objective of the study was to evaluate top-down cracked pavements and assess their structural capacity as well as study in-place materials to propose the best identification of distress type, material selection, and rehabilitation methods to be used in Indiana.

\subsection{Scope of Research}

This research was primarily concerned with the formulation of a preliminary rehabilitation plan for top-down surface cracked pavements. The scope of the research was to identify sites in Indiana that exhibit surface top-down cracking and evaluate their condition, see Figure 2. From these sites, three particular sites exhibiting the top-down surface cracking distress on longitudinal wheel path were selected for further evaluation in the study. The evaluation included the structural response of the pavement section and analysis of material properties. Based on this evaluation a preliminary rehabilitation plan 
for top-down surface cracked pavements was formulated. Based on findings of this research, a more comprehensive study plan will be developed if needed.

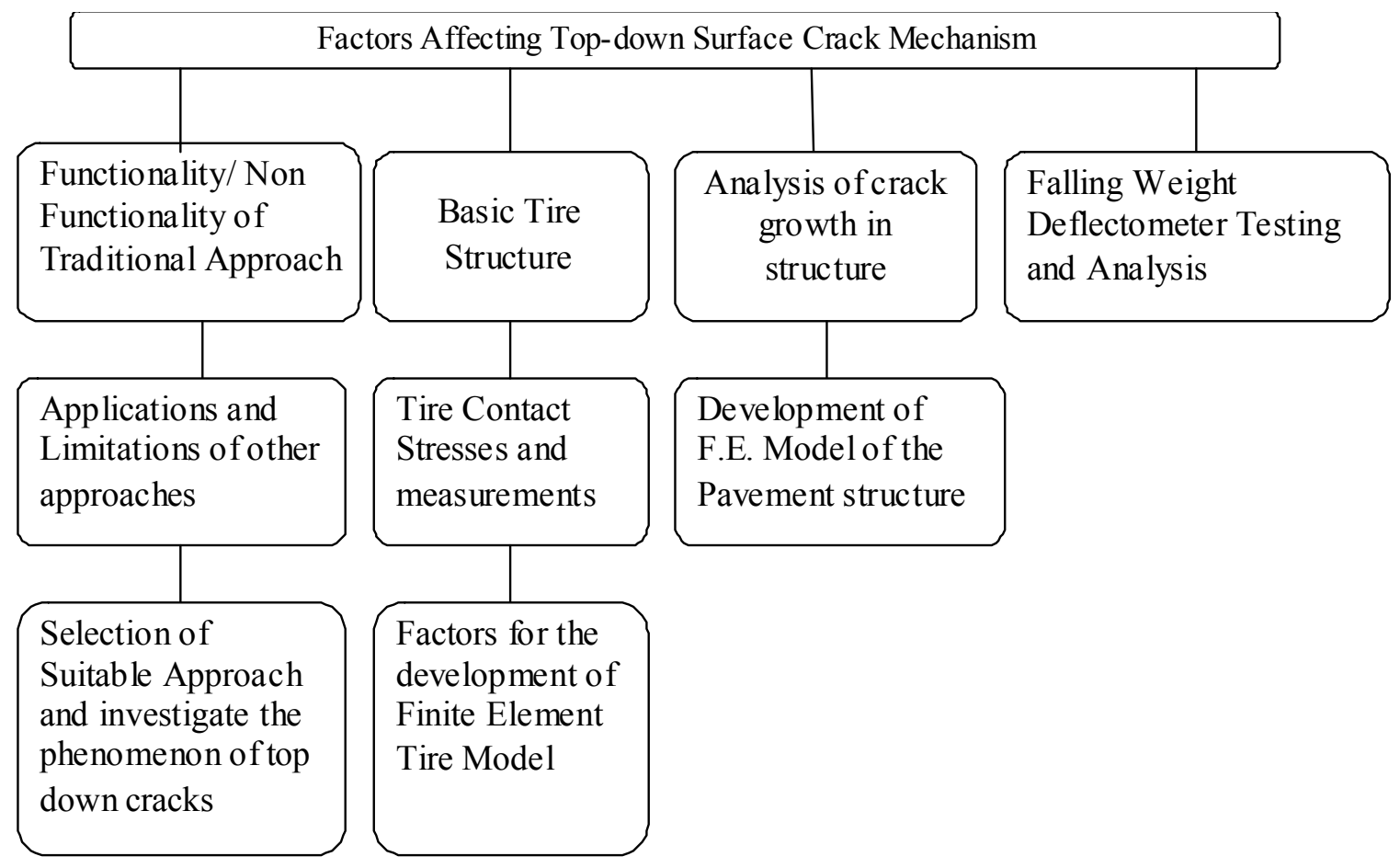

Figure 2: Flow Chart of Research Approach and Literature Review 


\section{LITERATURE REVIEW OF TOP-DOWN CRACKING}

Mechanistic pavement design has historically relied upon engineering assumptions that include the use of a wheel load modeled by a uniformly loaded contact patch (or multiple patches) and a single modulus value assigned to an asphaltic layer in pavement design (Brown \& Brunton, 1985; Shell International Petroleum Company, 1978). These assumptions are considered reasonable when determining stresses and strains at the underside of the pavement layers away from the loading points. Therefore, the current mechanistic-empirical pavement methods are based on the tensile strains at the bottom of asphalt layers to prevent bottom-up fatigue cracking and compressive strains at the top of the subgrade to prevent subgrade rutting. However, when trying to determine the pavement response close to the wheel loads this type of analysis will be incapable of capturing the effects of temperature depth gradients within the pavement structure and the effect of complex tire-pavement interactions. The analysis of these last two aspects is considered to be a key component to the understanding of the surface cracking phenomena similar to the surface rutting mechanisms in the asphalt pavements.

However, there are different views among researchers whether the surface cracking phenomena is caused only by the pavement surface stresses, as discussed above, or whether the pavement structure plays some role in the top-down cracking formation. Nevertheless, items that have been associated to the surface cracking phenomena include: 1) pavement tire loading such as load magnitude and tire type effects; 2) pavement temperature and temperature gradients; 3) asphalt binder and mix aging; 4) pavement structure; 5) mix properties and raw materials used; and 6) issues related to the construction such as segregation of mix.

\subsection{Top-down Cracking Phenomenon}

Top-down cracking in asphalt pavements initiates from the top and propagate downwards through the asphalt concrete layer over time. Svasidisant, Schorsch and Baladi 
(2002) have defined three categorizers for the top-down cracking. In the first stage single short longitudinal cracks appear just outside the wheel path in the pavement surface. Over time the cracking reaches a second stage where the short longitudinal cracks grow longer and sister cracks develop parallel to and within 0.3 to 1.0 meters from the original cracks. At the third stage the parallel longitudinal cracks are connected via short transverse cracks.

Also, Myers, Roque and Ruth (1998) report the location of surface cracks being just outside the wheel path and the cracks penetrate to depths ranging from just under pavement surface to the entire depth of asphalt layer.

The Federal Highway Administration (FHWA) Accelerated Loading Facility (ALF) study (Stuart, Mogawer \& Romero, 2001) for bottom-up fatigue cracking showed that the transverse bottom-up cracking started in the wheel path area. Longitudinal top-down cracks occurred at the outer edges of the wheel paths where the surface of the pavement has a high curvature. Also fatigue cracks were smaller at $28^{\circ} \mathrm{C}$ than at 19 and $10^{\circ} \mathrm{C}$, indicating how crack propagation changes with temperature.

The time interval for the cracks to appear seems to be very versatile ranging from one year to five years. The study by Svasidisant et al. (2002) shows that surface cracks had propagated through all asphalt layers in a 15 year old pavement with rubblized base. In pavements with the same base structure but only 9 to 10 years old, surface cracks had propagated $100 \%$ through the surface layers but only about $50 \%$ and $20 \%$ through the intermediate and base layers, respectively.

\subsection{Pavement Loading and Tire Effects}

For the analysis of surface cracking, it is believed that lateral stresses initiate cracking at the pavement surface which somehow propagates downwards. These cracks are neither of the traditional fatigue nor reflective nature. Hugo and Kennedy (1985) attributed cracks to the presence of horizontal shear stresses induced on the pavement surface. Analytical work by Kunst (1990) illustrated how inward radial horizontal stresses could lead to tension at the edges of circular load. 
Jacobs (1995) described the occurrence of maximum tensile stresses at the surface of the pavement through analytical evaluation and predicted tensile stresses at the edge of a truck tire on the pavement surface, which were sufficient to cause fracture. The tensile stresses were found to dissipate rapidly with increasing depth; i.e., they existed in the top $10 \mathrm{~mm}$ of the asphalt layer. Tensile stresses were generated at the edge of tire load because measurements were obtained from a bias ply truck tire.

Myers (2000) stated that longitudinal surface cracking appears to be initiated by significant tensile stresses (Mode I tensile failure) that are induced under radial truck tires. Thermal stresses contribute to the initiation mechanism as a secondary factor.

Research stated that cracks advance only in critical conditions. The mechanism of crack development is highly dependent of load spectra (magnitude and position) and differential pavement temperature gradients and pavement structure. Tensile stresses were found to be more significant in thicker and stiffer asphalt concrete pavements. Therefore the mill and fill rehabilitation technique may be more suitable to prevent surface cracking than overlay. However, use of a linear elastic layer analysis did not allow for analysis of crack growth or discontinuities in the pavement.

Myers (2000) also explained that the tire structure has significant influence on contact stresses. The stress state induced by radial or wide base radial tires were determined to be potentially more detrimental to pavement surface than the stress state induced by bias ply tires.

There are distinct differences in the fabrication of radial and bias-ply tires. In biasply tires, the air container is made from crisscrossing layers of rubberized fabric and in radial tires it is formed by radially running plies of rubberized cord or steel cord on commercial vehicle tires.

\subsection{Temperature Depth Gradients}

Temperature effects in asphaltic materials have very significant effects on the stiffness of the asphalt layers. The pavement structure will experience a wide range of 
temperatures as a function of the daily and annual variation of temperature/climate. Climatic effects models can be used to predict the in-situ pavement temperatures. These models have been calibrated against real pavements and can be considered reasonably accurate.

In work conducted by Rowe, Sauber, Fee and Soliman (2001) it has been shown that by using layered elastic analysis and a uniform distributed load it is possible to compute significant tensile stress at the surface of the pavement adjacent to the wheel loading when temperature depth gradients are considered. Consequently, the use of proper temperaturedepth information is also considered of prime importance as the correct definition of tire loading.

A paper by Svasidisant et al. (2002) reports $30^{\circ} \mathrm{C}$ diurnal temperature difference between the asphalt surface and base course during daytime and $10^{\circ} \mathrm{C}$ temperature difference during nighttime. These temperature differences cause differential stiffness values in the asphalt pavement.

Schorsch et al. (2001) report that negative temperature differences which are consistent of evening and nighttime temperatures produce the highest surface tensile stresses in the pavement. They also recommend that to prevent the effects of nighttime temperatures, the asphalt base course should be designed at higher stiffness than the asphalt surface course.

Usually it is expected for bottom-up cracking that thin pavements $(<150 \mathrm{~mm})$ are in strain control thus requiring softer binder and mix to prevent fatigue, and thick pavements $(>150 \mathrm{~mm})$ are in stress control requiring stiffer binder and mix to prevent cracking. However, the FHWA-ALF study (Stuart et al. 2001) concluded that mixtures were most of the time in stress control regardless of the depth of the pavement structure and most of the cracking happened in the intermediate $19^{\circ} \mathrm{C}$ temperature and not in $28^{\circ}$ or $10^{\circ} \mathrm{C}$. Also, the model of loading changed from strain to stress for $100 \mathrm{~mm}$ pavement with a change in temperature from 28 to $19^{\circ} \mathrm{C}$. 


\subsection{Pavement Structure}

Structural issues affecting pavement age are more controversial. The study done by Matsuno and Nishizawa (1991) concluded that pavement cross section had little effect on high tensile strains that developed to the pavement surface due to the soft asphalt mix. They attributed to the top-down cracking caused by the mix properties at pavement surface. They concluded that in one to five year old pavements high tensile strains in hot pavement surface were causing cracking because at shadowy areas the cracking was absent. Also, Myers et al. (1998) have concluded that the pavement structure had little to do with the surface tensile stresses initiation, and surface cracking was caused by high tensile stresses generated at pavement surface by the radial truck tires. However, Myers (2000) concludes the pavement structure affects crack propagation.

In a study by Uhlmeyer et al (2000) three to eight year old pavements which were more than $160 \mathrm{~mm}$ (6.3 in) thick exhibited top-down cracking in and around the wheel paths. They concluded that the pavement thickness has an effect on the surface cracking initiation which contradicts the previous findings.

Svasidisant et al. (2002) studied asphalt overlays on top of rubblized concrete slabs. They concluded that differential stiffness differences in the asphalt pavement surface and base layers could result in significant tensile stresses at the pavement surface. The magnitude of the surface tensile stresses increases as:

- Ratio of asphalt surface course to the base course moduli increases

- Base layer moduli increases such as stabilized or rubblized base

- Thickness of the asphalt layer increases in pavements with conventional aggregate base

They also found that the quality of the rubblization process has a direct impact on the modulus of the rubblized layer which can vary from 200 to 13,000 MPa. The mechanistic analysis results also suggest that the rubblized layer underneath the asphalt layer may cause top-down cracking, although it reduces the rutting and bottom-up cracking potential. 


\subsection{Aging}

The aging of asphalt binder has been attributed to be the major cause of top-down cracking in many studies such as Hugo \& Kennedy (1985) in South Africa, Wambura et al. (1990) in Kenya, and Gerritsen (1987) in Netherlands. In South Africa and Kenya, severe age hardening occurred in two year old pavements that had high air void content, in this case around 8\%. In Kenya the severe age hardening happened in the top few millimeters of the asphalt pavement surface. Studies in Netherlands (Gerritsen, 1987) also report severe age hardening of newly constructed pavement surface that was not properly compacted and also had low binder content.

\subsection{Mix Composition and Raw Materials}

Harvey and Tsai (1996) studied the effects of asphalt and air void content on mix fatigue and stiffness. The variables in the fatigue study were: one aggregate and asphalt source, five asphalt contents ranging from 4 to $6 \%$, and three air void contents ranging from 1 to $3 \%, 4$ to $6 \%$ and 7 to $9 \%$. The test used was third-point controlled strain flexural beam test developed under the SHRP research program. A $10 \mathrm{~Hz}$ haversine wave was used and testing was carried out at $19^{\circ} \mathrm{C}\left(66^{\circ} \mathrm{F}\right)$ temperature. Two strain levels were used $(300$ and 150 micro-strains) with average fatigue life of 50,000 and 500,000 repetitions, respectively. They concluded that the results clearly indicate that the low air void content increased fatigue life and mixture stiffness. Increased asphalt content increased fatigue life and decreased stiffness.

Micromechanics study of top-down cracking by Myers, Mohammad and Fu (2003)

state that rutting and cracking may be related and bottom-up and top-down cracking may not be the only patterns of cracking. They predicted tensile stresses inside the pavement below surface which is consistent to top-down cracking predicted by FEM analysis. Cracking took place at a higher temperature where rutting is usually assumed to be dominant. This finding can be supported by the findings by Matsuno and Nishizawa (1991) 
who concluded that surface cracking took place at higher pavement temperatures.

The WesTrack experiment (Tsai, Harvey \& Monismith, 2001) indicated that fine and fine-plus mixtures were less prone to bottom-up cracking than coarse graded mixtures. A study by Pellinen, Christensen, Rowe, and Scharrok (2004) suggests that the mix volumetric property that best correlated to the cracking in the WesTrack experiment was Voids Filled with Asphalt (VFA), although the correlation was at best moderate. Mixtures that had VFA above 53\% had less cracking than mixtures with VFA below the average. The other volumetrics for crack resistant mixtures were $\mathrm{Vb}_{\text {eff }}>9 \%$, air void content $<6 \%$, and Voids in mineral Aggregate (VMA) $<14 \%$.

Based on the report by the independent WesTrack evaluation group, "Performance of Coarse Graded Mixes at WesTrack - Premature Rutting" (FHWA Final Report, 1998), the mixture performance at WesTrack was different than typically seen on other high truck traffic pavements. Coarse mixtures cracked during the winter months and then rutted during the summer months. Evaluators noted that usually pavements that exhibit fatigue cracking do not exhibit significant plastic deformation. Also, the fatigue cracks developed first in the transverse direction and then in the longitudinal direction. They noted that usually, longitudinal cracks are the first sign of fatigue, followed by the transverse cracks (which indicates top-down cracking pattern).

\subsection{Construction Issues}

The construction issues have been reported to affect the formation of surface cracks. Surface defects can cause surface cracking based by Uhlmeyer et al. (2000). A study by Schorsch et al. (2001) found that surface cracks initiated from the segregate pavement areas. They conducted field and laboratory tests to quantify the segregation using nuclear gauge measurements to identify the air void differences in the segregated and nonsegregated areas. Laboratory measurements included indirect tensile strength, gradation, and binder content measurements to verify segregation. Unfortunately loading time or test temperature was not reported for comparisons. Segregated spots had lower tensile strength 
than non-segregated areas.

A poor pavement compaction has been cited as a source of surface crack initiation and propagation in pavements in several studies discussed above. Based on the research conducted in Africa, air void content around $8 \%$ was considered poor, while this is the typical required in-situ air void content in the U.S. The European mix design and construction specifications tend to require lower design and in-situ air void contents. For instance, in Finland the required in-situ air void content of the mix (measured using dry method) is less than 5\% to prevent aging and moisture damage in the mix (PANK,1995).

Schorsch et al. (2001) found that in segregated pavements the air void content varied between 1.8 to $12 \%$. The average air void content of the segregated pavements was $6.1 \%$ with standard deviation of $2.8 \%$. The non-segregated control sections had an average of $3.8 \%$ air void with standard deviation of $2 \%$. The highest measured air void content in the control cores was $8.1 \%$. This suggests that the low air void content provides better resistance against cracking.

Based on the literature it can be concluded that the air void threshold for better performing mixtures seems to be less than $6 \%$. 


\section{COLLECTION AND ANALYSIS OF SITE DATA}

\subsection{Site Selection}

Several candidate pavement sites were evaluated based on visual survey and site inspections. The pavement sites that were selected for inspection were checked for the following factors: 1) pavement structure consisting of only unbound and asphaltic bound layers; 2) pavement with relatively heavy traffic; 3) pavements with minimal rutting; 4) materials used for the pavement to be typical for the state; and 5) thickness of the asphalt layers greater than $200 \mathrm{~mm}$ (8 inches).

Based on the preliminary visual survey and site inspection, three sites were selected for further evaluation. These three sites were:

1. Site 1- I-65 North of Lafayette, County: Jasper, District: La Porte Mile Post: 224-223

Lanes/Direction: 2/ South Bound Lane

Construction Let Date: January 12, 1993, pavement age 11 years

2. Site 2- I-65 Near Indianapolis, County: Marion, District: Greenfield Mile Post: $115 / 6$

Lanes/Direction: 3/ South Bound Lane

Construction Let Date: November, 1992, pavement age 12 years

3. Site 3-US-421 Madison, County: Jefferson, District: Seymour

Mile Post: 2

Lanes/Direction: 2/ North Bound Lane

Construction Let Date: May 18, 1999, pavement age 4.5 years

Based on the preliminary visual inspection, the I-65 North site had longitudinal cracking in the middle of the lanes and some wheel path cracking in all lanes for both directions. Cracks had been sealed with asphalt. The selected test section was in the south 
bound lane between mileposts 224 and 223. The exact location was after the Ferry Oak Street bridge (looking from the north).

The I-65 Loop site had longitudinal and some low severity alligator cracking in all 6 lanes for both directions. The selected test area was in the south bound lane before the Martin Luther King Exit starting from milepost 115+6 after the Exit 115 sign.

US-421 in Madison had longitudinal outer wheel path cracking in the driving lane on upgrade in the north bound direction that had slower traffic. However, no cracking in the downhill direction where the traffic speed is higher was observed. Also in this site cracking was concentrated on the fill areas. Two possible coring locations, $1 \& 2$, were marked on the pavement in the northbound driving lane.

Table 1 summarizes the pavement structure for the sites selected for the top-down crack study. The design thickness of the pavement layers and the materials for each site were obtained from the INDOT database. The asphalt mix in the I-65 North and US-421 Madison site were constructed over rubblized concrete while the I-65 Loop near Indianapolis was constructed over granular base material. The overall design thickness for HMA for Site1, I-65 North, was $370 \mathrm{~mm}$ (14.5 inch), for Site 2, I-65 Loop, was $545 \mathrm{~mm}$ (21.5 inch), and for Site 3, US-421 Madison, was $200 \mathrm{~mm}$ ( 8 inch).

Location of the survey sites are marked on the Indiana map in Figure 3. The exact locations of the three selected sites are shown in the detailed maps in Figure 4, Figure 5, and Figure 6. These sites were subjected to detailed pavement evaluations. 
Table 1: Design thicknesses for the study sites

\begin{tabular}{|l|l|l|l|}
\hline \multicolumn{3}{|l|}{ SITE 1 I-65 NORTH OF LAFAYETTE } \\
\hline $\begin{array}{l}\text { LAYER } \\
\text { NO }\end{array}$ & \multicolumn{2}{l|}{ DESIGN } & DESCRIPTION \\
& THICKNESS & \\
\hline (in) & (mm) & \\
\hline 1 & $1.5^{\prime \prime}$ & 38.10 & HMA Surface \\
\hline 2 & $13^{\prime \prime}$ & 330.2 & HMA Base \\
\hline 3 & $10^{\prime \prime}$ & 254.0 & Rubblized Concrete \\
\hline 4 & $6 "$ & 152.4 & SubgradeTreatment Type 2 \\
\hline
\end{tabular}

\begin{tabular}{|l|l|l|l|}
\hline \multicolumn{4}{|l|}{ I-65 LOOP NEAR INDIANAPOLIS } \\
\hline $\begin{array}{l}\text { LAYER } \\
\text { NO }\end{array}$ & \multicolumn{2}{l|}{$\begin{array}{l}\text { DESIGN } \\
\text { THICKNESS }\end{array}$} & \multicolumn{1}{l|}{ DESCRIPTION } \\
\hline (in) & $(\mathbf{m m})$ & \\
\hline 1 & $1 "$ & 25.40 & $60 \mathrm{~kg} / \mathrm{m}^{2}$ Bituminous Surface $11 \mathrm{HV}$ \\
\hline 2 & $3 "$ & 76.20 & $180 \mathrm{~kg} / \mathrm{m}^{2}$ Bituminous Binder 8 or $9 \mathrm{HV}$ \\
\hline 3 & $14 "$ & 355.6 & $687.27 \mathrm{~kg} / \mathrm{m}^{2}$ Bituminous Base $2 \mathrm{HV}$ \\
\hline 4 & $3.5^{\prime \prime}$ & 88.90 & $218.18 \mathrm{~kg} / \mathrm{m}^{2}$ Bituminous Base $5 \mathrm{D}$ \\
\hline 5 & $12^{\prime \prime}$ & 304.8 & Compacted Aggregate Type O \\
\hline 6 & $6 "$ & 152.4 & Subgrade Treatment Type O \\
\hline
\end{tabular}

\begin{tabular}{|l|l|l|l|}
\hline \multicolumn{4}{|l|}{ US-421 MADISON SECTION } \\
\hline $\begin{array}{l}\text { LAYER } \\
\text { NO }\end{array}$ & \multicolumn{2}{l|}{ DESIGN } \\
THICKNESS & DESCRIPTION \\
\hline (in) & $(\mathbf{m m})$ & \\
\hline 1 & $1.25 "$ & 31.75 & $75 \mathrm{~kg} / \mathrm{m}^{2}$ HMA Surface $9.5 \mathrm{~mm}$ \\
\hline 2 & $2.75^{\prime \prime}$ & 69.85 & $165 \mathrm{~kg} / \mathrm{m}^{2}$ HMA Intermediate $19 \mathrm{~mm}$ \\
\hline 3 & $4 "$ & 101.6 & $240 \mathrm{~kg} / \mathrm{m}^{2}$ HMA Base $25 \mathrm{~mm}$ \\
\hline 4 & $9 "$ & 228.6 & Rubblized Concrete \\
\hline 5 & $6 "$ & 152.4 & Subgrade Treatment Type 2 \\
\hline $60 \mathrm{~kg} / \mathrm{m}^{2}=110 \mathrm{lb} / \mathrm{syd}$ & \\
\hline
\end{tabular}




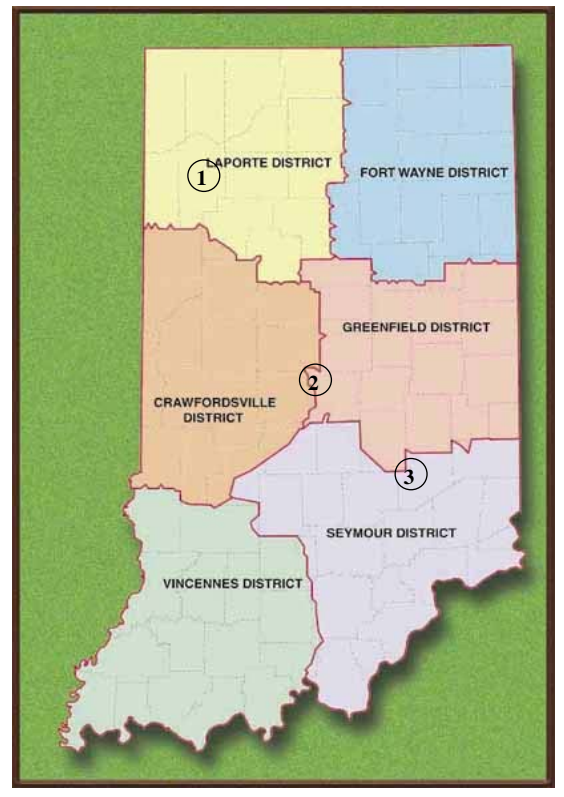

Figure 3: Map of Indiana with selected study sites

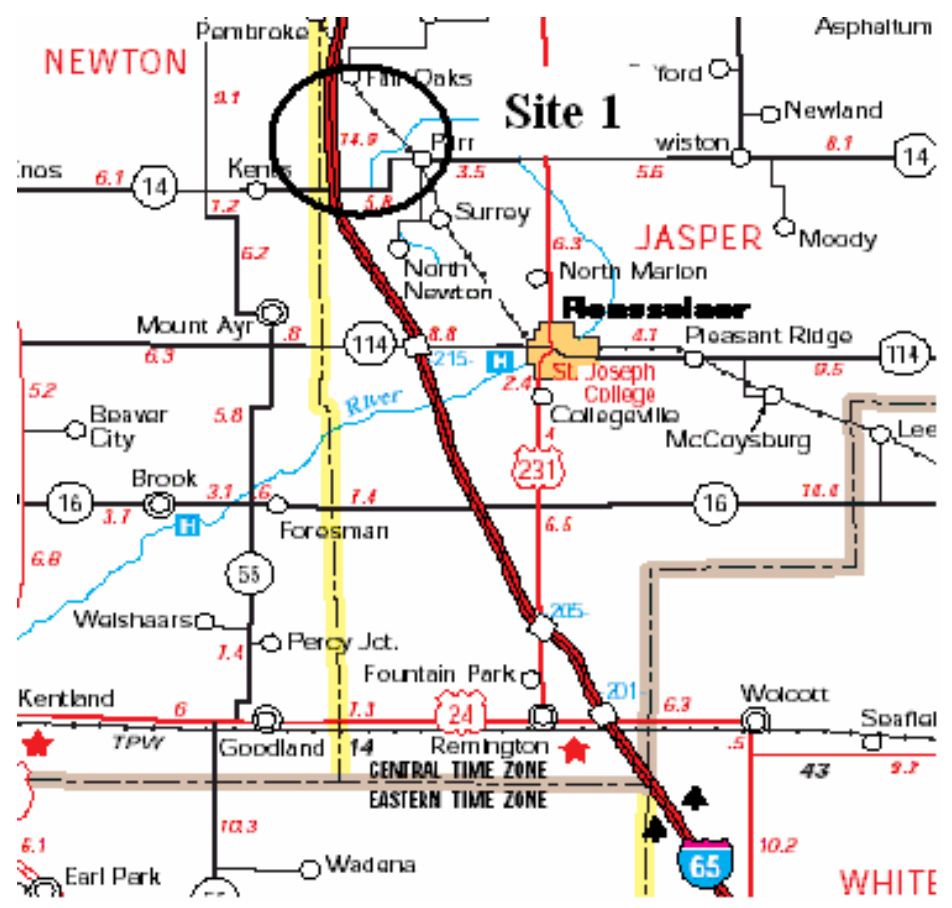

Figure 4: SITE 1 I-65 North of Lafayette 


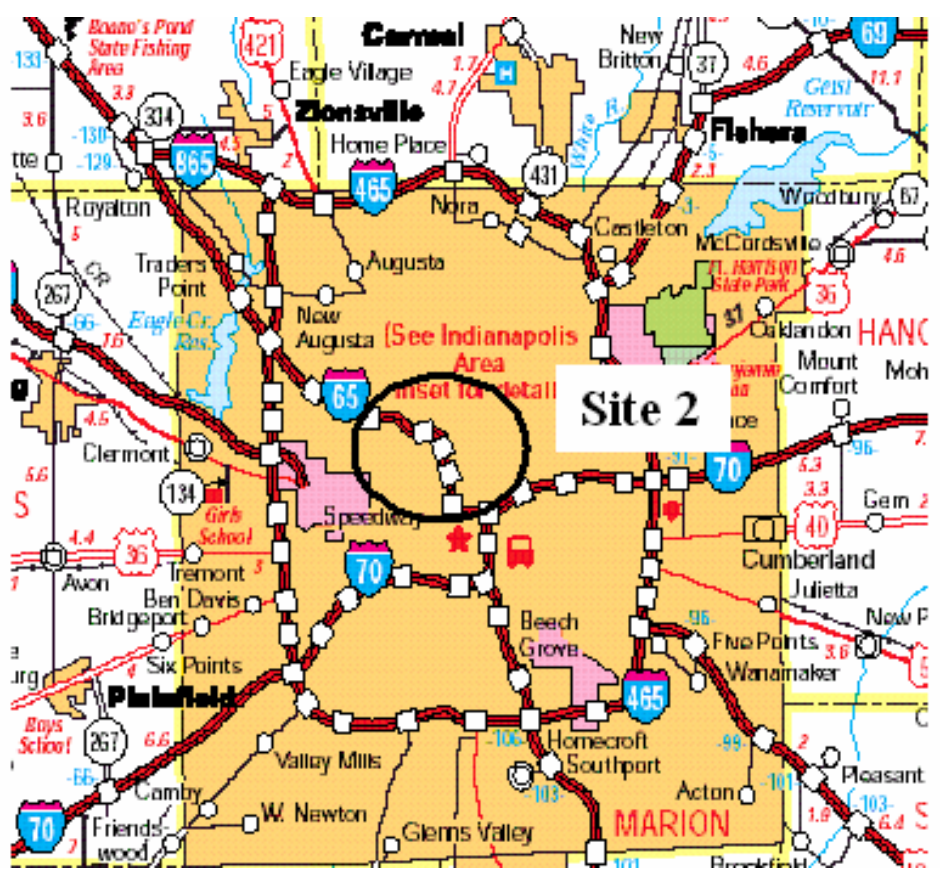

Figure 5: SITE 2 I-65 Near Indianapolis

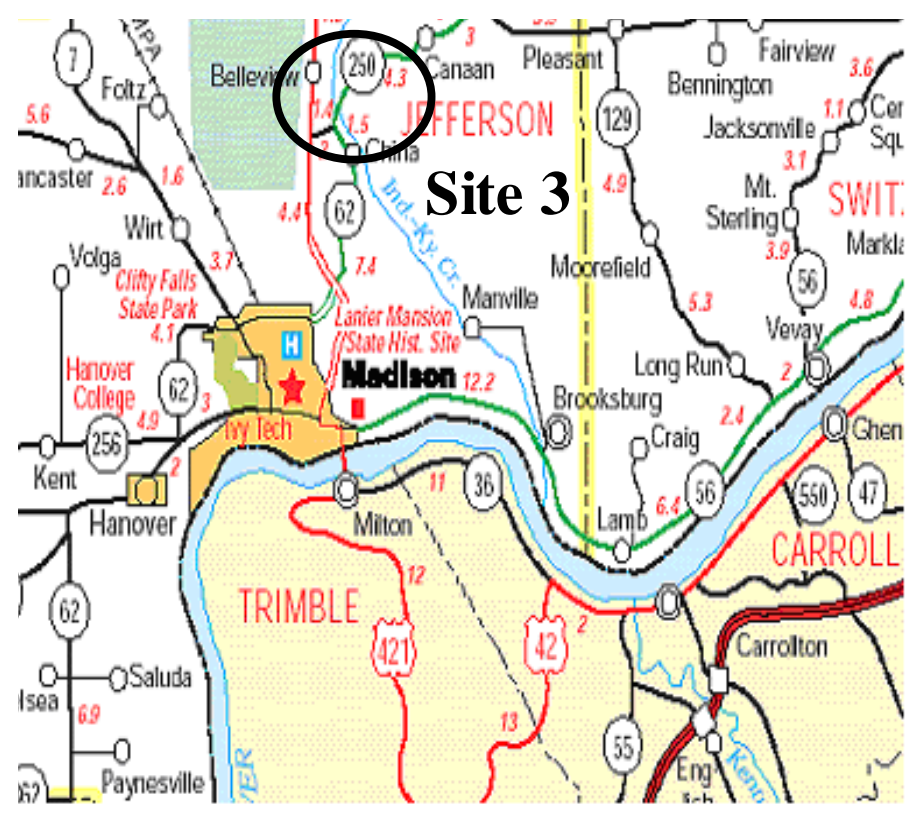

Figure 6: SITE 3 US-421 Madison 


\subsection{Visual Survey of Study Sites}

\subsubsection{Overall Distress Survey}

For the three sites selected, visual survey included a detailed recording of distress data. The recorded distress information included fatigue cracking, alligator cracking, block cracking, edge cracking, wheel path longitudinal cracking, non wheel path longitudinal cracking, transverse cracking, rutting, and excessive bleeding for the flexible pavements. This data was then used to construct distress maps, which included the identified distress type and severity levels. Each data sheet contains two $15.25 \mathrm{~m}$ (50 ft) maps which represent $30.5 \mathrm{~m}(100 \mathrm{ft})$ of the test section. The detailed distress data survey sheets are provided in Appendix A.

The distress survey was conducted only for the driving lane. For each site, two sections of $15 \mathrm{~m}$, being $500 \mathrm{~m}$ apart were surveyed. The detailed distress patterns were recorded for a distance of $20 \mathrm{~m}$ before and after the location from which the cracked cores were obtained. The Distress Identification Manual for the Long Term Pavement Performance Project was used as a standard guide for interpretation, identification, and rating of observed distresses.

Figure 7 to Figure 9 show the pictures of the three sites from where the cores were taken. Figure 7(a) shows severe longitudinal cracking on the wheel path as well as on the centerline of pavement of Site 1, I-65 North. Most of the wide cracks were sealed with bitumen and most of the centerline cracking was sealed with bitumen. Figure 7(b) shows a close up of the location on the wheel path from where the cracked samples No. 1 and No. 2 were obtained.

Figure 8(a) shows longitudinal surface cracking on left side of left wheel path on Site 2, I-65 loop near Indianapolis. The figure is marked with locations from where the cracked cores were obtained. Figure 8(b) shows a closer view of the hair line cracked pavement location. 


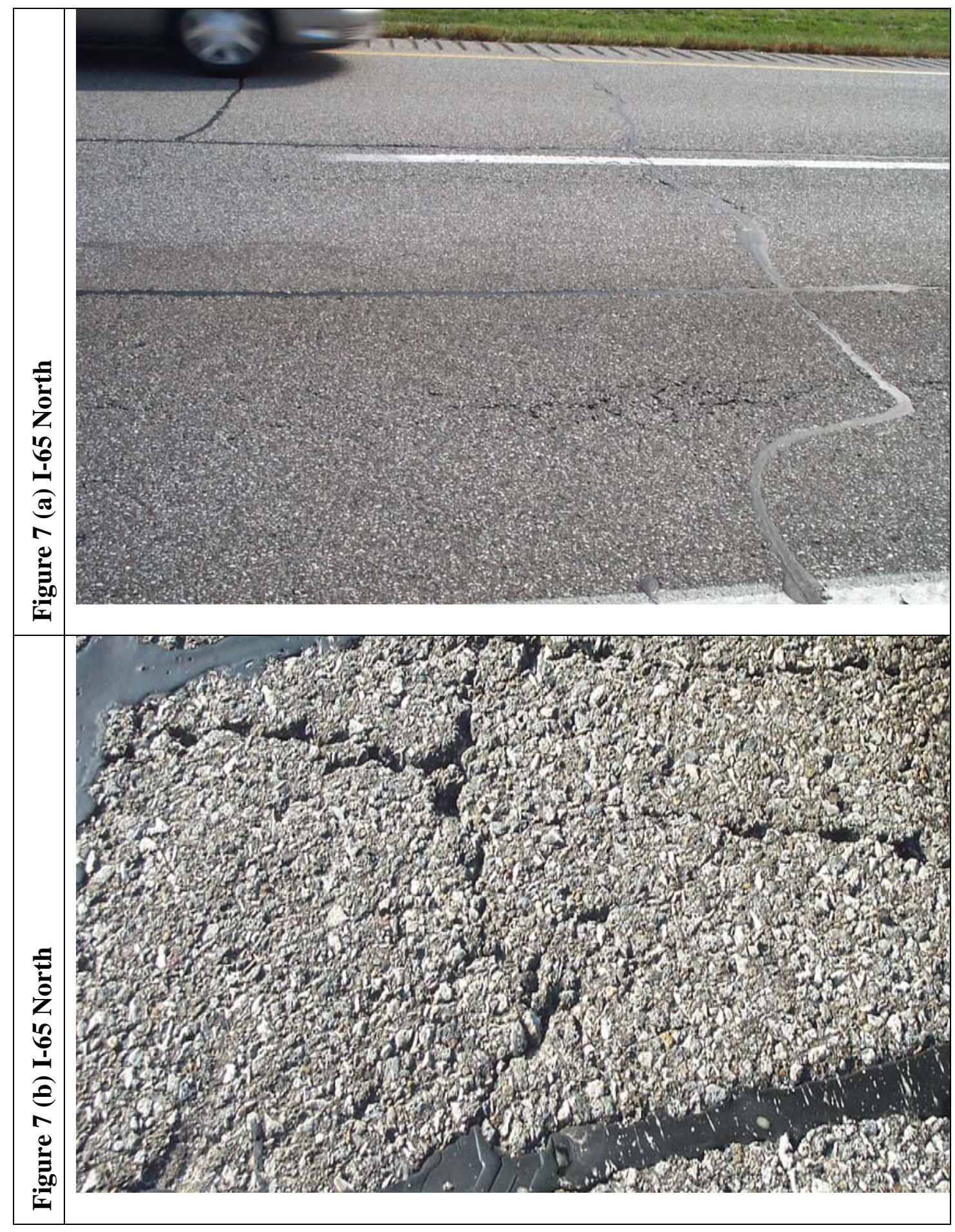

Figure 7: Site 1 I-65 North of Lafayette 


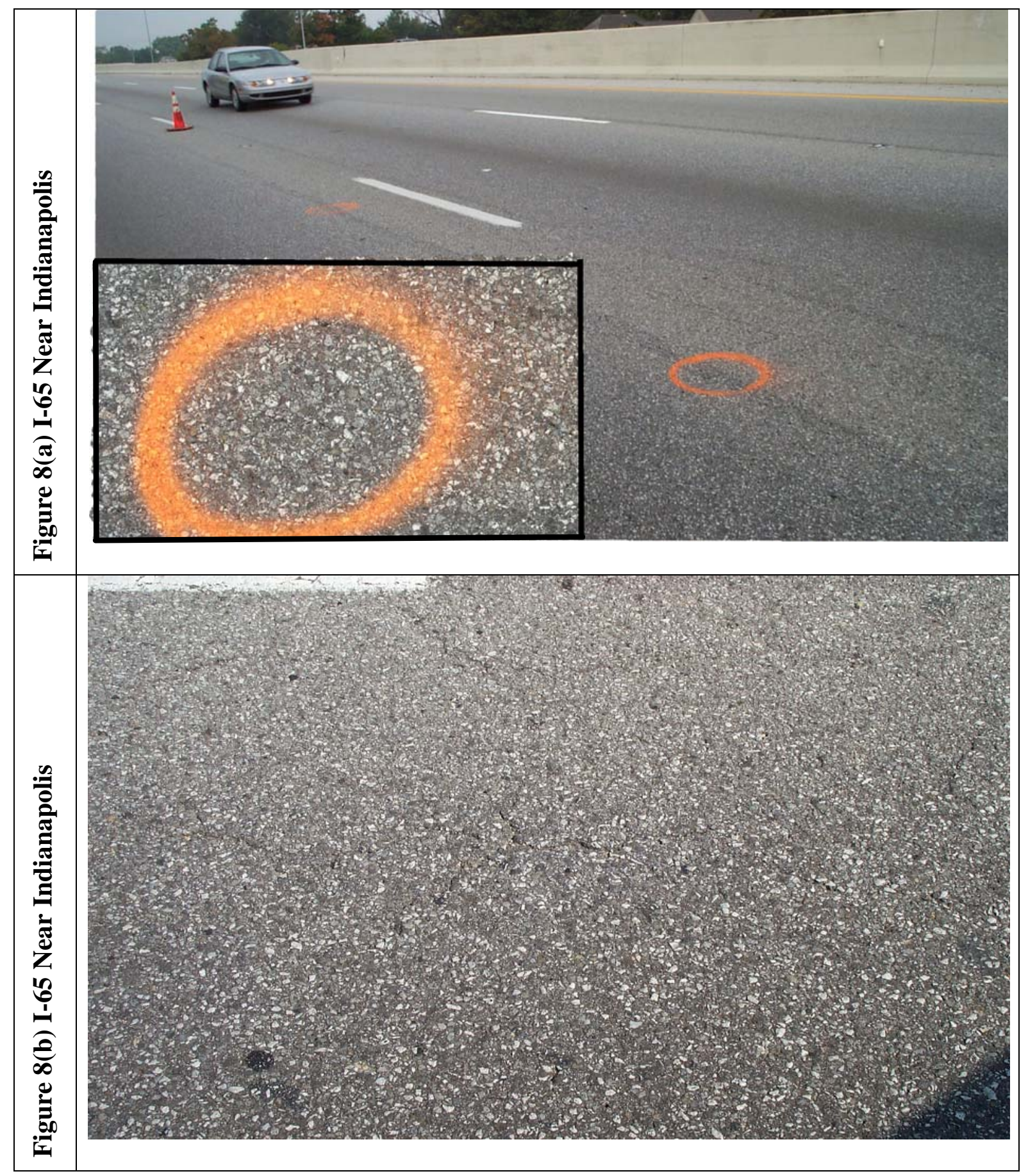

Figure 8: Site 2 I-65 near Indianapolis 


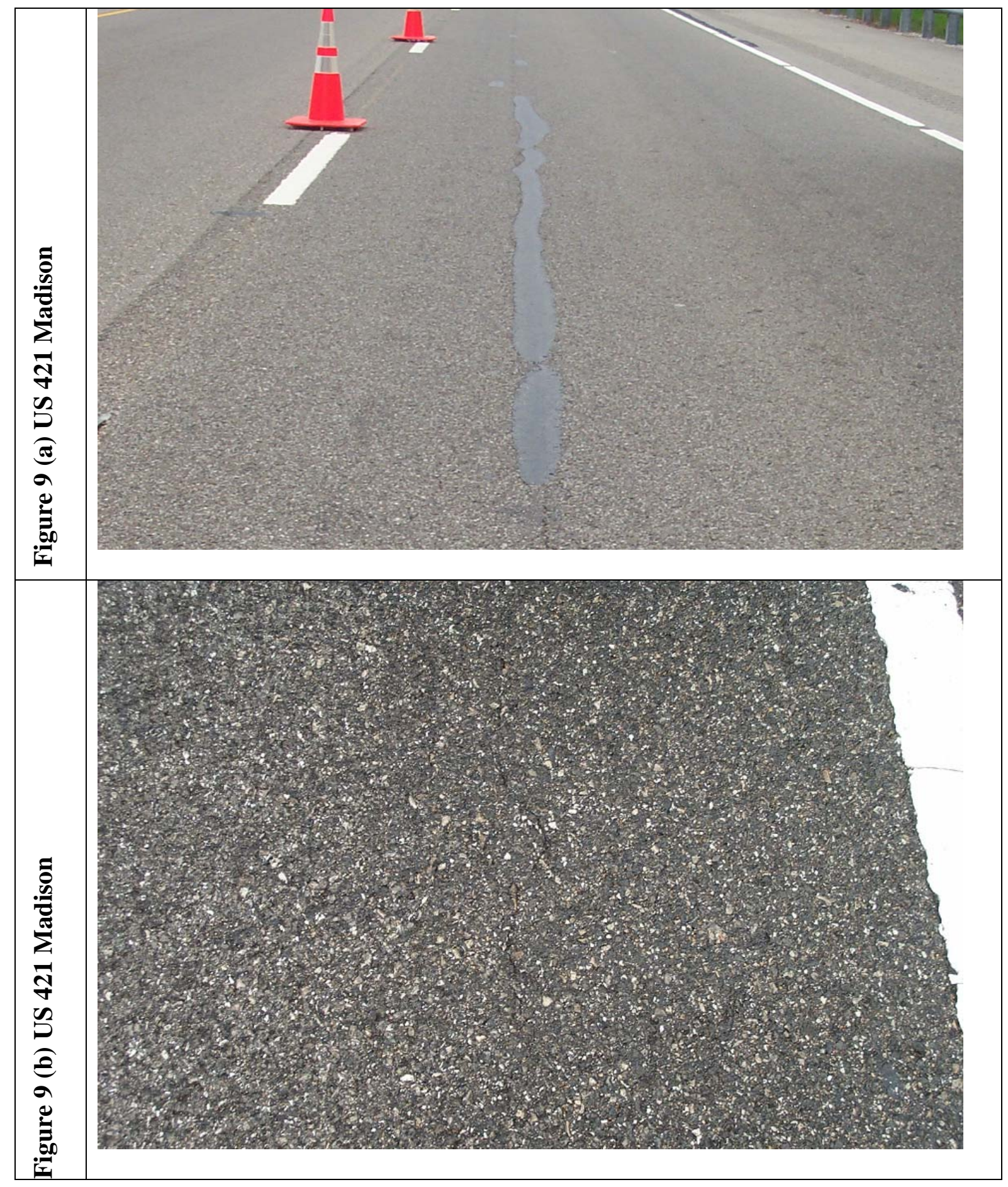

Figure 9: Site 3 US 421 Madison 
Figure 9(a) shows the surface cracked left wheel path line with low severity alligator cracking and Figure 9(b) shows the cracked pattern near the wheel path of Site 3, US-421 near Madison.

A summary of the distress survey is shown in Table 2. The distress types associated with asphalt concrete surface pavements, as per the distress identification manual, are shown in the left column. The units of measurement for each of the distress types are also identified in the left column. The extent of the measured distress for each particular level of severity is entered in the severity level columns identified as low, moderate, or high. The value " 0 " is entered for any distress types or severity levels not existing on the visual survey.

It was observed that Site 1, I-65 North, had the most distresses while the other two sites, Site 2, I-65 near Indianapolis, and Site 3, US-421 Madison, had very negligible distresses. The average longitudinal crack length for Sites 1, 2 and 3 were $126 \mathrm{~m}, 102.5 \mathrm{~m}$, and $83 \mathrm{~m}$, respectively.

\subsubsection{Location of Longitudinal Surface Cracks}

Inspection of distress survey maps and photos taken from the pavements indicate those surface cracks were not located the same way in each studied pavement. In Site 1 and 3 surface cracks were located in the wheel path while in Site 2 cracks were approximately $0.5 \mathrm{~m}$ outside the wheel path. However, for Sites 2 and 3 cracking seemed to be concentrated more on the left side of the pavement lane. Table 3 summarizes the findings.

Based on literature review, top-down cracks may initiate from the segregated areas in the pavement, which exhibit weaker material properties. Based on the visual survey, none of the sites seem to have exhibited load-end segregation as Figure 10, Figure 11 (a), and Figure 11 (b) show. Load-end segregation manifests itself as coarser and more open mat texture repeating about 25 to 30 meter intervals. However, this finding was not verified by laboratory testing. 


\section{Table 2: Report of distress data of study sites}

\begin{tabular}{|c|c|c|c|c|c|c|c|}
\hline \multicolumn{8}{|c|}{ DISTRESS SURVEY FOR PAVEMENTS WITH ASPHALT CONCRETE SURFACES } \\
\hline \multicolumn{2}{|l|}{ Site } & \multicolumn{3}{|c|}{ TSite 1 I-65 North Of Lafayette } & \multicolumn{3}{|c|}{ Site 1 I-65 North Of Lafayette } \\
\hline \multicolumn{2}{|l|}{ Section ID } & \multicolumn{3}{|c|}{ Section 1} & \multicolumn{3}{|c|}{ Section 2} \\
\hline \multicolumn{2}{|c|}{ Date of Distress Survey $(\mathrm{mm} / \mathrm{dd} / \mathrm{yy})$} & \multicolumn{3}{|c|}{ 9/26/2002 } & \multicolumn{3}{|c|}{ 9/26/2002 } \\
\hline \multicolumn{2}{|c|}{ Surveyors } & \multicolumn{3}{|c|}{ K.B. } & \multicolumn{3}{|l|}{ K.B. } \\
\hline \multicolumn{2}{|c|}{ Photos, video or both with survey $(P, V, B)$} & \multicolumn{3}{|l|}{$\mathrm{P}$} & \multicolumn{3}{|l|}{$\mathrm{P}$} \\
\hline \multirow[b]{2}{*}{ OBS. NO. } & \multirow[b]{2}{*}{ DISTRESS TYPE } & \multicolumn{3}{|c|}{ SEVERITY LEVEL } & \multicolumn{3}{|c|}{ SEVERITY LEVEL } \\
\hline & & LOW & MODERATE & $\mathrm{HIGH}$ & LOW & MODERATE & $\mathrm{HIGH}$ \\
\hline 1 & Fatique Cracking (Square Meters) & 15.5 & 75 & 0 & 6 & 0 & 0 \\
\hline 2 & Block Cracking(Square Meters) & 2.75 & 0 & 0 & 0 & 0 & 0 \\
\hline 3 & Edge Cracking (Meters) & 5 & 0 & 0 & 0 & 0 & 0 \\
\hline \multirow[t]{3}{*}{4} & \begin{tabular}{|l} 
Longitudinal Cracking (Meters) \\
\end{tabular} & 41 & 0 & 0 & 85 & 0 & 0 \\
\hline & 4a Wheel Path Length Sealed (Meters) & 22 & 0 & 0 & 0 & 0 & 0 \\
\hline & 4b Non-Wheel Path Length Sealed (Meters) & 19 & 0 & 0 & 55 & 0 & 0 \\
\hline 5 & Transeverse Cracking (Meters) & 10.5 & 6.2 & 0 & 5 & 11.25 & 0 \\
\hline & 5a Number of cracks & 4 & 2 & 0 & 2 & 4 & 0 \\
\hline & 5b Length Sealed (Meters) & 10.5 & 6.2 & 0 & 3.5 & 11.25 & 0 \\
\hline Site & & Site $2 \mathrm{I}-\mathrm{C}$ & 5 Loop near In & napolis & Site $21-6$ & Loop near Ind & napolis \\
\hline Section ID & & Section & & & Section & & \\
\hline Date of Dis & stress Survey $(\mathrm{mm} / \mathrm{dd} / \mathrm{yy})$ & $10 / 1 / 200$ & & & $10 / 1 / 200$ & & \\
\hline Surveyors & & K.B. & & & K.B. & & \\
\hline Photos, vic & deo or both with survey $(P, V, B)$ & $\mathrm{P}$ & & & $\mathrm{P}$ & & \\
\hline & & & EVERITY LE) & & & EVERITY LEV & \\
\hline OBS. NO. & DISTRESS TYPE & LOW & MODERATE & $\mathrm{HIGH}$ & LOW & MODERATE & $\mathrm{HIGH}$ \\
\hline 1 & Fatigue Cracking (Square Meters) & 5 & 0 & $\overline{0}$ & 225 & 0 & $\overline{0}$ \\
\hline 2 & Block Cracking(Square Meters) & 0 & 0 & 0 & 0 & 0 & 0 \\
\hline 3 & Edge Cracking (Meters) & 0 & 0 & 0 & 0 & 0 & 0 \\
\hline 4 & Longitudinal Cracking (Meters) & 50 & 0 & 0 & 52.5 & 0 & 0 \\
\hline & 4a Wheel Path Length Sealed (Meters) & 0 & 0 & 0 & 0 & 0 & 0 \\
\hline & 4b Non-Wheel Path Length Sealed (Meters) & 0 & 0 & 0 & 0 & 0 & 0 \\
\hline 5 & Transeverse Cracking (Meters) & 0 & 0 & 0 & 0 & 0 & 0 \\
\hline & 5a Number of cracks & 0 & 0 & 0 & 0 & 0 & 0 \\
\hline & 5b Length Sealed (Meters) & 0 & 0 & 0 & 0 & 0 & 0 \\
\hline Site & & Site 3 S & 421 Madison & & Site $3 \mathrm{SF}$ & 421 Madison & \\
\hline Section ID & & Section & & & Section & & \\
\hline Date of Dis & stress Survey (mm/dd/yy) & 9/26/200 & & & 9/26/200 & & \\
\hline Surveyors & & S.C. & & & S.C. & & \\
\hline Photos, vic & deo or both with survey $(P, V, B)$ & $\mathrm{P}$ & & & $\mathrm{P}$ & & \\
\hline & & & EVERITY LE & & & EVERITY LEV & \\
\hline OBS. NO. & DISTRESS TYPE & LOW & MODERATE & $\mathrm{HIGH}$ & LOW & MODERATE & $\mathrm{HIGH}$ \\
\hline 1 & Fatiaue Cracking (Square Meters) & 0 & 0 & 0 & 22 & 0 & 0 \\
\hline 2 & Block Cracking(Square Meters) & 0 & 0 & 0 & 0 & 0 & 0 \\
\hline 3 & Edge Cracking (Meters) & 0 & 0 & 0 & 0 & 0 & 0 \\
\hline 4 & \begin{tabular}{|l} 
Longitudinal Cracking (Meters) \\
\end{tabular} & 29 & 0 & 0 & 54 & 0 & 0 \\
\hline & 4a Wheel Path Length Sealed (Meters) & 24 & 0 & 0 & 39 & 0 & 0 \\
\hline & 4b Non-Wheel Path Length Sealed (Meters) & 0 & 0 & 0 & 0 & 0 & 0 \\
\hline 5 & \begin{tabular}{|l|} 
Transeverse Cracking (Meters) \\
\end{tabular} & 0 & 0 & 0 & 0 & 0 & 0 \\
\hline & 5a Number of cracks & 0 & 0 & 0 & 0 & 0 & 0 \\
\hline & 5b Length Sealed (Meters) & 0 & 0 & 0 & 0 & 0 & 0 \\
\hline
\end{tabular}


Table 3: Location of Surface Cracks.

\begin{tabular}{|l|l|l|l|l|}
\hline $\begin{array}{l}\text { LOCATION OF } \\
\text { SURFACE CRACKING }\end{array}$ & SITE-1 & SITE-2 & SITE-3 & $\begin{array}{l}\text { POSSIBLE } \\
\text { SEGREGATION }\end{array}$ \\
\hline Lane width (m) & 3.5 & 4.0 & 3.5 & - \\
\hline Left wheel path & Yes & No & Most & Yes - screed extensions \\
\hline Right wheel path & Yes & No & Some & Yes - screed extensions \\
\hline Outside of left wheel path & No & Most & No & Yes - screed extensions \\
\hline Outside of right wheel path & No & Some & No & Yes - screed extensions \\
\hline Centerline cracking & Yes & No & No & Yes - auger gear box \\
\hline
\end{tabular}

Longitudinal surface cracking in Site 3 was systematically located in the left wheel path area with some symmetrical cracking in the right wheel path; see Figure 11 (b). This may indicate some longitudinal mix segregation caused by screed extensions in the paver. The width of the paving lane is approximately 3.5 meters, which means that screed extensions were used to cover the entire paving width with one paver pass. The screed extensions can cause segregation of the mix depending on the specifics of the screed used and segregation tendency of the mix.

For Site 2 the outside wheel path cracking may also be initiated by segregation caused by screed extensions and edges of tunnel similarly as described for Site 3 above. In this case the weak area of the pavement is 0.5 meters outside of the wheel path which is consistent with the wider paving lane width of 4 meters; see Figure 11 (a).

For Site 1 the centerline cracking may be caused by segregation by the auger gear box in the center of the paver screed. The gear box may cause segregation as the mix is transported from the tunnel to the augers. The wheel path cracking may also be initiated from the areas of segregated mix, although in this case it seems to be less likely; see Figure 10. 


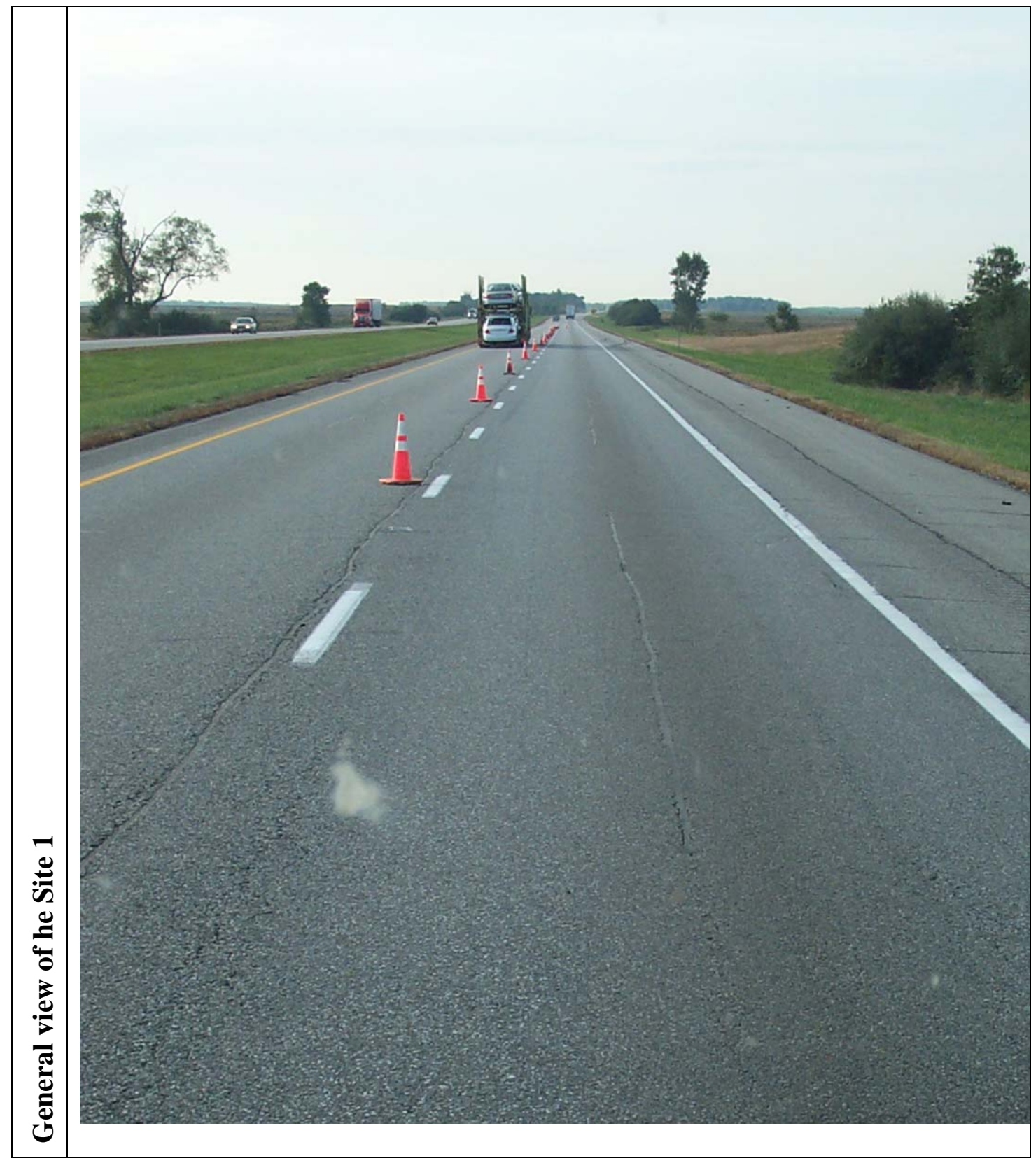

Figure 10: Site 1, I-65 North of Lafayette. 


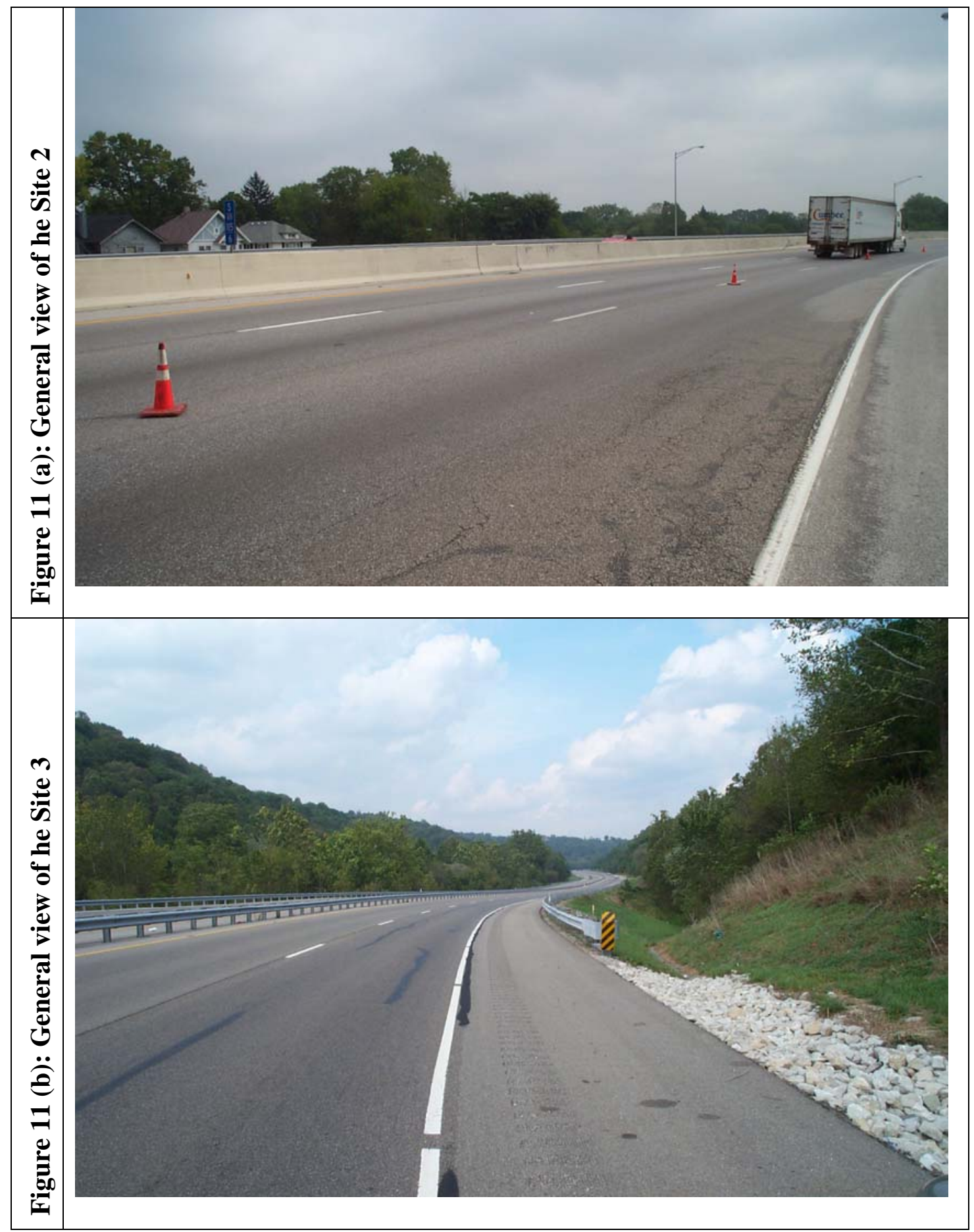

Figure 11: Site 2, I-65 Loop and Site 3, US-421 Madison. 


\subsection{Distress Data Collection from INDOT PMS}

The INDOT collects distress information for the interstates every year and for noninterstates every alternate year for the Pavement Management System (PMS). The distress data is obtained from the Path Runner data collection vehicle. The vehicle includes sensors, cameras, computers and other related equipment. It collects data at a speed of $70 \mathrm{mph}$ and stores road condition data and images in real time in the on-board computer hard disk. The detailed distress data record obtained from the Path Runner data collection vehicle is provided in Appendix B. The distress information is gathered for a 500 foot section of road beginning each reference post. The results from the survey measurements displayed as an output are:

1. The IRI (International Roughness Index): It is the measure of the ride of the pavement. It measures the "bumpiness" of the pavement in terms of inches per mile.

2. Rut: It is the measure of the average depth of ruts in the wheel paths of the pavement. Rutting is most common on bituminous pavements and a severely rutted pavement would have average ruts of $6.3 \mathrm{~mm}(0.25 \mathrm{inch})$ or larger.

3. PCR (Pavement Condition Rating): It is the measure of the distresses on a pavement surface. These distresses include transverse cracking, longitudinal cracking, blocking cracking, etc. The pavement is reviewed at each reference post for 500 feet, the distresses are rated for severity and quantity, and a value is determined

4. Roadway horizontal and vertical curve information

An overall Pavement Condition Rating (PCR) index is calculated using the following equation:

$$
\text { PCR }=100-\text { Total deduct points }
$$

The deduct points are composed of weight value, severity and extent of the distress. The PCR is a composite index of all the varying types of distresses ranked on a scale of 100 to 0 , with 100 being perfect and zero being impassable. A PCR of 50 is generally 
considered unacceptable. The distress ratings are presented in Appendix B.

As a summary, the average values of IRI, PCR and Rut Depth over the respective mileposts were calculated for the three study sites, see Table 4. Site 1 had moderately good PCR rating, whereas Site 2 and Site 3 showed good pavement condition with low severity distresses. Site $2 \mathrm{had}$ the lowest measured rut depth, $1.9 \mathrm{~mm}$, although the other two sites also had very little rutting. Overall, the PMS survey results are in good agreement with the visual survey results discussed earlier.

\section{Table 4: Pavement Condition Parameters}

\begin{tabular}{|l|l|l|l|l|l|}
\hline SITE ID & $\begin{array}{l}\text { MILE } \\
\text { POST }\end{array}$ & $\begin{array}{l}\text { SURVEY } \\
\text { YEAR }\end{array}$ & $\begin{array}{l}\text { Average IRI } \\
\text { (in/mile) }\end{array}$ & $\begin{array}{l}\text { PCR } \\
\text { (Scale 100-0) }\end{array}$ & $\begin{array}{l}\text { Average RUT } \\
\text { (mm) / (in) }\end{array}$ \\
\hline Site 1 I-65 & $223-224$ & 2001 & 74 & 93.33 & $4.2 / 0.167$ \\
\hline Site 2 I-65 & $115.6-118$ & 2001 & 115 & 99.80 & $1.9 / 0.076$ \\
\hline Site 3 U-421 & $1.0-3.0$ & 2001 & 54 & 99.00 & $4.1 / 0.163$ \\
\hline
\end{tabular}

\subsection{Falling Weight Deflectometer (FWD) Testing}

\subsubsection{FWD Testing}

Falling Weight Deflectometer (FWD) testing enables determination of the stiffness moduli of the pavement layers by measuring the pavement deflected shape (deflection basin) under applied load, as illustrated in Figure 12, whereas Figure 13 shows the FWD in use on Site 1 (I-65, north of Lafayette).

FWD deflection testing was conducted along three test lines for each site - lane center, left and right hand wheel paths. The lane center testing was conducted at $25 \mathrm{~m}$ spacing throughout the entire $500 \mathrm{~m}$ section. The testing in the wheel paths was concentrated at the crack locations where testing was at $10 \mathrm{~m}$ centers. The adopted spacing ensured a sufficient number of samples to back-calculate the pavement layer stiffness moduli. The testing used stress levels of approximately 450,600 , and $750 \mathrm{kPa}$. A 
schematic example of the testing plan is shown in Figure 14.

The response of the pavement to impulse loading was measured with a set of nine velocity transducers (geophones) placed on different radial distances from the center of the loaded area, see Table 5. The data is normally reduced to three deflection parameters that relate to the different structural components of the pavement, e.g., foundation and bound layers. The assumption made is that the outer deflection sensors relate to the soil foundation while the shape of the deflection bowl close to the center of loading relates to the strength of the upper pavement layers. A summary of pavement response parameters is presented in Table 6.

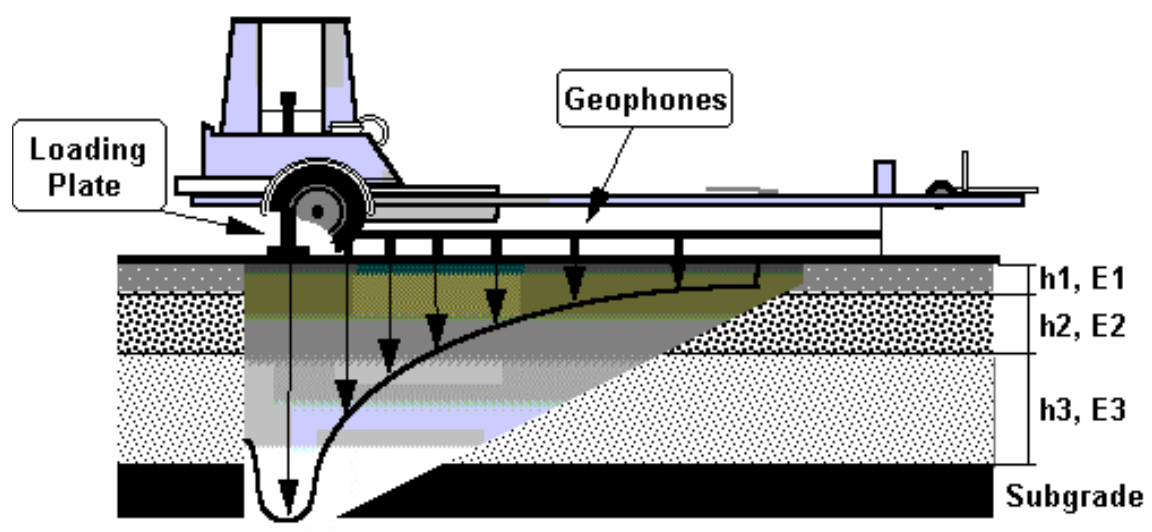

(Note: This schematic shows seven deflection readings. The work on this project made use of equipment with nine measurements)

Figure 12: Schematic of standard loading configuration and deflection basin 


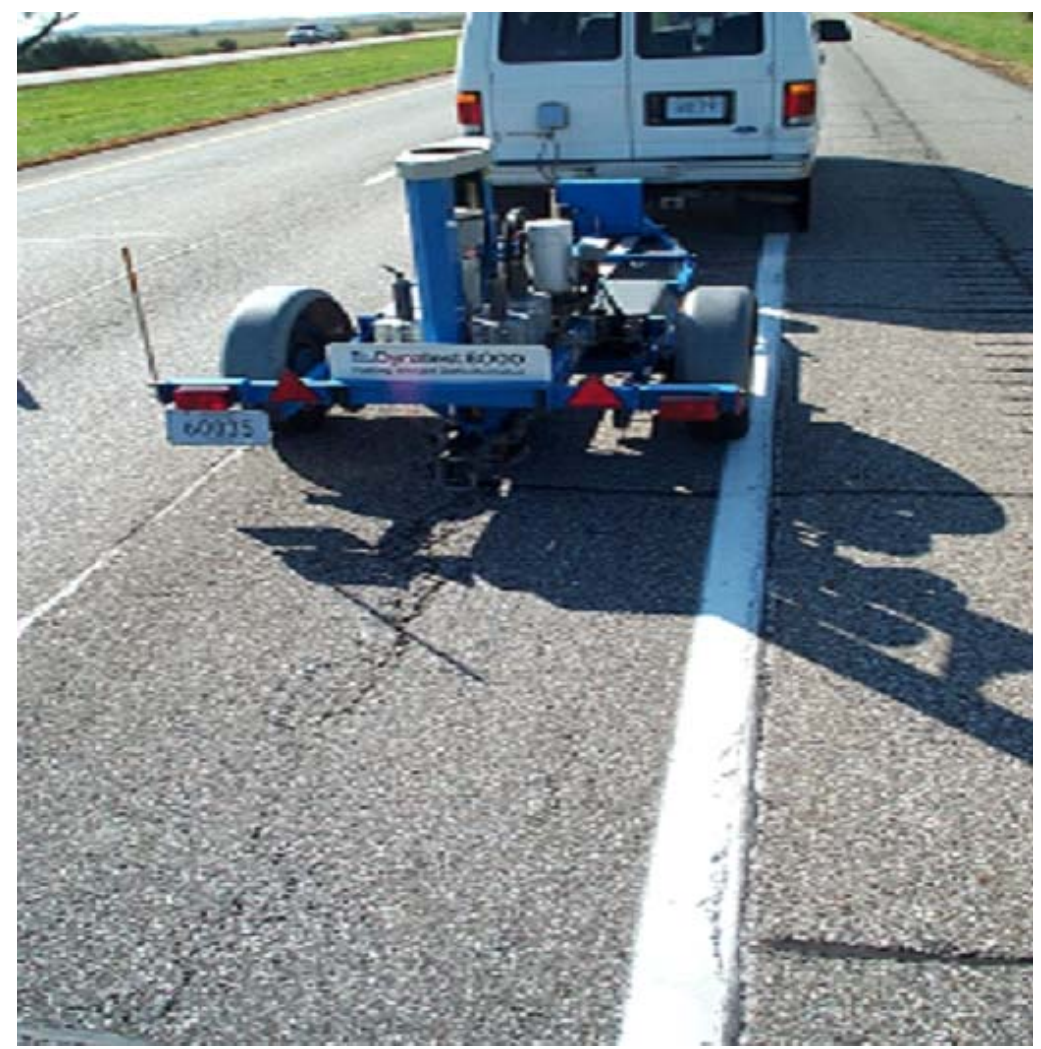

Figure 13: FWD testing on Site 1 (I-65 North of Lafayette).
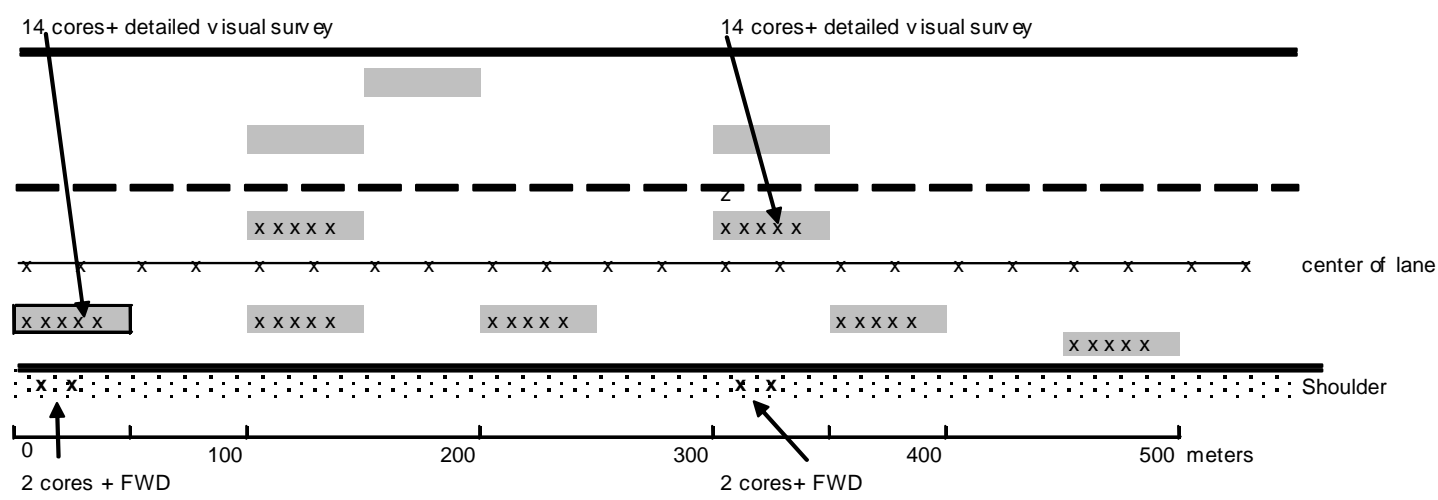

Note: Cores were not taken from the shoulder of site 1

Figure 14: Illustration of the locations for FWD measurements 
Table 5: Geophone spacing

\begin{tabular}{|l|l|l|}
\hline TRANSDUCER & $\begin{array}{l}\text { RADIAL } \\
\text { DISTANCE } \\
\text { (mm) }\end{array}$ & $\begin{array}{l}\text { RADIAL } \\
\text { DISTANCE } \\
\text { (in) }\end{array}$ \\
\hline $\mathrm{d} 1$ & 0 & 0 \\
\hline $\mathrm{d} 2$ & 203 & 8 \\
\hline $\mathrm{d} 3$ & 305 & 12 \\
\hline $\mathrm{d} 4$ & 457 & 18 \\
\hline $\mathrm{d} 5$ & 610 & 24 \\
\hline $\mathrm{d} 6$ & 914 & 36 \\
\hline $\mathrm{d} 7$ & 1219 & 48 \\
\hline $\mathrm{d} 8$ & 1524 & 60 \\
\hline $\mathrm{d} 9$ & 1828 & 72 \\
\hline
\end{tabular}

Table 6: Observations made from deflection

\begin{tabular}{|l|l|}
\hline \multicolumn{1}{|c|}{$\begin{array}{c}\text { DEFLECTION } \\
\text { PARAMETER }\end{array}$} & \multicolumn{1}{c|}{ PAVEMENT RESPONSE } \\
\hline $\mathrm{d} 1$ & $\begin{array}{l}\text { Provides an indication of total pavement performance. The } \\
\text { overall pavement structure appears to be reasonably uniform. }\end{array}$ \\
\hline $\mathrm{d} 1-\mathrm{d} 3$ & $\begin{array}{l}\text { Provides an indication of the condition of upper pavement } \\
\text { layers. }\end{array}$ \\
\hline $\mathrm{d} 7$ & Provides an indication of the soil stiffness. \\
\hline
\end{tabular}

Figure 15, Figure 16, and Figure 17 illustrate deflection profiles for Sites 1, 2 and 3, respectively. The figures show the deflection bowls are plotted as a function of twenty-one test stations.

From these plots of the deflection parameters we can summarize the pavement deflection response, as follows:

- Site 1 - The overall performance of this pavement (d1) indicates a reasonably high degree of variability. The variation in performance is associated with changes in deflection response of both the soil foundation and the rubblized base layers. The design thickness was $370 \mathrm{~mm}$. 


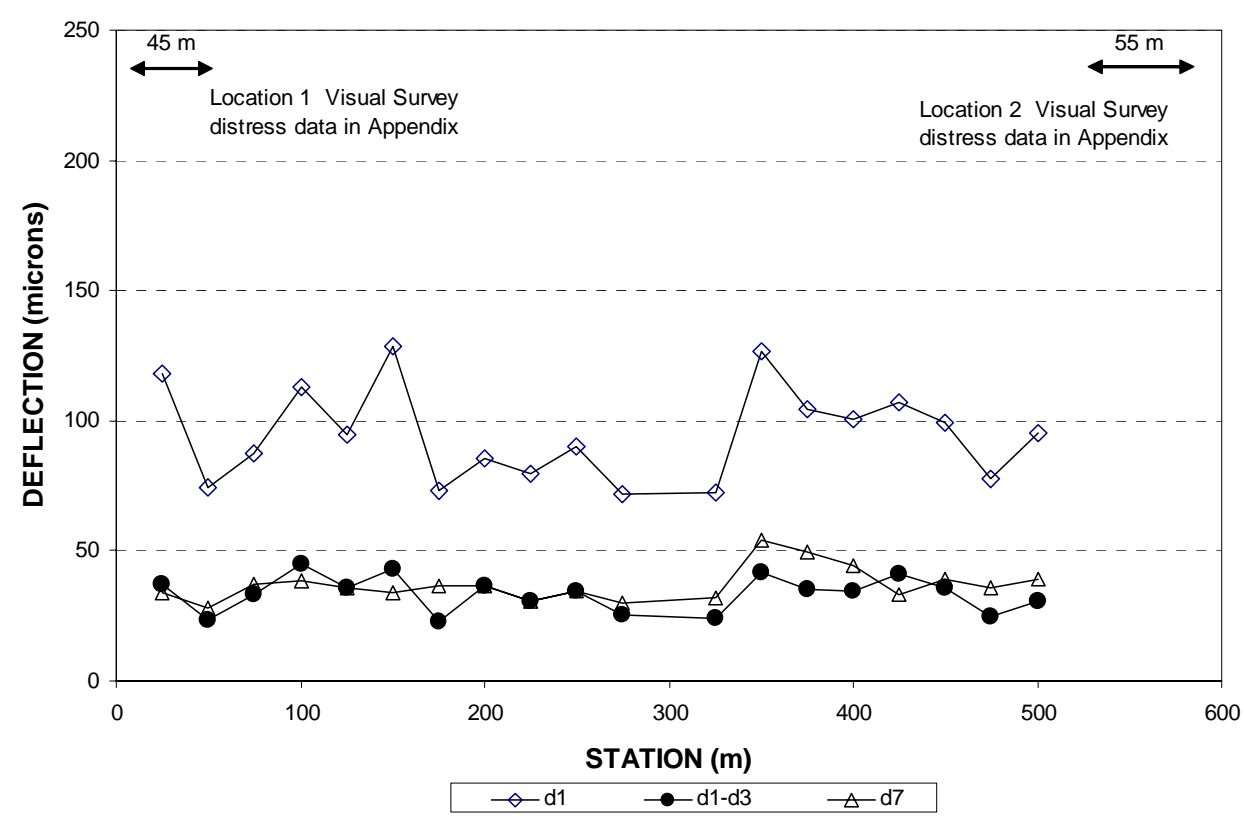

Figure 15: Inspection of Deflection Profile, Site 1 I-65 North

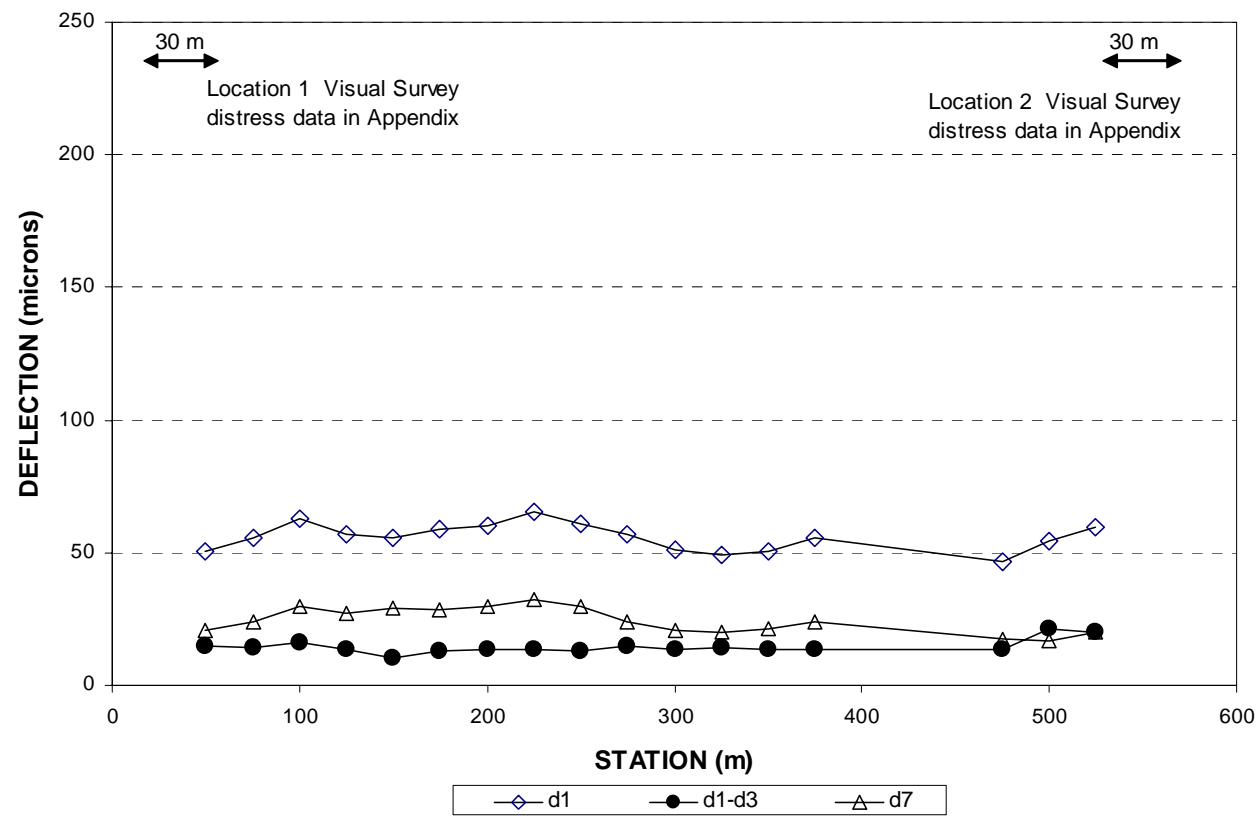

Figure 16: Inspection of Deflection Profile, Site 2 I-65 Loop 


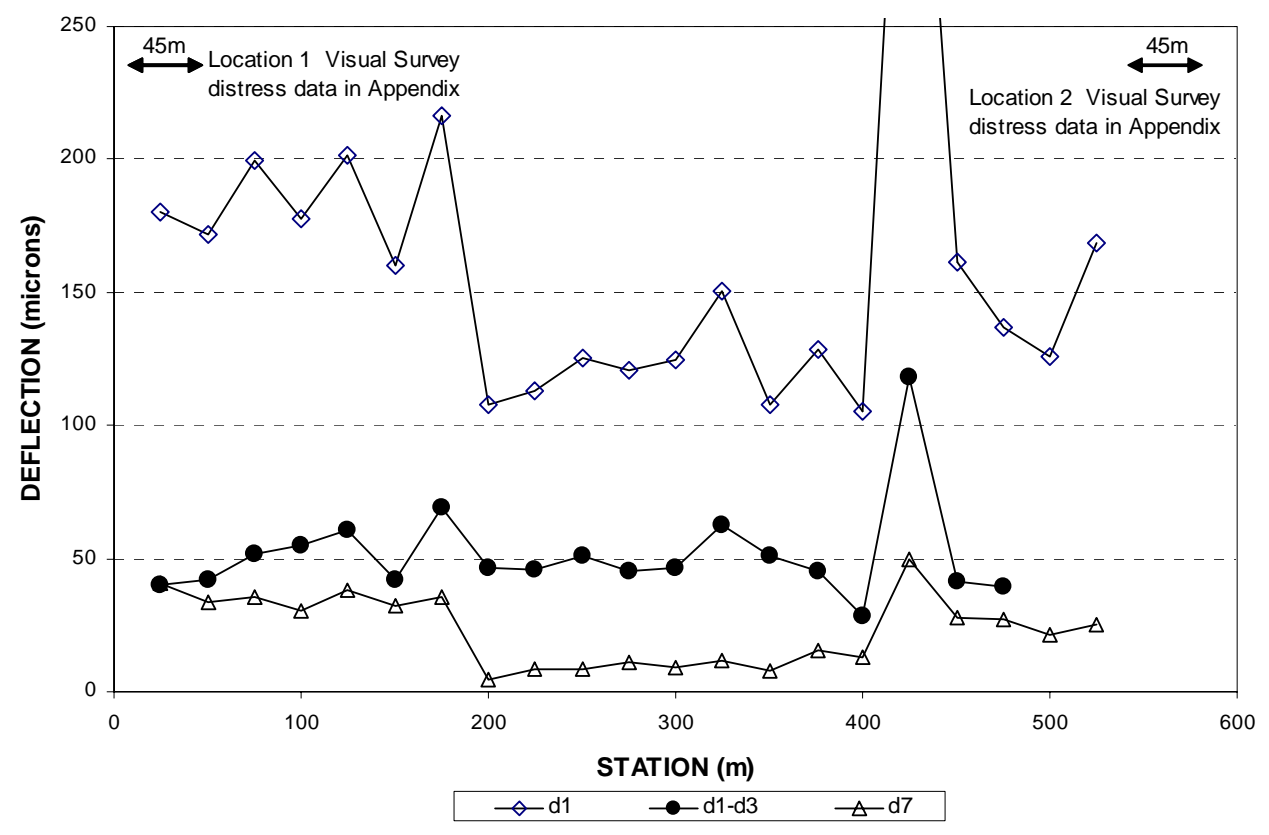

Figure 17: Inspection of Deflection Profile, Site 3 US 421 Madison

- Site 2 - This section has a relatively low and uniform deflection, due to the flexible base and thickness of construction used. The design thickness was $545 \mathrm{~mm}$.

- Site 3 - At test point 400 there is a large peak in deflection. This could be caused by a crack or some other local defect. The deflection response indicates higher deflections for the two thirds end, whereas the middle third has lower and more uniform deflections. The deflection profile $\mathrm{d} 7$ indicates a change in construction at two test points in the rubblized base layer. The design thickness was $200 \mathrm{~mm}$.

\subsubsection{Back-calculation of Stiffness Moduli}

The stiffness moduli of the pavement layers were determined from the FWD deflection data using back-calculation software DAPS ${ }^{\text {TM }}$ (Deflection Analysis of Pavement Software). This software models the pavement as a quasi-static problem representing the stiffnesses of the various layers by linear elastic moduli (with a Poisson's ratio) in an 
axisymetric layered elastic analysis.

In the determination of stiffness of the pavement layers the effect of the soil structure and method of modeling has been found to be of considerable importance (Rohde et al., 1992) on the fit of the deflection bowl. This aspect is considered in the software used by allowing selection of different soil models to represent the soil foundation. Selected deflection data was analyzed using the various methods allowed to assess which model best accounted for the deflection response. Based upon this analysis a model that computes a linear subgrade modulus with a specified depth resting over a rigid half space was adopted for the entire analysis; see Figure 18.

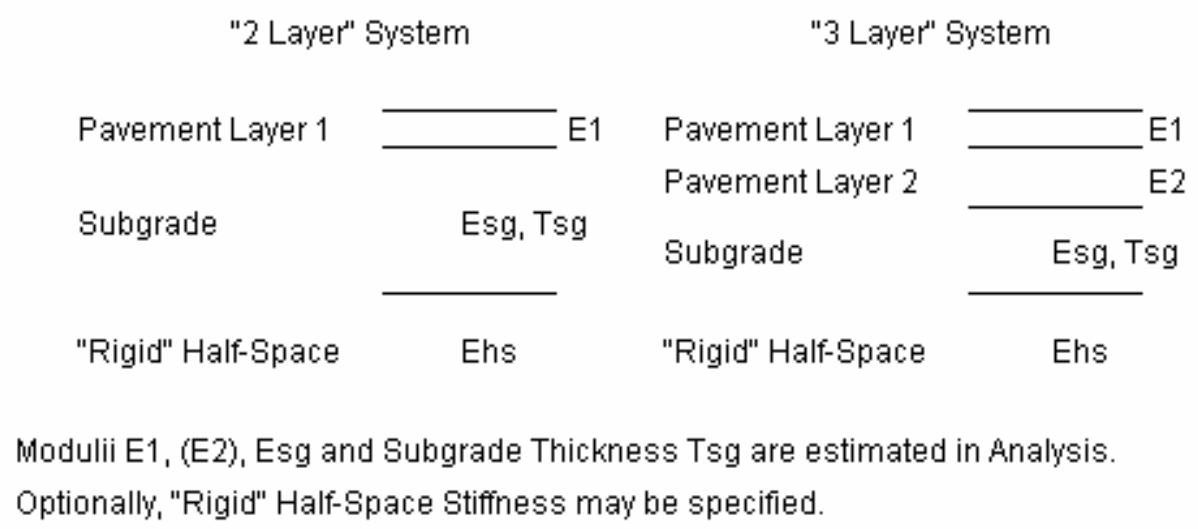

Figure 18: Definition of Rigid Half-Space and Subgrade Stiffness Model

The stiffness optimization uses a singular decomposition matrix analysis technique. In this process seven deflections for each bowl were used in the analysis. Checks for linearity in the pavement structural response indicated that the pavement could be treated as a linear system and that stress dependent effects on soil material properties did not significantly affect the analysis. Consequently, the best-fit solution from the back analysis was used from the analysis of the three tests at each test location, i.e., the bowl fit with the lowest rms (root-mean-square) error.

A least-square solution process was applied, employing seven of the nine measured 
deflections as parameters characterizing the bowl. The rigid base (half-space) beneath the subgrade allows, to some extent, for known effects of non-linearity within the subgrade soil. Rohde et al., (1992) noted the importance of including a depth-to-bedrock calculation and the effect that this can have on surface deflections. The rigid base depth is used as an unknown to be solved for, along with the layer stiffness. After experimentation with different soil models and bedrock stiffness values, a constant value of 10,000 MPa stiffness was assigned to bedrock in the calculation procedures. A least-square solution to these simultaneous equations was obtained by an iterative process using an over-determined equation set and Singular Value Decomposition technique (Press et al., 1986).

In the equations, the partial derivatives are estimated numerically, by elastic layer analysis. The deflection analysis provides the measured deflection bowl and the resulting fitted back-calculated bowl. A typical result is illustrated in Figure 19.

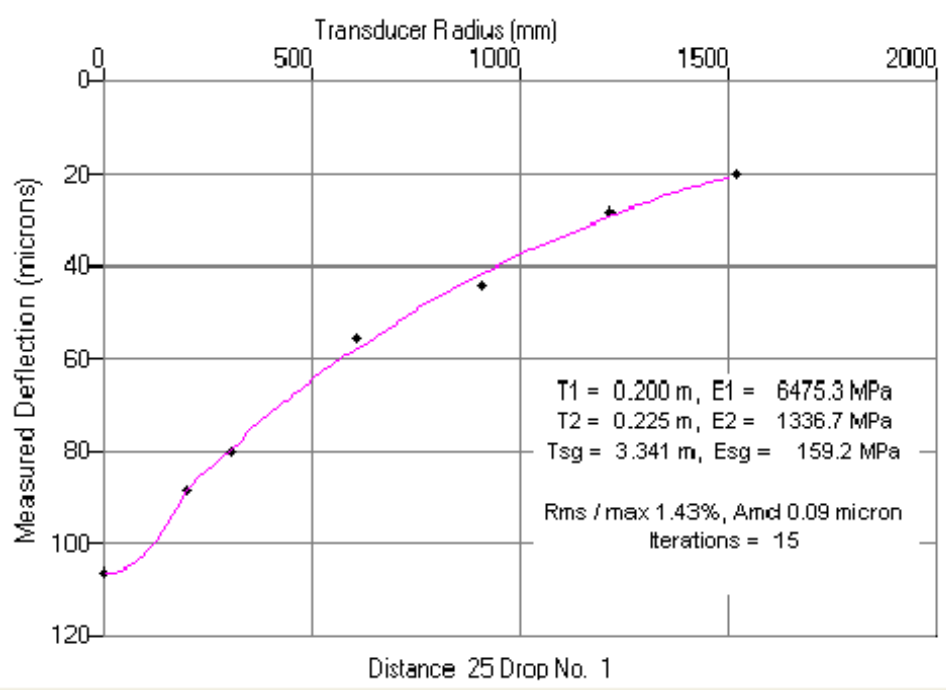

Figure 19: Example of fitted and measured FWD bowls, Site 3 US-421 Madison.

The results from this analysis are summarized in Table 7 for the median and 15percentile properties. The median is quoted rather than the mean since gross errors that often result in misleading values are excluded. For pavement design and rehabilitation a value similar to the 15 -percentile is often adopted since this gives a lower measure of the 
pavement stiffness and allows for the variability in materials to be considered.

For Site 1, both wheel paths had stiffer mix than the center area, while for Site 2 and 3 the opposite was true. The modulus values shown in Table 7 are not temperature corrected so comparison between the sites cannot be made.

Table 7: Statistical Analysis of FWD data.

\begin{tabular}{|c|c|c|c|c|}
\hline \multirow{2}{*}{\multicolumn{2}{|c|}{$\begin{array}{l}\text { LOCATION OF TESTING AND } \\
\text { STATISTIC }\end{array}$}} & \multicolumn{3}{|c|}{ STIFFNESS (MPa) } \\
\hline & & ASPHALT & SUBBASE & SOIL \\
\hline \multicolumn{5}{|c|}{$\begin{array}{l}\text { SITE 1: I-65 North of Lafayette } \\
\end{array}$} \\
\hline \multirow{2}{*}{ Left Wheel Path } & Median & 11,602 & 1,175 & 306 \\
\hline & 15 percentile & 9,487 & 498 & 274 \\
\hline \multirow{2}{*}{ Center } & Median & 7,995 & 799 & 319 \\
\hline & 15 percentile & 5,356 & 291 & 234 \\
\hline \multirow{2}{*}{ Right Wheel Path } & Median & 9,696 & 479 & 295 \\
\hline & 15 percentile & 7,747 & 234 & 255 \\
\hline \multicolumn{2}{|c|}{ Avg. Median Modulus } & 9,764 & 818 & 307 \\
\hline \multicolumn{2}{|c|}{ Avg. 15\% Modulus } & 7,530 & 341 & 254 \\
\hline \multicolumn{5}{|c|}{ SITE 2: I-65 Indianapolis } \\
\hline \multirow{2}{*}{ Left Wheel Path } & Median & 8,421 & 407 & 437 \\
\hline & 15 percentile & 7,049 & 103 & 131 \\
\hline \multirow{2}{*}{ Center } & Median & 10,901 & 96 & 681 \\
\hline & 15 percentile & 9,633 & 41 & 303 \\
\hline \multirow{2}{*}{ Right Wheel Path } & Median & 9,518 & 177 & 589 \\
\hline & 15 percentile & 8,635 & 70 & 390 \\
\hline \multicolumn{2}{|c|}{ Avg. Median Modulus } & 9,613 & 227 & 569 \\
\hline \multicolumn{2}{|c|}{ Avg. 15\% Modulus } & 8,439 & 71 & 275 \\
\hline \multicolumn{5}{|c|}{ SITE 3: US-421 Madison } \\
\hline \multirow{2}{*}{ Left Wheel Path } & Median & 3,062 & 622 & 259 \\
\hline & 15 percentile & 2,681 & 488 & 158 \\
\hline \multirow{2}{*}{ Center } & Median & 4,917 & 1490 & 239 \\
\hline & 15 percentile & 4,086 & 675 & 130 \\
\hline \multirow{2}{*}{ Right Wheel Path } & Median & 3,268 & 642 & 276 \\
\hline & 15 percentile & 2,758 & 500 & 179 \\
\hline \multicolumn{2}{|c|}{ Avg. Median Modulus } & 3,749 & 918 & 258 \\
\hline \multicolumn{2}{|c|}{ Avg. 15\% Modulus } & 3,175 & 554 & 155 \\
\hline
\end{tabular}




\subsubsection{Structural Capacity}

The structural capacities were assessed using AASHTO 1993 Pavement Design guide methodology (Huang, 2002) by estimating the effective structural number $\mathrm{SN}_{\text {eff }}$ of the studied pavements. By knowing the effective structural capacity of the pavement the additional structural capacity can be estimated to upgrade the pavement condition to the desired serviceability, $\mathrm{p}_{1}$.

The structural capacity was first assessed by estimating layer coefficients $a_{i}$ for different pavement layer using the back-calculated modulus values. Table 8 shows the measured pavement surface and air temperatures during FWD testing. Pavement temperatures were calculated using Equation (3) at 1/3 depth of each total asphalt layer thickness.

Table 8: Air and pavement temperatures for FWD back-calculation.

\begin{tabular}{|l|l|l|l|l|l|}
\hline SITE & $\begin{array}{l}\text { TEST } \\
\text { LINE }\end{array}$ & $\begin{array}{l}\text { SURFACE } \\
\text { TEMP. }\left({ }^{\mathbf{0}} \mathbf{C}\right)\end{array}$ & $\begin{array}{l}\text { AIR } \\
\text { TEMP. }\left({ }^{\mathbf{0}} \mathbf{C}\right)\end{array}$ & $\begin{array}{l}\text { DEPTH } \\
(\mathbf{m m})\end{array}$ & $\begin{array}{l}\text { PAVEMENT } \\
\text { TEMP. }\left({ }^{\circ} \mathbf{C}\right)\end{array}$ \\
\hline 1 & Left & 12.5 & 16.0 & 122.7 & 14.4 \\
\hline 1 & center & 9.1 & 12.7 & 122.7 & 11.0 \\
\hline 1 & right & 14.7 & 18.0 & 122.7 & 16.6 \\
\hline \multicolumn{2}{|c|}{ AVG. } & 12.1 & 15.6 & 122.7 & 14.0 \\
\hline 2 & left & 2.3 & 6.0 & 176.7 & 4.3 \\
\hline 2 & center & 2.9 & 5.8 & 176.7 & 4.4 \\
\hline 2 & right & 3.2 & 6.3 & 176.7 & 4.9 \\
\hline \multicolumn{2}{|c|}{ AVG. } & 2.8 & 6.1 & 176.7 & 5.0 \\
\hline 3 & left & 29.3 & 25.6 & 66.7 & 27.7 \\
\hline 3 & center & 25.6 & 24.2 & 66.7 & 24.8 \\
\hline 3 & right & 32.5 & 26.6 & 66.7 & 30.1 \\
\hline \multicolumn{2}{|c|}{ AVG. } & 29.1 & 25.5 & 66.7 & 28.0 \\
\hline
\end{tabular}

Table 9 shows the back-calculated temperature corrected HMA modulus values and back-calculated base and subgrade values for the three sites. Modulus values were corrected to $20^{\circ} \mathrm{C}$ temperature. Temperature correction was done using the Witczak et al. (Andrei, Witczak \& Mirza, 1999) stiffness predictive model by using relative stiffness 
ratios between the measured and targeted pavement temperatures. Based on the magnitude of the asphalt mix modulus, a structural number $\mathrm{a}_{1}=0.44$ was assigned to the asphalt layers. For Site 1 and 3, which had the rubblized Portland Cement Concrete base layer, the layer coefficient $\mathrm{a}_{2}=0.22$ was assigned following INDOT's pavement design practice. For Site 2 , the $\mathrm{a}_{2}=0.15$ was assigned estimating the layer coefficient from the back-calculated modulus value using Equation (2). Using Equation (3) and assuming the drainage coefficient $\mathrm{m}=1$, the effective structural numbers $\mathrm{SN}_{\text {eff }}$ were computed. In Equation (3), D is the thickness of the layer. All back-calculated modulus values were average modulus values obtained from Table 7.

$$
\begin{aligned}
& a_{2}=0.249\left(\log E_{2}\right)-0.977 \\
& S N_{\text {eff }}=a_{1} D_{1}+a_{2} D_{2} m
\end{aligned}
$$

\begin{tabular}{|c|c|c|c|c|c|c|c|}
\hline \multirow{2}{*}{$\begin{array}{l}\mathrm{E}_{\mathrm{AC}}(\mathrm{MPa}) \\
@ 20^{\circ} \mathrm{C}\end{array}$} & \multirow{2}{*}{$\begin{array}{l}E_{\text {Base }} \\
\text { (MPa) }\end{array}$} & \multirow{2}{*}{$\begin{array}{l}\mathbf{M}_{\mathrm{R}} \\
\text { (MPa) }\end{array}$} & \multicolumn{2}{|c|}{$\begin{array}{l}\text { HMA } \\
\text { LAYER }\end{array}$} & \multicolumn{2}{|c|}{$\begin{array}{l}\text { BASE } \\
\text { LAYER }\end{array}$} & \multirow{2}{*}{$\mathrm{SN}_{\text {eff }}$} \\
\hline & & & $\mathbf{a}_{1}$ & $\mathbf{D}_{1}$ (in) & $\mathbf{a}_{2}$ & $\mathbf{D}_{2}$ (in) & \\
\hline 6,752 & 818 & 307 & 0.44 & 14.5 & 0.22 & 16.0 & 9.9 \\
\hline & & & 0.2 & 20.9 & 0.1 & 18. & 11.9 \\
\hline 6,263 & 918 & 258 & 0.44 & 8.0 & 0.22 & 15.0 & 6.8 \\
\hline
\end{tabular}

Table 9: $\mathrm{SN}_{\text {eff }}$ based on assigned layer coefficient values.

According to AASHTO 1993 Design Guide, an alternative way of estimating the effective structural number is to use deflection far from the load to obtain the subgrade resilient modulus $\mathrm{M}_{\mathrm{R}}$. Deflection sensors $\mathrm{d} 7$ and $\mathrm{d} 1$ were used in the analysis, and all deflection values were temperature corrected using the AASHTO temperature correction tables.

Table 10 shows the back-calculated subgrade modulus values using this method. The $\mathrm{SN}_{\text {eff }}$ was computed using Equation (4) where D is the total pavement layer thickness, and $E_{p}$ is the effective modulus of all pavement layers above the subgrade. 


$$
S N_{e f f}=0.0045 D \sqrt[3]{E_{p}}
$$

Deflection sensors $\mathrm{d} 7$ and $\mathrm{d} 1$ were used in the analysis, and all deflection values were temperature corrected using the AASHTO temperature correction tables.

Table 10: $\mathrm{SN}_{\text {eff }}$ based on deflection sensors $\mathrm{d} 7$ and $\mathrm{d} 1$.

\begin{tabular}{|l|l|l|l|}
\hline $\begin{array}{l}\text { SUBGRADE } \\
\mathbf{M}_{\mathbf{R}}(\mathbf{M P a})\end{array}$ & $\mathbf{E}_{\mathbf{p}}$ (MPa) & $\mathbf{D}$ (in) & $\mathbf{S N}_{\text {eff }}$ \\
\hline 287 & 2,046 & 30.5 & 9.1 \\
\hline 423 & 2,212 & 38.8 & 12.0 \\
\hline 474 & 1,016 & 23.0 & 5.5 \\
\hline
\end{tabular}

The highest pavement thickness in the AASHTO guide temperature correction tables is only $240 \mathrm{~mm}$ and only Site 3 complied with this. The other two sites, however, were much thicker. Therefore, the analysis was also done using the deflection temperature correction based on the relative pavement stiffness approach described above. The $\mathrm{SN}_{\text {eff }}$ was also computed using back-calculated $\mathrm{M}_{\mathrm{R}}$ values with Equation (4) and estimating $\mathrm{E}_{\mathrm{p}}$ using Equation (5) and then applying Equation (4). Table 11 summarizes results from all methods giving the average $\mathrm{SN}_{\text {eff }}$ values of 8.5, 10.2, and 6.1 for Sites 1, 2 and 3, respectively. It can be assumed that their average values are closest to the actual structural numbers of the sites.

$$
E_{p}=\frac{E_{n}}{h^{3}}\left(\sum_{i=1}^{n} h^{i} \sqrt[3]{\frac{E_{i}}{E_{n}}}\right)^{3}
$$

where:

$$
\begin{aligned}
& \mathrm{h}=\text { existing layer thickness } \\
& \mathrm{n}=\text { number of sublayers for which modulus values are computed } \\
& \mathrm{i}=\text { sublayer for which a modulus value is computed }
\end{aligned}
$$


Table 11: Average Effective Structural Number and traffic carrying capacity.

\begin{tabular}{|l|l|l|l|l|}
\hline SITE & $\mathbf{E}_{\mathbf{p}} \mathbf{( M P a )}$ & $\begin{array}{l}\text { SUBGRADE } \\
\mathbf{M}_{\mathbf{R}} \text { (MPa) }\end{array}$ & $\mathbf{S N}_{\text {eff }}$ & $\begin{array}{l}\mathbf{W}_{\mathbf{1 8}} \\
\mathbf{1 0}^{\mathbf{8}} \text { ESALs }\end{array}$ \\
\hline 1 & 2,187 & 271 & 8.5 & 22.6 \\
\hline 2 & 1,682 & 462 & 10.2 & 341 \\
\hline 3 & 2,274 & 287 & 6.1 & 2.61 \\
\hline
\end{tabular}

The 18-kip ESALs traffic $\mathrm{W}_{18}$ was computed using AASHTO 1993 flexible pavement design equation (Huang, 2002) with $\mathrm{S}_{0}=0.35$, Reliability $=95 \%$, and $\Delta \mathrm{PSI}=$ 1.7. The subgrade $M_{R}$ values shown in Table 11 are corrected by $C=0.33$ for the analysis.

After modulus temperature correction, Site 1 had the highest asphalt layer stiffness followed by Site 3 and 2, as Table 9 shows. The lower stiffness in Site 2 can be explained by the thick open graded asphalt layer that was used at the bottom of the layer. In the mix analysis it was assumed that the air void content of the open graded layer was $18 \%$.

The cracked wheel paths did not have a lower modulus compared to the center of the pavement lane, as would be expected if the top-down cracking had weakened the pavement structure. All sites have excellent structural capacity despite the surface cracking. Based on the computed structural numbers and estimated traffic levels, Site 2 is a perpetual pavement based on the AASHTO 1993 Pavement Design Guide methodology. 


\section{LABORATORY TESTING}

\subsection{Coring}

Several $150 \mathrm{~mm}$ (6 inch) diameter cores were obtained from the surface cracked pavements of each site to check the existence of top-down cracking and to measure mixture and binder properties. Three cores from the cracked area, nine to eleven cores from the uncracked section around it, and two cores from the shoulder were obtained. Since there were two test locations per site, the total number of cores ranged from 29 to 32 depending on the study site.

The coring locations, mile posts, and exact distances between cores for the three sites are mapped in the distress data sheets presented in Appendix A. Figure 20 shows the coring location for Site 1 (I-65 North of Lafayette).

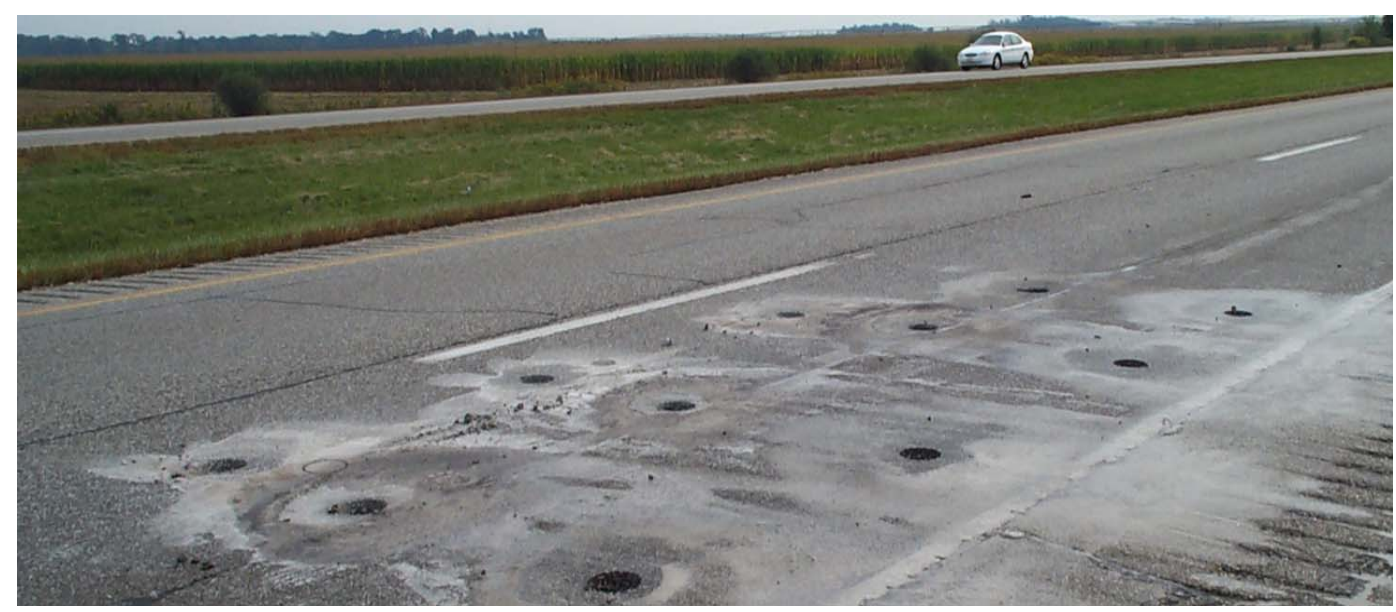

Figure 20: Coring locations in the pavement, Site 1.

Appendix C presents a detailed log in sheet for the obtained cores for the three sites. It also shows results of the core ID numbers, measured core thicknesses, inspection notes, and a detailed plan of testing responsibilities. 


\subsection{Laboratory Test Plan}

Material testing followed a scheme that would enable mixture properties to be tied to the fundamental performance prediction properties, see Figure 21. Only the upper portion of the pavement section that exhibited surface cracking was included in the analysis for material properties.

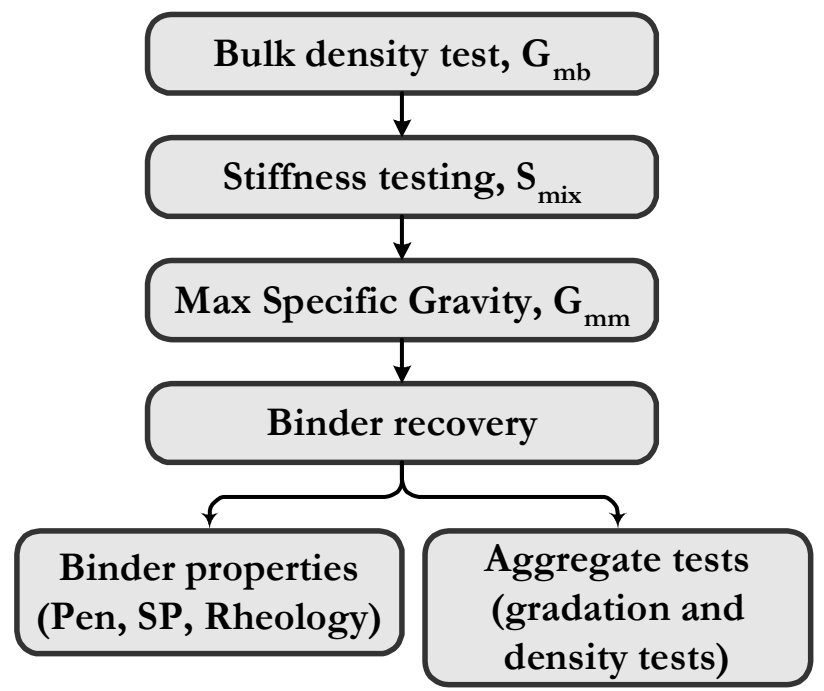

Figure 21: Laboratory testing plan for cores

The laboratory testing program was carried out with the help of North Central Superpave Center (NCSC). Test plan included binder and mixture consistency and mechanical tests to identify the mix properties that might affect the top-down cracking. The various mix parameters relating to different mixture properties are shown in Table 12. Table 12 also indicates the test method used for each parameter tested and test conditions.

Appendix $\mathrm{C}$ shows a detailed plan of testing with respect to the testing agency, the amount of material needed for binder testing, and results of the core thickness measurements and sample condition inspections. 
Table 12: Measured parameters and test procedures

\begin{tabular}{|c|c|c|c|c|c|}
\hline TEST METHOS & PARAMETER & $\begin{array}{l}\text { TESTING } \\
\text { ORDER }\end{array}$ & $\begin{array}{l}\text { NUMBER OF CORES PER SITE TO } \\
\text { BE TESTED }\end{array}$ & NOTES & $\begin{array}{l}\text { TESTING } \\
\text { AGENCY }\end{array}$ \\
\hline AASHTO T166 & Bulk Sp.Gravity, $\mathrm{G}_{\mathrm{mb}}$ & 1 & all 22 intact cores per site & 22 per site, 66 total & Purdue \\
\hline AASHTO TP7 & Shear Stiffness $\left|G^{*}\right|$ & 2 & 2 cores per site, $4,10,20,40$ and $55^{\circ} \mathrm{C}$ & $2\left|\mathrm{G}^{*}\right|$ per site, 6 total & NCSC \\
\hline AASHTO TP9 & Creep Compliance D(t) & 2 & $\begin{array}{l}6 \text { cores per site, }-20,-10,0^{\circ} \mathrm{C}(2 \text { cores per } \\
\text { temperature })\end{array}$ & $6 \mathrm{D}(\mathrm{t})$ per site, 18 total & $\mathrm{NCSC}$ \\
\hline ААНТО ТР9 & Indirect tensile strength & 2 & $\begin{array}{l}6 \text { cores using same specimen as for } \mathrm{D}(\mathrm{t}), 2 \\
\text { cores per temperature, }-20,-10,0^{\circ} \mathrm{C}\end{array}$ & $\begin{array}{l}6 \text { Strength values per site, } \\
18 \text { total }\end{array}$ & $\mathrm{NCSC}$ \\
\hline AASHTO T 209 & $\begin{array}{l}\text { Maximum specific } \\
\text { gravity, } \mathrm{G}_{\mathrm{mm}}\end{array}$ & 3 & $\begin{array}{l}\text {-combine } 2 \text { to } 3 \text { cores to get one } 1.5 \mathrm{~kg} \\
\mathrm{G}_{\mathrm{mm}} \text { sample } \\
\text {-make } 2 \text { samples per site }\end{array}$ & $2 \mathrm{G}_{\mathrm{mm}}$ per site, 6 total & Purdue \\
\hline AASHTO TP2 & $\begin{array}{l}\text { Extraction to get binder } \\
\text { content, } \mathrm{P}_{\mathrm{b}}\end{array}$ & 4 & $\begin{array}{l}\text {-use } G_{m m} \text { samples to get respective binder } \\
\text { content }\end{array}$ & $2 P_{b}$ per site, 6 total & NCSC \\
\hline AASHTO TP2 & Binder recovery & 4 & $\begin{array}{l}\text {-all } 28 \text { cores per site if needed } \\
\text {-recover } \mathrm{G}_{\mathrm{mm}} \text { samples separately to obtain } \\
\mathrm{P}_{\mathrm{b}}\end{array}$ & $\begin{array}{l}\text { one "set" of binder } \\
\text { samples (rheological) per } \\
\text { site using all cores }\end{array}$ & $\mathrm{NCSC}$ \\
\hline $\begin{array}{l}\text { AASHTO T11\& } \\
\text { T27 }\end{array}$ & Gradation & 5 & $\begin{array}{l}\text { Use recovered aggregate from both } \mathrm{G}_{\mathrm{mm}} \\
\text { samples }\end{array}$ & $\begin{array}{l}2 \text { gradations per site, } \\
6 \text { total }\end{array}$ & Purdue \\
\hline AASHTO T49 & Penetration at 2 temp & 6 & $\begin{array}{l}\text { one test per site (note each test normally } \\
\text { includes three needles in tin) }\end{array}$ & 2 Pen per site, 6 total & $\mathrm{NCSC}$ \\
\hline AASHTO T53 & Softening Point & 6 & 2 replicates per site & $2 T_{R \& B}$ per site, 6 total & $\mathrm{NCSC}$ \\
\hline AASHTO TP5 & $\begin{array}{l}\text { DSR frequency sweep at } \\
5 \text { temperatures }\end{array}$ & 6 & $\begin{array}{l}2 \text { replicates per site } \\
\text { tests at } 76,35,64,52,40,25 \text { and } 15^{\circ} \mathrm{C} \text { in } \\
\text { range } 0.1 \mathrm{rad} / \mathrm{sec} \text { to } 10 \mathrm{rad} / \mathrm{sec} \text {. Use IP } \\
\text { standard to get strain levels. }\end{array}$ & 2 test per site, 6 total & $\mathrm{NCSC}$ \\
\hline AASHTO TP3 & DTT at 2 temperatures & 6 & $\begin{array}{l}1 \text { replicates per site (needs } 6 \text { specimens per } \\
\text { test), }-6,-12 \text { and }-18{ }^{\circ} \mathrm{C}\end{array}$ & 6 test per site, 18 total & NCSC \\
\hline
\end{tabular}




\subsection{Measured Layer Thicknesses}

The pavement structure in each study site consisted of full depth asphalt. Sites I-65 North and US-421 had rubblized concrete base, and I-65 near Indianapolis had compacted subgrade base. The structural design thicknesses for the full depth asphalts were $370 \mathrm{~mm}$, $530 \mathrm{~mm}$, and $200 \mathrm{~mm}$, respectively. The obtained cores were inspected and different pavement layers in the cores were measured using a caliper.

The measured pavement layer thicknesses are summarized in Table 13. It was observed that the average measured thickness of full depth asphalt converged in the case of Site 3, US-421 Madison, where the design thickness was $200 \mathrm{~mm}$. For Site 2, the difference between the measured HMA thickness of $474 \mathrm{~mm}$ and design thickness of $530 \mathrm{~mm}$ was 75 $\mathrm{mm}$. By inspection it was obvious that the cores were not obtained through the full thickness of the pavement, because the last layer was the large aggregate drainage layer designated as Bituminous Base $2 \mathrm{HV}$, instead of the finer base layer of Bituminous Base $5 \mathrm{D}$ (see Table 1). For Site 1, the difference between measured HMA thickness of $311 \mathrm{~mm}$ and design thickness of $370 \mathrm{~mm}$ is $59 \mathrm{~mm}$. Again, it can be assumed that the obtained core did not include a full thickness of the designed base layer.

Table 13: Measured layer thicknesses.

\begin{tabular}{|c|c|c|c|c|c|c|c|c|}
\hline \multicolumn{3}{|c|}{ SITE 1: I-65 North } & \multicolumn{3}{|c|}{ SITE 2: I-65 Loop } & \multicolumn{3}{|c|}{ SITE 3: US-421 Madison } \\
\hline \multirow{2}{*}{ LAYER } & \multicolumn{2}{|c|}{ THICKNESS } & \multirow{2}{*}{ LAYER } & \multicolumn{2}{|c|}{$\begin{array}{c}\text { THICKNES } \\
\text { S }\end{array}$} & \multirow{2}{*}{ LAYER } & \multicolumn{2}{|c|}{ THICKNESS } \\
\hline & $(\mathbf{m m})$ & (in) & & $(\mathrm{mm})$ & (in) & & $(\mathbf{m m})$ & (in) \\
\hline Surface 9.5 & 30.6 & 1.2 & Surface 9.5 & 30.6 & 1.2 & Surface 12.5 & 33.2 & 1.3 \\
\hline Interm 12.5 & 114.8 & 4.5 & Interm 12.5 & 66.3 & 2.6 & Interm 19.0 & 76.5 & 3.0 \\
\hline Interm 19.0 & 89.3 & 3.5 & Interm 19.0 & 122.4 & 4.8 & Base 25.0 & 89.3 & 3.5 \\
\hline Base 25.0 & 76.5 & 3.0 & Base $63.6^{*}$ & 255.0 & 10.0 & - & - & - \\
\hline Total & 311.1 & 12.3 & Total & 474.3 & 18.7 & Total & 198.9 & 7.8 \\
\hline
\end{tabular}


Also the maximum nominal aggregate size of each mix was estimated measuring the nominal maximum aggregate size (NMAS) of the mixtures. The estimated nominal maximum aggregate is given next to the layer type information in Table 13. Estimation was done by randomly measuring the size of aggregates from the cores.

\subsection{Inspection of Cracks from Cores}

\subsubsection{Visual Inspection}

The three cores obtained from the cracked locations of pavement were examined to investigate the length of the top-down cracks and their orientation in the pavement. The visual inspection indicated that cracks did not seem to penetrate deeper than the thin surface layer.

Figure 22 shows pictures of three cracked cores, one core from each test site. For Site 1, the core ID is S2, for Site 2 the core ID is S20, and for Site 3 the core ID is S21. It is evident that the surface cracks did not penetrate visibly through the cores. The figure also shows the various pavement layers and aggregate size of the mix. Note that the core shown for Site 2 and 3 does not present the full depth of the pavement because the bottom part of the core was not retrieved during coring.

A detailed crack inspection was done for all cracked cores. Figures 23, 24, and 25 show obtained core, core location, and measured crack length for the three sites. Figure 23 shows Site 1 with visible cracking in the surface of the core. The thickness of the crack was $20 \mathrm{~mm}$ and crack orientation was downward skewed. The visible surface crack did not seem to penetrate further to the pavement than to the surface course. 

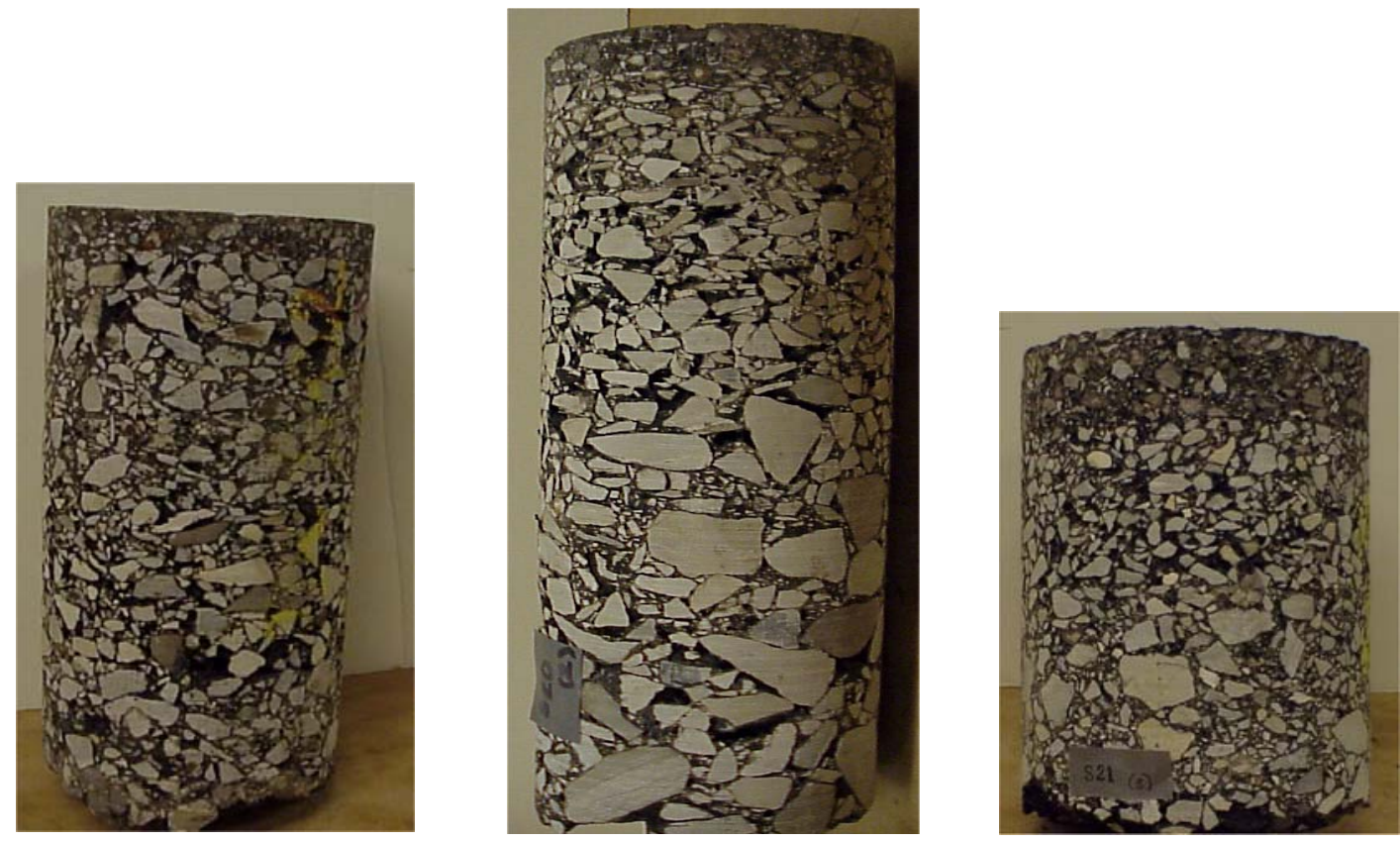

Site 1: Core height $300 \mathrm{~mm}$ Site 2: Core height $430 \mathrm{~mm}$ Site 3: Core height $200 \mathrm{~mm}$

Figure 22: Surface cracked cores obtained from the studied pavement sites.

Figure 24 shows typical cracking of Site 2, where the cracks were more like narrow hairline cracks with a low visibility. Again, the crack does not seem to penetrate further to the pavement than to the surface layer. The length of the crack was $22 \mathrm{~mm}$ and it was oriented vertically downward. The core shown in this figure is not a full length core because the large size aggregate layer created a weaker joint and layers were separating during handling of the cores.

Figure 25 shows a typical cracking of Site 3, where the cracks were more visible being in the centerline of the pavement. The core shown in this figure was taken from the left wheel path from a thin hairline cracked section. The crack length was $15 \mathrm{~mm}$ being half of the surface layer thickness, and the crack was oriented vertically downward. 


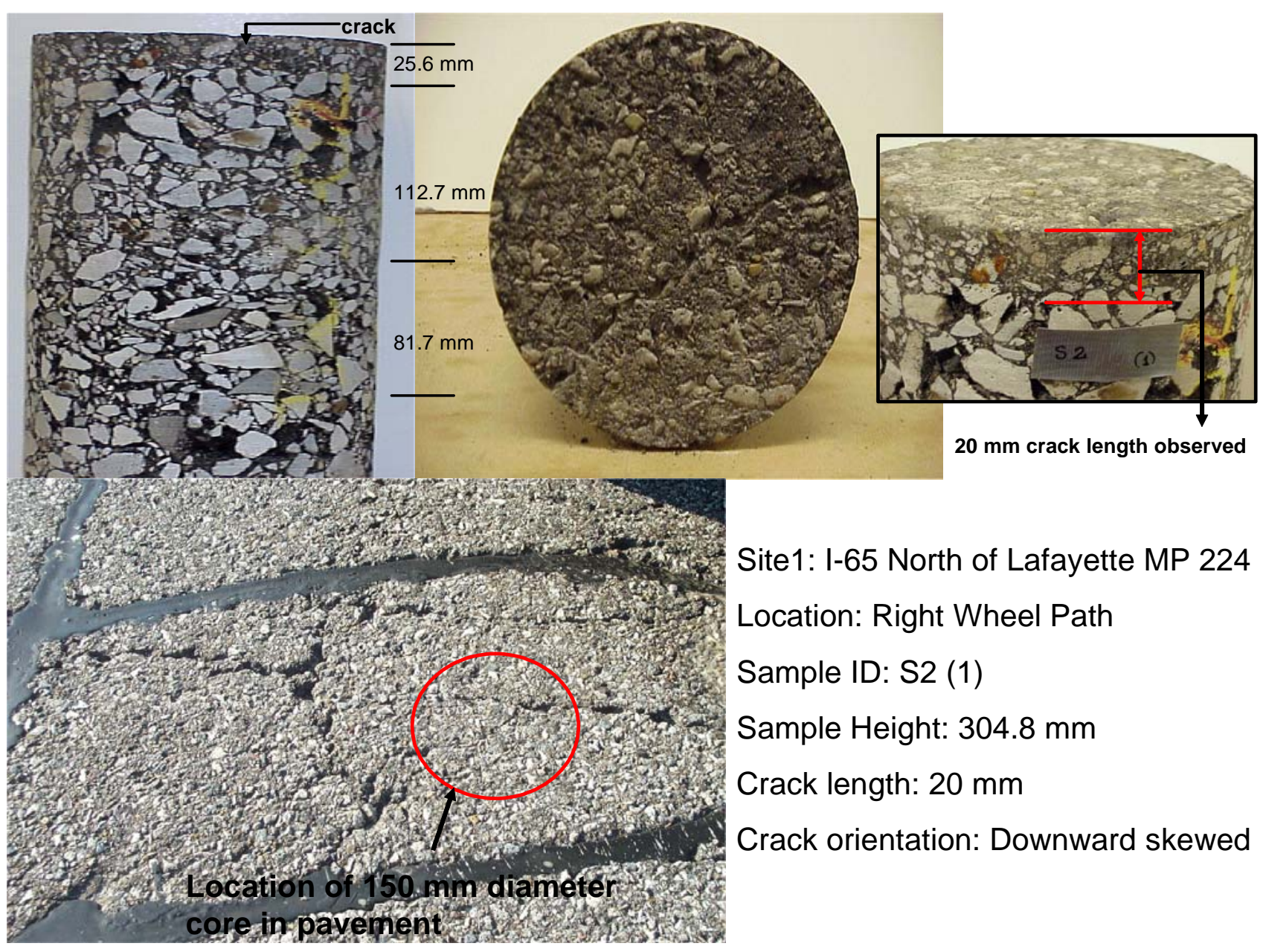

Figure 23: Inspection of Cracks, Site 1, I-65 North. 


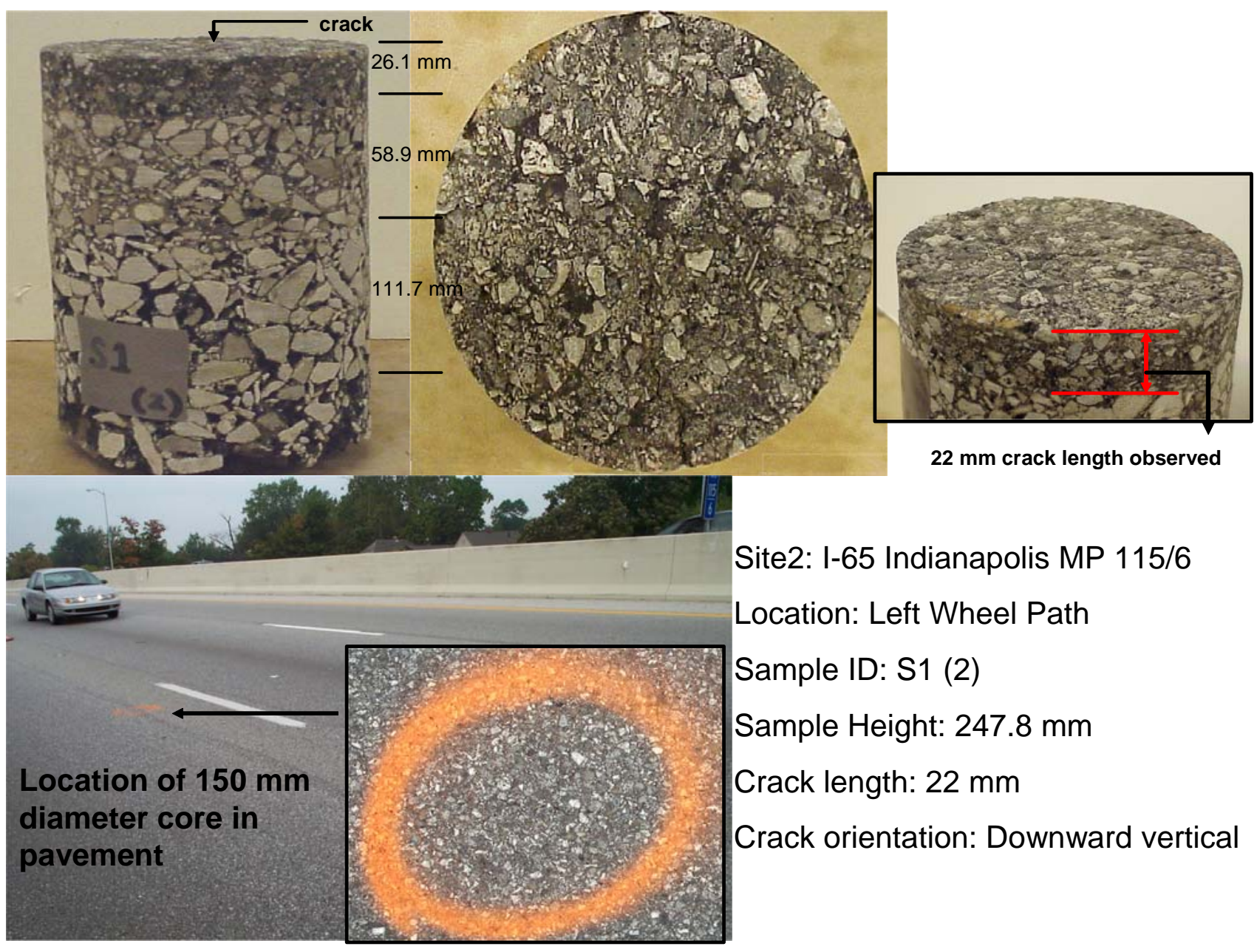

Figure 24: Inspection of Cracks, Site 2, I-65 Loop. 

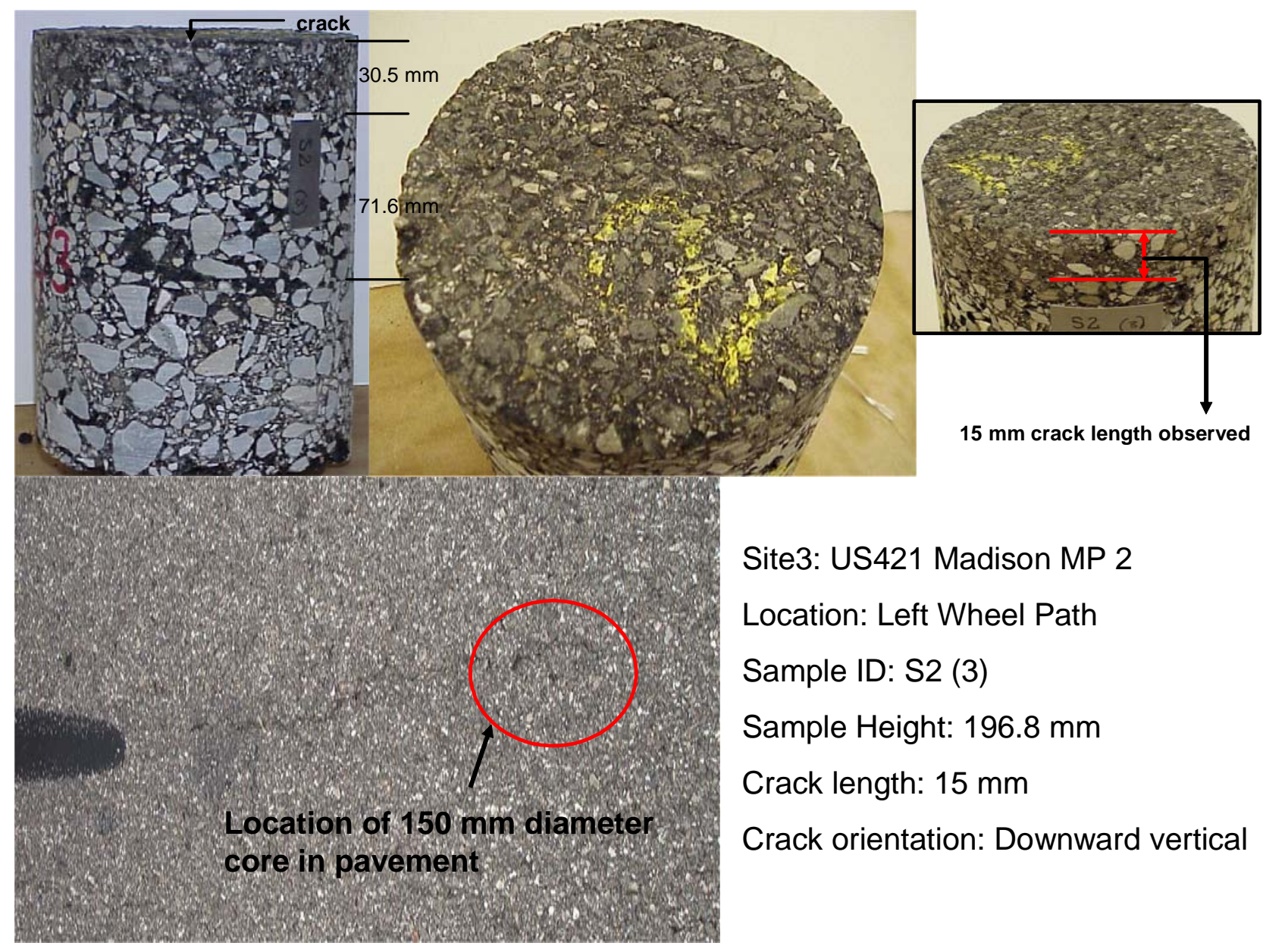

$15 \mathrm{~mm}$ crack length observed

Site3: US421 Madison MP 2

Location: Left Wheel Path

Sample ID: S2 (3)

Sample Height: $196.8 \mathrm{~mm}$

Crack length: $15 \mathrm{~mm}$

Crack orientation: Downward vertical

Figure 25: Inspection of Cracks, Site 3, US-421 Madison. 


\subsubsection{Imaging Analysis}

Based on the visual observations, the length of the crack was approximately $20 \mathrm{~mm}$ from the surface. A three dimensional (3-D) imaging analysis using X-ray Tomography (CAT scanning) was performed on cracked cores to investigate the path and mechanism of crack propagation in the pavement, and to compare the results of the crack length from the imaging analysis with the visual observations. The imaging analysis was conducted at the Turner Fairbank Highway Research Center (TFHRC) with the Simulation, Imaging and Mechanics of Asphalt Pavement (SIMAP) program, see Figure 26.

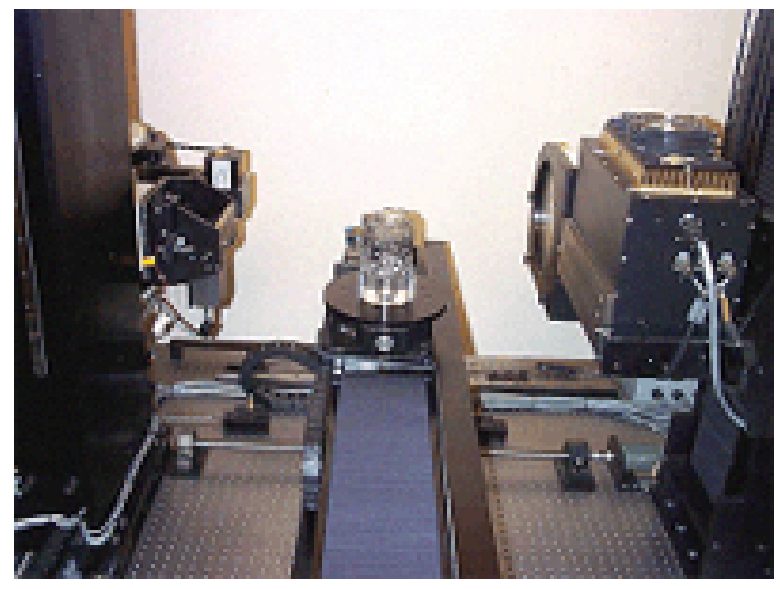

Figure 26: X-Ray Scanning at TFHRC

The X-ray tomography imaging is a non-destructive technique to investigate the internal structure of materials. It measures the path of X-rays through the material. It differs from the traditional X-ray technique with respect to energy. The technique for producing a tomography image includes data acquisition, reconstruction of structure and picture processing. For data acquisition, the structure is rotated while being exposed to high-energy $\mathrm{X}$-ray beams. The radiation that is not absorbed by the material is detected and digitally saved as raw data. For reconstruction of image, the data is analyzed mathematically to produce a cross sectional picture of the scanned image. The picture is then processed with 
different scales of colors for representing different phases, internal cracks, geometrical characteristics and deformations. The X-ray tomography has been applied various ways to study the asphalt concrete such as 3-D imaging of specimen, predicting mechanical response of mixture by applying mechanics to 3-D images, analyzing segregation of aggregate structure, and distribution of air void contents.

For each study site, one $150 \mathrm{~mm}$ diameter core obtained from the cracked area of the pavement was analyzed by X-ray Tomography Analysis (CAT scanning). From Site 1, core ID S16 (1), Site 2 core ID S1 (2), and Site 3 core ID S2 (3) were analyzed. Note that the scanned cores for Site 2 and 3 are the same cores shown in Figures 23 and 24.

A cross-sectional picture of the cores was reconstructed from the scanned image. The 3-D picture was then sliced into 184 slices for Site1 and Site3, and 186 slices for Site 2, to investigate crack propagation inside the core. Figure 27 shows the same scanned slice in three different color combinations, green, red and black \& white. The ID of the core shown in Figure 27 is S16 (1) and it is from Site1 I-65 north of Lafayette. No visible cracks can be detected inside the core.

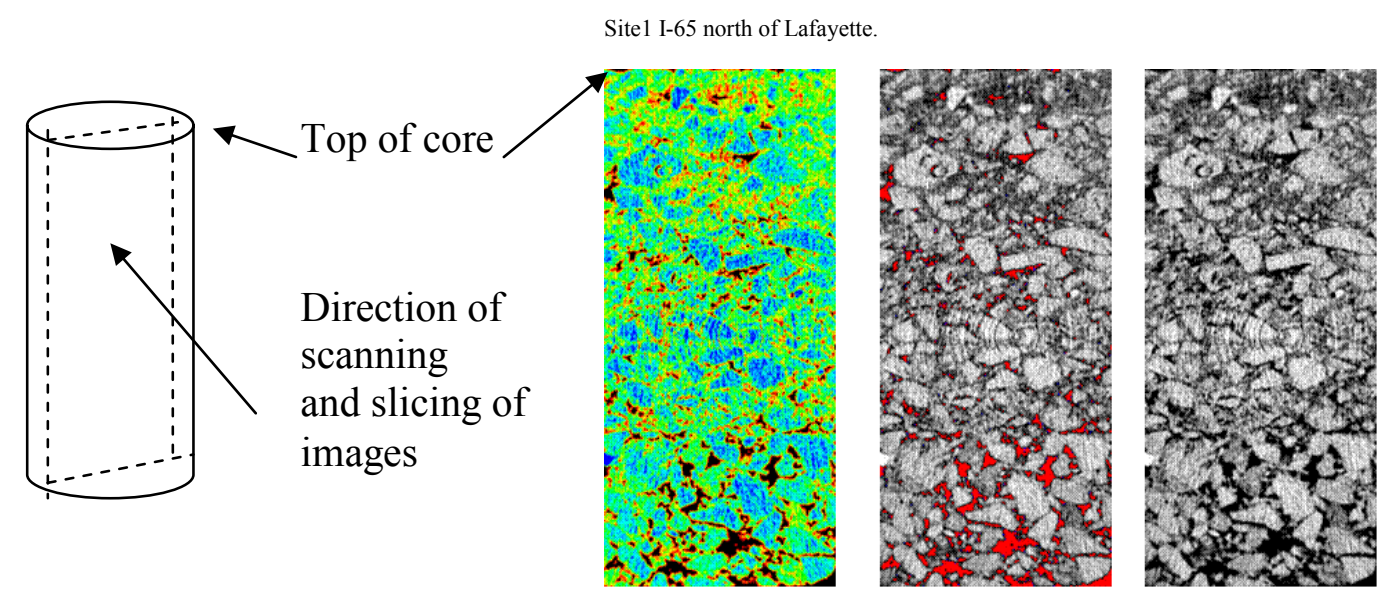

Green, red and black and white images

Figure 27. Scanning of Cores. 
Figure 28 shows another example of the inspected core. The ID of the core is S2 (3) from Site 3. Inspection tried to identify direction of crack propagation, average height of cracks, and cracking pattern from the X-ray tomography sliced images. Inspection of images indicates that the visible crack seen in the top of the core does not penetrate deeper to the core than the surface layer, agreeing with the visual observations.

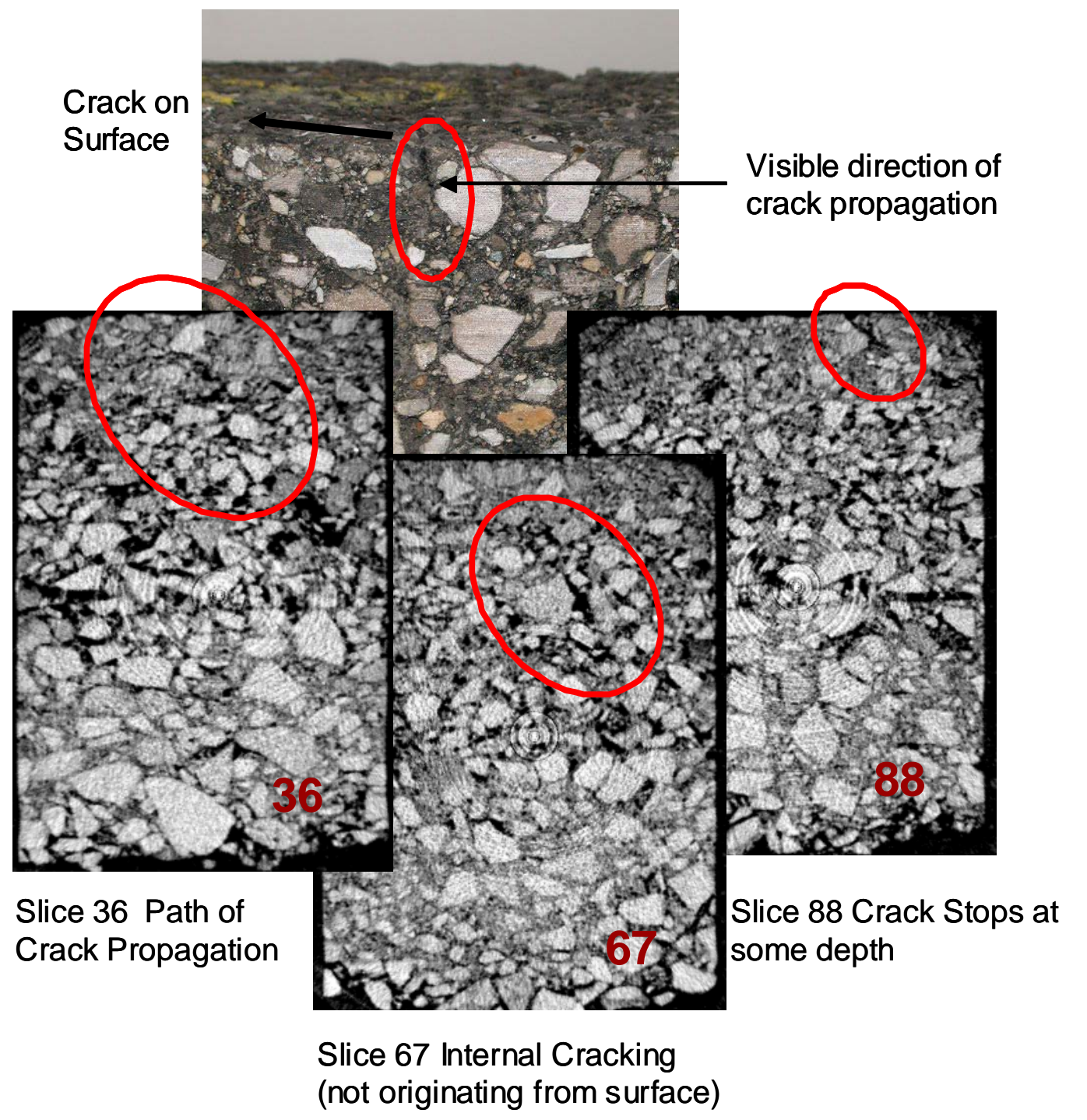

Figure 28: Site 3 US421 Madison ID S2 (3) 
4.5 Test Results for Conventional Asphalt Binder Properties

The penetration test is an empirical test used to measure the consistency of asphalt binder. The penetration test was performed at $25^{\circ} \mathrm{C}$ and $45^{\circ} \mathrm{C}$ test temperature in accordance with the AASHTO T49 test procedure. The test results are presented in Table 14.

Table 14: Penetration Test Results

\begin{tabular}{|c|c|c|c|c|c|c|}
\hline \multirow{3}{*}{ REPLICATE } & \multicolumn{3}{|c|}{ TEMPERATURE $25^{\circ} \mathrm{C}$} & \multicolumn{3}{|c|}{ TEMPERATURE $45^{\circ} \mathrm{C}$} \\
\hline & \multicolumn{3}{|c|}{ PENETRATION (0.1 mm) } & \multicolumn{3}{|c|}{ PENETRATION (0.1 mm) } \\
\hline & SITE 1 & SITE 2 & SITE 3 & SITE 1 & SITE 2 & SITE 3 \\
\hline 1 & 11 & 18 & 10 & 67 & 90 & 70 \\
\hline 2 & 10 & 19 & 11 & 64 & 90 & 70 \\
\hline 3 & 11 & 20 & 11 & 65 & 89 & 68 \\
\hline Average & 10.7 & 19.0 & 10.7 & 65.0 & 90.0 & 69.0 \\
\hline Std Dev & 0.58 & 1.00 & 0.58 & 1.53 & 0.58 & 1.15 \\
\hline $\mathrm{CV} \%$ & 5 & 5 & 5 & 2 & 1 & 2 \\
\hline
\end{tabular}

The requirements for the penetration graded asphalt cements (ASTM D946) are presented in Table 15. The measured binder penetrations are less than the lowest penetration grade of neat binders, indicating significant binder hardening. The original binder grade for Site 3 was PG 70-22 which refers approximately to Pen 40-50 binder. The original binder type information for the other sites was not available. Site 2 had the softest binder penetration being 19 while the other two sites had $10.7\left(25^{\circ} \mathrm{C}\right)$.

Table 15: ASTM requirements for penetration graded asphalt cements

\begin{tabular}{|l|c|c|c|c|c|c|c|c|c|c|}
\hline \multirow{3}{*}{$\begin{array}{l}\text { Penetration } \\
\text { at } 25^{\circ} \mathrm{C}\end{array}$} & \multicolumn{10}{|c|}{ PENETRATION GRADE } \\
\cline { 2 - 11 } & $40-50$ & \multicolumn{2}{|c|}{$60-70$} & \multicolumn{2}{c|}{$85-100$} & \multicolumn{2}{c|}{$120-150$} & \multicolumn{2}{c|}{$200-300$} \\
\cline { 2 - 11 } & Min & Max & Min & Max & Min & Max & Min & Max & Min & Max \\
\cline { 2 - 11 } & 40 & 50 & 60 & 70 & 85 & 100 & 120 & 150 & 200 & 300 \\
\hline
\end{tabular}


The ring and ball softening point testing was conducted according to AASHTO T53; see Table 16. Site 2 had the lowest softening point of $62.8^{\circ} \mathrm{C}$ which is in agreement with the penetration test results. However, the difference was not large compared to the other sites.

Table 16. Ring and Ball Softening Point

\begin{tabular}{|l|l|l|l|}
\hline \multirow{2}{*}{ REPLICATE } & \multicolumn{3}{|c|}{$\mathbf{T}_{\text {Ring\&Ball }}\left({ }^{\circ} \mathbf{C}\right)$} \\
\cline { 2 - 4 } & SITE 1 & SITE 2 & SITE 3 \\
\hline 1 & 65.0 & 62.5 & 65.5 \\
\hline 2 & 65.0 & 63.0 & 65.5 \\
\hline Average & 65.0 & 62.8 & 65.5 \\
\hline
\end{tabular}

\subsection{Test Results for Asphalt Mixture Composition}

The bulk specific gravity $\left(\mathrm{G}_{\mathrm{mb}}\right)$ values were measured for the surface layer $(\sim 25 \mathrm{~mm}$ thick HMA layer) for each sample obtained from all three study sites in accordance with AASHTO T166 test procedure. The core samples were collected from the pavement over the left, center, and the right wheel paths and the $G_{m b}$ values have been calculated and tabulated correspondingly. Detailed test data is shown in Appendix D.

The theoretical maximum specific gravity $\left(\mathrm{G}_{\mathrm{mm}}\right)$ values were measured in accordance with AASHTO T209 test procedure. For obtaining the $\mathrm{G}_{\mathrm{mm}}$, two to three cores were combined to get a $1.5 \mathrm{~kg}$ sample. The test required two samples per site, so a total of six cores were required per site. The $\mathrm{G}_{\mathrm{mm}}$ test results are presented in Appendix D. As a summary, the $\mathrm{G}_{\mathrm{mm}}$ for Site 1 was 2.486, for Site 2 it was 2.502, and for Site 3 it was 2.458 . The design $\mathrm{G}_{\mathrm{mm}}$ value for Site3 was 2.433 based on the JMF provided by INDOT, which was somewhat lower than the measured $G_{m m}$ value of 2.458 , but this is still within the acceptable difference of two laboratories. The JMFs data was not available for the other sites.

The percentages of air voids in the total mix were determined from the relation between $G_{m m}$ and $G_{m b}$ values. A summary of the calculated air void content values are 
presented in Table 17. The detailed air void calculations are presented in Appendix D. The density in the left wheel path or the right wheel path is higher than the center of the pavement for Site1, I-65 North, due to the traffic loading and mix densification in the wheel paths. This phenomenon is not as clear for the other two sites. The age of Site 1 was 11 years compared to the 12 and 4.5 years for Sites 2 and 3, respectively. Site 3 had only half of the rutting compared to Site 1 so traffic has not yet had enough time to densify the pavement. Site 2 had also only half of the rutting compared to Site 1, which indicates more densification/shear resistant mix compared to Site 1. The average air void content for Site 1 and Site 2 are within typical in-situ density requirements of $92.5 \%$ of $\mathrm{G}_{\mathrm{mm}}$, but Site 3 , Location 2 has significantly higher air void content.

The FWD results agree with these findings indicating that some densification in the wheel path has occurred in Site 1 because of the increased stiffness of the mix. The other two sites did not show mix densification based on FWD stiffness measurements.

Table 17: Summary of percent air void content.

\begin{tabular}{|c|c|c|c|c|c|c|}
\hline \multirow{2}{*}{$\begin{array}{l}\text { POSITION } \\
\text { IN THE } \\
\text { PAVEMENT }\end{array}$} & \multicolumn{2}{|c|}{$\begin{array}{l}\text { SITE } 1 \text { I-65 } \\
\text { NORTH }\end{array}$} & \multicolumn{2}{|c|}{$\begin{array}{l}\text { SITE } 2 \text { I-65 } \\
\text { INDIANAPOLIS }\end{array}$} & \multicolumn{2}{|c|}{$\begin{array}{l}\text { SITE } 3 \text { US-421 } \\
\text { MADISON }\end{array}$} \\
\hline & $\begin{array}{c}\text { Location } \\
1\end{array}$ & $\begin{array}{l}\text { Location } \\
2\end{array}$ & $\begin{array}{c}\text { Location } \\
1\end{array}$ & $\begin{array}{c}\text { Location } \\
2\end{array}$ & $\begin{array}{c}\text { Location } \\
1\end{array}$ & $\begin{array}{c}\text { Location } \\
2\end{array}$ \\
\hline LWP & 6.1 & 6.7 & 8.5 & 8.2 & 9.3 & 11.6 \\
\hline CENTER & 8.6 & 7.6 & 6.4 & 8.4 & 8.9 & 11.3 \\
\hline RWP & 6.8 & 6.8 & 6.1 & 8.5 & 8.8 & 9.5 \\
\hline SHOULDER & - & - & 8.0 & 9.1 & 7.5 & 8.8 \\
\hline Average & 7.2 & 7.0 & 9.0 & 8.5 & 8.6 & 10.3 \\
\hline Std Dev & 1.31 & 0.51 & 1.31 & 0.14 & 0.26 & 1.13 \\
\hline CV\% & 18.1 & 7.2 & 14.5 & 1.6 & 3.0 & 10.9 \\
\hline \multicolumn{7}{|c|}{ LWP= Left Wheel Path } \\
\hline \multicolumn{7}{|c|}{ RWP $=$ Right Wheel Path } \\
\hline
\end{tabular}

The gradation data for the mixtures were determined according to the AASHTO T11 and T27 procedures. The chart of aggregate gradation with the restricted zone and control points corresponding to Nominal Maximum Aggregate Size (NMAS) $9.5 \mathrm{~mm}$ is presented 
in Appendix D. The average gradation curve for all three study sites passes through the restricted zone and fell well within the minimum and maximum control points for the NMAS $9.5 \mathrm{~mm}$. For all three sites, the surface mix gradation was on the coarse side of the gradation curve.

The extraction of binder content was performed in accordance with the AASHTO TP2 test procedures. The average binder contents were 5.4, 5.9, and 6.3\% for Sites 1, 2, and 3 , respectively. For Site 3, the average extracted binder content of $6.3 \%$ and the JMF design binder content of $6.2 \%$ compared well. For other sites, the JMF data was not available, however, Site 1 had almost one percent lower binder content than Site 3.

\subsubsection{In-situ Volumetric Properties}

Table 18 summarizes the in-situ volumetric properties for the three surface mixtures. Compared to the WesTrack crack resistant mixtures discussed in Chapter 2, Site 3 had enough binder in the mix compared to the other sites that had less than $9 \%$ which is needed for a good cracking resistance. Also, Site 1 and 3 mixtures had VFA less than 53\% and VMA $>14 \%$ which indicates poor cracking resistance in the mixture.

The in-situ volumetric properties deviate from the mix design values, as expected. Based on JMF for Site 3, the design $\mathrm{V}_{\mathrm{a}}=4 \%$, VMA $=15.2 \%$, VFA $=73.7 \%$, and $\mathrm{V}_{\text {beff }}=$ $11.2 \%$.

Table 18: In-situ volumetric properties.

\begin{tabular}{|l|l|l|l|}
\hline $\begin{array}{c}\text { MIX VOLUMETRIC } \\
\text { PROPERTY }\end{array}$ & SITE 1 & SITE 2 & SITE 3 \\
\hline VMA, \% & 16.9 & 16.7 & 19.8 \\
\hline VFA, \% & 51.8 & 55.8 & 49.0 \\
\hline $\mathrm{V}_{\text {beff } \%} \%$ & 8.8 & 8.6 & 9.7 \\
\hline $\mathrm{V}_{\mathrm{a}} \%$ & 8.2 & 7.4 & 10.1 \\
\hline
\end{tabular}




\section{ANALYSIS OF RHEOLOGICAL AND MECHANICAL TEST DATA}

\subsection{Master Curve Construction}

The material characterization of sampled pavements included the following two tasks: 1) Binder master curve construction from the measured binder test data; and 2) Mix master curve construction from the measured mix test data. The master curve allows a full material characterization of a visco-elastic property as a function of loading time and temperature. Both the binder and mixture master curves were constructed by combining the measured test data in a certain way to create a full temperature range master curve.

The binder tests included the Dynamic Shear Rheometer Test (DSR) at high and intermediate test temperatures and the Direct Tensile Test (DTT) at cold temperatures. The mix testing included the intermediate and high temperature SST-Shear Frequency Sweep shear modulus testing and low temperature Creep Compliance testing which together should give the data for the full temperature range for mix master curve.

The rheological data were analyzed in the RHEA $^{\mathrm{TM}}$ software (Rowe, 2000) to determine the relaxation spectra of the tested binders and mixtures. Using calculated relaxation spectra (Baumgaertel and Winter, 1989) and a simple Poisson's ratio conversion between shear and extensional modulus, the measured data sets were transposed into a desired master curve at desired reference temperature.

The scheme for constructing the master curve is by empirical shifts of data obtained at different temperatures along a logarithmic time or frequency axis by a shift factor $\left(\mathrm{a}_{\mathrm{T}}\right)$. Since time-temperature superposition holds, the various relaxation times, in the case of a given relaxation process, have the same temperature dependence. Thus, the relaxation behavior at one temperature can be superimposed on another temperature by shifting an amount $\left(\mathrm{a}_{\mathrm{T}}\right)$ along the logarithmic time axis. Once the shift factors have been determined, the reduced frequencies $(\xi)$ can be calculated for the temperature isotherms that have to be shifted to the reference temperature to develop the master curve. The reduced frequency is given by: 


$$
\xi=\omega \cdot a_{T}
$$

where $\omega$ is angular velocity obtained from $\omega=2 \pi f$ where $f$ is the loading frequency. The reduced frequency can be represented in the logarithmic form as:

$$
\log (\xi)=\log (\omega)+\log \left(a_{T}\right)
$$

The RHEA ${ }^{\mathrm{TM}}$ software generates the estimated values of constants $\mathrm{C}_{1}$ and $\mathrm{C}_{2}$ for the Williams, Landel and Ferry (WLF) relation (Williams, Lendel \& Ferry, 1955) which is given by:

$$
\log \left(a_{T}\right)=\frac{-C_{1} \cdot\left(T-T_{R}\right)}{C_{2}+\left(T-T_{R}\right)}
$$

\subsection{Asphalt Binder Testing and Analysis}

\subsubsection{Dynamic Shear Rheometer Test}

The dynamic shear rheometer (DSR) is used to characterize the viscous and elastic behavior of asphalt binders at high and intermediate service temperatures. The shear frequency sweep tests were performed at seven temperatures of $76^{\circ} \mathrm{C}, 64^{\circ} \mathrm{C}, 52^{\circ} \mathrm{C}, 40^{\circ} \mathrm{C}$, $35^{\circ} \mathrm{C}, 25^{\circ} \mathrm{C}$ and $15^{\circ} \mathrm{C}$ according to the AASHTO TP5 with loading rate of 0.1 to $10 \mathrm{~Hz}$. Test results for the measured binder complex shear modulus $\left|\mathrm{G}^{*}\right|$ and phase angle $\delta$ are given in Appendix E

\subsubsection{Direct Tensile Test}

The Direct Tensile Test (DTT) was performed in accordance to the AASHTO TP3 test procedure to determine the low temperature tensile stresses and strains of asphalt binder. The tests were performed at temperatures of $-18^{\circ} \mathrm{C},-12^{\circ} \mathrm{C}$ for Site $1,-18^{\circ} \mathrm{C},-12^{\circ} \mathrm{C}$, and $-6^{\circ} \mathrm{C}$ for Site $2,-12^{\circ} \mathrm{C}$ and $-6^{\circ} \mathrm{C}$ for Site 3, which are within the standard range of $0^{\circ} \mathrm{C}$ to $-36^{\circ} \mathrm{C}$, where the asphalt exhibits brittle behavior. The specimens were loaded in 
tension at a constant strain rate of $1 \mathrm{~mm} / \mathrm{min}$ until break. Test results are shown in Appendix F.

\section{Strength, Strain and Energy to Failure}

The raw test data was analyzed using the eVDTT software developed by Abatech. This software uses the "RAW" data file produced by the control software of the DTT test device to conduct the analysis in accordance with the current TP3 analysis procedure (AASHTO, 2000). The data is also corrected for start-up errors using the procedure defined by Rowe, D’Angelo, Ho and Sharrock (2002). For each data set a plot of the stress versus strain was inspected to ensure that the data was of consistent quality, see Appendix F. Following inspection of the test results the mean data was then reported for each material evaluated as per the example given in Table 19.

Table 19. Typical test report generated by eVDTT software

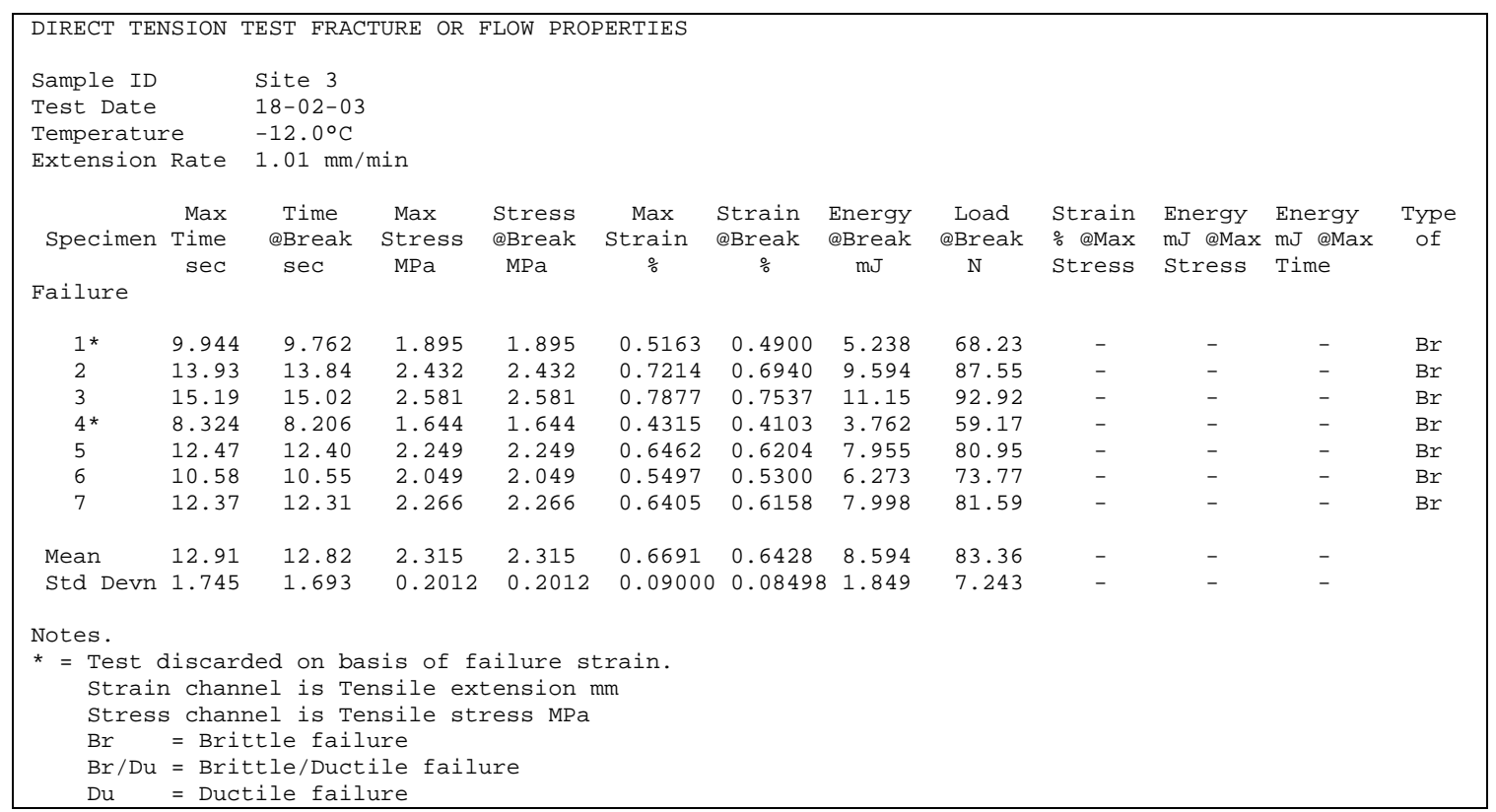

Table 20 shows a summary of the DTT test results. The strains at failure are quite low 
indicating brittle behavior. The lowest two values obtained from the test were excluded from the means. Site 2 had the lowest strain $0.4299 \%$ at $-12^{\circ} \mathrm{C}$ indicating the most brittle behavior, although the conventional binder testing indicated that this binder was the softest of the measured binders.

Table 20. Measured failure stress and strain from DTT test.

\begin{tabular}{|c|c|c|c|c|}
\hline \multirow{2}{*}{ SITE } & $\begin{array}{c}\text { Temperature } \\
\left({ }^{\circ} \mathrm{C}\right)\end{array}$ & $\begin{array}{c}\text { Max Stress at Break } \\
(\mathrm{MPa})\end{array}$ & $\begin{array}{c}\text { Strain at Break } \\
(\%)\end{array}$ & $\begin{array}{c}\text { Energy at Break } \\
(\mathrm{mJ})\end{array}$ \\
\hline $\begin{array}{c}\text { Site 1 I-65 } \\
\text { North }\end{array}$ & -12 & 2.792 & 1.062 & 17.67 \\
\cline { 2 - 5 } & -18 & 2.390 & 0.4122 & 5.297 \\
\hline \multirow{2}{*}{$\begin{array}{c}\text { Site 2: I-65 } \\
\text { Loop }\end{array}$} & -6 & 1.382 & 1.618 & 14.55 \\
\cline { 2 - 5 } & -12 & 1.395 & 0.4299 & 3.402 \\
\hline $\begin{array}{c}\text { Site 3: US- } \\
\text { 421 }\end{array}$ & -18 & 1.596 & 0.3110 & 2.796 \\
\cline { 2 - 5 } & -12 & 2.337 & 1.906 & 27.81 \\
\hline
\end{tabular}

Determination of Binder Rheology from DTT Results

The DTT test is a constant strain rate test and consequently the data can be used to define rheology of the binder relaxation modulus, E(t) for loading times used in the DTT test. The relaxation modulus $\mathrm{E}(\mathrm{t})$ was determined numerically from the DTT result by using the time-deformation information considering $E(t)$ as the slope of the stress-strain curve. Since time is linearly related to strain, stress versus time relation can be converted to stress versus strain. The Christensen-Anderson-Marasteanu (CAM) functional fitting model was used for fitting $\mathrm{E}(\mathrm{t})$ as follows:

$$
E(t)=\frac{\sigma(t)}{\varepsilon(t)}=\frac{\sigma(t)}{t . \&}
$$

A relation developed by Rowe et al., (2002) was used for fitting raw stress to time data directly, seeking the 5 parameters A, B, C, D, and E. 


$$
(\sigma(t)-D)=3000 \times(t-E) \times \&\left[\left(1+\left(\frac{t-E}{A}\right)^{B}\right)^{\left(\frac{-C}{B}\right)}\right]
$$

where:

$$
\begin{aligned}
\sigma(\mathrm{t}) & =\text { stress at time } \mathrm{t} \\
\& & =\text { strain rate } \\
\mathrm{D} & =\text { delta-stress } \\
\mathrm{E} & =\text { delta-time } \\
\mathrm{A}, \mathrm{B}, \mathrm{C} & =\text { constants }
\end{aligned}
$$

This determination is illustrated in Figure 29 where the tangent slope of the stress strain curve is equal to the relaxation modulus.

During the direct tension test some non-linear behavior can occur at large values of strain and/or close to the fracture strain. Consequently, in the analysis process the data used for the rheology measurements is limited to that which will be within the linear viscoelastic (LVE) limit for the binders. The LVE limit is taken from the work conducted during the Strategic Highway Research Program (Anderson et al., 1994) and implemented in the dynamic shear rheometer (DSR) test procedure TP5 (AASHTO, 1993) as follows:

$$
\gamma=12.0 /\left(G^{*}\right)^{0.29}
$$

where:

$$
\begin{aligned}
& \gamma \quad=\text { shear strain in percent } \\
& \mathrm{G}^{*}=\text { complex modulus in } \mathrm{kPa} \\
& \quad \gamma=e^{\left(\frac{12.044362}{G^{* 0.122203}-1.15129497}\right)}
\end{aligned}
$$

where:

$$
\mathrm{G}^{*} \quad=\text { complex modulus in } \mathrm{Pa}
$$

To make use of these equation $\mathrm{E}(\mathrm{t})$ is approximated to $3 \mathrm{G}^{*}$ and the equations are then applied as LVE limits. 


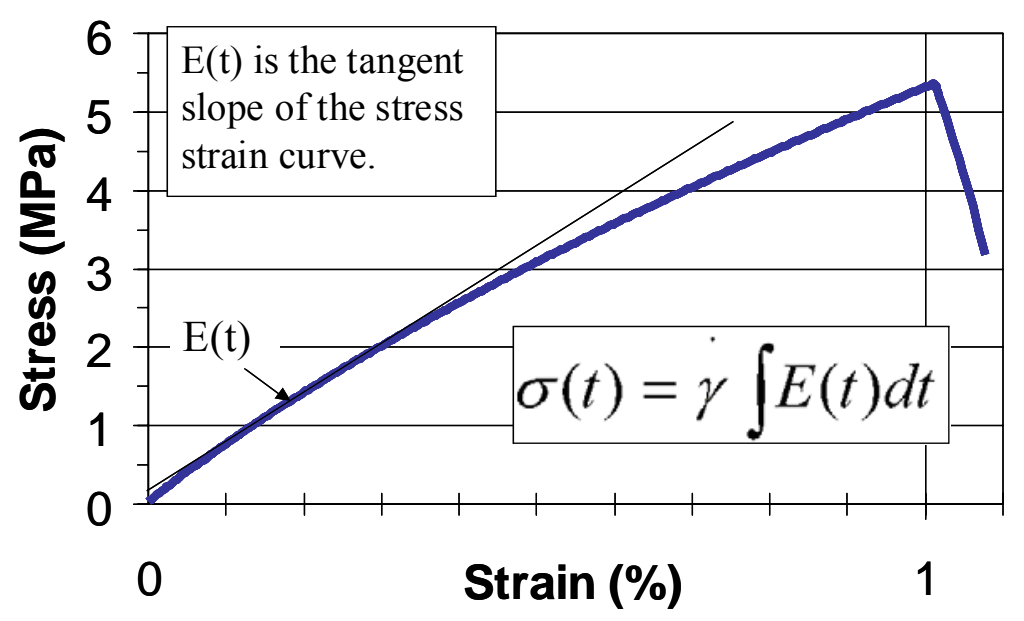

Figure 29. Determination of the relaxation modulus from the DTT.

Figure 30 illustrates the application of the LVE limits to a DTT data set. This example also shows the two stiffness isotherms. These isotherms have been calculated using the slope information and by fitting the CAM model (Rowe et al., 2002) to the data set as indicated in the figure. In addition, the lines representing the LVE limits of equations 1 and 2 are also shown. The isotherms adopted for subsequent analysis were those determined by fitting of the CAM model using start up adjustment procedures developed by Rowe et al. (2002). Isotherms from multiple tests have been combined for timetemperature shifting and the construction of master curves.

\section{Time-temperature shifting and Construction of Master Curves from DTT Data}

The software RHEA ${ }^{\mathrm{TM}}$ has been used for the development of the master curves in this project. The time temperature shifting method adopted follows the traditional approach of shifting the modulus values along the horizontal axis to form a smooth curve modulus. The shift procedures for producing a master curve were developed by various researchers. Gordon and Shaw (1994) defined various computerized methods that can be applied for the characterization of visco-elastic materials. The production of master curves involves steps as follows: 


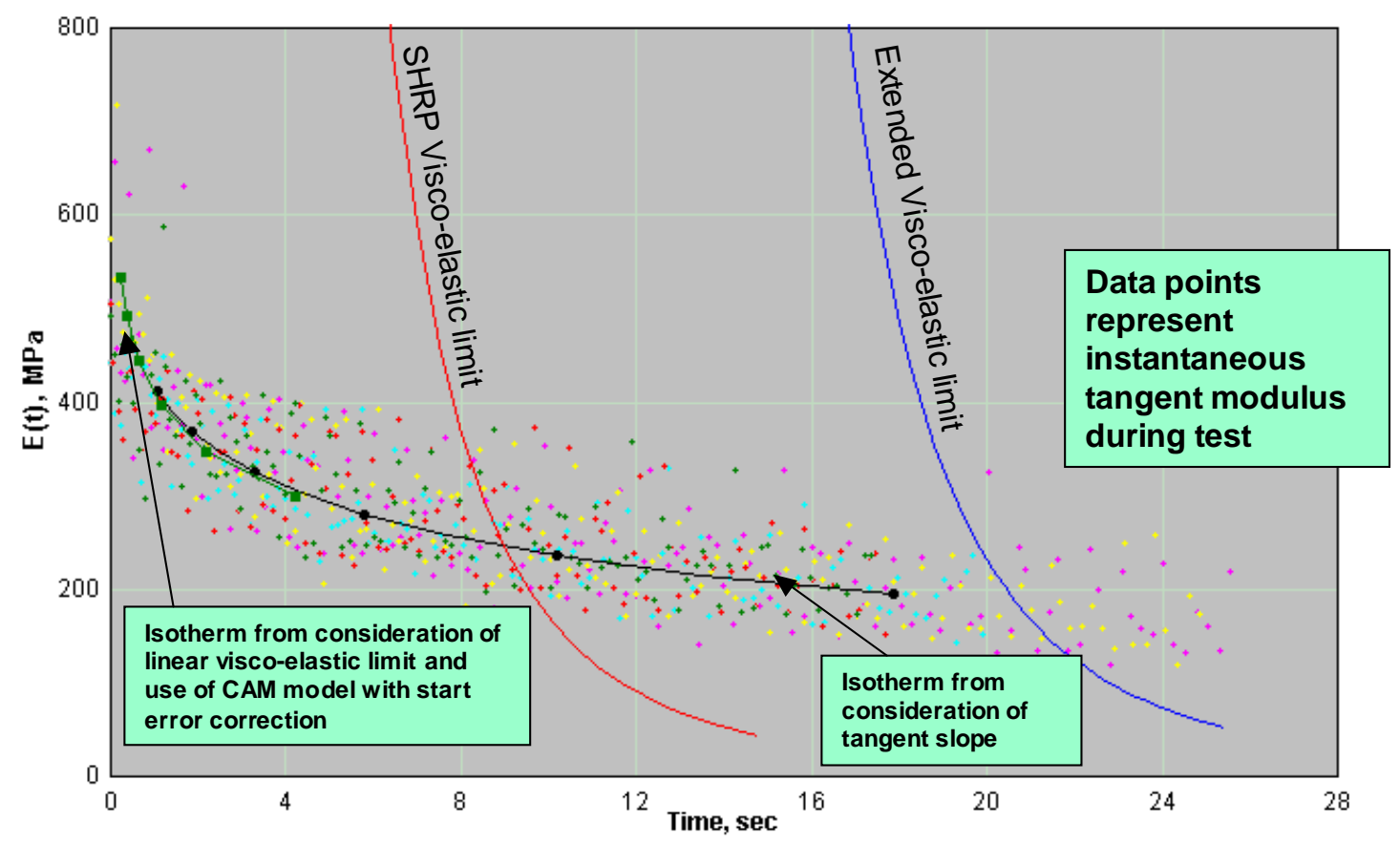

Figure 30. Application of linear visco-elastic limit for $\mathrm{E}(\mathrm{t})$.

1. An initial estimate of the shift using WLF equation (7) (Williams et al., 1955) with standard constants of $\mathrm{C}_{1}=17.44$ and $\mathrm{C}_{2}=51.6$ was applied.

2. The fit was refined by using a pairwise shifting technique and straight lines representing each data set.

3. The fit was further refined using pairwise shifting with a polynomial representing the data being shifted. The order of the polynomial taken is the minimum value between $(n+1)$, where $n$ is the number of data points - or $-\Delta f$ (the number of decades of frequency - or time).

4. WLF and Arrhenius parameters were then calculated from the resulting final shifts.

An example of the isotherms, shifted $\mathrm{E}(\mathrm{t})$ master curve (at reference temperature of $18^{\circ} \mathrm{C}$ ) and the linearized Arrhenius fit are presented in Figure 31 to Figure 33. The data defines the cold temperature rheology in the range 100 to $800 \mathrm{MPa}$, and it was merged with 
DSR rheological measurements to define a more complete master curve of binder stiffness.

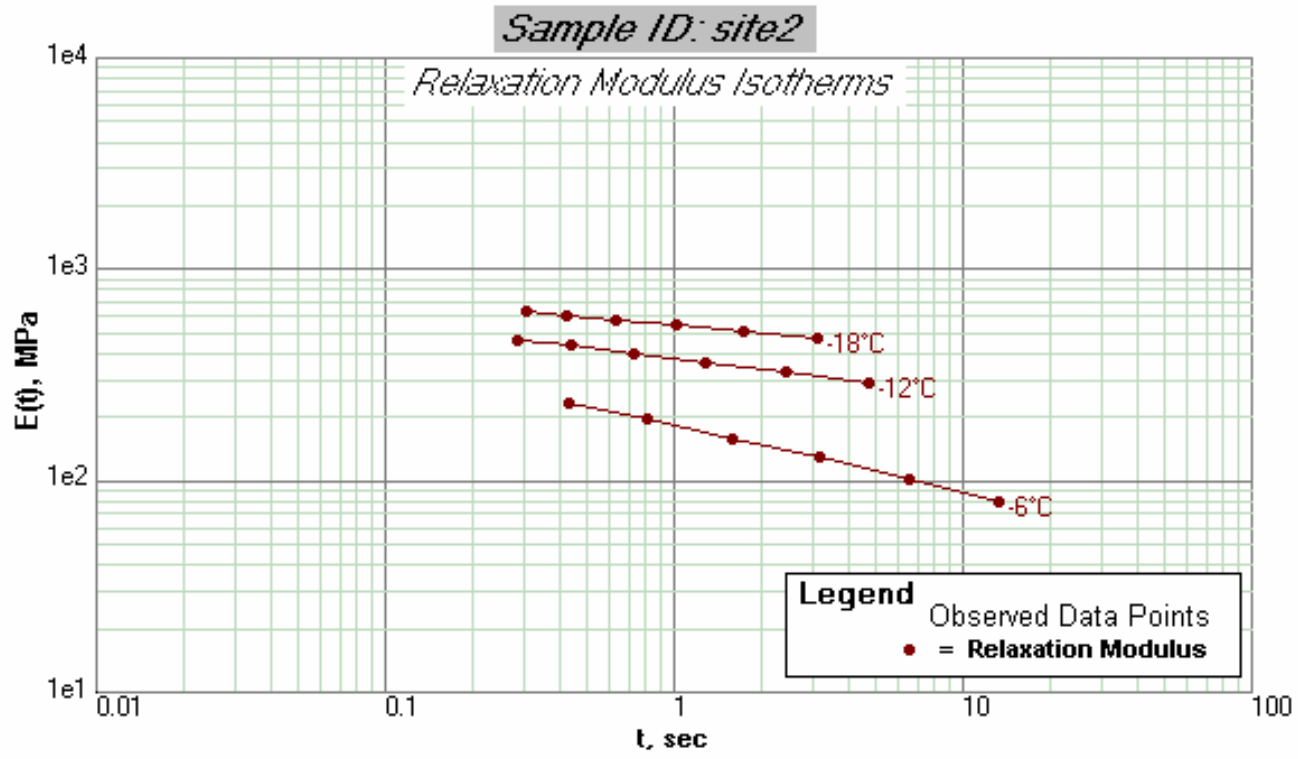

Figure 31. Isotherms of E(t) developed from the DTT.

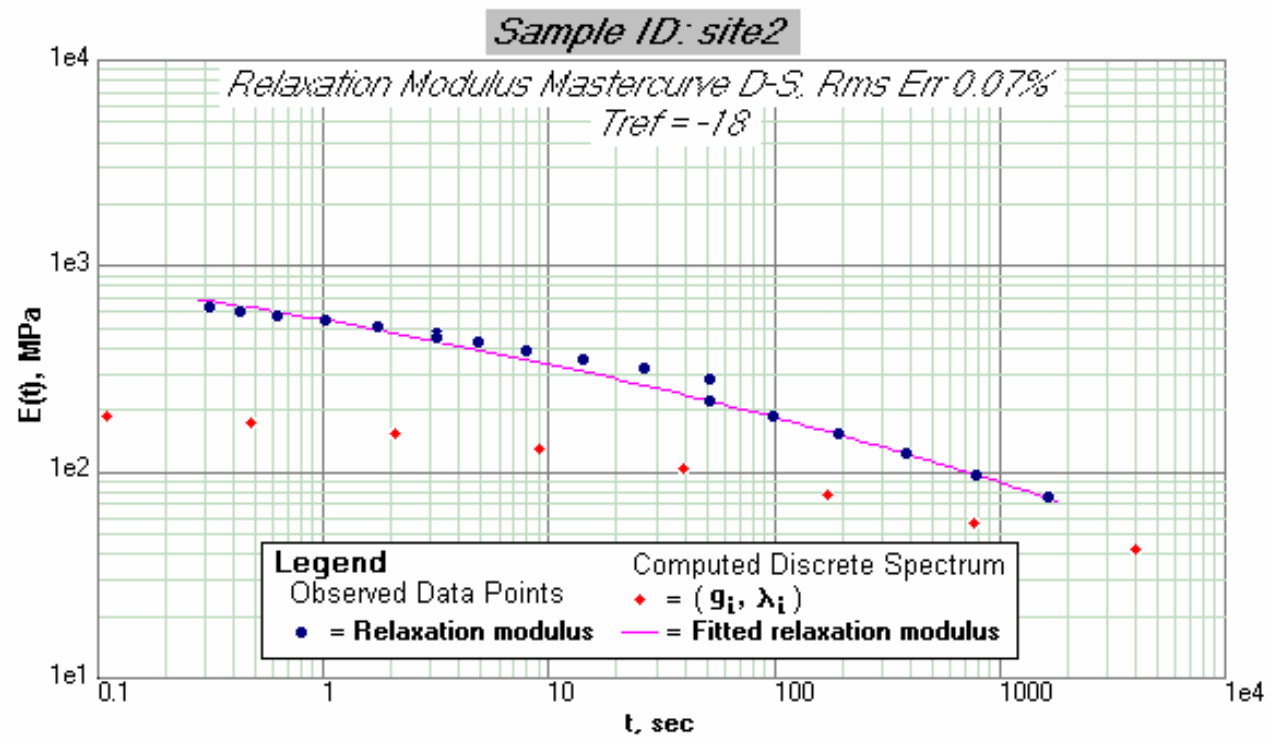

Figure 32. Master curve of $\mathrm{E}(\mathrm{t})$ developed from the DTT, Tref $=-18^{\circ} \mathrm{C}$ 


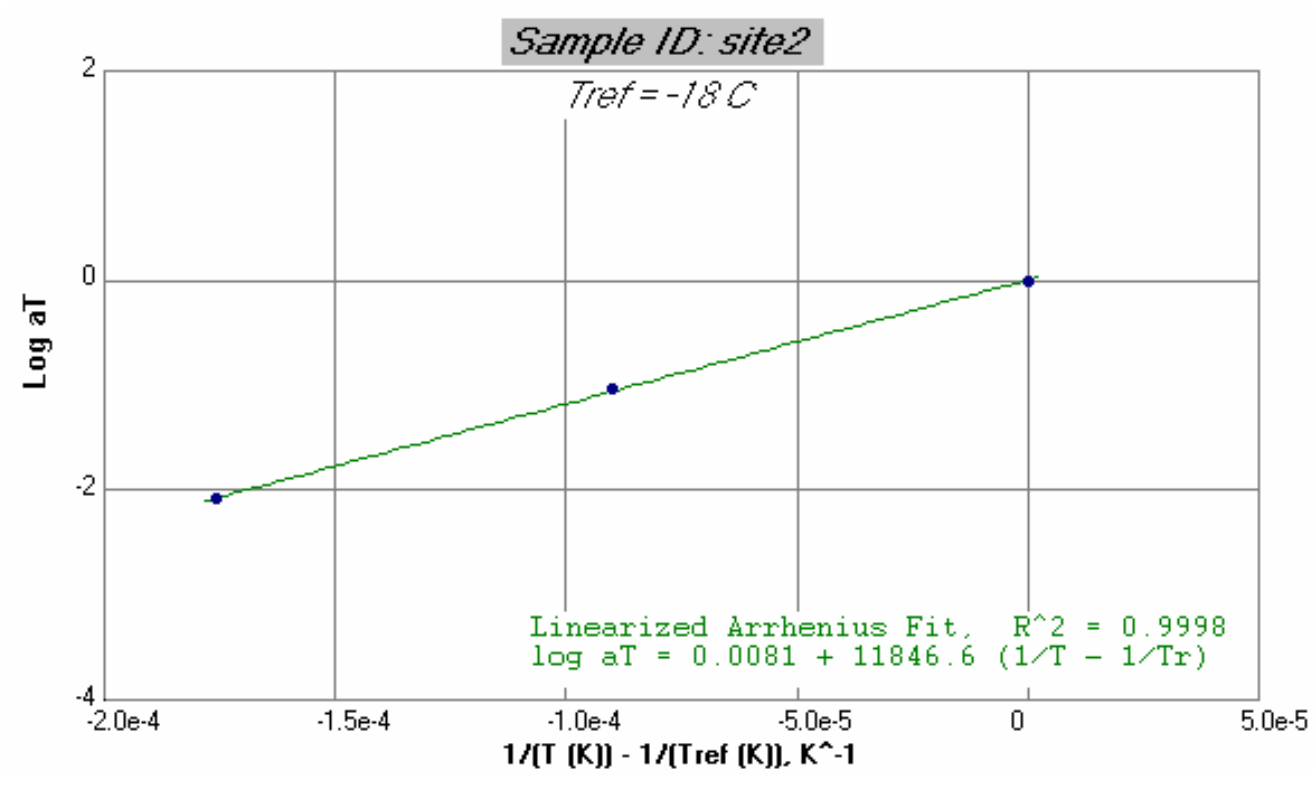

Figure 33. Linearized Arrhenius shift factors developed from the DTT.

\subsubsection{Determination of Critical Cracking Temperature(CCT)}

In addition, the DTT data is used to compute the critical cracking temperature as defined in the MP1A binder specification (AASHTO, 2001a) and using an adaptation of the numerical procedures defined in PP-42 (AASHTO, 2001b; Rowe et al., 2002). The computed thermal stress and measured strength data are illustrated in Figure 34. It can be observed that in two cases the direct tension test data did not intersect with the estimated stress data. In these instances the thermal strength data has been extrapolated in order that an estimation of the critical cracking temperature can be made.

The critical cracking temperature data is summarized in Table 21. Results indicate that the oldest sites (Site 1\&2) have the poorest performance with the highest cracking temperature and the newest site (Site 3) has the best performance with the lowest cracking temperature. These results may reflect the effect of binder aging and the time that the sites have been in service. In addition, it should be noted that these tests have all been made on recovered binder which will affect the results to some extent - although this is not known. 


\begin{tabular}{|c|c|c|c|c|c|}
\hline - & $\begin{array}{l}\text { Site } 1 \text { - Thermal Stress } \\
\text { Site } 2 \text { - Fracture Strength }\end{array}$ & 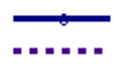 & $\begin{array}{l}\text { Site } 1 \text { - Fracture Strength } \\
\text { Site } 3 \text {-Thermal Stress }\end{array}$ & $\begin{array}{l}--- \\
=-\boldsymbol{F}=\end{array}$ & $\begin{array}{l}\text { Site } 2 \text { - Thermal Stress } \\
\text { Site } 3 \text { - Fracture Strength }\end{array}$ \\
\hline
\end{tabular}

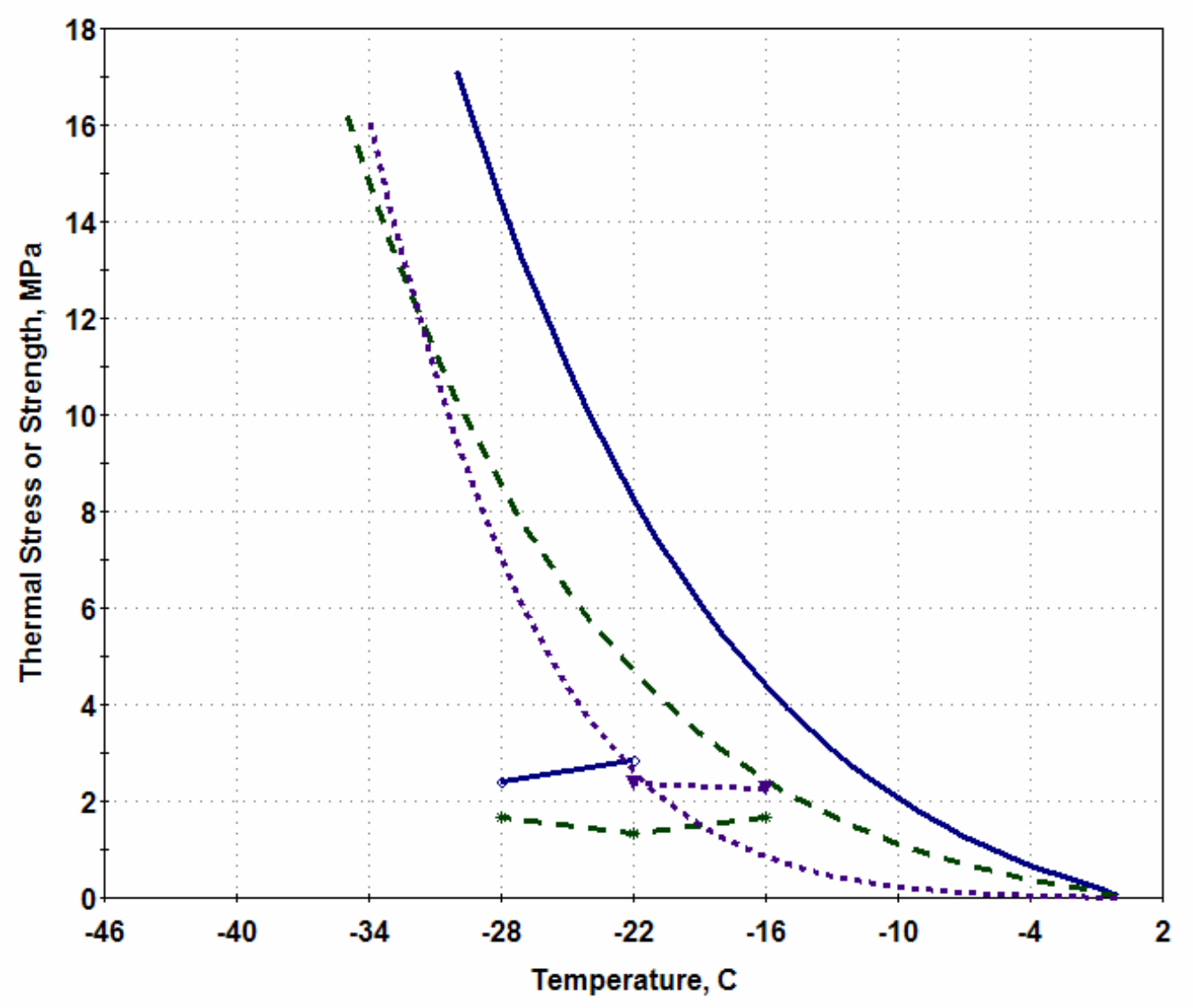

Figure 34. Thermal Stress and Strength Data - Sites 1 to 3

Table 21. Summary of Estimated Critical Cracking Temperatures for Site 1 to 3

\begin{tabular}{|l|c|}
\hline LOCATION & T $\left._{\text {Critical }}{ }^{\circ} \mathbf{C}\right)$ \\
\hline SITE 1 I-65 North of Lafayette & -13.7 \\
\hline SITE 2 I-65 Loop & -14.7 \\
\hline SITE 3 US-421 Madison & -21.4 \\
\hline
\end{tabular}




\subsubsection{Combined Binder Master Curves}

Using the software tool RHEA ${ }^{\mathrm{TM}}$, the two data sets $\left|\mathrm{G}^{*}\right|$ from DSR test and relaxation modulus $\mathrm{E}(\mathrm{t})$ from the DTT test were combined to produce master curves for the binder shear complex modulus $\left|\mathrm{G}^{*}\right|$. The steps in performing this analysis were as follows:

5. The storage G' and loss modulus G' data from the DSR testing was fitted with the software. The storage modulus was obtained from equation $G^{\prime}=\left|G^{*}\right| \cos \delta$ and the loss modulus was obtained from the equation $G^{\prime \prime}=\left|G^{*}\right| \sin \delta$. The constructed $\left|\mathrm{G}^{*}\right|$ master-curve was adopted.

6. The computed E(t) from the DTT data was fitted with the software. The constructed relaxation modulus $\mathrm{E}(\mathrm{t})$ master curve was adopted.

7. For the combined master curve both data sets need to have the same data format. Therefore, the $\mathrm{E}(\mathrm{t})$ modulus was converted to the shear modulus, i.e., storage and loss modulus by using pseudo data points. Extensional data was converted to the shear data using the simple Poisson's ratio conversion of $G=E /[2(1+v)]$ with Poisson's ratio of 0.5; see Figure 35(a).

8. The combined master curve was obtained by shifting all data to the reference temperature of $25^{\circ} \mathrm{C}$; see Figure $35(\mathrm{~b})$.

Figure 35 shows the constructed master curve for Site 1; Figure 36 shows Site 2; and Figure 37 shows the master curve for Site 3. In each figure the first figure (a) presents the raw data or measured data without the shifting for storage modulus $G^{\prime}$ and loss modulus G'. In each figure the second figure (b) shows the shifted data for the shear complex modulus $\left|\mathrm{G}^{*}\right|$ as a function of reduced frequency (angular velocity in radians per second). The figures also show the measured and shifted phase angle as a function of reduced frequency. As the frequency decreases the phase angle approaches $90^{\circ}$ indicating pure viscous material behavior. 


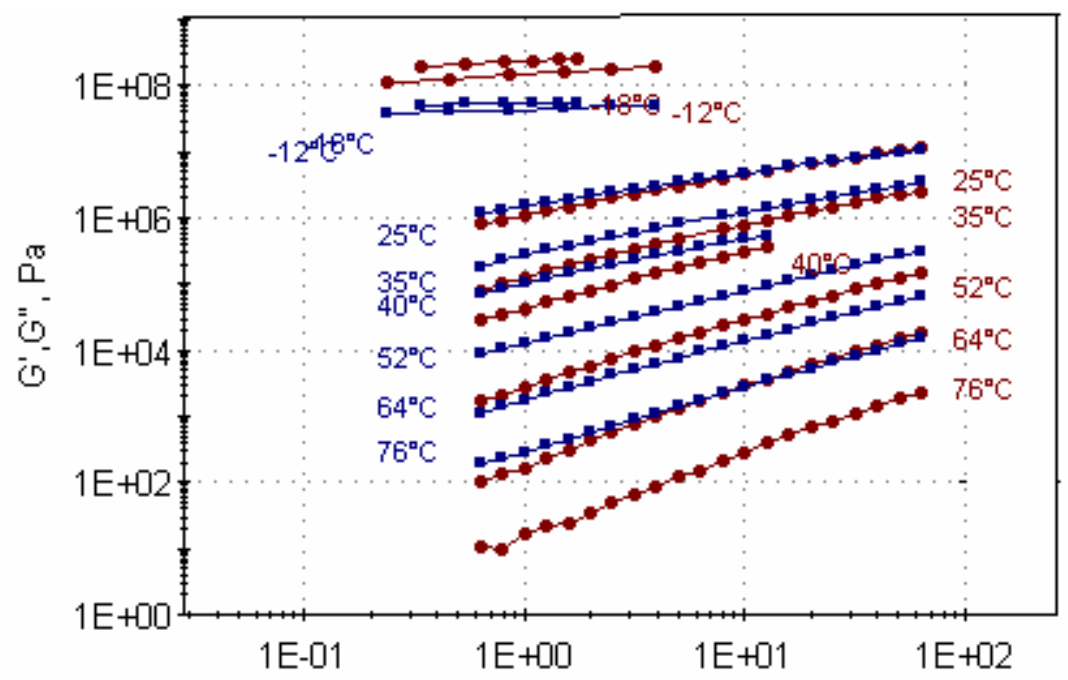

Frequency, rad/sec

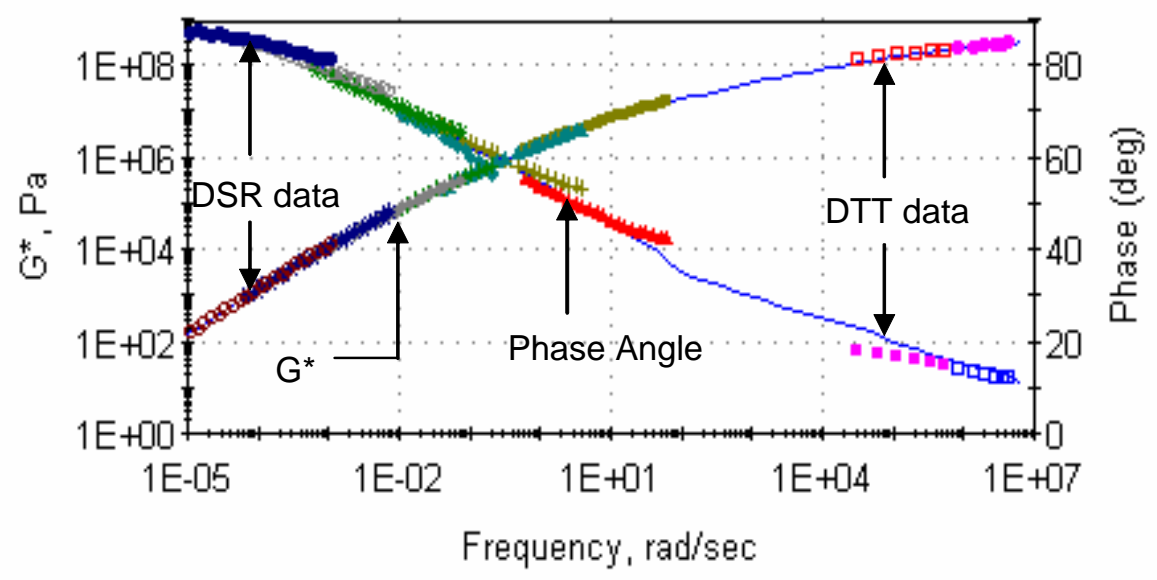

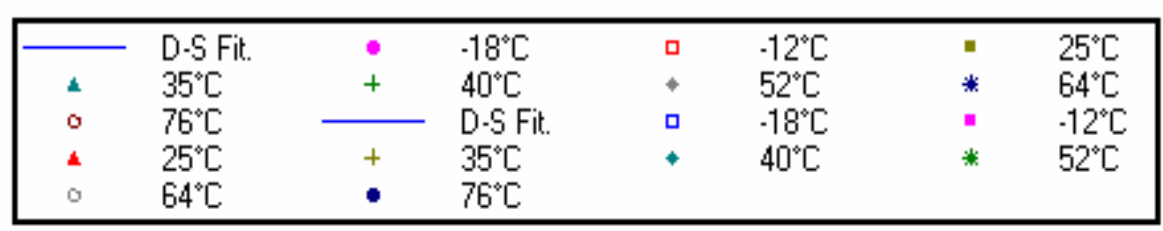

Figure 35: Master curve for shear complex modulus $\left|G^{*}\right|$, Site1. 

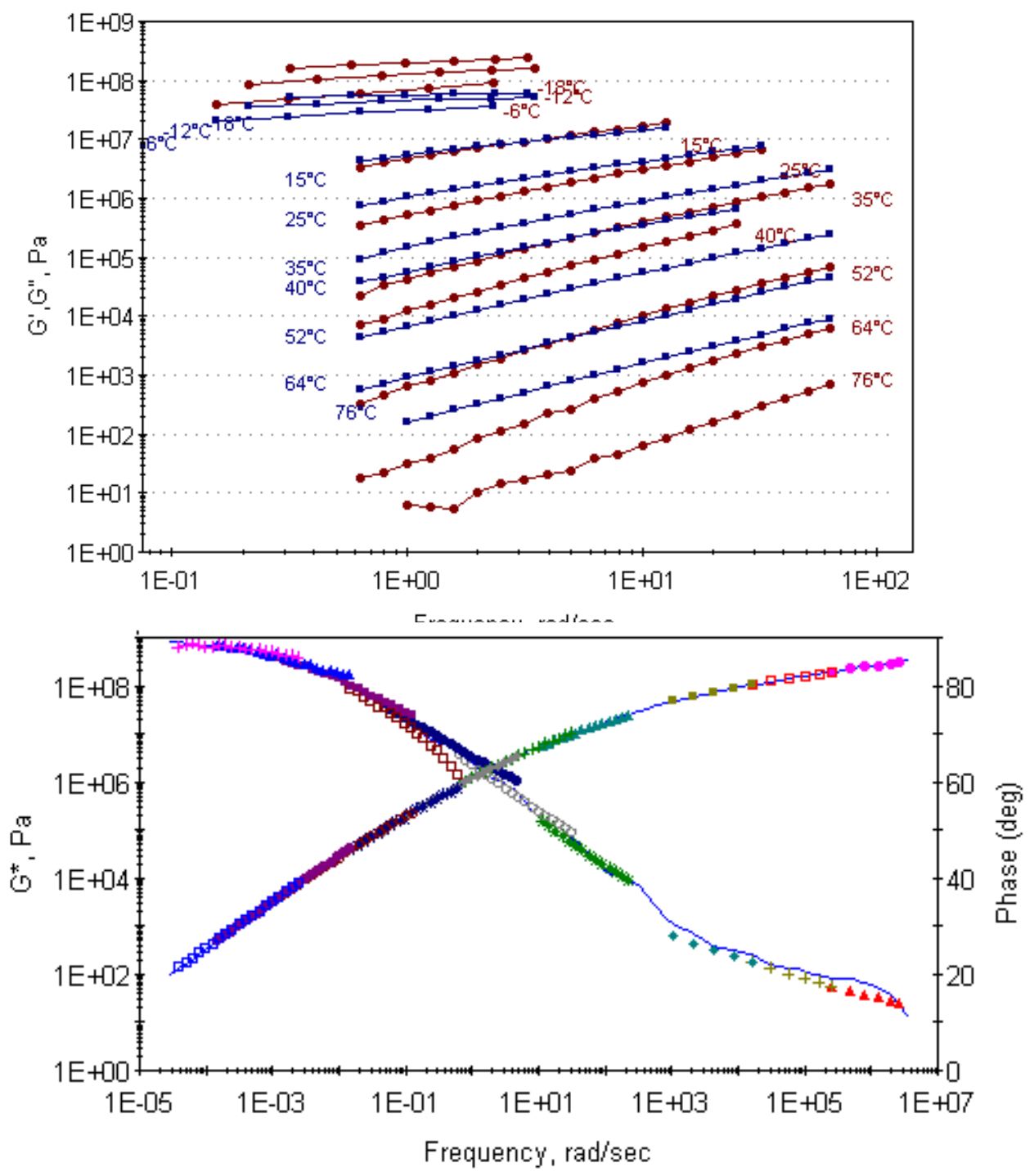

\begin{tabular}{|c|c|c|c|c|c|c|c|}
\hline & $G^{*}$ Fit. & - & $-18^{\circ} \mathrm{C}$ & व & $-12^{\circ} \mathrm{C}$ & - & $-6^{\circ} \mathrm{C}$ \\
\hline$\star$ & $15^{\circ} \mathrm{C}$ & + & $25^{\circ} \mathrm{C}$ & $\bullet$ & $35^{\circ} \mathrm{C}$ & $*$ & $40^{\circ} \mathrm{C}$ \\
\hline 0 & $52^{\circ} \mathrm{C}$ & - & $64^{\circ} \mathrm{C}$ & व & $76^{\circ} \mathrm{C}$ & - & Phase Fit. \\
\hline . & $-18^{\circ} \mathrm{C}$ & + & $-12^{\circ} \mathrm{C}$ & + & $-6^{\circ} \mathrm{C}$ & * & $15^{\circ} \mathrm{C}$ \\
\hline 0 & $25^{\circ} \mathrm{C}$ & $\bullet$ & $35^{\circ} \mathrm{C}$ & व & $40^{\circ} \mathrm{C}$ & - & $52^{\circ} \mathrm{C}$ \\
\hline$\star$ & $64^{\circ} \mathrm{C}$ & + & $76^{\circ} \mathrm{C}$ & & & & \\
\hline
\end{tabular}

Figure 36: Master curve for shear complex modulus $\left|G^{*}\right|$, Site2. 

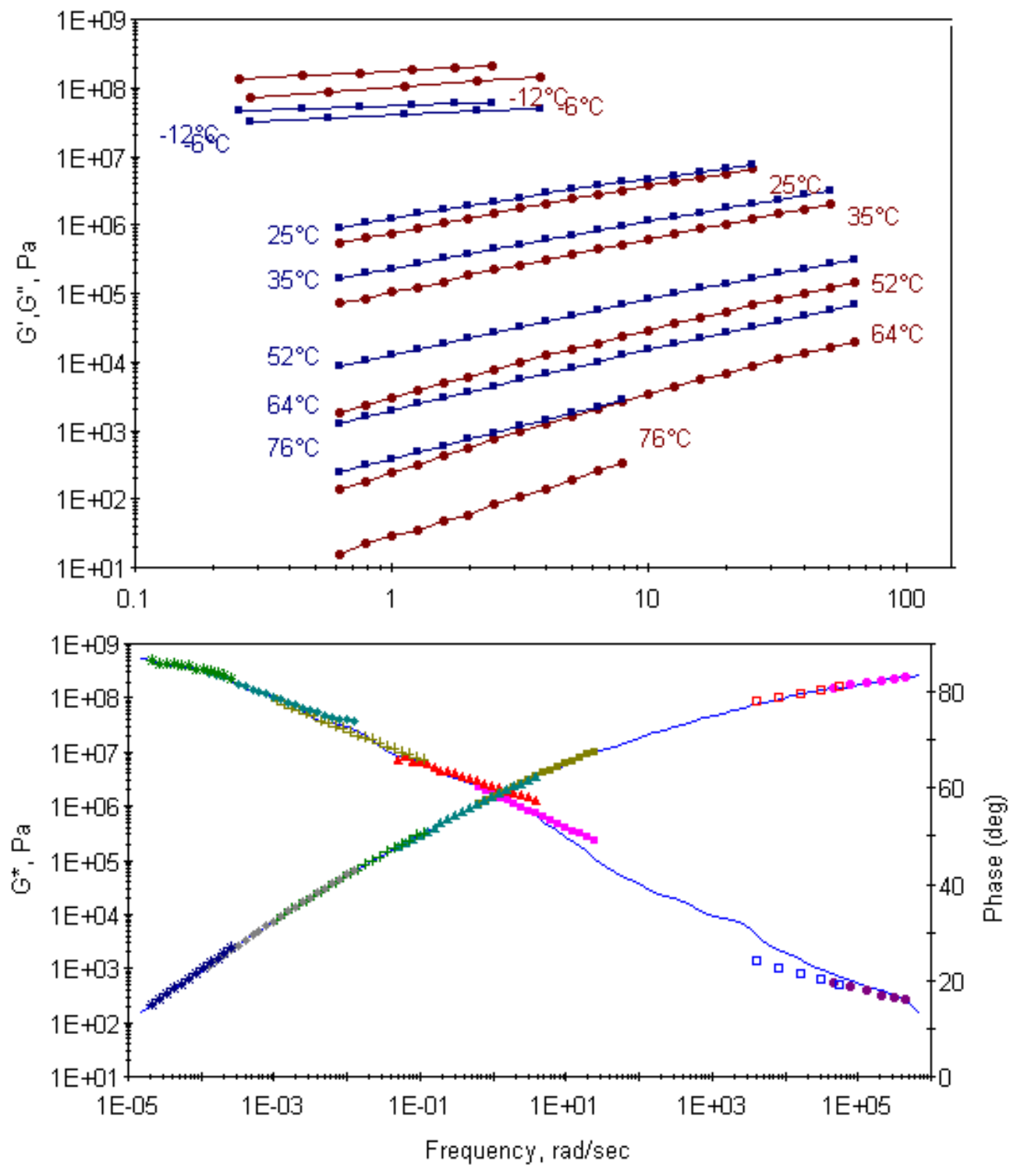

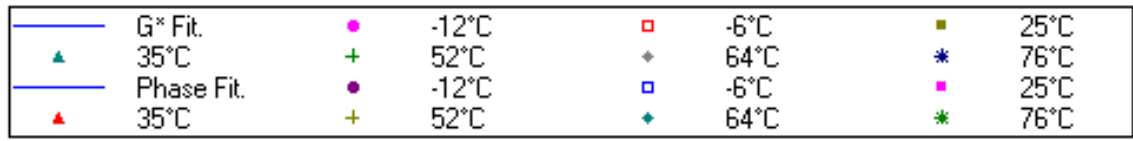

Figure 37: Master curve for shear complex modulus $\left|G^{*}\right|$, Site3. 
Figure 38 compares the constructed master curves. The master curves were obtained by fitting Christensen-Anderson (CA) model (Christensen \& Anderson, 1992) through the data obtained from the RHEA $^{\mathrm{TM}}$ software. This procedure is explained in the following chapter. At high and intermediate temperatures Site 2 had the softest binder while Site 1 and Site 3 had similar binder properties. This is in agreement with the measured conventional binder properties. At low temperatures Site 3 had the stiffest binder while Site 2 still had the softest binder, although differences were not large.

From the DSR data it was estimated that the high temperature performance grade for Site 1 binder was PG 82, for Site 2 PG 76, and for Site 3 PG 82. Thus, Site 1 had aged three PG grades while Site 2 and 3 had aged two PG grades.

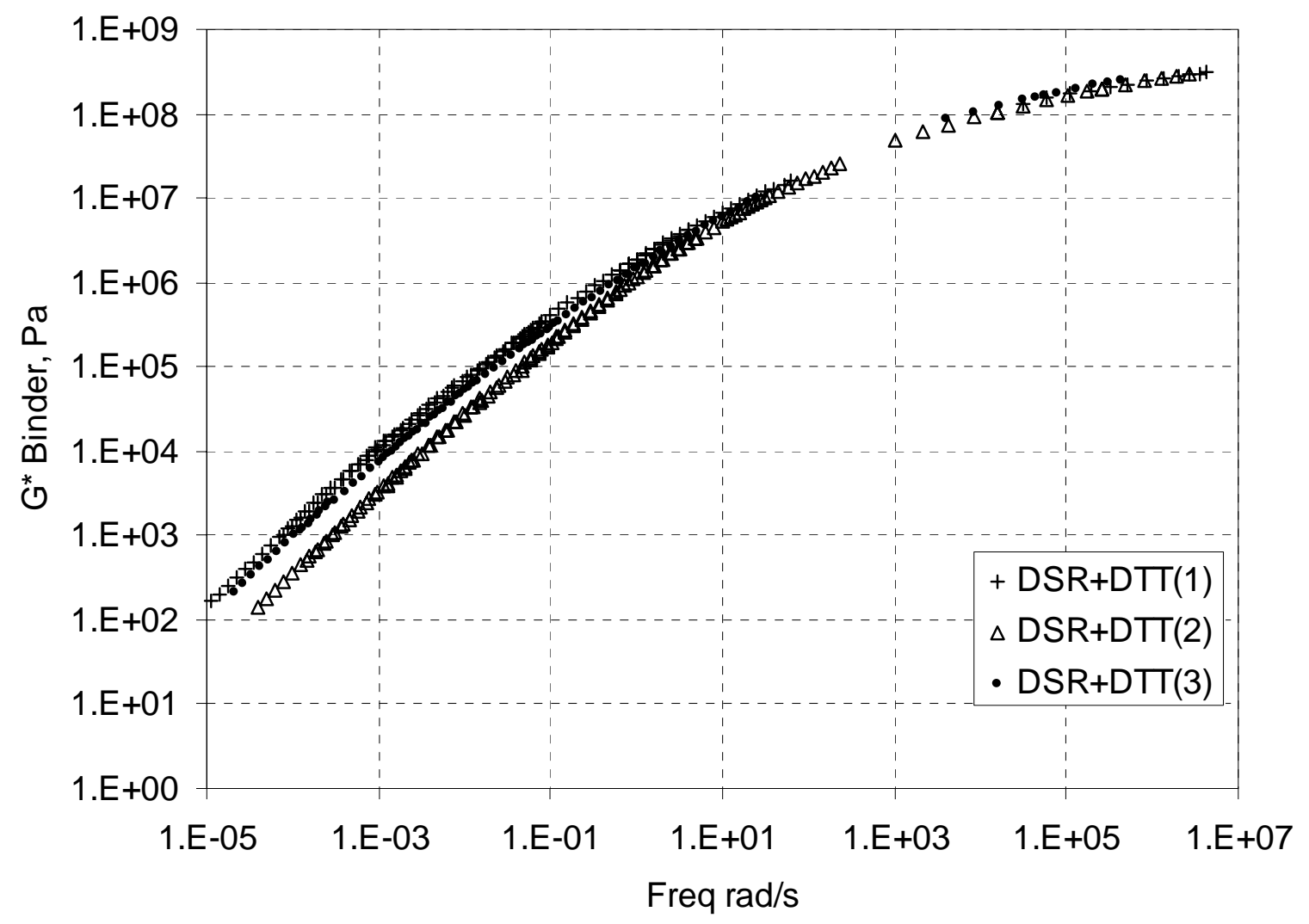

Figure 38: Comparison of binder shear stiffness $\left|G^{*}\right|$ master curves. 


\subsubsection{Relaxation Modulus}

In terms of the relaxation modulus, Site 1 has a large rms (root mean square) error using the CAM relationship with a fixed glassy modulus. If the CAM relationship is used then the error reduces to $0.31 \%$ with a lower glassy modulus of $1515.7 \mathrm{MPa}$. Using the CAM parameters, see Table 22, Site 3 has the largest critical time, exponent and asymptote slope. At purely viscous behavior this slope becomes 1 so it can be stated that in the range tested Site 3 demonstrates more viscous behavior compared to site 1 and 2 .

Table 22: Analysis parameters using CAM model

\begin{tabular}{|l|c|c|c|}
\hline PARAMETER & SITE 1 & SITE 2 & SITE 3 \\
\hline Arrhenius gradient $\mathrm{a}_{1}$ & 32753.09 & 26668.26 & 29066.61 \\
\hline Glassy modulus $(\mathrm{MPa})$ & 3000 & 3000 & 3000 \\
\hline Critical time $(\mathrm{sec})$ & 956.18 & 0.46 & 720.9 \\
\hline Exponent & 0.08 & 0.114652 & 0.136115 \\
\hline Asymptote log-log slope & 0.340494 & 0.320393 & 0.725398 \\
\hline rms error \% & 10.01 & 1.22 & 0.9 \\
\hline
\end{tabular}

The parameters used enable construction of the master curves as illustrated in Figure 39 from which it can be observed that the curvature results in a lower stiffness at longer loading times. The flatter slopes of Sites 1 and 2 are more indicative of oxidized materials as would be expected when considering the relative ages of the sites. The binder in Site 3 has significantly better relaxation properties (e.g. slope of master curve at loading time at approximately 60 seconds on this plot - equivalent to an m-value for a binder being considered for $\mathrm{a}-22$ grade) at the conditions associated with thermal cracking. In addition, at the loading time of 60 seconds Site 3 has the lowest relaxation modulus with Site 1 having the highest which is consistent with the age of Site 3 and Site 1. Site 2 had been in service one year more than Site 1 but the binder in the mix had slightly better relaxation properties compared to Site 1. These findings are in agreement with the critical cracking temperature calculations, as expected. 


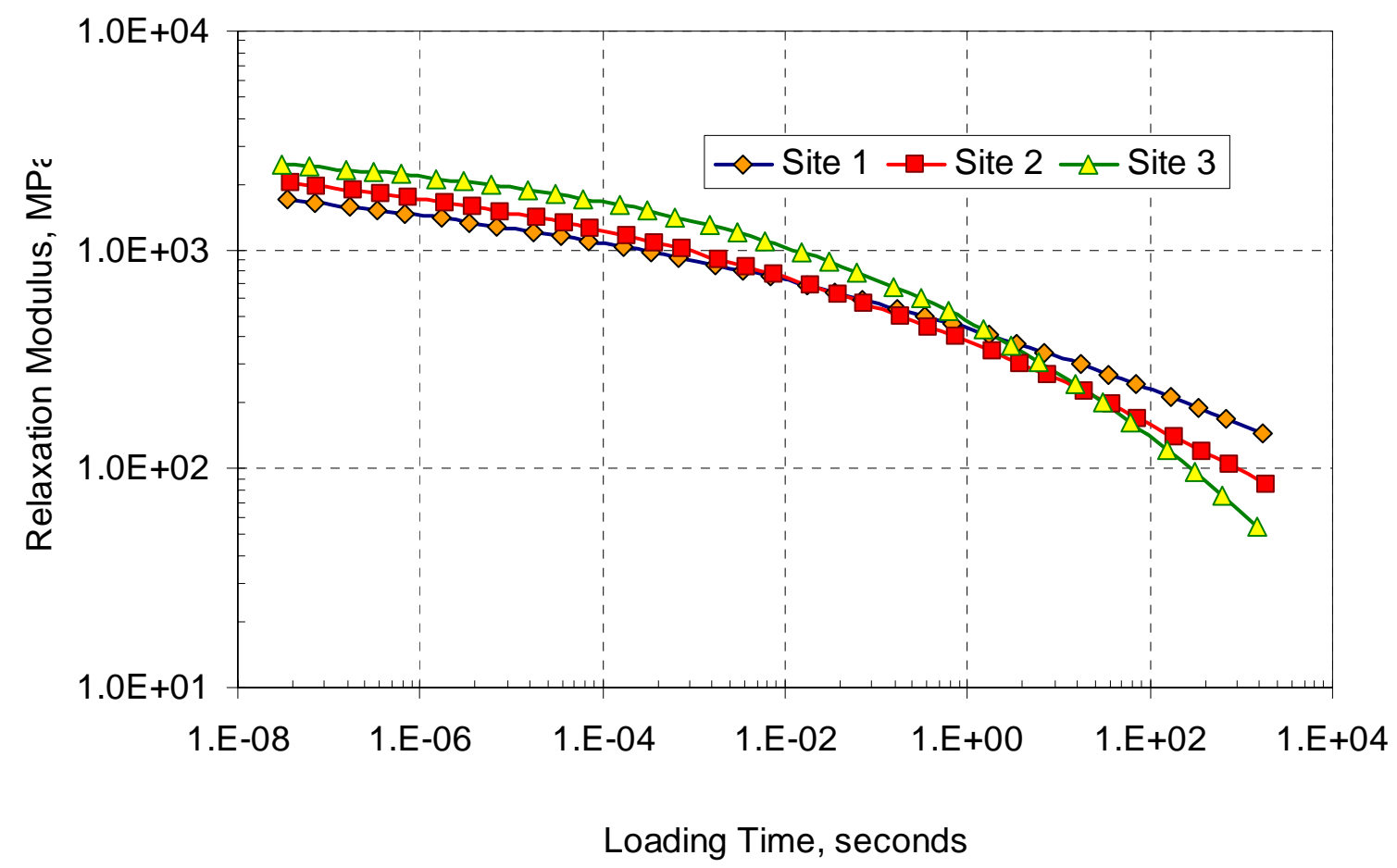

Figure 39: Relaxation modulus $\mathrm{E}(\mathrm{t})$ master curve, $\mathrm{T}_{\mathrm{ref}}=-12^{\circ} \mathrm{C}$.

\subsection{Asphalt Mixture Testing and Analysis}

\subsubsection{SST Shear Frequency Sweep Test}

The frequency sweep test at constant height with the Superpave Shear Tester (SST) was performed in accordance to AASHTO TP7 to determine the shear stiffness of the mix. Two cores were taken per site, so a total number of six cores were tested at temperatures of $4,10,20,40$ and $55^{\circ} \mathrm{C}$. However, cores for Site 1 and 2 were too thin to be tested as is, so the two cores were glued together and tested simultaneously. Only in Site 3 were the two cores tested separately. Loading time ranged from 0.01 to $10 \mathrm{~Hz}$. Test results are shown in Appendix G.

The data was analyzed using the RHEA ${ }^{\mathrm{TM}}$ software and the results are presented in graphical plots in Figure 40, Figure 41, and Figure 42. For the analysis, the reference 
temperature was selected to be $25^{\circ} \mathrm{C}$ and glass transition temperature $0^{\circ} \mathrm{C}$. The coefficient of expansion below and above the glass transition temperature was selected to be 0.00002 ${ }^{\circ} \mathrm{C}$ which is within the typical range of thermal coefficient for linear expansion of hot mix asphalt (Williamson, 1972).

In the analysis of Site 1 data, one data point was removed from the coldest temperature isotherm at $4^{\circ} \mathrm{C}$ for shifting of the isotherms. There was some noise observed in the data points for the warmest temperature isotherm of $55^{\circ} \mathrm{C}$ as well. The modifications made to the raw data can be observed in Figure 40. In Site 2 data analysis, the isotherm at temperature $4^{\circ} \mathrm{C}$ was obviously in error and was removed from the analysis. In the analysis of Site 3 the two data sets were averaged.

Figure 43 compares the three developed master curves. Overall, at high temperatures, Site 2 had the stiffest mix, and Sites 1 and 3 had very similar mix stiffness. At cold temperatures, Site 3 had the softest mix and Site 1 and 2 had similar stiffness. This disagrees with the measured binder stiffness information because the softest binder in the high and intermediate temperatures was Site 2 binder. So the mix volumetric and aggregate properties altered the ranking of mixtures regarding the stiffness information.

\subsubsection{Creep Compliance D(t) and Indirect Tensile Strength Tests}

The IDT tests were performed at temperatures of $-20,-10$ and $0^{\circ} \mathrm{C}$ on triplicate specimens to determine the Creep Compliance $\mathrm{D}(\mathrm{t})$ and indirect tensile strength in accordance with the AASHTO TP9 procedure. The specimens were equilibrated at room temperature between tests which should eliminate any physical hardening. However, while inspecting the IDT data it became obvious that the data was in error and acquisition problems during testing were causing the poor data quality; the resolution for LVDTs used in the testing was apparently too large and differences in the creep data were not detected. The IDT creep data was not analyzed further due to the poor data quality. 

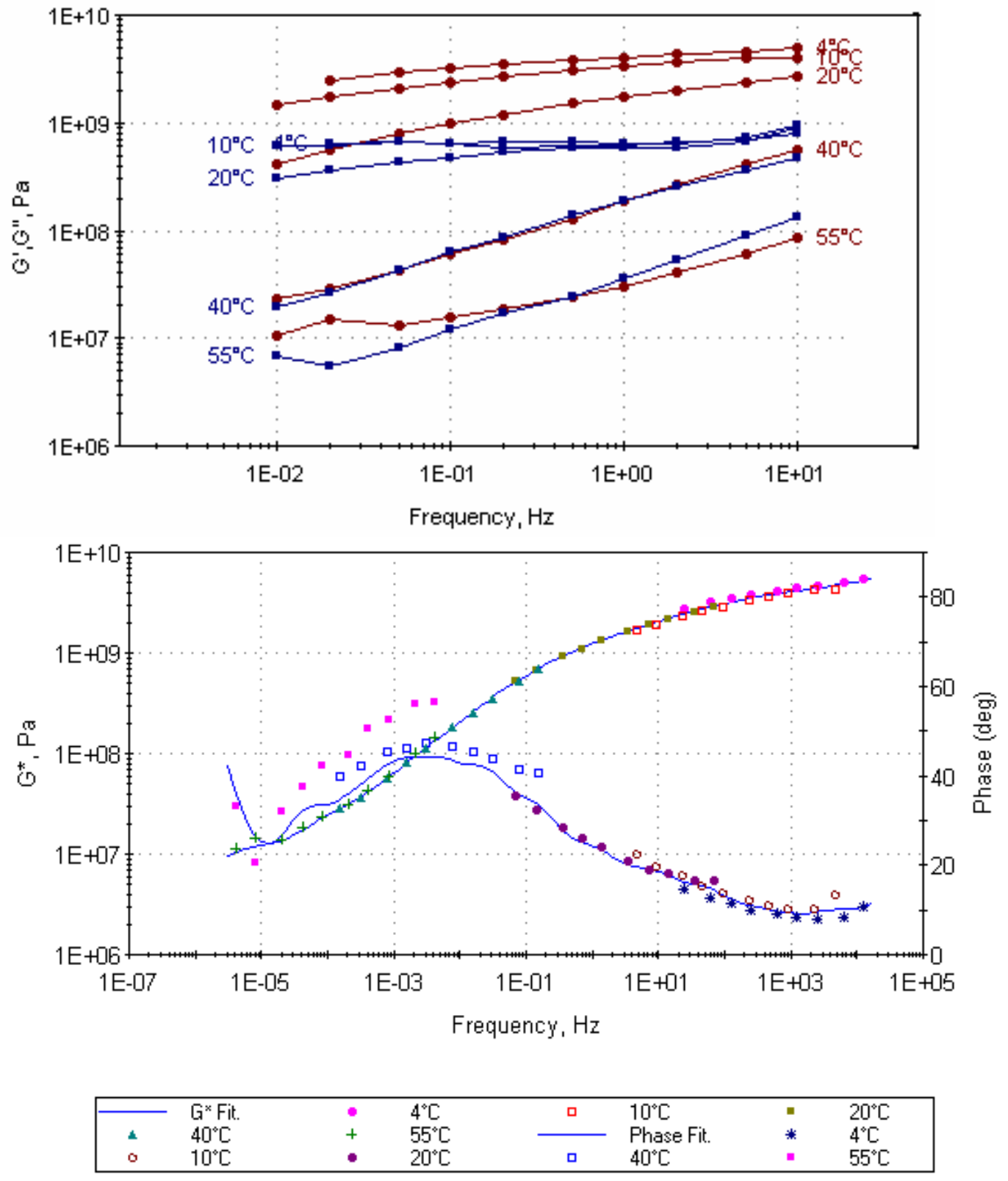

Figure 40: Master curves for Site 1 I-65 North of Lafayette 


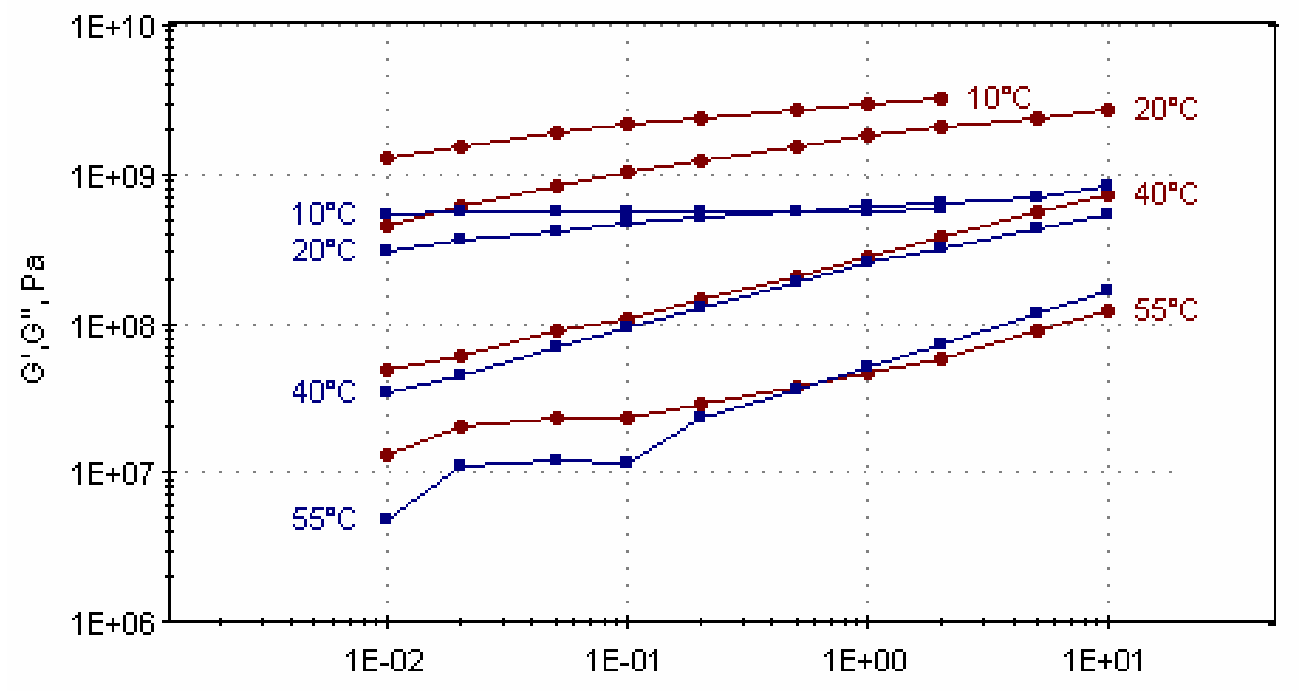

Frequency, $\mathrm{Hz}$

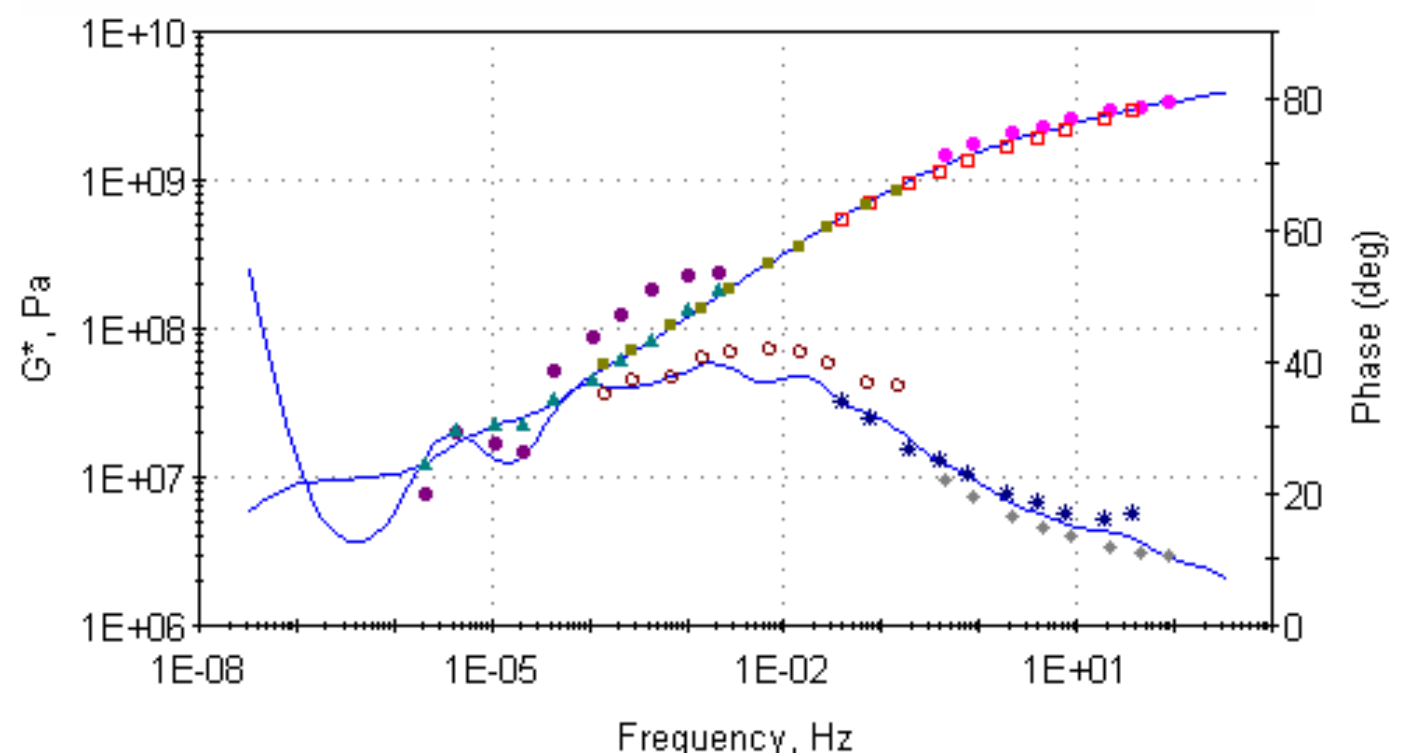

Frequency, $\mathrm{Hz}$

\begin{tabular}{|llllllll|}
\hline & $G^{*}$ Fit. & $*$ & $10^{\circ} \mathrm{C}$ & $\square$ & $20^{\circ} \mathrm{C}$ & $*$ & $40^{\circ} \mathrm{C}$ \\
\cline { 3 - 5 } & $55^{\circ} \mathrm{C}$ & & Phase Fit. & $*$ & $10^{\circ} \mathrm{C}$ & $*$ & $20^{\circ} \mathrm{C}$ \\
\hline & $40^{\circ} \mathrm{C}$ & $*$ & $55^{\circ} \mathrm{C}$ & & & & \\
\hline
\end{tabular}

Figure 41: Master curves for Site 2 I-65 Near Indianapolis 

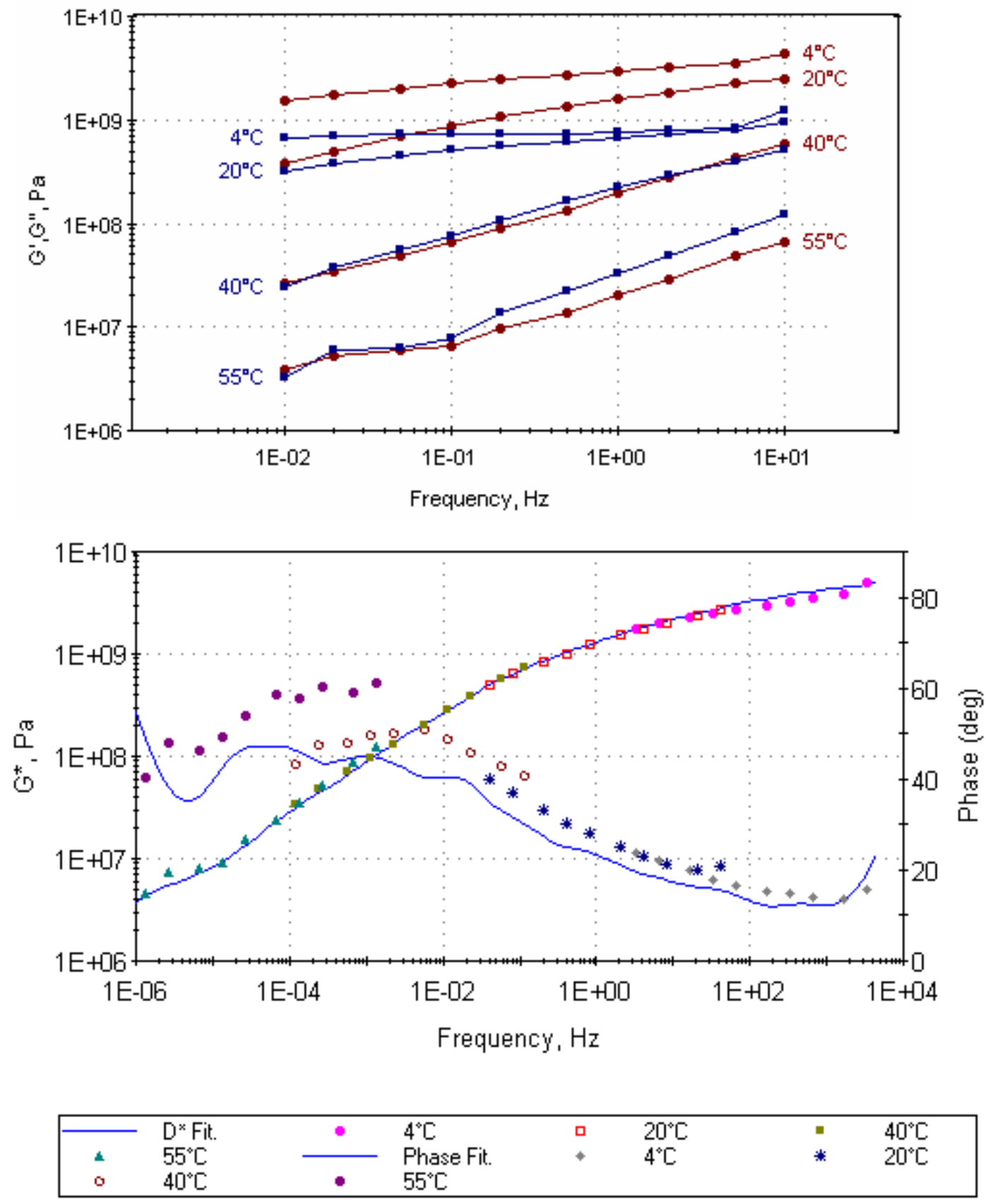

Figure 42: Master curves for Site 3 US 421 Madison 


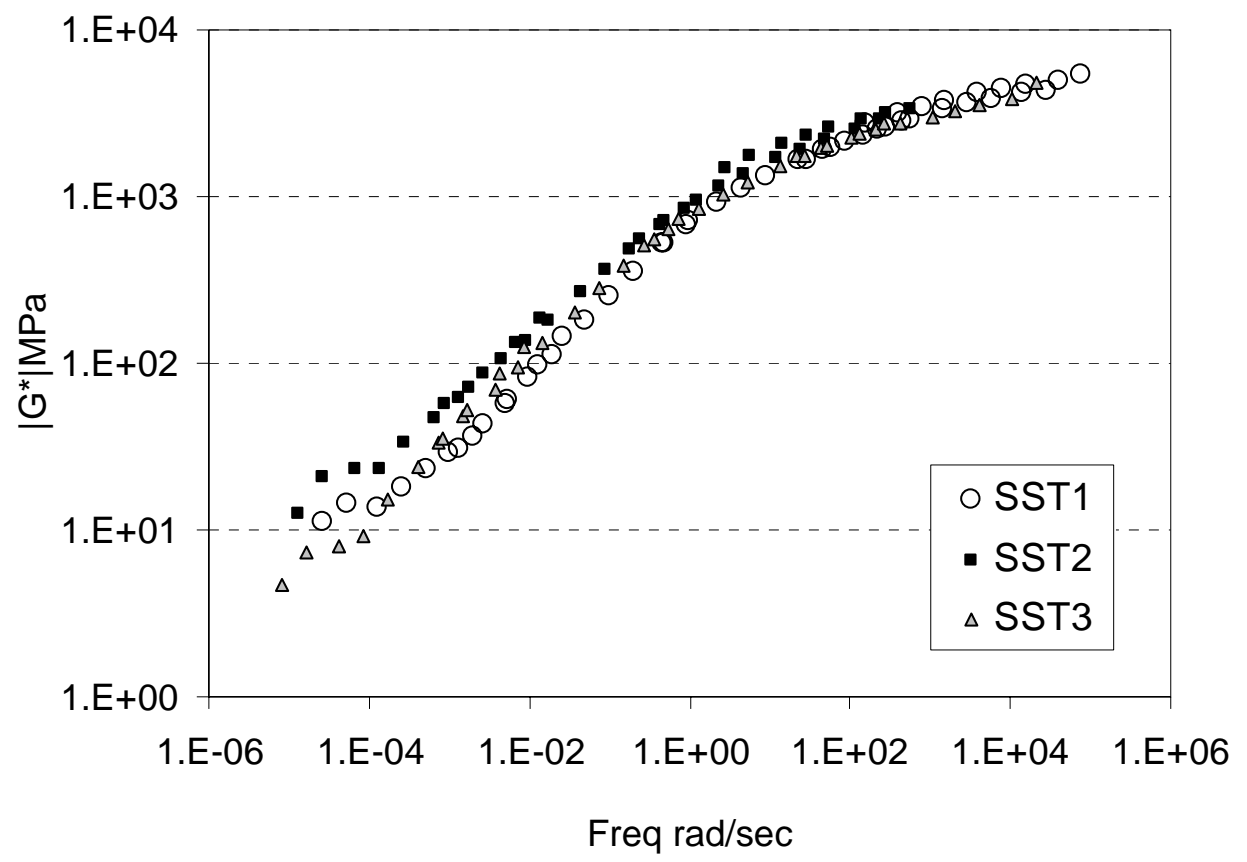

Figure 43: Summary of SST mix shear stiffness master curves.

A summary of the indirect strength data is shown in Table 23 . At -20 and $-10^{\circ} \mathrm{C}$ Site 3 had the lowest strength although the binder stiffness of Site 3 was the same as for Site 1. The low strength can be explained with the higher air void content in the mixture, see Table 23. At zero degree temperature Site 3 mix stiffness was comparable to Site 1 . The better agreement was due to the lower air void content of the tested specimens for Site 3, as Table 23 indicates.

Table 23: Summary of Indirect Tensile Strength Test Results.

\begin{tabular}{|l|c|c|c|c|c|c|}
\hline \multirow{2}{*}{ SITE } & \multicolumn{6}{|c|}{ IDT STRENGTH (kPa) } \\
\cline { 2 - 7 } & \multicolumn{2}{|c|}{$\mathbf{- 2 0}^{\circ} \mathbf{C}$} & \multicolumn{2}{c|}{$-\mathbf{- 1 0}^{\circ} \mathbf{C}$} & \multicolumn{2}{c|}{ 0 $^{\circ}$} \\
\hline & Strength & Va (\%) & Strength & Va (\%) & Strength & Va (\%) \\
\hline SITE 1 I-65 North & 2505 & 6.6 & 2464 & 8.1 & 2148 & 7.1 \\
\hline SITE 2 I-65 Loop & 2121 & 8.5 & 2136 & 8.1 & 1637 & 8.7 \\
\hline SITE 3 US-421 & 1768 & 10.8 & 1853 & 10.2 & 2022 & 9.4 \\
\hline
\end{tabular}




\section{VISCO-ELASTIC 3-D FINITE ELEMENT MODELING}

The research approach for the analysis of top-down cracked pavements included the Finite Element analysis of stress/strain distribution at the top of the pavement surface. The analysis made use of material property sets determined from analysis of FWD and laboratory test data, a climatic effects model, and a 3-D visco-elastic finite element model, as illustrated in Figure 44.

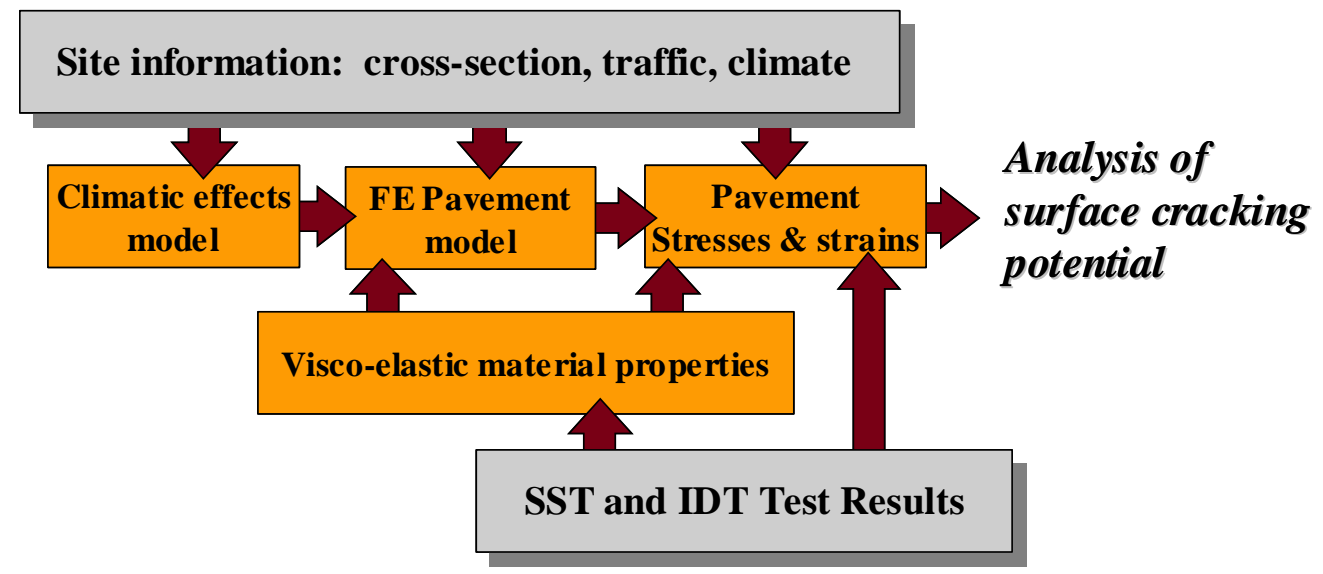

Figure 44. Analysis scheme.

The objective for the material model development for mix and binder properties was to obtain the relationships to describe the complex dynamic modulus and phase angle, for a range of pavement temperatures between $-20^{\circ} \mathrm{C}$ to $54^{\circ} \mathrm{C}$ for the $\mathrm{FE}$ analysis. The approaches considered were a combination of the Superpave Shear Test (SST) and Indirect Tensile Test (IDT) datasets for the mix, and the combination of Dynamic Shear Rheometer (DSR) and Direct Tensile Test (DTT) datasets for the binder. The assumptions, procedures and parameters in the development of these models have been explained in detail in the following sections. 


\subsection{Development of Material Models for FE Analysis}

\subsubsection{Base Binder Model}

For the development of the material model for the binder, separate base course and surface binder data sets were used. For the base course binder, pavement layer thickness information was collected for the three study sites and was verified that the HMA base layer was a typical AC 20 binder (comparable to PG 64-22). Since the binder properties were not evaluated for the base course layer, the calculations have been performed using a typical AC20 binder data set (Rowe and Pellinen, 2002). The Dynamic Shear Rheometer (DSR) test data for a range of temperatures from $15^{\circ} \mathrm{C}$ to $80^{\circ} \mathrm{C}$ after rolling thin film oven (RTFOT) aging was used with Bending Beam Rheometer (BBR) data conducted at temperatures of -18 , -24 and $-30^{\circ} \mathrm{C}$. The two data sets were merged to obtain binder properties over the wide range of temperatures $-30^{\circ} \mathrm{C}$ to $80^{\circ} \mathrm{C}$ which was comparable to the range of temperature of our interest from -20 to $55^{\circ} \mathrm{C}$.

The Christensen-Anderson (CA) model was fitted to the binder master curve to determine the parameters in the equation:

$$
\begin{aligned}
& \left|G^{*}(\omega)\right|=G g\left[1+\left(\omega_{c} / \omega\right)^{(\log 2) / R}\right]^{-R / \log 2} \\
& \delta(\omega)=\frac{90}{1+\left(\omega / \omega_{c}\right)^{(\log 2) / R}}
\end{aligned}
$$

where:

$$
\begin{array}{ll}
\left|\mathrm{G}^{*}(\omega)\right| & =\text { Complex shear modulus } \\
\mathrm{G}_{\mathrm{g}} & =\text { Glassy modulus, typically } 1 \mathrm{GPa} \\
\omega \mathrm{c} & =\text { Crossover frequency, } \mathrm{rad} / \mathrm{s} \\
\mathrm{R} & =\text { Rheological index } \\
\delta(\omega) & =\text { Phase angle, in degrees }
\end{array}
$$


A good fit was observed when the binder data, $\left|\mathrm{G}^{*}\right|$, and phase angle were obtained as illustrated in Figure 45. The parameters of the CA model, glassy modulus $G_{g}$, crossover frequency $\omega_{\mathrm{c}}$ and rheological index R for the binder were determined using the corresponding WLF parameters at the reference of temperature $15^{\circ} \mathrm{C}$, see Table 24 .

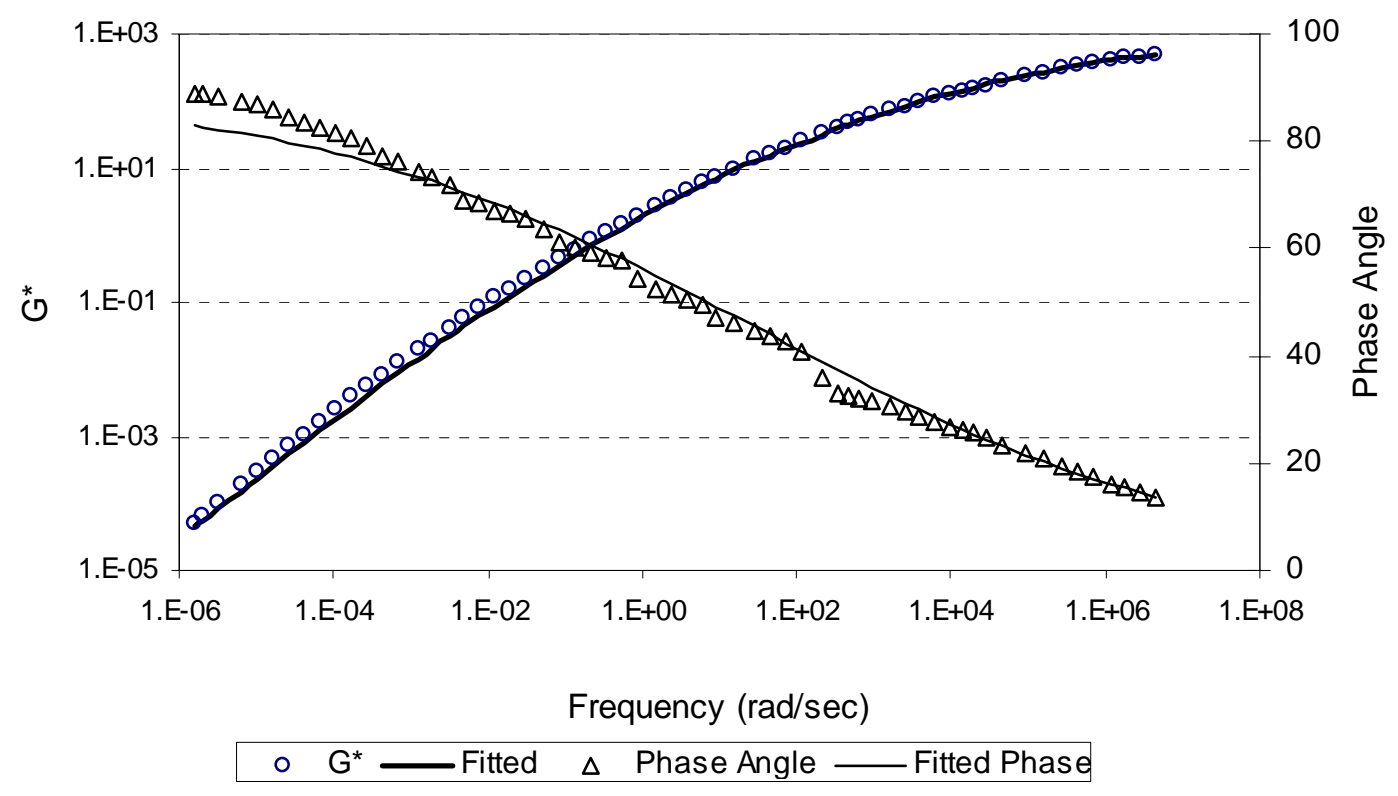

Figure 45: CA fit for binder $\left|G^{*}\right|$ and phase angle for all site for base binder.

Table 24: Parameters for CA model for base binder

\begin{tabular}{|l|l|l|}
\hline \multicolumn{4}{|l|}{ MASTER CURVE PARAMETERS FOR BASE BINDER } \\
\hline Glassy Modulus & $\mathrm{G}_{\mathrm{g}}(\mathrm{MPa})$ & 1542 \\
\hline Rheological Index & $\mathrm{R}$ & 2.06438 \\
\hline Crossover Frequency & $\omega_{\mathrm{c}}(\mathrm{rad} / \mathrm{sec})$ & 32.44 \\
\hline Reference Temperature & $\mathrm{T}_{\mathrm{R}}{ }^{\circ} \mathrm{C}$ & 15 \\
\hline WLF RELATION & \multicolumn{2}{|l|}{} \\
\hline Constants C1 and C2 & $\mathrm{C} 1$ & 22.77 \\
\hline & $\mathrm{C} 2$ & 184.7 \\
\hline Reference Temperature & $\mathrm{T}_{\mathrm{R}}{ }^{\circ} \mathrm{C}$ & 15 \\
\hline Glassy Temperature & $\mathrm{T}_{\mathrm{g}}{ }^{\circ} \mathrm{C}$ & -20 \\
\hline
\end{tabular}




\subsubsection{Surface Binder Model}

For the surface binder analysis, the Dynamic Shear Rheometer (DSR) $\left|G^{*}\right|$ data and the Direct Tension Test (DTT) relaxation modulus $\mathrm{E}(\mathrm{t})$ data were merged to provide a combined dataset which encompasses the entire range of pavement temperatures. The combined data set analyzed in Chapter 5 was used for the model development for the binder properties. A separate master curve model for binder properties in addition to the master curve development using RHEA software was needed to get the master curve in the form that subsequent FE analysis would be efficient and fast.

Figure 46, Figure 47, and Figure 48 illustrate plots of master curve of shear complex modulus $\left|\mathrm{G}^{*}\right|$ and phase angle $\delta$ for the surface mix binders using CA fitting function, as described above. The parameters for the CA model, glassy modulus $\mathrm{G}_{\mathrm{g}}$, crossover frequency $\omega_{\mathrm{c}}$, and rheological index $\mathrm{R}$ were determined using a non linear least square fit and the corresponding WLF parameters at the same reference temperature of $25^{\circ} \mathrm{C}$ are presented in Table 25.

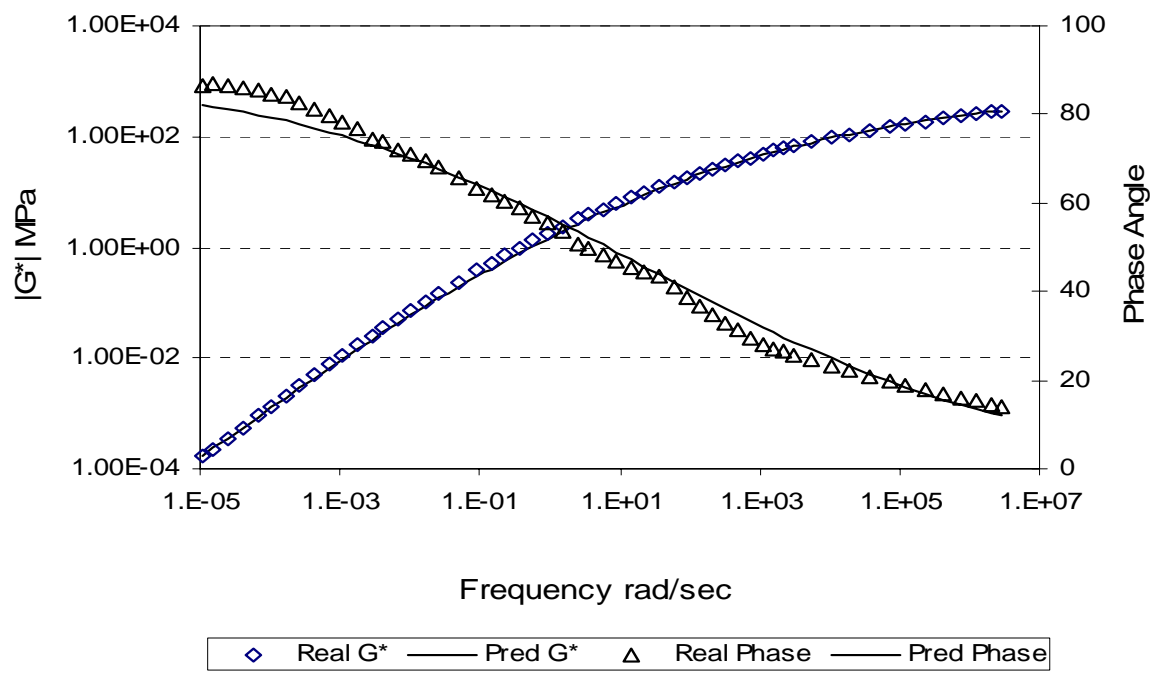

Figure 46: C-A fit for $\mathrm{G}^{*}$ and phase angle for Site 1 surface binder. 


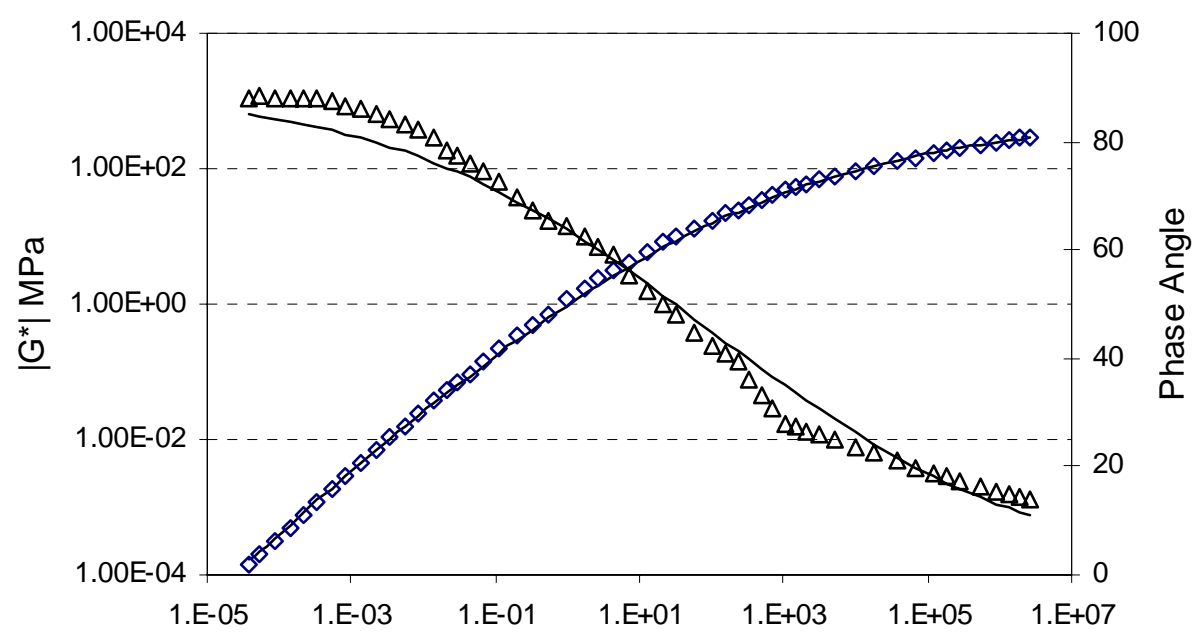

Frequency $\mathrm{rad} / \mathrm{sec}$

$\diamond$ Real G* $^{\star}$ - Pred G* $\Delta \quad$ Real Phase — Pred Phase

Figure 47: C-A fit for $\mathrm{G}^{*}$ and phase angle for Site 2 surface binder.

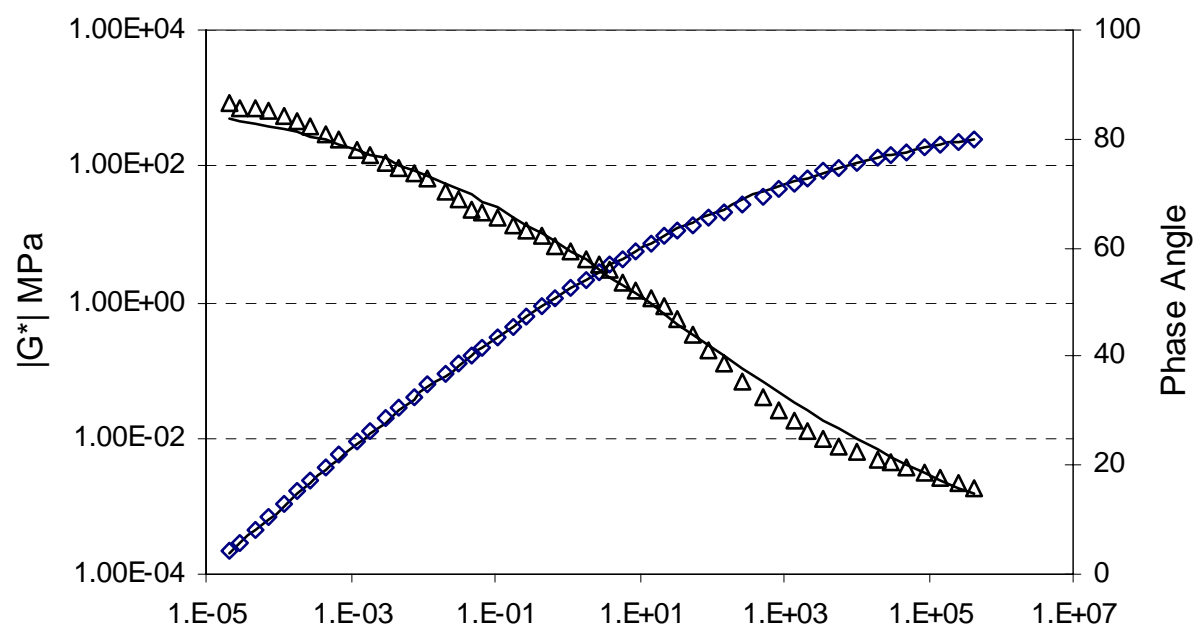

Frequency $\mathrm{rad} / \mathrm{sec}$

$\diamond$ Real G* $^{\star}$ Pred G* $\Delta \quad$ Real Phase — Pred Phase

Figure 48: CA fit for binder $\left|G^{*}\right|$ and phase angle for Site 3 surface binder. 
Table 25: Parameters for CA model for surface binder

\begin{tabular}{|l|l|c|c|c|}
\hline MASTER CURVE PARAMETERS \\
\hline & Symbol & Site 1 & Site 2 & Site 3 \\
\hline Glassy Modulus & $\mathrm{G}_{\mathrm{g}}(\mathrm{MPa})$ & 713.2 & 564.3 & 662.6 \\
\hline Rheological Index & $\mathrm{R}$ & 1.87469 & 1.56266 & 1.68473 \\
\hline Crossover Frequency & $\omega_{\mathrm{c}}(\mathrm{rad} / \mathrm{sec})$ & 26.2758 & 97.9859 & 45.3541 \\
\hline Reference Temperature & $\mathrm{T}_{\mathrm{R}}{ }^{\circ} \mathrm{C}$ & 25 & 25 & 25 \\
\hline WLF RELATION & $\mathrm{C}_{1}$ & 29.58 & 23.39 & 21.23 \\
\hline Constants $\mathrm{C}_{1}$ and $\mathrm{C}_{2}$ & $\mathrm{C}_{2}$ & 259.94 & 214.18 & 187.3 \\
\hline \multicolumn{5}{|l|}{} \\
\hline Reference Temperature & $\mathrm{TR}^{\circ} \mathrm{C}$ & 25 & 25 & 25 \\
\hline Glassy Temperature & $\mathrm{T}_{\mathrm{g}}{ }^{\circ} \mathrm{C}$ & -20 & -20 & -20 \\
\hline
\end{tabular}

\subsubsection{Selected Mix Stiffness Approach}

In the analysis of the mix data, the Superpave Shear Test (SST) dataset and the Indirect Tensile Test (IDT) data set were going to be merged to provide a combined data set which encompasses the entire range of pavement temperatures from $-20^{\circ} \mathrm{C}$ to $55^{\circ} \mathrm{C}$. The combined data set analyzed in Chapter 5 was used for a model development for the mix properties.

Due to the errors in the IDT data the combined master curves for Sites 2 and 3 could not be developed. An alternative approach was selected to obtain the needed mixture stiffness for the FE analysis employing stiffness predictive equations. The Hirsch model, based on composite material behavior, is a fundamental material model approach for determining the mix stiffness (Christensen, Pellinen, and Bonaquist, 2002). The stiffness modulus of the asphalt mix can be directly estimated from binder modulus, voids in mineral aggregate (VMA) and voids filled with asphalt binder (VFA). The model for the dynamic complex extensional modulus $\left|\mathrm{E}^{*}\right|$ is given by: 


$$
\begin{aligned}
& \left|E^{*}\right|_{\text {mix }}=P_{c}\left[4,200,000\left(1-\frac{V M A}{100}\right)+3\left|G^{*}\right|_{\text {binder }}\left(\frac{V F A \times V M A}{10,000}\right)\right] \\
& +\left(1-P_{c}\right)\left[\frac{1-V M A / 100}{4,200,000}+\frac{V M A}{3 V F A\left|G^{*}\right|_{\text {binder }}}\right]^{-1}
\end{aligned}
$$

where:

$\mathrm{P}_{\mathrm{c}} \quad=$ aggregate contact volume, as a volume fraction

$$
P_{c}=\frac{\left(20+\frac{V F A \times 3\left|G^{*}\right|_{\text {binder }}}{V M A}\right)^{0.58}}{650+\left(\frac{V F A \times 3\left|G^{*}\right|_{\text {binder }}}{V M A}\right)^{0.58}}
$$

The aggregate contact volume, $\mathrm{P}_{\mathrm{c}}$, is the portion of aggregate particles in intimate contact with each other. As the aggregate contact volume increases, the modulus and strength also increases. High values of $\mathrm{P}_{\mathrm{c}}$ indicate very effective structures producing good strengths and stiffness which is typical at low temperatures. Low values of $\mathrm{P}_{c}$ indicate structure with low strength and stiffness and tend to occur at high temperatures.

The parameters required for the Hirsch model can be calculated from the volumetric composition of the mixture using Equations (15) and (16), where $V_{a}$ is air voids and $V_{\text {beff }}$ is the effective binder volume.

$$
\begin{aligned}
& V M A=V_{\text {beff }}+V_{a} \\
& V F A=\left(\frac{V_{\text {beff }}}{V_{\text {beff }}+V_{a}}\right) * 100
\end{aligned}
$$

The parameters required for the Hirsch model were calculated from the measured volumetric composition of the studied mixtures. The VMA and VFA values are shown in Table 18. The binder stiffness $\left|\mathrm{G}^{*}\right|_{\text {binder }}$ was obtained from the developed CA fitted binder 
master curves, discussed above.

Figure 49 compares the mix master curves obtained by fitting only the SST mix data and predicted stiffness master curves using the Hirsch predictive model. The SST master curve was converted to uniaxial loading mode by Equation $\left|G^{*}\right|=0.0603\left|E^{*}\right|^{1.0887}$. The SST master curves gave lower values for the mixture stiffness at high temperature with as low as $10 \mathrm{MPa}$. This suggests that the SST data is not giving comparable mix stiffness values in relation to the uniaxially measured stiffness. Therefore, it was decided that the predicted mix stiffness was used in the subsequent FE analysis.

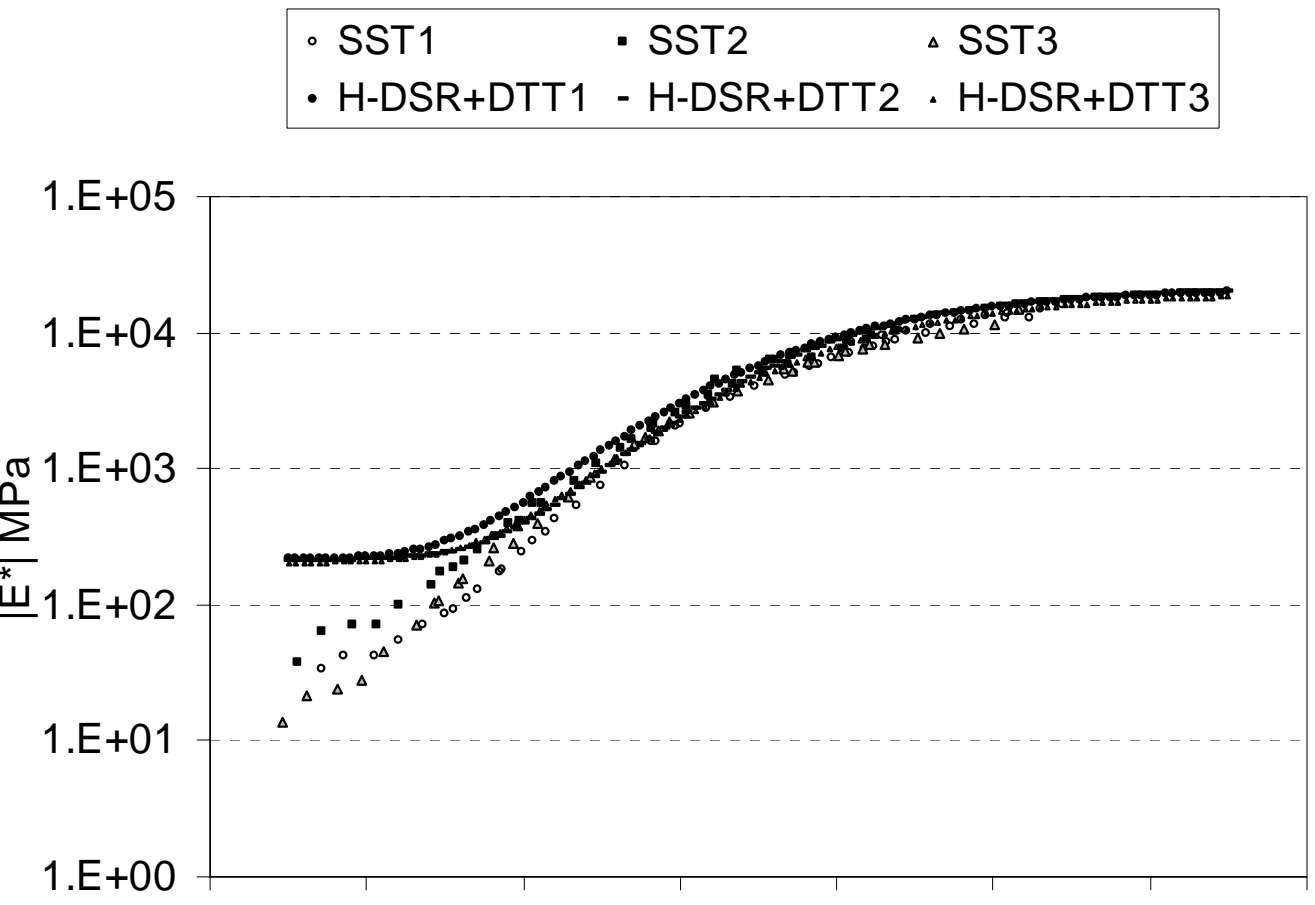

1.E-06 1.E-04 1.E-02 1.E+00 1.E+02 1.E+04 1.E+06 1.E+0ع

Freq rad/sec

Figure 49: Comparison of mix master curves.

\subsubsection{Visco-elastic Model Development for FE Analysis}

For the analysis of the pavement structure, a linear visco-elastic rheological model 
was employed. Work initially concentrated on the use of the Burger's model since it was considered that this would be adequate to consider the range of loading times of interest. This aspect was investigated by performing an analysis of a pulse load on a cylindrical specimen. The pulse load time was chosen to be similar to the traffic speeds to be used in the finite element analysis. This analysis of the pulse suggested that in order to describe the shape of the load and deformation response the five relaxation times are needed. Consequently, the standard two element representation of the Burgers' model was replaced with the more generalized five element model. The parameters for the model were obtained by fitting relaxation spectra using stiffness data from the Hirsch model.

\subsection{Mesh Design and Gaussian Quadrature}

During the 1990's Rowe, Brown, Sharrock and Bouldin (1995) developed a finite element analysis approach for pavement design. A modification to this software is proposed for the analysis of the pavement structures for surface cracking propensity. The analysis method can deal with the visco-elastic nature properties of asphalt materials, allows temperature depth gradients to be modeled, enables the definition of complex wheel loads and allows materials to be damaged at different rates within the pavement structure.

The software consists of a "core" FE program that interacts with other programs and subroutines that provide information on material properties, pavement temperatures and traffic conditions. The greater part of the existing finite element code, initially drawn upon for program development, is based on work described by Owen and Hinton (1980).

\subsubsection{Pavement Depths at Gauss Points}

In the 3-D finite element analysis of the pavement structure, the stresses and strains are obtained at the four Gauss points of the 20 node element chosen to represent the HMA layers. The pavement depths have been calculated corresponding to the Gauss points and tabulated in Table 26. Climatic data at distances D1 and D2, shown in Table 26, from the 
surface of the pavement are analyzed for obtaining the temperatures corresponding to these points.

Table 26: Pavement Depths corresponding to Gauss Points for FE analysis

\begin{tabular}{|c|c|c|c|c|c|c|c|}
\hline \multicolumn{8}{|c|}{ SITE 1 I-65 NORTH OF LAFAYETTE } \\
\hline & $\begin{array}{l}\text { Depth } \\
\text { of HMA } \\
\text { Layers } \\
\text { (in) }\end{array}$ & 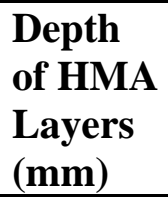 & Layer/2 & $\begin{array}{l}\text { Gauss } \\
\text { Pt\#2 }\end{array}$ & $\begin{array}{l}\text { Distance } \\
\text { above and } \\
\text { below } \\
\text { Centerline }\end{array}$ & $\begin{array}{l}\text { Distance1 } \\
\text { From Top } \\
\text { D1 }\end{array}$ & $\begin{array}{l}\text { Distance } 2 \\
\text { From Top } \\
\text { D2 }\end{array}$ \\
\hline Layer 1 & 1.5 & 38.1 & 19.05 & 0.577 & 10.99852 & 8.1 & 27.1 \\
\hline Layer 2 & 13 & 330.2 & 165.1 & 0.577 & 95.32053 & 107.9 & 273.0 \\
\hline \multicolumn{8}{|c|}{ SITE 2 I-65 NEAR INDIANAPOLIS } \\
\hline & $\begin{array}{l}\text { Depth } \\
\text { of HMA } \\
\text { Layers } \\
\text { (in) }\end{array}$ & $\begin{array}{l}\text { Depth } \\
\text { of HMA } \\
\text { Layers } \\
(\mathrm{mm})\end{array}$ & Layer/2 & $\begin{array}{l}\text { Gauss } \\
\text { Pt\#2 }\end{array}$ & $\begin{array}{l}\text { Distance } \\
\text { above and } \\
\text { below } \\
\text { Centerline }\end{array}$ & $\begin{array}{l}\text { Distance1 } \\
\text { From Top } \\
\text { D1 }\end{array}$ & $\begin{array}{l}\text { Distance } 2 \\
\text { From Top } \\
\text { D2 }\end{array}$ \\
\hline Layer 1 & 1 & 25.4 & 12.7 & 0.577 & 7.332348 & 5.4 & 18.1 \\
\hline Layer 2 & 20.5 & 520.7 & 260.35 & 0.577 & 150.3131 & 135.4 & 395.8 \\
\hline \multicolumn{8}{|c|}{ SITE 3 US 421 MADISON } \\
\hline & $\begin{array}{l}\text { Depth } \\
\text { of HMA } \\
\text { Layers } \\
\text { (in) } \\
\end{array}$ & 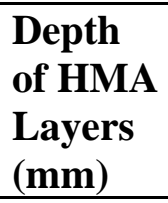 & Layer/2 & $\begin{array}{l}\text { Gauss } \\
\text { Pt\#2 }\end{array}$ & $\begin{array}{l}\text { Distance } \\
\text { above and } \\
\text { below } \\
\text { Centerline }\end{array}$ & $\begin{array}{l}\text { Distance1 } \\
\text { From Top } \\
\text { D1 }\end{array}$ & $\begin{array}{l}\text { Distance } 2 \\
\text { From Top } \\
\text { D2 }\end{array}$ \\
\hline Layer 1 & 1.25 & 31.75 & 15.875 & 0.577 & 9.165436 & 6.7 & 22.6 \\
\hline Layer 2 & 6.75 & 171.45 & 85.725 & 0.577 & 49.49335 & 68.0 & 153.7 \\
\hline
\end{tabular}

A pavement representation for Site 1, I-65 North of Lafayette, indicating the position of Gauss points is shown in Figure 50.

\subsubsection{Pavement Temperatures}

Climatic factors play a dominating role in asphalt pavement design procedures since they affect permanent deformation and fatigue cracking as well as other modes of pavement distress. In order to enable a rigorous analysis of climatic effects to be 
introduced, a FE heat flow model was used to generate 24 temperature-depth profiles, one for each hour of the day. The calculations are repeated for twelve periods corresponding to each of the twelve months of the year. The model uses an energy balance calculation with boundary conditions that consist of a heat transfer coefficient used in conjunction with air temperature, together with a radiation flux, at the upper surface and a fixed temperature at $1 \mathrm{~m}$ depth, equal to the average monthly air temperature. The computation is started at dawn, assuming a constant temperature with depth for simplicity. The heat flow equations are integrated by an explicit time stepping procedure, while, simultaneously, the heat transfer conditions at the surface are varied with time according to the predetermined patterns of air temperature together with direct and diffuse radiation. After 24 hours, dawn again is reached. The temperature-depth variation found at this time is treated as a new estimate of the starting conditions and the time stepping process is repeated for another 24 hours. In this way, successive approximations to the initial boundary conditions are obtained. When the initial and final states of the 24-hour period match closely, the desired solution for the period has been determined. The radiation at the surface is obtained as follows:

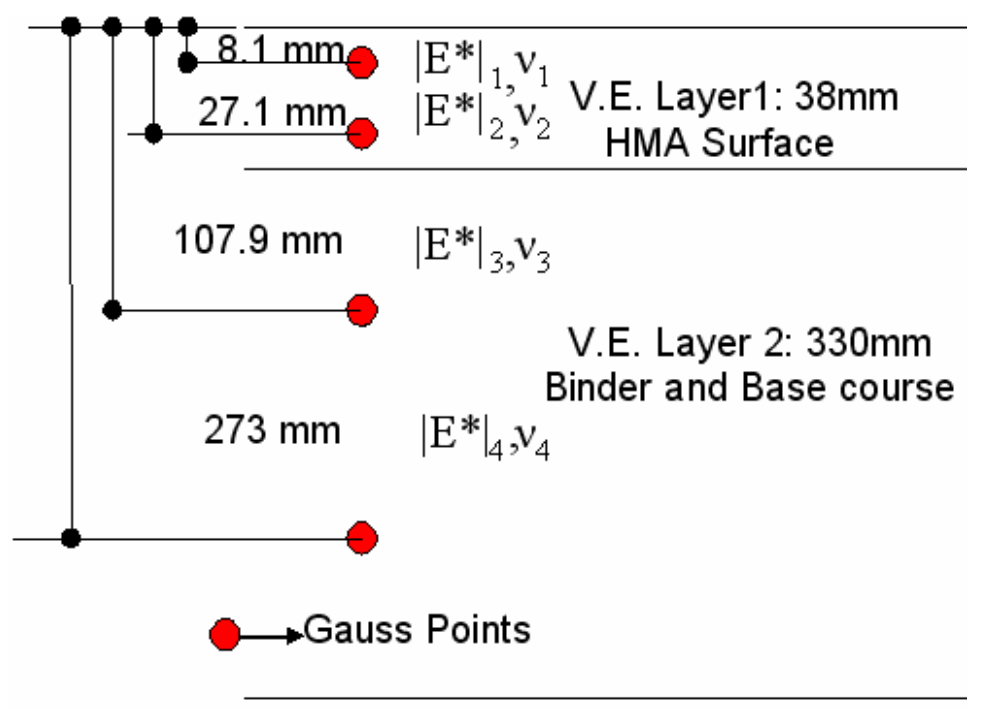

Figure 50: Pavement Representation for Site 1 I-65 North 
Day: A mean value of solar constant of $1362 \mathrm{~W} / \mathrm{m}^{2}$ is assumed, i.e. the radiation intensity normal to the sun's direction above the earth's atmosphere. This is taken to vary seasonally by $+/-3.5 \%$ due to the varying radius of the earth's orbit. Generally accepted published information on the proportion of the radiation reaching the ground is assumed, dependent on the elevation of the sun, the height above sea level and cloud cover. An absorbtivity of 0.9 is taken for the asphaltic materials.

Night: A constant re-radiation of $120 \mathrm{~W} / \mathrm{m}^{2}$ to space is assumed. This is developed and terminated linearly during the first hour and last hour of darkness, to give a pattern continuous with the daytime radiation input.

An approximate daily variation of air temperature for each month is constructed from average daily maximum and minimum temperatures, with an allowance of plus and minus a number of standard deviations to cover the required proportion of the extremes, varying linearly with maximum and minimum temperature over the year. Together with the computed surface temperature, this defines the remaining surface heat transfer, using a heat transfer coefficient of $23 \mathrm{~W} / \mathrm{m}^{2} /{ }^{\circ} \mathrm{C}$.

The heat flow calculation is done iteratively, employing the previously mentioned FE method. Typical thermal properties are assumed for the asphaltic mixture as follows:

- Conductivity $\left(\mathrm{K}_{\mathrm{c}}\right) \quad 1.5 \mathrm{w} / \mathrm{m} .{ }^{\circ} \mathrm{K}$

- Mass Density $(\rho) \quad 2400 \mathrm{~kg} / \mathrm{m}^{3}$

- Specific Heat ( Cp ) $\quad 960 \mathrm{~J} / \mathrm{kg} .{ }^{\circ} \mathrm{K}$

The above properties are used to obtain diffusivity, as follows:

$$
\kappa=\frac{K_{c}}{(\rho \times C p)}
$$

Thus, the default value used in the FE heat flow calculations for diffusivity is $6.51 \mathrm{e}-7 \mathrm{~m}^{2} / \mathrm{s}$.

The result from this analysis is 288 temperature depth gradients (24 for each month of the year) with a single gradient representing a typical hour of one of the 12-months. 
Statistical bias can be applied to the calculated temperature depth gradients - for example the computations can be performed for mean conditions or for conditions representing a high or low multiple of the standard deviation from the mean. This statistical aspect is of considerable importance since damage to asphalt mixtures occurs generally at the extreme of climatic conditions - both for plastic flow and cracking.

This entire computation procedure has recently been calibrated (Pellinen et al., 2004) against data collected from the WesTrack program and, while computationally is marginally different from the procedure implemented with the new NCHRP 1-37A design method, it allows rapid computation of effects due to the manner in which it is integrated with other analysis tools.

Pavement temperatures are available from a 10-year climatic database file collected during the Strategic Highway Research Program (Rowe, 1996). These data files were analyzed to produce pavement temperature depth profiles for the state of Indiana. With the LeapsPro ${ }^{\mathrm{TM}}$ Software, the envelope of annual temperature depth variation was obtained for each study site. Figure 51 shows the temperature depth variation. The hourly temperature variation data for each month were also recorded. The maximum and minimum temperatures are summarized and presented in Table 27.

Table 27: Maximum and Minimum pavement temperature-depth values

\begin{tabular}{|c|l|l|l|l|l|l|l|l|}
\hline \multicolumn{3}{|l|}{ SITE 1 } & \multicolumn{3}{l|}{ SITE 2 } & \multicolumn{2}{l|}{ SITE 3 } \\
\hline $\begin{array}{l}\text { Depth } \\
(\mathbf{m m})\end{array}$ & $\mathbf{T}_{\min }$ & $\mathbf{T}_{\max }$ & $\begin{array}{l}\text { Depth } \\
(\mathbf{m m})\end{array}$ & $\mathbf{T}_{\min }$ & $\mathbf{T}_{\max }$ & $\begin{array}{l}\text { Depth } \\
(\mathbf{m m})\end{array}$ & $\mathbf{T}_{\min }$ & $\mathbf{T}_{\max }$ \\
\hline 0 & -23.32 & 56.92 & 0 & -20.34 & 57.15 & 0 & -16.56 & 57.54 \\
\hline 25 & -22.19 & 53.91 & 25 & -19.27 & 54.08 & 25 & -15.49 & 54.45 \\
\hline 50 & -21.25 & 51.43 & 50 & -18.38 & 51.66 & 50 & -14.6 & 52.06 \\
\hline 75 & -20.62 & 49.36 & 75 & -17.77 & 49.54 & 75 & -13.99 & 49.92 \\
\hline 100 & -20.01 & 47.4 & 100 & -17.21 & 47.62 & 100 & -13.42 & 48.03 \\
\hline 125 & -19.38 & 45.64 & 125 & -16.61 & 45.81 & 125 & -12.82 & 46.2 \\
\hline 150 & -18.75 & 44.03 & 150 & -16.01 & 44.17 & 150 & -12.22 & 44.59 \\
\hline 200 & -17.9 & 41.52 & 200 & -15.28 & 41.83 & 200 & -11.5 & 42.25 \\
\hline 250 & -17.31 & 39.51 & 250 & -14.66 & 39.63 & 250 & -10.88 & 40.09 \\
\hline 300 & -16.86 & 37.81 & 300 & -14.24 & 37.93 & 300 & -10.47 & 38.4 \\
\hline
\end{tabular}


Figure 51 shows the plot of annual maximum and minimum temperature depth variation for Site $1 \mathrm{I}-65$ North of Lafayette. The minimum temperature was $-23.32^{\circ} \mathrm{C}$ and the maximum temperature was $56.92^{\circ} \mathrm{C}$.

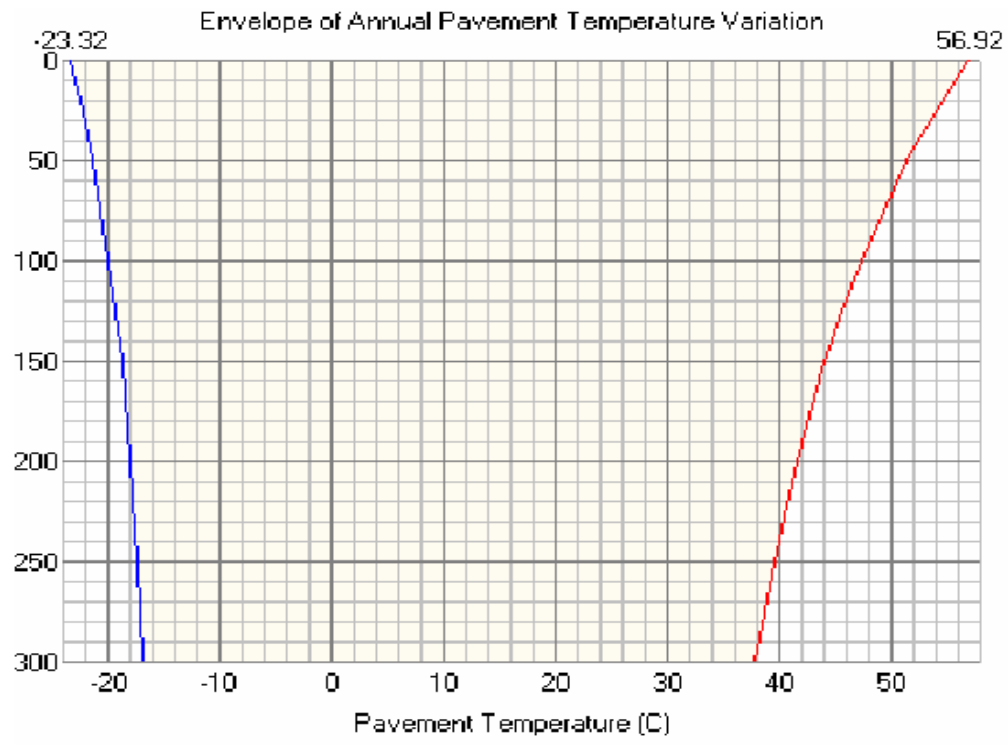

Figure 51: Site 1 Annual temperature-depth variation

After obtaining the pavement temperature-depth gradient in Table 27, the temperatures at Gauss points are calculated by fitting a climatic model to the temperature depth curve. This method is automated in some of the software application previously developed and involves fitting the data computed by the climatic effects model with six parameters $\left(\mathrm{P}_{1} \mathrm{P}_{2} \mathrm{P}_{3} \mathrm{P}_{4} \mathrm{P}_{5}\right.$ and $\left.\mathrm{P}_{6}\right)$. The gradients are expressed in an exponential form given by:

$$
T(z)=P_{1}+P_{2} e^{-2 z}+P_{3} e^{-5 z}+P_{4} e^{-8 z}+P_{5} e^{-11 z}+P_{6} e^{-14 z}
$$

where:

$$
\begin{array}{ll}
\mathrm{t} & =\text { Temperature, }{ }^{\circ} \mathrm{C} \\
\mathrm{z} & =\text { Depth, } \mathrm{m}
\end{array}
$$


$\mathrm{P}_{1}-\mathrm{P}_{6}=$ Fitting parameters

While this approach has been found acceptable in automated procedures a similar procedure was used to interpolate data from the model by fitting a third order polynomial to the plot of recorded maximum and minimum temperature data. The fit obtained by this procedure proved sufficiently accurate to enable a good interpolation of the temperatures at various depths for this project.

The temperature corresponding to the Gauss points were obtained using the climatic model for each site. The temperature-depth values at the Gauss points are presented in Table 28 .

Table 28: Temperature at gauss points for $\mathrm{FE}$ analysis

\begin{tabular}{|c|c|c|c|c|c|c|c|c|}
\hline \multicolumn{3}{|l|}{ SITE 1} & \multicolumn{3}{|c|}{ SITE 2} & \multicolumn{3}{|c|}{ SITE 3} \\
\hline $\begin{array}{l}\text { Depth } \\
\text { mm }\end{array}$ & $\begin{array}{l}\text { Temp } \\
\max \end{array}$ & $\begin{array}{l}\text { Temp } \\
\text { min }\end{array}$ & $\begin{array}{l}\text { Depth } \\
\text { mm }\end{array}$ & $\begin{array}{l}\text { Temp } \\
\text { max }\end{array}$ & $\begin{array}{l}\text { Temp } \\
\text { min }\end{array}$ & $\begin{array}{l}\text { Depth } \\
\text { mm }\end{array}$ & $\begin{array}{l}\text { Temp } \\
\text { max }\end{array}$ & $\begin{array}{l}\text { Temp } \\
\text { min }\end{array}$ \\
\hline \multicolumn{3}{|c|}{ HMA Layer 1} & \multicolumn{3}{|c|}{ HMA Layer 1} & \multicolumn{3}{|c|}{ HMA Layer 1} \\
\hline 8.1 & 55.89 & -22.9 & 5.4 & 56.42 & -20.05 & 6.7 & 56.65 & -16.22 \\
\hline 27.1 & 53.82 & -22.17 & 18.1 & 54.97 & -19.57 & 22.6 & 54.87 & -15.62 \\
\hline \multicolumn{3}{|c|}{ HMA Layer 2} & \multicolumn{3}{|c|}{ HMA Layer 2} & \multicolumn{3}{|c|}{ HMA Layer 2} \\
\hline 107.9 & 47.09 & -19.68 & 135.4 & 45.52 & -16.26 & 68 & 50.55 & -14.14 \\
\hline 273 & 40.57 & -16.94 & 395.8 & 37.84 & -12.91 & 153.7 & 44.95 & -12.11 \\
\hline
\end{tabular}

\subsubsection{Loading Time/ Frequency}

The loading time and frequencies were calculated for a typical range of vehicular speed of 35 to $60 \mathrm{mph}$. The relationship between the thickness of HMA layer (mm), vehicle speed $(\mathrm{km} / \mathrm{hr})$ and loading time $(\mathrm{s})$ is given by:

$$
\log t=5 \times 10^{-4} h-0.2-0.94 \log V
$$


The lowest loading frequency was $22 \mathrm{rad} / \mathrm{sec}$ and the highest frequency was 73.8 $\mathrm{rad} / \mathrm{sec}$. With reference to the maximum and minimum loading frequency at each site, a decade of frequency $(10-100 \mathrm{rad} / \mathrm{sec})$ was selected for the calculation of stiffness of the mix for the finite element model using the Burger's model discussed in Section 6.1.4.

\subsection{Wheel Load Modeling}

The wheel load was decomposed into a contact area made up of 120 sub-patches, each of which can have a normal and shear component applied. Consequently, transverse and longitudinal forces associated with the tire loading were combined into a single force vector that acts on the surface of the loaded sub-patch.

The contact patch is time-stepped across the problem. This makes the analysis relatively complex and time consuming. This is the reason that the relaxation modes and visco-elastic layers are limited to two and the grid size was not further refined, thereby enabling the problem to be solved on a PC with a reasonable degree of accuracy.

There are some important observations with regards to tire loading:

- $\quad$ Stress reversals exist across each rib

- Stress reversals longitudinally- compression in front and tension at rear

- Higher stresses on outside rib of radial tires

- Result is a complex stress distribution

- Tire loading is simplified into multiple contact patches with normal and shear loading

The wheel load has been decomposed into a contact area made up of 120 subpatches, each of which can have a normal and shear component applied. Consequently, transverse and longitudinal forces associated with the tire loading have been combined into a single force vector that acts on the surface of the loaded sub-patch. The model makes use of a finite-element model (Zienkiewicz, Nayak \& Owen, 1972; Owen et al., 1980; Owen, Prakash and Zienkiewicz, 1974) with quadratic hexahedral elements visco-elastic elements representing the asphalt material as shown in Figure 52. 

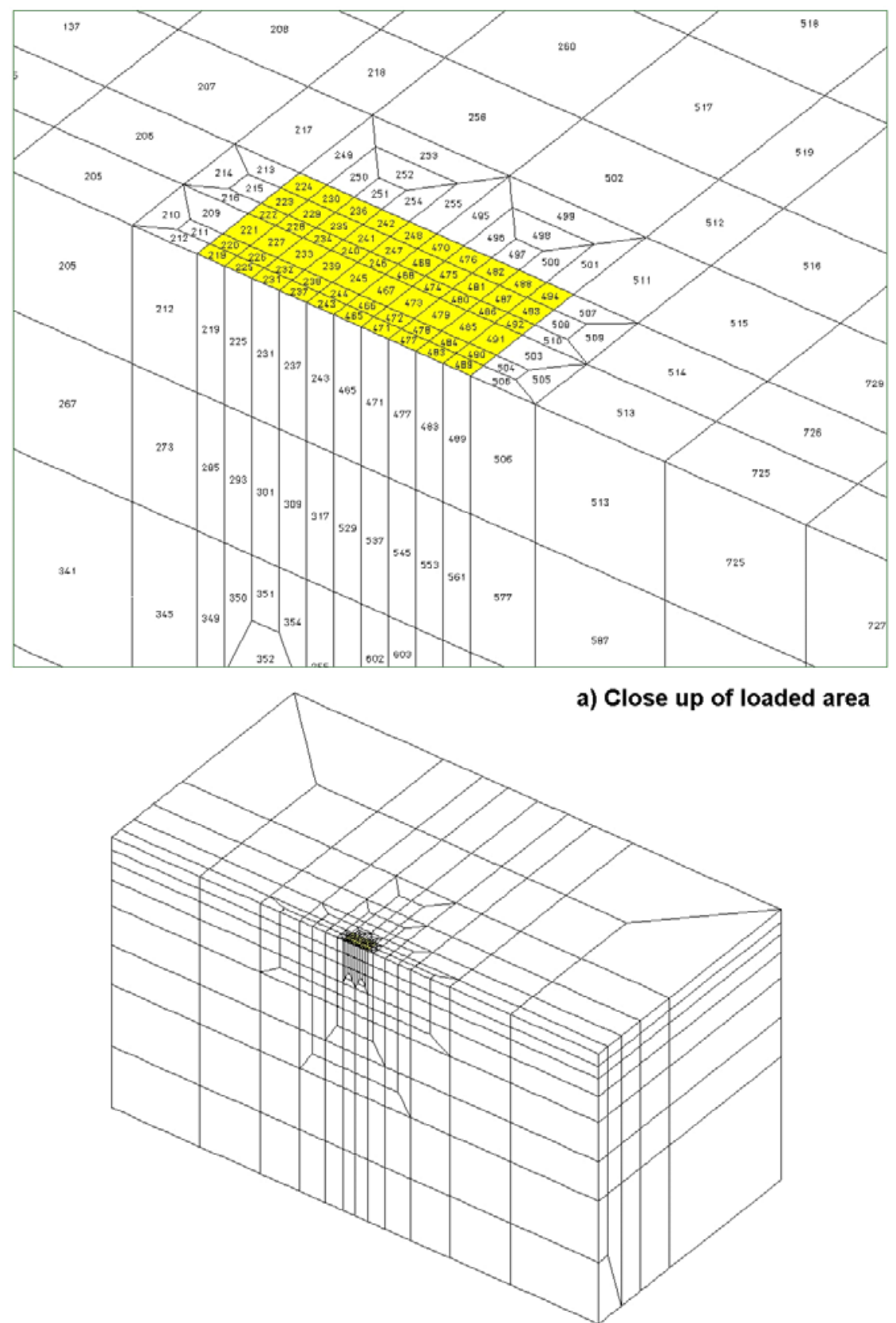

b) General view of grid

Figure 52: Mesh used to represent complex wheel loading on 3-D analysis.

The contact patch is time-stepped across the problem. This makes the analysis relatively complex and time consuming. This is the reason that the relaxation modes and 
visco-elastic layers have been limited to two and the grid size has not been further refined thus enabling the problem to be solved on a PC with a reasonable degree of accuracy.

This type of analysis allows the effects of both variations in wheel load contact stresses across the wheel and temperature depth gradients in the pavement to be modeled thus meeting the objectives discussed above. The major limitation of this analysis is that no provision is currently made for the consideration of the crack propagation once initiation has occurred. However, it could be argued that the major design consideration is the prevention of crack initiation.

\subsection{Pavement Modeling}

The pavement structure is considered as comprising two visco-elastic layers with variable temperature depth and hence, stiffness properties. One of these layers is used to model the HMA surface layer while the binder course and base layers are combined in the remaining visco-elastic layers. The foundation property sets are considered as elastic layers with information obtained through the analysis of the FWD data. The material property sets combined with the visco-elastic and elastic models define the structure being analyzed.

The first part of the analysis conducted was a check calculation to ensure that viscous-elastic response of the material model was reasonable. This was performed by the consideration of a pulse load test that had a similar range of loading speed to the pavement with the materials being considered. A Poisson's ratio of 0.3 was used in the analysis because it gave more realistic results compared to the Poisson's ratio of 0.4 .

The displacements obtained for Site 1 are illustrated in Figure 53. The maximum deflection that occurs in this with the loading is 129 microns. The current FE code shows some permanent strain at the end of the pulse. This aspect requires some further investigation since the recovery should be greater (i.e. virtually complete) given Hirsch "solid" VE material model used in the analysis. In addition, the effects of boundary 
symmetries are rather noticeable. The initial and final deflections are effectively due to a doubling of the load at the boundary of the pavement problem.

The change from a uniformly distributed load used in previous analysis to a detail stress pattern (variable contact stress and shear stress) going in towards and coming out of the central region of the finite element mesh causes some noticeable discontinuity in deflections. Further refinement is needed to correct this problem.

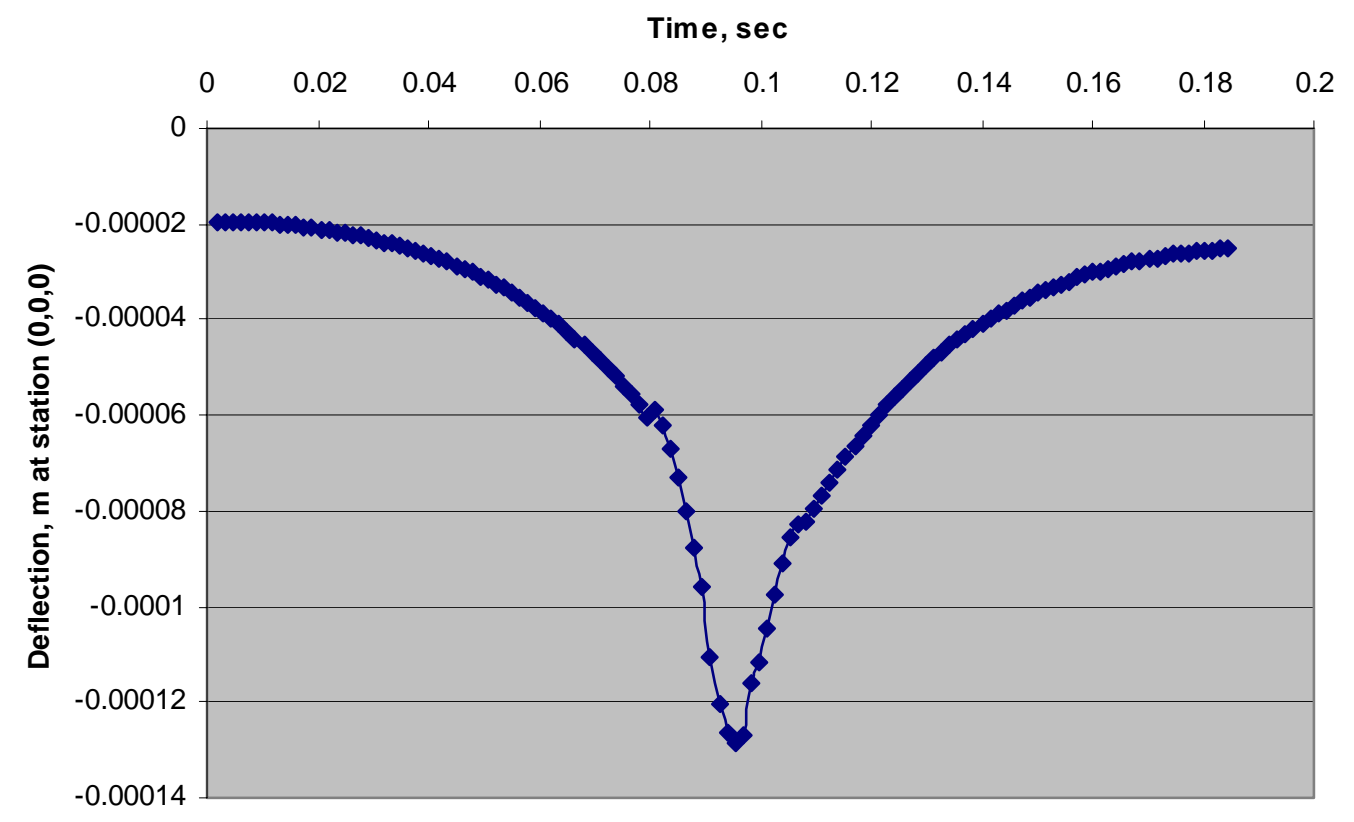

Figure 53: Displacements for site 1 using existing FE Code

\subsection{Elastic Layered Analysis System}

An existing computer program - LeapsPro ${ }^{\mathrm{TM}}$ (Layered Elastic Analysis of Pavement Structures) was used for the elastic layered analysis. LeapsPro ${ }^{\mathrm{TM}}$ makes use of a core layered elastic program which interacts with a number of routines to develop a pavement problem for analysis. However, for this application a special version of the LEAP software was produced that could handle a complex wheel load. This consisted of separation of the 
wheel into 192 contact patches as illustrated in Figure 54. The magnitude of vertical load on each circular loading element is illustrated in Figure 55. The total magnitude of the loaded area was consistent with the loading required to produce a $40 \mathrm{kN}$ wheel load (approximately 18 kip axle load).

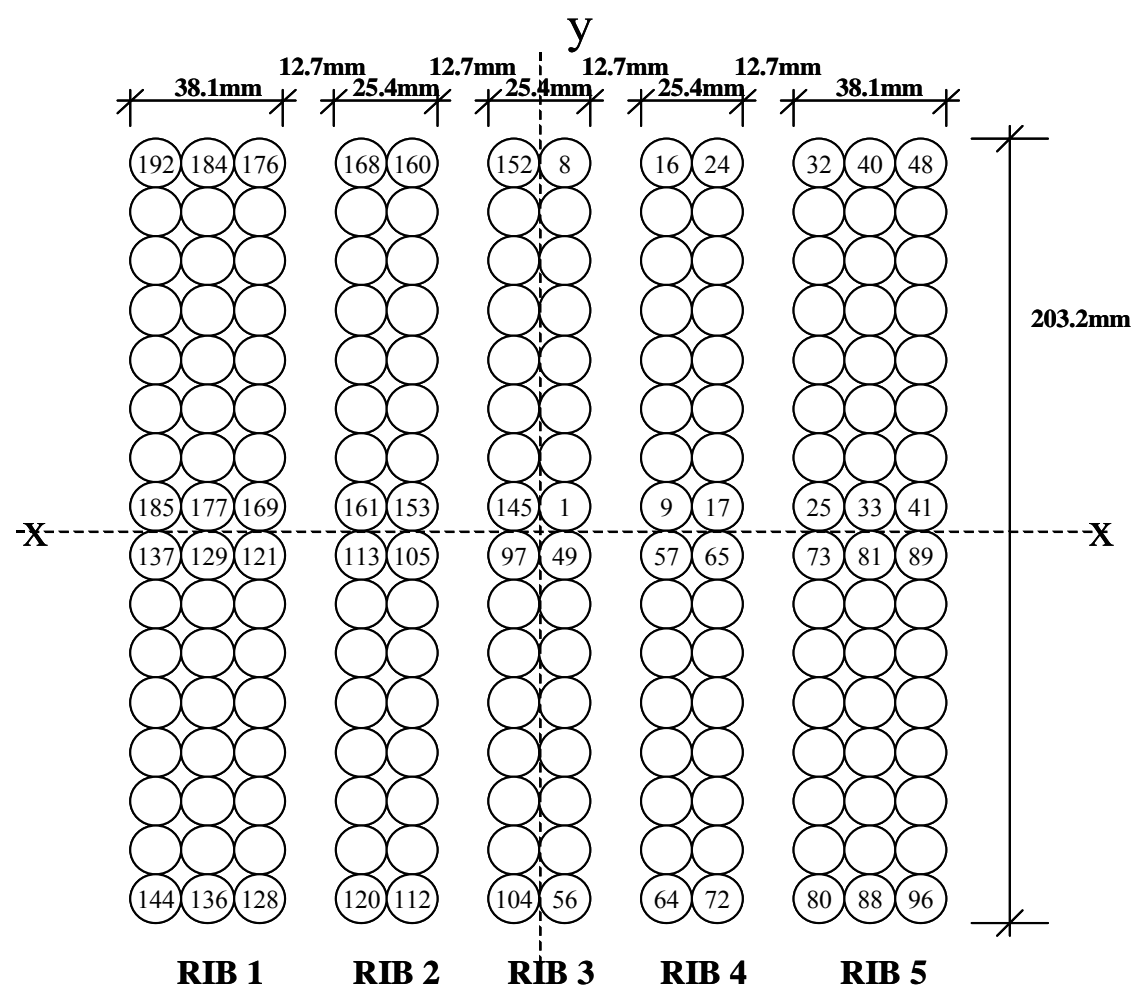

Figure 54: Representation of wheel load in elastic layer analysis

\section{$\underline{\text { Pavement Layers }}$}

The pavement layers in LEAPS consist of asphalt layers of an elastic soil foundation. The asphalt pavement layers were subdivided into a wearing course and base layer. These layers were again sub-divided into two layers - with each sub layer being assigned its own temperature and modulus in the same manner as used for the finite element analysis. 


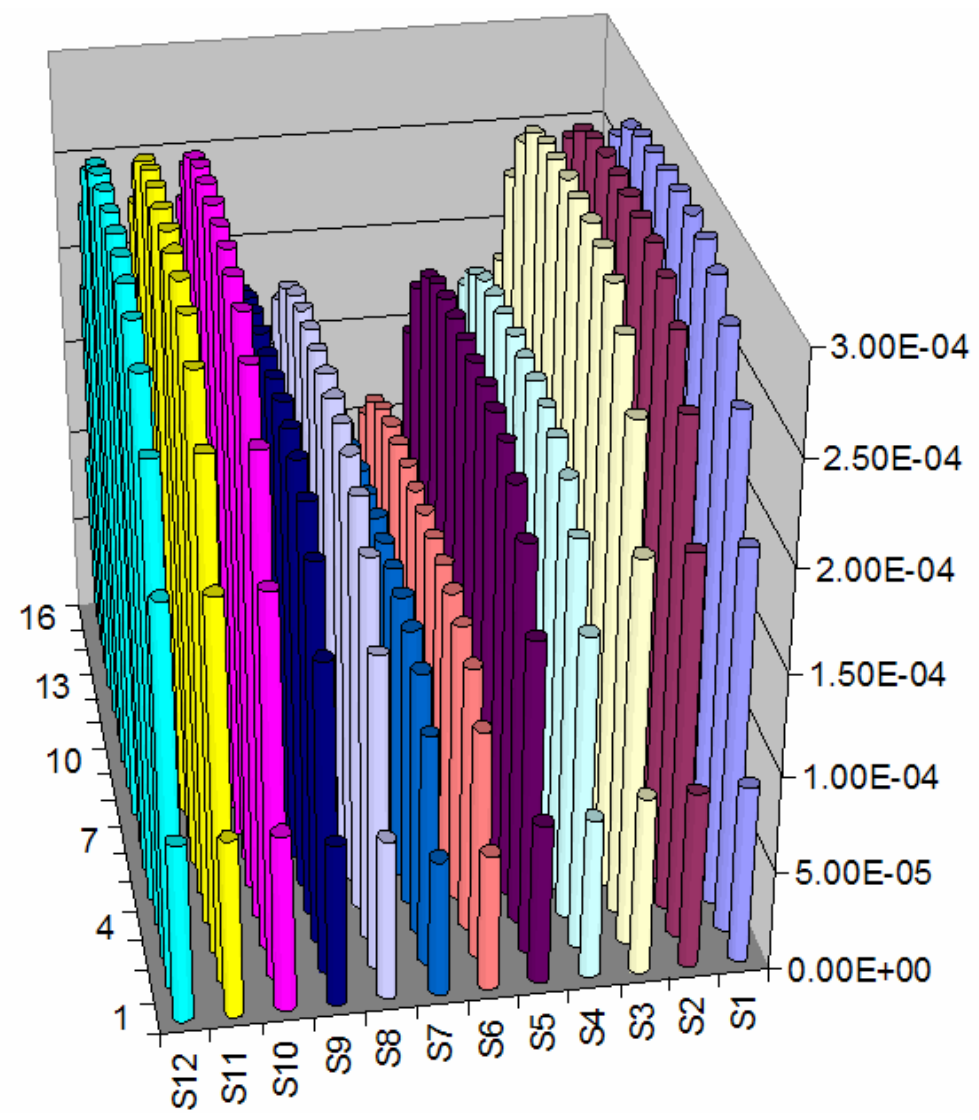

Figure 55: Relative magnitude of loads on each contact patch, MN

\section{$\underline{\text { Loading Time }}$}

A loading time consistent with $80 \mathrm{~km} / \mathrm{h}$ (approximately $50 \mathrm{mph}$ ) was used for the analysis. The loading time was not varied with depth but this could be added in subsequent analysis if considered necessary.

\section{$\underline{\text { Asphalt Material Properties }}$}

Measured material properties were used to define a complete master curve. The Hirsch model was then used to develop the mixture stiffness for each temperature considered. 


\section{Computations}

Computations where then produced for each site producing for 50 points that represent a transverse slice of the pavement - with 25 points computed for the surface properties and 25 for the base over a distance of $250 \mathrm{~mm}$ from the center of the loaded area. The radius of the loaded area is approximately $115 \mathrm{~mm}$. From this analysis, many data representations can be made. Tensile strain, compressive strain all vary across the section and these have been combined into a single parameter - the octahedral shear strain as a relative measure of the damage likely to occur at any one point. The octahedral shear strain is computed from the results of the elastic analysis as follows:

$$
\gamma_{o c t}=\frac{2}{3}\left[\left(\varepsilon_{x}-\varepsilon_{y}\right)^{2}+\left(\varepsilon_{y}-\varepsilon_{z}\right)^{2}+\left(\varepsilon_{z}-\varepsilon_{x}\right)^{2}+6\left(\gamma_{x y}^{2}+\gamma_{x z}^{2}+\gamma_{y z}^{2}\right)\right]^{0.5}
$$

The computed data in this format is presented in Figure 56 to Figure 61.

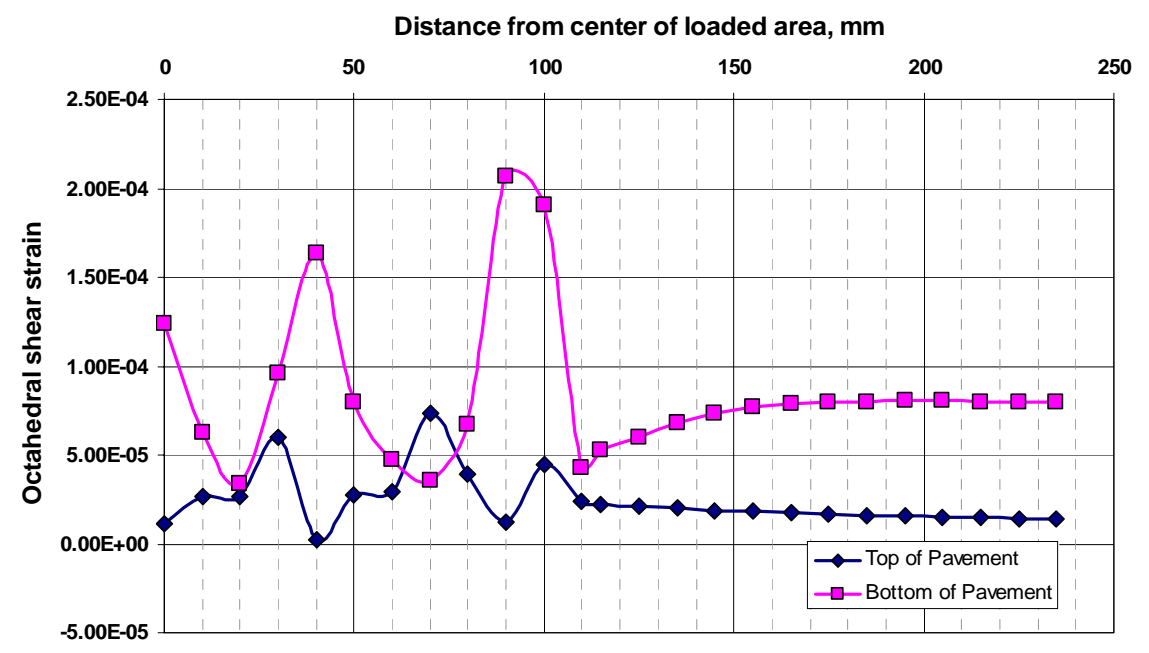

Figure 56: Variation of octahedral shear strain across transverse profile of pavement ( wheel radius $=115 \mathrm{~mm})$, Site 1 , cold extreme. 


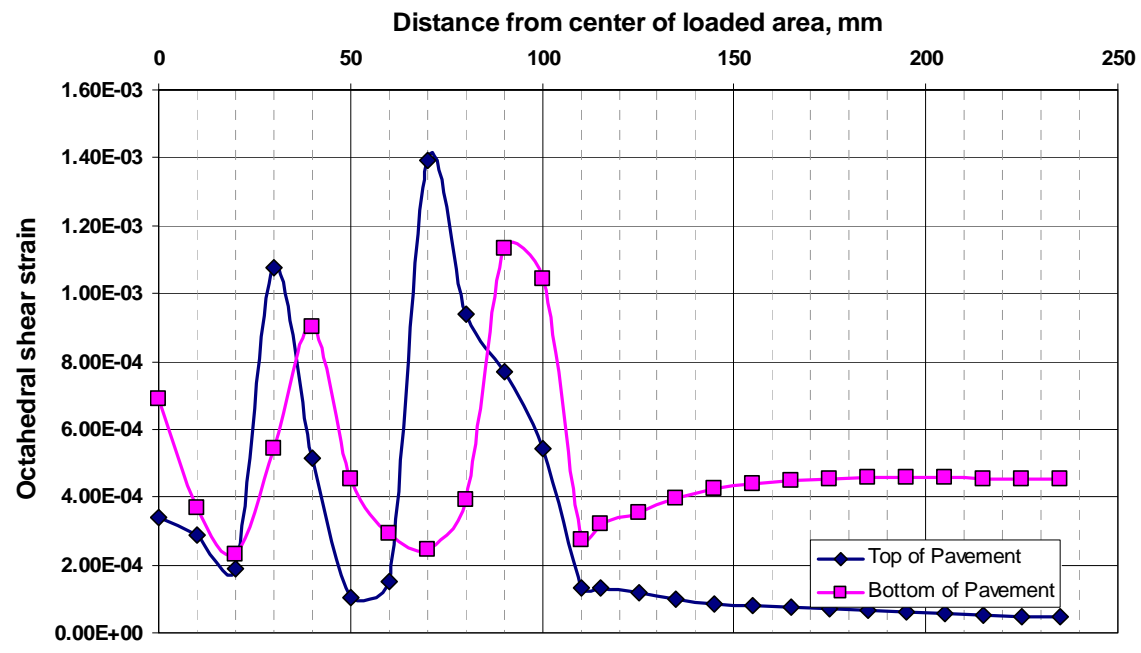

Figure 57: Variation of octahedral shear strain across transverse profile of pavement (wheel radius $=115 \mathrm{~mm})$, Site 1 , hot extreme.

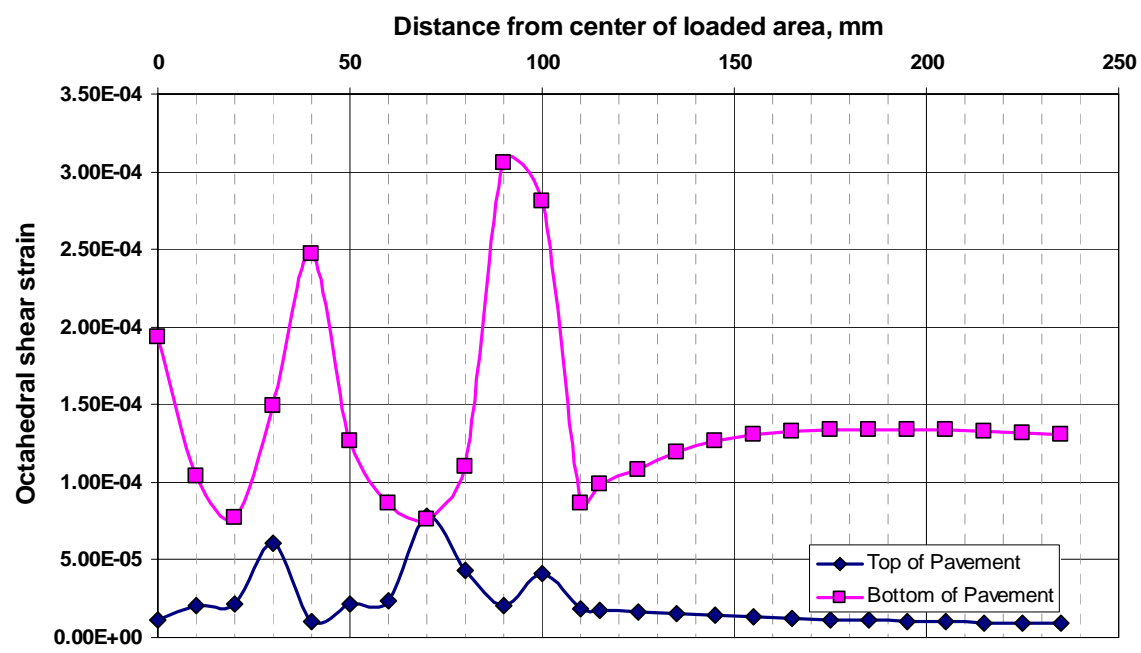

Figure 58: Variation of octahedral shear strain across transverse profile of pavement (wheel radius $=115 \mathrm{~mm})$, Site 2 , cold extreme. 


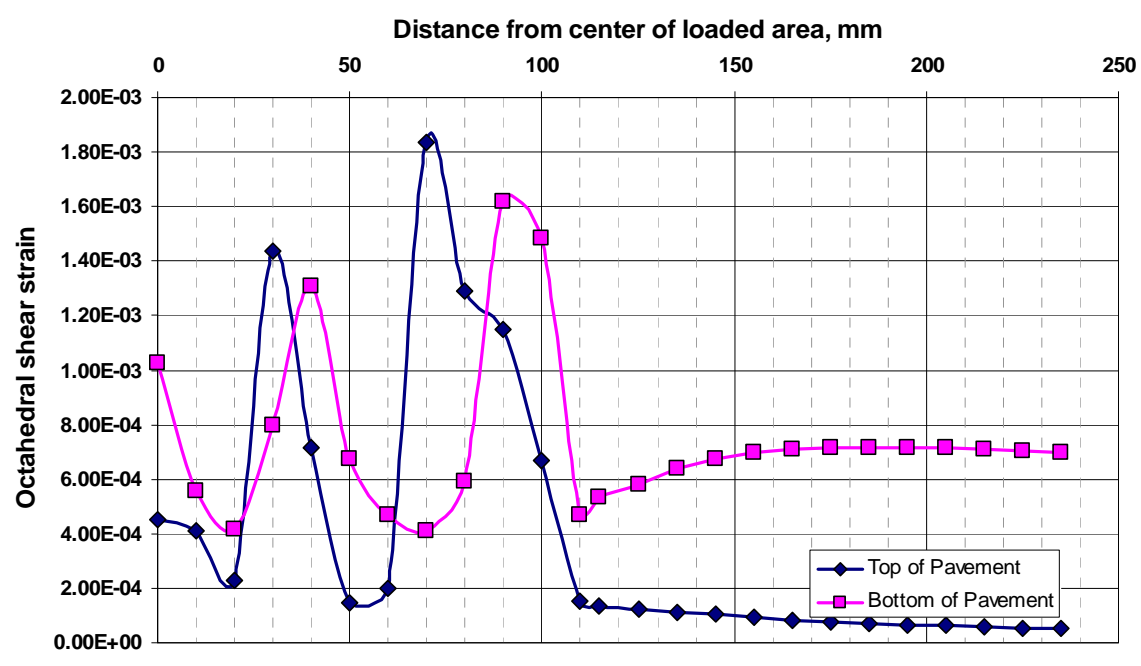

Figure 59: Variation of octahedral shear strain across transverse profile of pavement (wheel radius $=115 \mathrm{~mm})$, Site 2 , hot extreme.

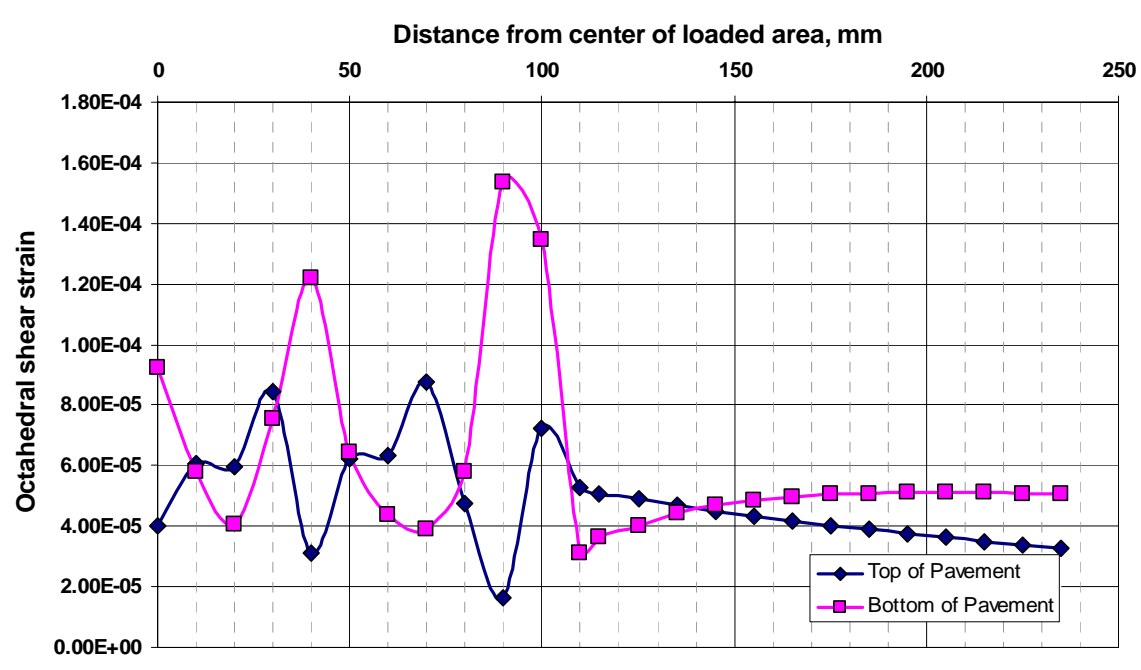

Figure 60: Variation of octahedral shear strain across transverse profile of pavement (wheel radius $=115 \mathrm{~mm})$, Site 3 , cold extreme. 


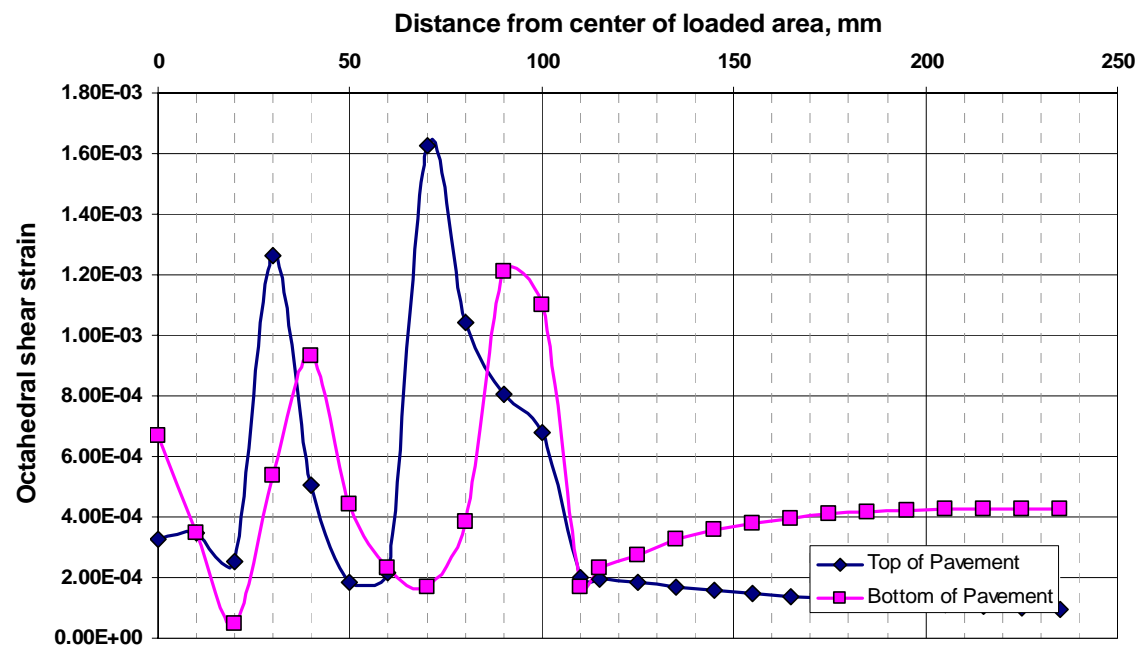

Figure 61: Variation of octahedral shear strain across transverse profile of pavement (wheel radius $=115 \mathrm{~mm})$, Site 3 , hot extreme.

\subsection{Pavement Analysis Summary}

A considerable challenge exists in modeling a pavement structure with vertical and shear components of loading that are then subsequently represented as variable values over a loaded area. Modifications have been made to two types of analysis systems to enable the complex load effects to be studied, viz. finite element and layered elastic analysis programs.

\subsubsection{Finite Element}

Issues concerning the accurate modeling of a visco-elastic material in the finite element system need resolving but considerable progress has been made. This software needs additional work to complete the definition of input and output data. However, we can note the following:

- A larger number of relaxation times are needed to enable the load pulse to be accurately modeled. This number is most likely between 5 and 10 . 
- The effects of boundary conditions were noticeable on the analysis.

- The Poisson's ratio value made a significant impact on the results. This suggests that a method for varying the Poisson's ration with stiffness will be needed.

As this model is refined, better solutions will be made to obtain properties at the base and surface of the layers.

\subsubsection{Elastic Layer Analysis}

Analysis suggests that the winter cold condition has the largest magnitude of octahedral shear strain at the underside of the pavement whereas in the hot condition this is reversed with the largest magnitude on the surface. The variation in strain magnitude across the profile is quite surprising and it is suggested that additional calculations be performed to verify these findings. The relative magnitude of strains (expressed in micro strain units) is presented in Table 29.

Table 29: Magnitude of octohedral shear strains $(\mu \varepsilon)$ for each site/condition.

\begin{tabular}{|l|l|l|l|l|l|l|}
\hline \multirow{2}{*}{ SITE AND CONDITION } & \multicolumn{2}{|c|}{ SITE 1: } & \multicolumn{2}{c|}{ SITE 2: } & \multicolumn{2}{c|}{ SITE 3: } \\
& I-65 North & \multicolumn{2}{c|}{ I-65 Loop } & \multicolumn{2}{c|}{ US-421 Madison } \\
\cline { 2 - 7 } & Cold & Hot & Cold & Hot & Cold & Hot \\
\hline Top of pavement & 73 & 1394 & 78 & 1837 & 87 & 1627 \\
\hline Bottom of pavement & 207 & 1131 & 306 & 1618 & 154 & 1210 \\
\hline
\end{tabular}

From inspection of this data it would be concluded that Site 2 is most susceptible to surface cracking followed by Site 3 and then Site 1. This is most likely because of the stiffer bases in the Site 1 and 3 locations. The absolute magnitude of the strains that are occurring in the hottest time of the year are very large compared to those used for typical pavement calculations using average annual air temperatures or some weighting of that parameter. This is due to the extreme conditions used in these calculations. These strains are considered more realistic of that occurring in the asphalt mix as a whole. The strain in 
the binder will be considerably larger in magnitude. Consequently, an important aspect of the performance of the asphalt binder will be to sustain large strains with little or no damage - and if damage does occur then the ability to heal.

The highest strains are occurring on the inside edge of the outer rib. This is obviously very dependent upon the exact nature of stress used in the calculation. At best, we could note that this complex stress distribution is more realistic than a uniformly distributed load. Much further work is required which is beyond the limited scope of this study to truly define the stress/strains that occur on the pavement surface due to loading. However, we can state with confidence that the propensity for a pavement to crack due to high magnitude of strains occurring near the loaded wheel area and/or immediately adjacent to the wheel is established.

It would appear, if we accept that the octahedral shear strain is a good descriptive parameter for damage, that the initiation of cracking is most likely to occur in the hotter summer months. The extent of propagation of cracks once they have occurred is beyond the scope of this work - although it is postulated that these may well propagate better under cold climate conditions when the material is more brittle. 


\section{SUMMARY, CONCLUSIONS AND RECOMMENDATIONS}

The objective of the study was to evaluate top-down cracked pavements and assess their structural capacity as well as study in-place materials to propose the best identification of distress type, material selection, and rehabilitation methods to be used in Indiana.

Research involved evaluating three surface cracked pavements during 2002 and 2003. A $500 \mathrm{~m}$ section of I-65 North of Lafayette was chosen as the first site (designated as Site 1), an I-65 section in downtown Indianapolis was the second site (Site 2), and US-421 in Madison was the third site (Site 3). Site 1 had 11 year old pavement, Site 2 had 12 year old pavement and Site 3 had 4.5 year old pavement. All these sites exhibited longitudinal wheel path cracking which was later identified as top-down cracking.

The research was carried out by conducting visual surveys, Falling Weight Deflectometer (FWD) testing, and coring from the cracked and non cracked pavement areas. Cores were first inspected and then subjected to a full laboratory-testing program to measure rheology and fracture properties of the binders used in the surface mixtures. Then, the measured material properties were utilized in a LE analysis program to investigate stresses and strains in the top and bottom of the pavement surface.

The following sections give a brief summary of visual survey and laboratory testing. Sections also present major conclusions based on the research findings. The two last sections discuss research recommendations and lay out an implementation plan.

\subsection{Summary of Laboratory and Field Test Results and Conclusions}

\section{$\underline{\text { Pavement Performance }}$}

Visual inspection and results from the INDOT PMS measurement database indicate that all sites had longitudinal wheel path cracking. The measured rut depth was less than $4.5 \mathrm{~mm}$ for all of the sites. The PCR (Pavement Condition Rating) was 93.3, 99.8, and 99, for Sites 1, 2, and 3, respectively. Pavement performance is summarized in Table 30, which 
shows the measured rut depths, smoothness, and distress rating values, as a reference. Based on these ratings, Site 1 had the most distresses, although it was one year younger than Site 2.

Table 30. Summary of Material Properties and Pavement Performance.

\begin{tabular}{|l|l|l|l|l|}
\hline \multirow{2}{*}{ PROPERTY } & $\begin{array}{l}\text { SITE 1 } \\
\text { I-65 North }\end{array}$ & $\begin{array}{l}\text { SITE 2 } \\
\text { I-65 Loop }\end{array}$ & $\begin{array}{l}\text { SITE 3 } \\
\text { US-421 Madison }\end{array}$ & AVERAGE \\
\hline Pavement age (years) & 11 & 12 & 4.5 & 7.8 \\
\hline Original Binder Grade & AC-20* & PG 64-22 & PG 70-22 & - \\
\hline Rut depth (mm) & 4.2 & 1.9 & 4.1 & 3.4 \\
\hline IRI (in/mile) & 74 & 115 & 54 & 81 \\
\hline PCR & 93.3 & 99.8 & 99.0 & 97.4 \\
\hline Fatigue cracking $\left(\mathrm{m}^{2}\right)$ & 36.8 & 27.5 & 2.2 & 22.1 \\
\hline Longitudinal cracking $(\mathrm{m})$ & 126 & 102.5 & 83 & 103.8 \\
\hline Penetration $(1 / 100 \mathrm{~mm})$ & 10.7 & 19.0 & 10.7 & 13.5 \\
\hline $\mathrm{T}_{\mathrm{R} \& \mathrm{~B}}\left({ }^{\circ} \mathrm{C}\right)$ & 65.0 & 62.8 & 65.0 & 64.3 \\
\hline $\mathrm{P}_{\mathrm{b}}(\%)$ & 5.4 & 5.9 & 6.3 & 5.9 \\
\hline Air Voids $(\%), \mathrm{WP} / \mathrm{CL}$ & $6.6 / 8.1$ & $7.8 / 7.4$ & $9.8 / 10.1$ & $8.1 / 8.5$ \\
\hline
\end{tabular}
PG64-22

*) Before Superpave binder grading INDOT was using AC-20 binder which most likely is close to

\section{Measured Crack Depth and Verification of Top-down Cracking}

The cores obtained from cracked areas were examined visually and also using x-ray tomography. The x-ray tomography testing was completed at Turner Fairbank Highway Research Center by the Federal Highway Administration. The visual inspection and x-ray tomography suggested that the cracks were confined in the thin surface mix and did not penetrate deeper into the pavement in any of the sites. The depth of the surface cracks were from 15 to $22 \mathrm{~mm}$ and the crack orientation was downward skewed for Site 1 and downward vertical for Sites 2 and 3. This confirms that the observed surface cracking is a top-down cracking. 


\section{Construction Issues}

Based on the visual survey, none of the sites seem to exhibit load-end segregation. Load-end segregation manifests itself as a coarser and more open mat texture repeating about 25 to 30 meter intervals. However, this finding was not verified by laboratory testing.

Longitudinal surface cracking in Site 3 was systematically located in the left wheel path area with some symmetrical cracking in the right wheel path. This may indicate some longitudinal mix segregation caused by screed extensions in the paver. The width of the paving lane is approximately 3.5 meters, which means that screed extensions were used to cover the entire paving width with one paver pass. The screed extensions can cause segregation of the mix depending on the specifics of the screed used and segregation tendency of the mix.

For Site 2 the outside wheel path cracking may also be initiated by segregation caused by screed extensions and edges of tunnel similarly as described for Site 3 above. In this case the weak area of the pavement is 0.5 meters outside of the wheel path which is consistent with the wider paving lane width of 4 meters.

For Site 1 the centerline cracking may be caused by segregation by the auger gear box in the center of the paver screed. The gear box may cause segregation as the mix is transported from the tunnel to the augers. The wheel path cracking may also be initiated from the areas of segregated mix, although in this case it seems to be less likely.

\section{$\underline{\text { Structural Capacity }}$}

The FWD testing indicated that all sites had excellent structural capacity and computed effective structural numbers $\mathrm{SN}_{\text {eff }}$ were 8.5, 10.2, and 6.1 for Sites 1, 2, and 3, respectively. The effective modulus of all pavement layers above the subgrade, $\mathrm{E}_{\mathrm{p}}$, was 2,187 MPa for Site 1, 1,682 MPa for Site 2, and 2,274 MPa psi for Site 3. The estimated $\mathrm{W}_{18}$ traffic base on the AASHTO 1993 Pavement Design Guide was over $10^{8}$ ESALs for all sites.

The thickness of the full depth asphalt pavement was $368 \mathrm{~mm}, 530 \mathrm{~mm}$ and $203 \mathrm{~mm}$ 
for the sites 1,2, and 3, respectively. Therefore, at least for Sites 1 and 2 the pavement thickness and structural capacity indicate "perpetual" pavement and, therefore, they will not exhibit bottom-up cracking. Site 3 in Madison is also structurally very strong due to the layer of rubblized concrete underneath the asphalt layers. To sum it up, it is not expected that bottom-up cracking will develop in these pavements.

\section{$\underline{\text { Binder Properties }}$}

Binder testing was completed only for the binder extracted from the $1.5-2 \mathrm{~mm}$ thick surface mix. Research findings for the conventional binder testing, penetration and ring and ball softening point, indicated relatively hard binders in all sites. Site 2 had the softest of the three binders tested. Measured penetration values ranged from 10 to 19, which fall out the lowest penetration grading of Pen 40/50. The original binder grade for Site 3 was PG 70-22, Site 3 had PG 64-22 binder, and Site 1 had AC-20 binder (comparable to PG64-22 binder). Based on Dynamic Shear Rheometer (DSR) testing it was estimated that the high temperature performance grade for Site 1 binder was PG 82, for Site 2 PG 76, and for Site 3 PG 82. Thus, Site 1 had aged three PG grades while Site 2 and 3 had aged two PG grades. Therefore, Site 2 binder was aged least and Site 3 binder was relatively aged the most.

Rheological testing agreed with the findings of conventional testing indicating that the Site 2 had softest binder when measuring with DSR. However, the relaxation modulus obtained from the combined DSR and Direct Tension Test (DTT) master-curve indicated that Site 3 had the most fast relaxing binder, which is consistent with the age of the sites. The DTT thus suggested that Site 3 had the most plastic and Site 2 the most brittle binder in the $-22^{\circ} \mathrm{C}$ temperature. This implies that the surface cracking is not related to the low temperature cracking phenomenon in the asphalt mixtures.

Binder properties are summarized in Table 30. Compared to binder properties found from the literature, the binder stiffness data does not seem to differ significantly from the "normally" aged binder stiffness values. 


\section{$\underline{\text { Mixture Properties }}$}

The mixture properties were also measured from the thin surface mix layer. Site 3 had the highest air void content average being 10.1\%, while Site 1 and 2 had 8.1\% and $7.4 \%$, respectively. It can be speculated that the high air void content in Site 3 has accelerated the binder aging compared to the other sites, although it had the highest binder content of $6.3 \%$ while Site 1 and 2 had $5.4 \%$ and $5.9 \%$ binder, respectively.

All mixtures were fine $9.5 \mathrm{~mm}$ surface mixtures and the amount of fines passing $0.075 \mathrm{~mm}$ sieve were 2.5 to $2.9 \%$ for Sites 1 and 3, while Site 2 had $5.8 \%$. The studied mixtures had effective binder volume between 8 to $10 \%$, and voids filled with asphalt ranging from 50 to $55 \%$. Literature suggests that a better mix cracking performance may be obtained by increasing mix density by compaction. In addition, mixtures with more fines may be more crack resistant than mixtures with low amount of fines.

The measured SST shear modulus of the mixtures did not agree with the measured binder properties. Site 2 had the stiffest mix although it had the softest binder. This test result could not be verified because the IDT Creep compliance test data was erroneous and could not be used in the analysis. However, the slightly lower rutting of Site 2 mixture under traffic may indicate stiffer mixture compared to Site 1. However, the SST measurement is only based on one replicate test result and two cores had to be glued together to get a thick enough specimen for testing. The IDT strength test data indicated that Site 1 had the highest tensile strength at all test temperatures $\left(-20,-10\right.$ and $\left.0^{\circ} \mathrm{C}\right)$ while at $0^{\circ} \mathrm{C}$ temperature Site 2 had the lowest tensile strength. Mix Properties are summarized in Table 30 . 


\subsection{Summary of Advanced Analysis and Conclusions}

\subsubsection{Pavement Modeling}

Pavement modeling was completed using a 3-D Finite Element code to compute stresses and strains in the pavement due to the wheel loads. Due to the problems in the accurate modeling of a visco-elastic material, the analysis was not successful but considerable progress has been made. However, the software needs additional work to complete the definition of input and output data.

An additional layered elastic analysis of the sites indicated that the octahedral shear strain in the top and bottom of the pavement could explain the top-down cracking potential of the pavements. However, due to the problems of obtaining reliable measured mixture stiffness values, predicted values were used. This may introduce some error in the analysis. Analysis indicated that Site 2 (with lowest predicted mixture modulus) had the highest octahedral shear strain values compared to the other sites. This may indicate higher topdown cracking potential if the cracking phenomenon is shear strain driven at high temperatures. However, this is not clear based on the analysis.

\subsubsection{Surface Crack Propagation}

The crack propagation in all sites was confined to the surface layers. If the propagation rate would stay the same, the predicted crack propagation as percent of crack depth would be as shown in Table 31.

Table 31: Crack depth \% of layer thickness.

\begin{tabular}{|l|l|l|l|l|l|}
\hline SITE & $\begin{array}{l}\text { PAV. } \\
\text { THICKNESS } \\
(\mathbf{m m})\end{array}$ & $\begin{array}{l}\text { CRACK } \\
\text { DEPTH } \\
(\mathbf{m m})\end{array}$ & $\begin{array}{l}\text { CRACK } \\
\text { DEPTH \% of } \\
\text { THICKNESS }\end{array}$ & $\begin{array}{l}\text { PAVEMENT } \\
\text { AGE } \\
\text { (years) }\end{array}$ & $\begin{array}{l}\text { CRACK } \\
\text { DEPTH\% } \\
\text { PER YEAR }\end{array}$ \\
\hline 1 & 368 & 20 & 5.4 & 11 & 0.5 \\
\hline 2 & 530 & 22 & 4.2 & 12 & 0.3 \\
\hline 3 & 203 & 15 & 7.4 & 4.5 & 1.6 \\
\hline
\end{tabular}


Figure 62 compares measured INDOT crack depth values to the crack depths reported by Svasdisant et al. (2001). They measured surface crack depths and pavement layer thicknesses from seven different pavement sections. Pavements were about 10 years old and some of them had rubblized base. Figure 62 suggests that when the thickness of the pavement is above $200 \mathrm{~mm}$ the top-down cracks are not likely to propagate through the entire pavement structure.

It was inferred from Svasdisant et al. report that from the measured 41 cores $74 \%$ of the surface mixtures had cracked through, while only $36 \%$ of intermediate and $20 \%$ of base mixtures had cracked through the entire lift thickness.

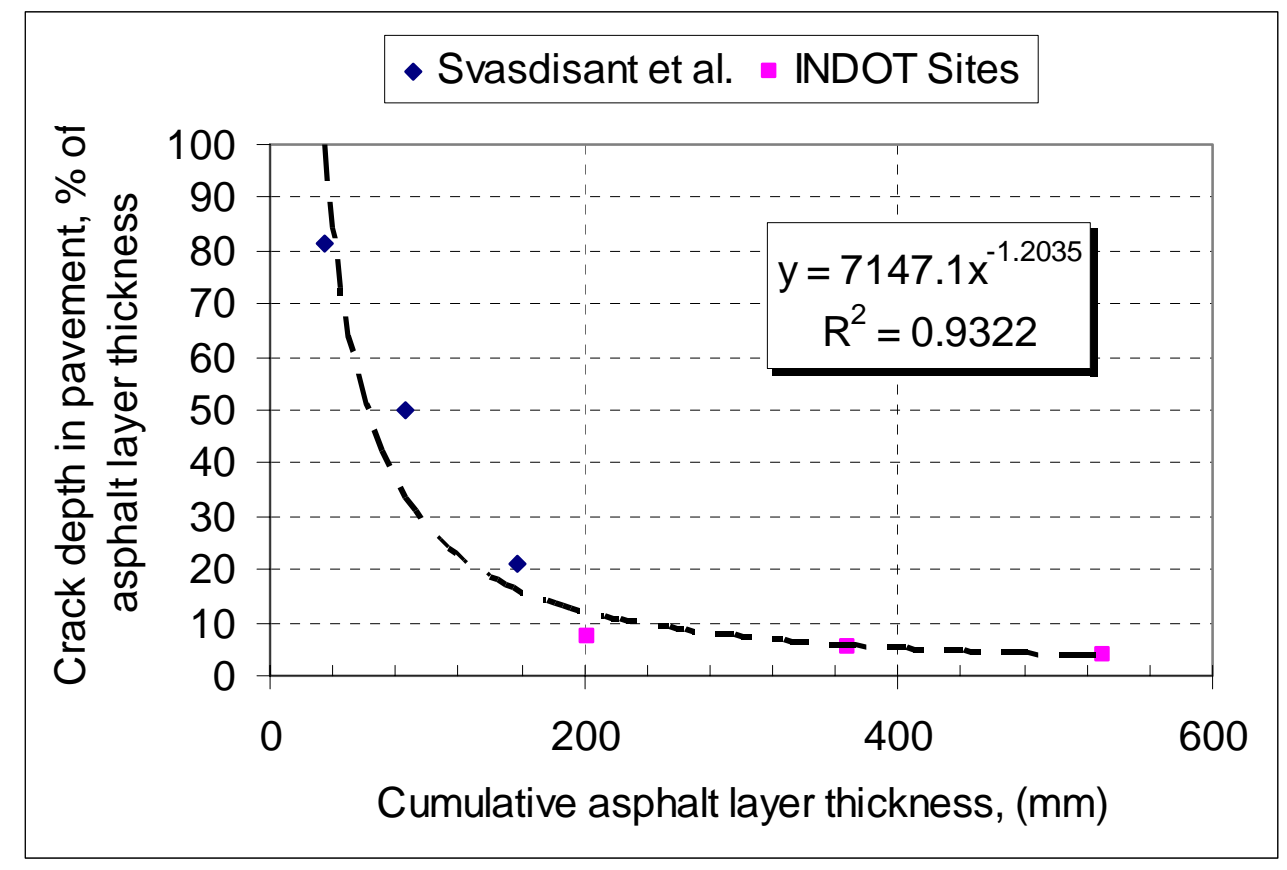

Figure 62: Measured crack depth as function of asphalt layer thickness.

\subsubsection{Ranking of Sites}

Table 32 shows the ranking of sites based on the measured binder and mix in-situ properties and the LE analysis. Ranking is done by arranging sites in order of most desired 
condition for each parameter/criteria considered. Assigned value of one indicates best performance. It is also assumed that the softer binder is better than a stiffer binder for topdown cracking.

Table 32: Ranking of Sties

\begin{tabular}{|l|l|l|l|l|l|l|l|l|l|}
\hline SITE & $\begin{array}{l}\text { Mix } \\
\text { Air } \\
\text { Voids }\end{array}$ & $\begin{array}{l}\text { Mix } \\
\text { Fines }\end{array}$ & $\begin{array}{l}\text { Critical } \\
\text { Cracking } \\
\text { Temp. }\end{array}$ & $\begin{array}{l}\text { DST\&DTT } \\
\left|\mathbf{G}^{*}\right|_{\text {binder }}\end{array}$ & $\mathbf{E ( t )}$ & $\begin{array}{l}\text { SST } \\
\left|\mathbf{G}^{*}\right|_{\text {mix }}\end{array}$ & $\begin{array}{l}\text { IDT } \\
\text { Strength }\end{array}$ & FWD & $\begin{array}{l}\text { LE } \\
\text { Anal. }\end{array}$ \\
\hline 1 & 2 & 3 & 3 & 3 & 3 & 1 & 1 & 2 & 1 \\
\hline 2 & 1 & 1 & 2 & 1 & 2 & 3 & 2 & 1 & 3 \\
\hline 3 & 3 & 3 & 1 & 3 & 1 & 1 & 3 & 3 & 1 \\
\hline & & & & 1 softest & & 1 softest & 1 highest & & \\
\hline
\end{tabular}

Based on this ranking, none of the sites seem to have properties far better than the others. The binder in Site 2 is softest but does not have good low temperature cracking properties. Hard binder in Site 3 has aged significantly compared to the other sites. The air void content in the mixtures seems to point in the direction that the binder aging is accelerated when the air void content exceeds $7.5 \%$. The higher amount of fines in the mix may prevent binder and mix aging as Site 2 properties suggest.

\subsection{Recommendations}

\subsubsection{Prevention of Top-down Cracking}

The energy approach based on Linear Elastic Fracture Mechanics (LEFM) states that "crack extension (i.e., fracture) occurs when the energy available for crack growth is sufficient to overcome the resistance of material. The material resistance may include the surface energy, plastic work, or other type of energy dissipation associated with a propagating crack" (Anderson, 1995). The energy release rate $G$ is defined as the rate of change in potential energy with crack area for a linear elastic material. At the moment of 
fracture $G=G_{c}$ where $G_{c}$ is the critical energy release rate which is a measure of fracture toughness. Hence, we can assume that pavement surface cracks are formed when the available energy provided by the tire loading cannot be absorbed by stain energy in the form of elastic bending or energy cannot dissipate in the form of plastic deformation of the structure. At fracture, energy is dissipated through creating fracture surfaces, in addition to energy dissipation through viscous and plastic flow.

This study was able to identify some material properties that most likely contribute to the fracture toughness and crack advancement in pavements; however, unfortunately this research was not able to distinguish structural reasons for top-down cracking. Literature review did not provide any conclusive evidence either. It can be speculated that there are several structural contributors to the pavement cracking such as mixture segregation, poor bonding between layers, thin layer thicknesses, and stiffness differentials between pavement layers.

It is obvious that the crack will find its way through the path of least resistance, so any weak area is vulnerable to crack initiation and propagation. The amount of energy tire loading introduces to the pavements today cannot be controlled by the pavement engineers (at least in a short term). Thus, the only thing that can be controlled in day to day operations is the material selection. Combining this with the use of current and new pavement design tools would be the most effective strategy to prevent pavement distresses. That is to say, as long as the models used in the pavement design methods are realistic and provide proper guidance. The best results will be achieved when all the above is combined with the enhanced construction practices. However, because most likely opposite measures are needed to prevent top-down and bottom-up cracking compared to the pavement rutting, a delicate balance is required while executing material selection for the pavement and mix designs.

The study recommendations can be divided into two categories 1) Material Selection and Construction practices, and 2) Structural Aspects. Due to the fact that only the first category items produced findings, recommendations for dealing with structural aspects are discussed in the implementation section. 
The list below sums up the recommendations to prevent top-down cracking in terms of material selection, material properties and construction practices:

- Reduce in-situ air voids content below or equal to $7 \%$ by requiring tighter density specification

- Limit the amount of fines in the mixture to 5 to $6 \%$

- No changes for binder grades is recommended at this point

- Prevent non-uniformities in the material properties by enhancing construction practices and QC/QA work including prevention of segregation during paving

The relatively high air void content of the studied asphalt mixtures, around 7 to $9 \%$, allowed a certain degree of aging in all sites to occur. These air void contents are not untypical of U.S. practice but better values can be achieved. It would be desirable to ensure that in well constructed pavements the as-built air void content would be in the range $5-6 \%$ - allowing for some densification over time. To guard against permanent deformation due to the secondary traffic densification, a stiffness requirement must be set for pavements having air void contents less than 4\%. This recommendation requires modifications to the construction specifications.

The requirement of more fines in the mixtures is based on the theory that mixture tensile strength (related to fracture toughness) will increase as more fines are used. However, mixture stiffness will also increase, which will make it more difficult to compact. The shape of fines, i.e. round or crushed, affects the mixture's compactability considerably. Therefore, there is a need to study compatibility of mixtures as a function of fines and the type of fines used.

The selection of binder grade and surface mix properties for preventing top-down cracking is quite controversial. However, it can be speculated that binders with low relaxation capacity are vulnerable for cracking. The balance between rutting and cracking is delicate, as mentioned earlier, and without further research this study cannot recommend to reduce binder stiffness used. 
Segregation creates weak spots in the pavements allowing crack initiation to occur. None of the sites had load-end segregation based on visual inspection. But crack patterns, especially at US-421 in Madison, indicate that lane segregation caused by construction practices might exist.

\subsubsection{Rehabilitation of Top-down Cracked Pavements}

Based on this research the identification of top-down cracking from the bottom-up cracking can be based on the knowledge of the thickness of the pavement structure and the pattern of the cracking. The top-down cracking manifests itself as a longitudinal cracking in the wheel path area or in the center of the lane. If layer thickness is above $200 \mathrm{~mm}$ it is unlikely that cracks will penetrate deeper than through the surface layer in the pavement. Coring and examining cracks from a few locations in the pavement can be used to verify the top-down cracking.

FWD testing and a structural analysis must be performed to confirm that the cracking has not weakened the pavement structure. If the structural capacity is good, the pavement can be rehabilitated by milling and replacing the surface mix.

The selection of the rehabilitation material is dependent on the structural capacity of the pavement. In the material selection, the recommendations given to prevent top-down cracking above should be followed.

\section{IMPLEMENTATION}

The implementation of this research can be divided into the short, medium and long term goals. The short and medium term implementation issues are related to the INDOT's current construction practices and possible changes in them. The medium and long term implementation goals are related to the pavement design issues and therefore to the future research in the local and possibly in the national level (Federal Highway Administration 
(FHWA) and National Cooperative Research Program (NHCRP)). The short and medium term local implementation issues include:

- Training of contractor and state personnel to enhance construction and QC/QA work (high priority)

- Development of top-down identification, prevention, and rehabilitation guide based on research findings (high priority)

- Modify current construction specifications to reduce segregation (high priority)

- Modify current pavement design practices (low priority)

- Research of tendency of asphalt mix to segregate (low priority)

A short description of items listed above is presented as follows. Training of personnel must be organized in cooperation with INDOT and Asphalt Pavement Association of Indiana. This way the issues hindering good quality can be identified and hopefully remedied. Issues that are needed to be included in the training are mixture compaction, lay down operations, and prevention of segregation.

A guide to identify top-down cracking and select rehabilitation strategy needs to address the following listed items. Not all of these items can be addressed with great detail and this guide must develop over time to incorporate any future research or empirical findings of pavement performance in Indiana.

- Identification of top-down cracking (visual survey and coring)

- Verification of pavement structural capacity using FWD

- Verification of bonding between layers with coring and with possible laboratory test

- Identification of segregation (visual survey, coring and laboratory measurements)

- Material Selection (stiffer or softer binder/mix compared to the replaced material and existing structure)

- Structural issues (surface layer thickness same as before or thicker?) 
- Construction practices (the need for tack coat, type of tack coat, type of rollers such as steel wheel or vibratory)

To implement the needs to modify current construction specifications related to the insitu density and amount of fines in the mixture, a research plan to establish the relationship between mix design and achievable in-situ mixture density must be developed. Some ideas how the research can be conducted are listed below:

- Use Superpave Gyratory Compactor (SGC) to establish a laboratory compaction curve for standard surface and base mixtures in Indiana. Select the standard mixture such that it represents typical aggregates and binder grade used.

- The compaction curve must be developed for different compaction temperatures by each temperature compacting mixture to the refusal density (zero percent air void content if possible).

- The laboratory gyratory compaction must be correlated to the field compaction by using field test strips. Densification using different roller types must be examined at various temperatures. This will establish equivalency of mix densification between field and laboratory compaction.

- As a part of the mix design process, require SGC compaction test for each designed mix to verify the mix compactability. If possible, use gyratory that can measure shear force during the compaction.

- Measure stiffness of the standard mixtures by SST Shear Frequency Sweep Test and axial dynamic modulus test and Indirect Tensile strength of the standard mixtures and correlate this to the JTRP SPR 2644 study findings.

- Correlate standard mixture material properties to pavement performance

- Modify standard mixtures by changing binder stiffness and/or the amount and type (round or crushed) of fines in the mix.

- To verify boundary conditions (i.e., simulation of real life pavement performance) possible Pur-Wheel tests can be performed. 
Pavement structure, i.e., layer thicknesses, number of layers, and type of layers (rigid or flexible) all affect pavement performance, in addition to the type of materials used. Literature suggests that differential stiffness differences affect the stress distribution and thus crack formation in the pavements. In this study two sites had rubblized base underneath the flexible pavement. How this contributes to the top-down cracks was not studied. The combined stress distribution in the pavement structure is affected by the environment and type and magnitude of loading, as we know. What we do not know is what is the worst (or best) possible pavement structure to prevent particular pavement distress and how distresses interact with each other.

To implement changes to the current pavement design practices and verify items related to the structural aspects and construction practices in the developed rehabilitation guide a research plan to study shear stresses and friction between tire and pavement must be developed. Some ideas how the research can be conducted are listed below:

- Construct trial pavement in the INDOT APT pit to study the role of bonding between surface and base layer. The bonding is also related to the friction between the tire and the surface mixture. The high shear stresses that can be developed in the APT by applying high wheel loading without wander provide a means to conducting accelerated pavement surface failure experiments. Testing can be conducted in varying pavement temperatures to separate the cracking and rutting phenomenon. The things related to the bonding of surface layer, the use of tack coat, type of tack coat and compaction are some of the variables.

- In a similar manner, the APT pit can be used to study the role of surface layer thickness for the formation of surface cracks and rutting. Also, the effect of stiff layer (rubberlized concrete) underneath the asphalt layers can be studied.

- This type of research would allow investigation of the issue of using stiff or soft binder in the overlay to replace top-down cracked surface mix (stiffness differentials, layer thickness and rutting versus cracking). 
As mentioned above cracks find their way through the least resistance and the coarse portion of segregated mixture typically have high air voids content, low binder content and low amount of fines compared to the job mix formula (Pellinen, 1985). All these properties contribute to the mixture's vulnerability to fracture.

Segregation may be caused by poor mixing or poor lay down of the mix and the degree of segregation is dependent on the mixture's tendency to segregate. The segregation tendency increases when mix has low amount of fines passing $0.075 \mathrm{~mm}$, low binder content, and large aggregate top size (Pellinen, 1985).

The segregation tendency of the mixtures should be considered in the mix design. It would be desirable to develop a quick laboratory method to measure segregation tendency. In the 70's Swedish researchers Hillgren and Sjöblom (1979) developed a method to measure segregation tendency of asphalt mixtures in the field and in the laboratory. Unfortunately testing requires binder extraction and gradation testing of $11 \mathrm{~kg}$ of asphalt mix which makes it less practical for frequent use. The method is based on dropping asphalt mix through a funnel and measuring binder content and gradation of fine and coarse portion of segregated mixture.

The segregation caused by paving operations and paver can be prevented to some extent by first understanding when the mix is segregated and then adjusting paver to reduce the segregation. Mixture transfer vehicles have been successful in reducing the load-end segregation but "machine" segregation caused by the paver is still not well understood. Field studies have shown that a thermal camera is an effective way to reveal the segregated spots by measuring temperature differentials in the hot mix asphalt. 
AASHTO, "Standard Test Method for Determining the Fracture Properties of Asphalt Binder in Direct Tension,” Designation TP3-00, Provisional Standards, 2000.

AASHTO, "Specification for Performance Graded Asphalt Binder," Provisional Standards MP1A, 2001a.

AASHTO, "Practice for Determination of Low-Temperature Performance Grade," Provisional Standards PP42, 2001b.

Abatech Inc. “Rheology Analysis - RHEA Software,” Version 0.9.78, 2002

Baumgaertel, M and Winter, H.H., "Determination of Discrete Relaxation and Retardation Time Spectra from Dynamic Mechanical Data," Rheol Acta 28:511-519 1989.

Baumgaertel, M., \& Winter, H.H., (1989). Determination of Discrete Relaxation and Retardation Time Spectra from Dynamic Mechanical Data. Rheological Acta, 511-519.

Brown, S.F. and Brunton, J.M., "An Introduction into the Analytical Design of Bituminous Pavements," 3rd Edition, University of Nottingham, Nottingham, England, 1985.

Gerritsen, A.H., van Gurp, C.A.P.M., van der Heide, J.P.J, Molenaar, A.A.A, and Pronk, A.C. Prediction and Prevention of Surface Cracking in Asphaltic Pavements, Proc. 6th International Conference on the Structural Design of Asphalt Pavements, Ann Arbor, 1987.

Christensen, D. W., \& Anderson, D. Interpretation of Dynamic Mechanical Test Data for Paving Grade Asphalt Cements. Journal of Association of Asphalt Paving Technologists, Vol. 61, pp. 67-116, 1992.

Christensen, D. W., Pellinen, T., \& Bonaquist, R. Hirsch Model for Estimating Modulus of Asphalt Concrete. Journal of Association of Asphalt Paving Technologists, Vol 72, 2003.

Gordon, V., and Shaw, M. Computer Programs for Rheologists, Hanser/Gardner Publications, 1994.

Finnish Pavement Tecnology Advisory Council (PANK). (1995). Finnish Asphalt Specifications 1995. Helsinki.

Hillgren, and Sjöblom, (1979). Separationsbenägenhet Hos Asfaltmassor. Svenska Bygnasentreprenörföreningen. Raport no. 23. Stockholm 1979, 30p. 
Hugo, F and Kennedy, T.W., "Surface Cracking of Asphalt Mixtures in Southern Africa," Proceedings of the Association of Asphalt Paving Technologists, Volume 54. 1985.

Huang, Y. Pavement Analysis and Design. $2^{\text {nd }}$ Ed. Prentice Hall, New Jersey, 2002.

Jacobs, M.M.J., “Cracking in Asphalt Mixes,” PhD, The Delft University of Technology, The Netherlands, 1995.

Kunst, P.A.J.C., "Surface Cracking in Asphalt Layers,” CROW Record 4, The Netherlands, 1990.

Matsuno, S., and T. Nishizawa. Mechanism of Longitudinal Surface Cracking in Asphalt Pavement, Proc. 7th International Conference on the Structural Design of Asphalt Pavements, Ann Arbor, 1992

Myers, L. A., "Development and Propagation of Surface-Initiated Longitudinal Wheel Path Cracks in Flexible Highway Pavements,” PhD Thesis, University of Florida, 2000.

Myers, L. A., R. Roque, and B. E. Ruth. Mechanisms of Surface-Initiated Longitudinal Wheel Path Cracks in High-Type Bituminous Pavements. Journal of the Association of Asphalt Paving Technologists, Vol. 67 pp. 401-432, 1998

Niederquell, M. Baladi, G.G.Y, and Chatti, K. Rubblization of Concrete Pavements: Field Investigation. In Transportation Research Record, 1730, TRB, National Research Council, Washington, D.C., 2001, pp. 150-160

Owen, D.R.J. and Hinton, E., "Finite Elements in Plasticity. Theory and Practice," Pineridge Press, Swansea, 1980.

Owen, D.R.J., Prakash, A. and Zienkiewicz, O.C., "Finite Element Analysis of Non-linear Composite Materials by use of Overlay Systems," Computers and Structures, Vol. 4, 1974, pp. $1251-1267$.

Performance of Coarse Graded Mixes at WesTrack - Premature Rutting. Analysis Conducted by an Independent Team, Final Report, June 1998, FHWA, FHWA-RD-99134. 1998.

Pellinen, T., Christensen, D.W., Rowe, G., Scharrok, M. Fatigue Transfer Models- How do they Compare? Paper presented in Transportation Research Board Annual Meeting, January 12-15, 2004.

Pellinen, T. (1985). Asfalttimassan epähomogeenisuuden ja lajittumisen vaikutuksesta asfalttipäällysteeseen. (On the Influence of Asphalt Mix Inhomogeneity and Segregation 
on Asphalt Pavement). University of Oulu, Laboratory of Road and Traffic Technology, Publication No. 2, Oulu. 125 p (38 Figs., 42 Tbls., 32 Refs.)

Rowe, G.M., "Application of the Dissipated Energy Concept to Fatigue Cracking in Asphalt Pavements,” PhD Thesis, University of Nottingham, January 1996.

Rowe, G.M., Sauber, R., Fee, F. and Soliman, N., "Development of Lon-Life Overlays for Existing Pavement Infrastructure Projects with Surface Cracking in New Jersey," Transportation Research Board/National Research Council, Transportation Research Circular, Number 503, December 2001, pp. 96-107.

Rowe G.M., and Sharrock, M.J., "Development of Standard Techniques for the Calculation of Master Curves for Linear-Visco Elastic Materials," The 1st International Symposium on Binder Rheology And Pavement Performance, The University of Calgary, Alberta, Canada, August 14 - 15, 2000.

Rowe, G.M., D’Angelo, J.A., Ho, S. and Sharrock, M.J., "Development of the Direct Tension Test Analysis Procedures for Thermal Crack Prediction” Proceedings of the forty-seventh annual conference of the Canadian Technical Asphalt Association, Calgary, Alberta, ISBN 0-921317-53-0, 2002, pp. 405-431.

Rowe, G., \& Brown, S., Sharrock, M., Bouldin, M. Visco-elastic analysis of Hot Mix Asphalt Pavement Structures. Transportation Research Record. n1482, pp44-51, 1995.

Shell International Petroleum Company, "Shell Pavement Design Manual," London, 1978.

Schorsch, M., Chnag, C-M., Baladi, G.Y. Effects of Segregation of the Initiation and Propagation of Top-Down Cracks. Paper presented in Transportation Research Board Annual Meeting, January 12-16, 2003.

Stuart, K., Mogawer, W., Romero, P. Validation of the Superpave Asphalt Binder Fatigue Cracking Parameter Using an Accelerated Loading Facility. Publication No. FHWARD-01-093. Turner Fairbank Highway Research Centre, McLean, VA.

Svasdisant, T., Schorch, M., and Baladi, G.Y. Mechanistic Analysis of Top-Down Cracks in Asphalt Pavements. Paper presented in Transportation Research Board Annual Meeting, January 13-17, 2002.

Tsai, B.W., Harvey, J., Monismith,C. WesTrack Fatigue Performance Prediction Using Miner's Law. Proceeding of Transportation Research Board, 81th Annual Meeting, Washington, D.C., 2000.

Uhlmeyer, J.S., K. Willoughby, L. M. Pierce and J. P. Mahoney. Top-Down Cracking in Washington State Asphalt Concrete Wearing Courses. In Transportation Research Record 1730, TRB, National Research Council, Washington, D.C., 2000, pp. 110-116 
Zienkiewicz, O.C., Nayak, G.C. and Owen, D.R.J., "Composite and Overlay Models in Numerical Analysis of Elasto-plastic Continua," International Symposium on Foundations of Plasticity, Warsaw, 1972.

Wambura, J. H. G., J. Maina and H. R. Smith. Kenya Bituminous Materials Study. In Transportation Research Record 1681, TRB, National Research Council, Washington, D.C., 1999, pp. 129-137

Williamson, R.H. Environmental Effects in Road Pavements and their Engineering Significance. PhD Thesis, University of Natal, Durban, Vol. 1, 1972

Williams, M.L., Landel, R.F. and Ferry, J.D., (1955) "The Temperature Dependence of Relaxation Mechanisms in Amorphous Polymers and Other Glass-Forming Liquids," Journal of the American Chemical Society, Volume 77, pp. 3701-3707. 


\section{APPENDIX A DISTRESS DATA SHEETS}

\section{Site 1: I-65 North of Lafayette}

\section{Location 1:}

SOUTH BOUND LANE

MP $224-223$, L $/ D=2$

State Assigned ID TOP DOWN CRACKING.

$$
\text { VISUAL SURVEY DISTRESS PATIERN SHAP Section ID DATE 09/26/02. }
$$

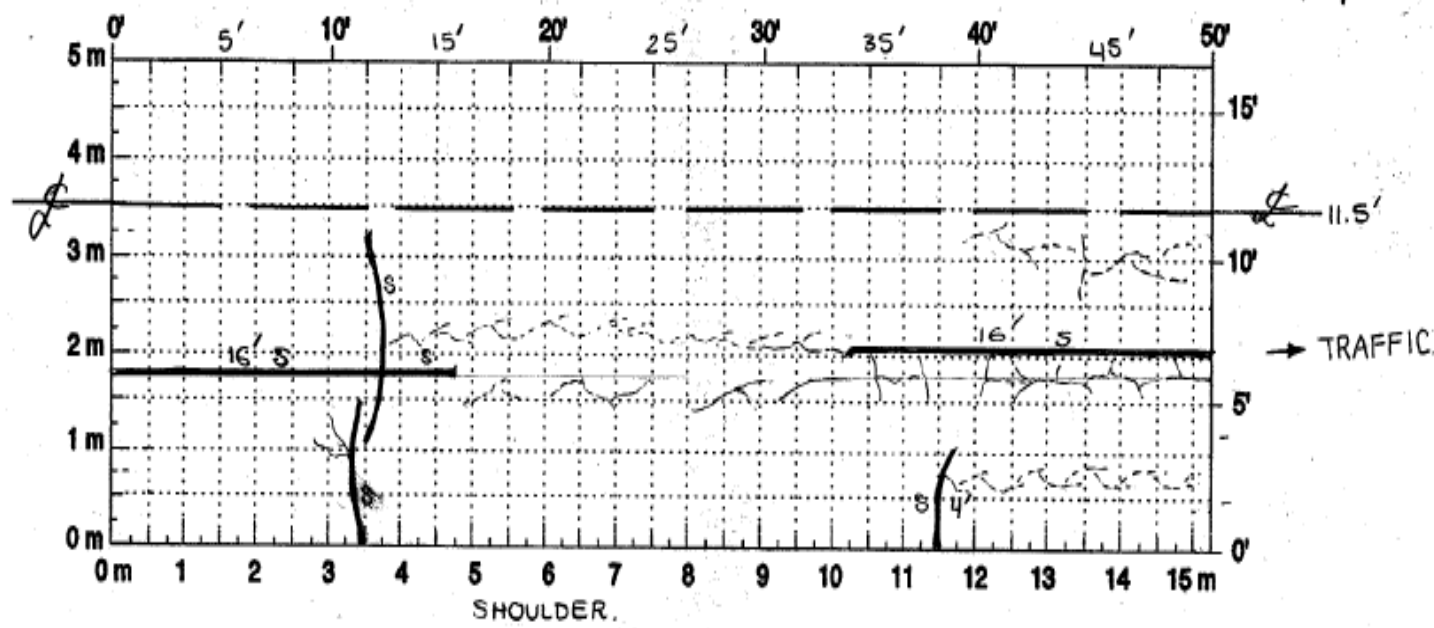

Comments: DETAILED PATTERN OF CRACKING $(15 \bar{m})$ BEFORE CORING.

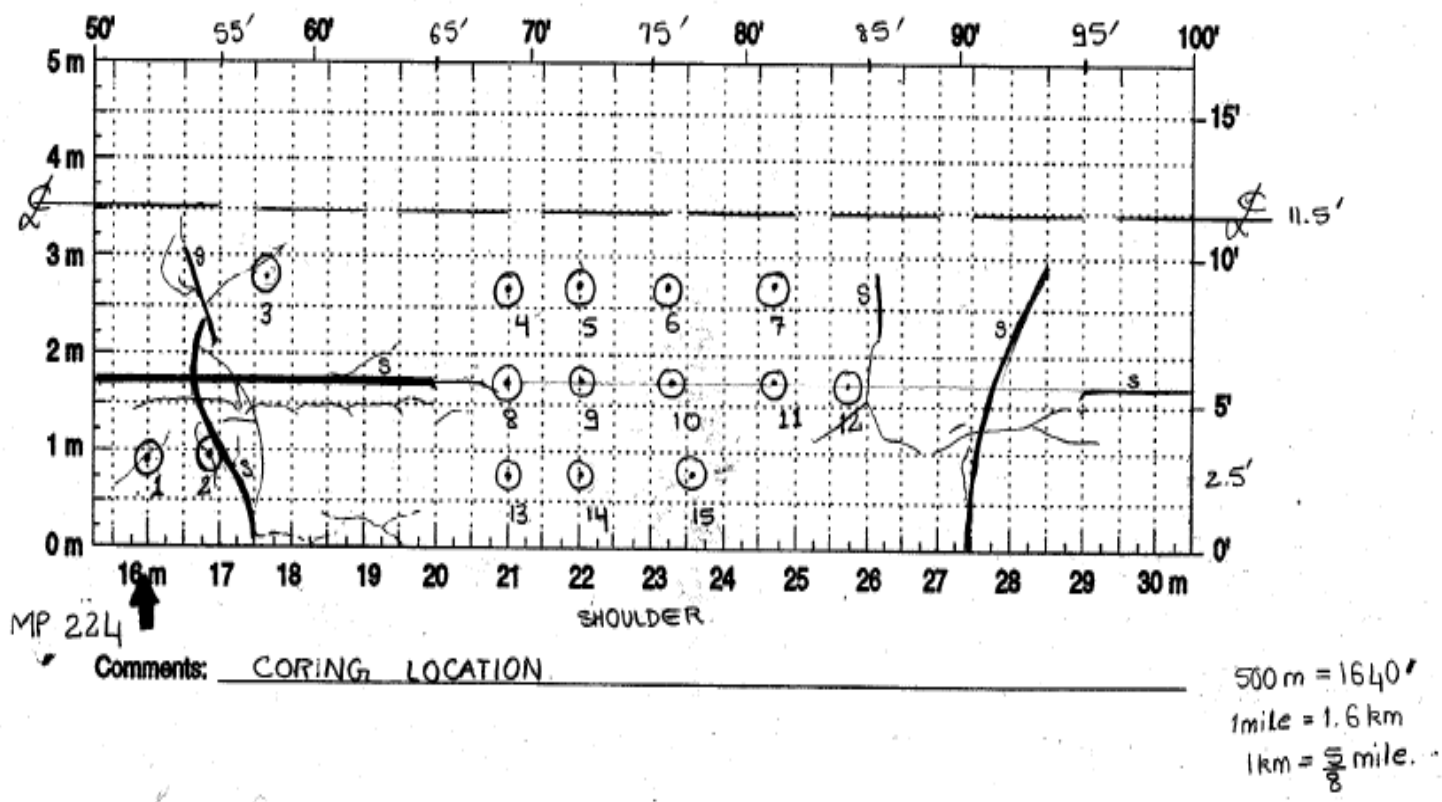




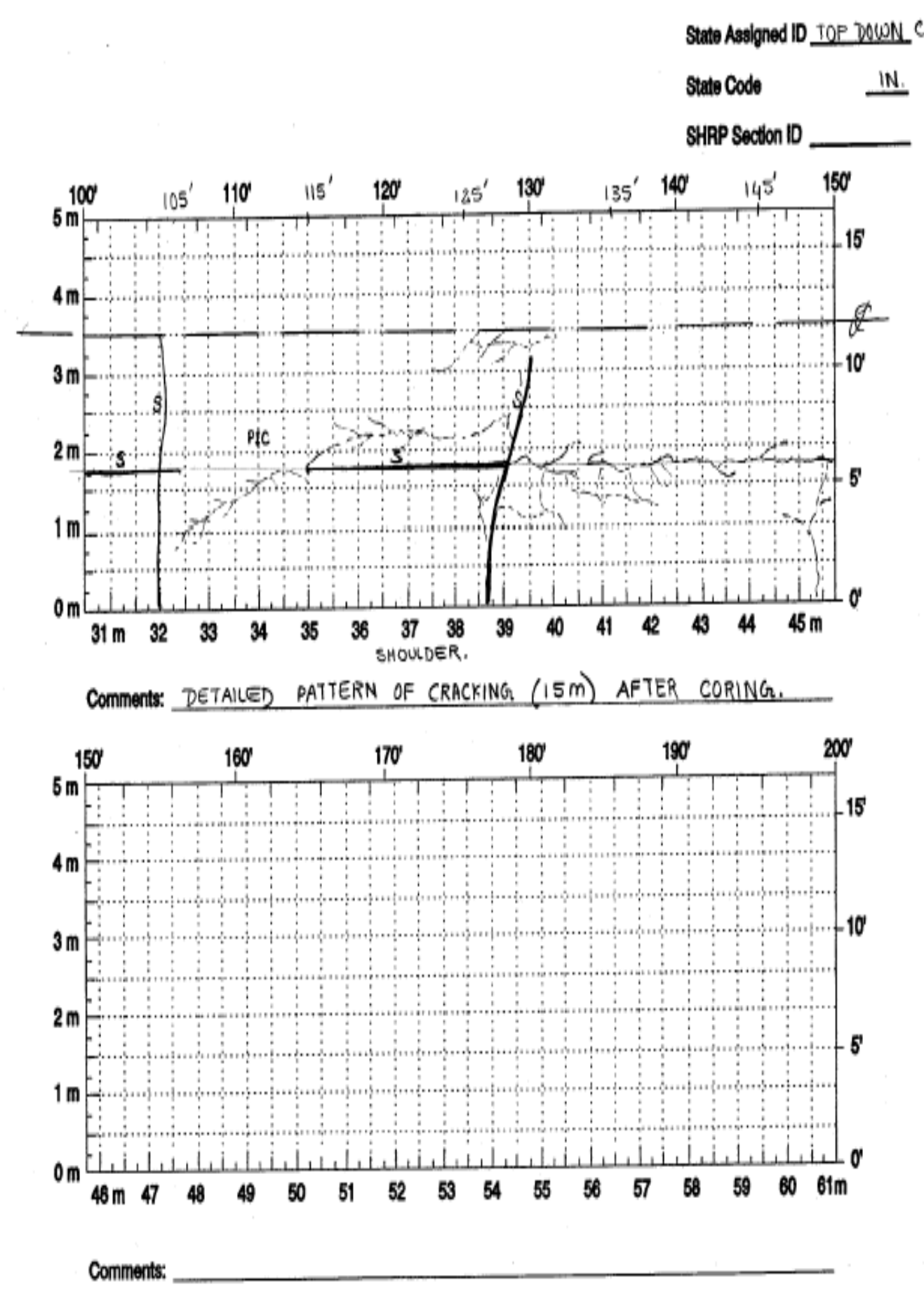

15 cores were obtained from location 1 of Site 1: I-65 North of Lafayette. 
Location 2:

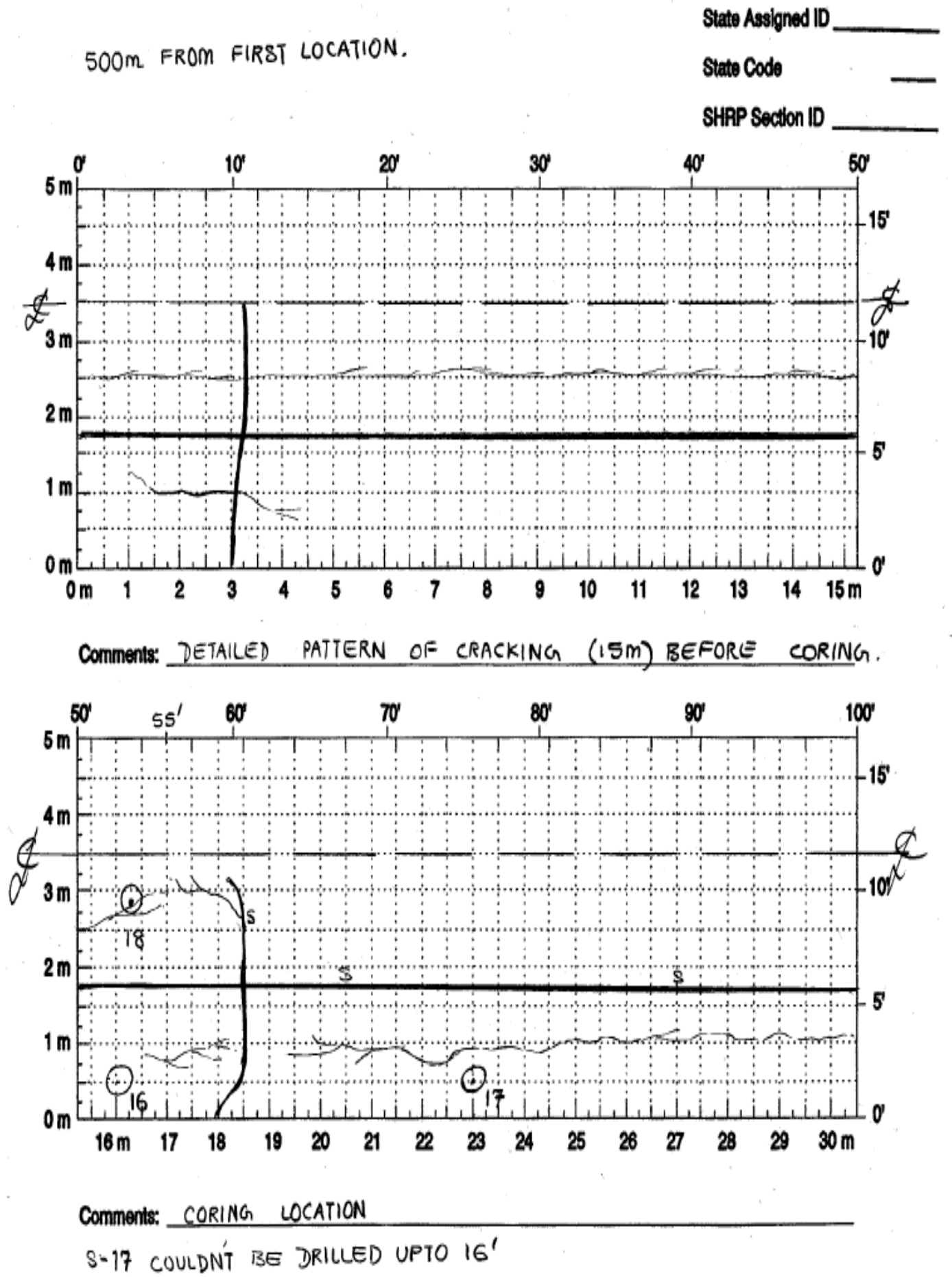




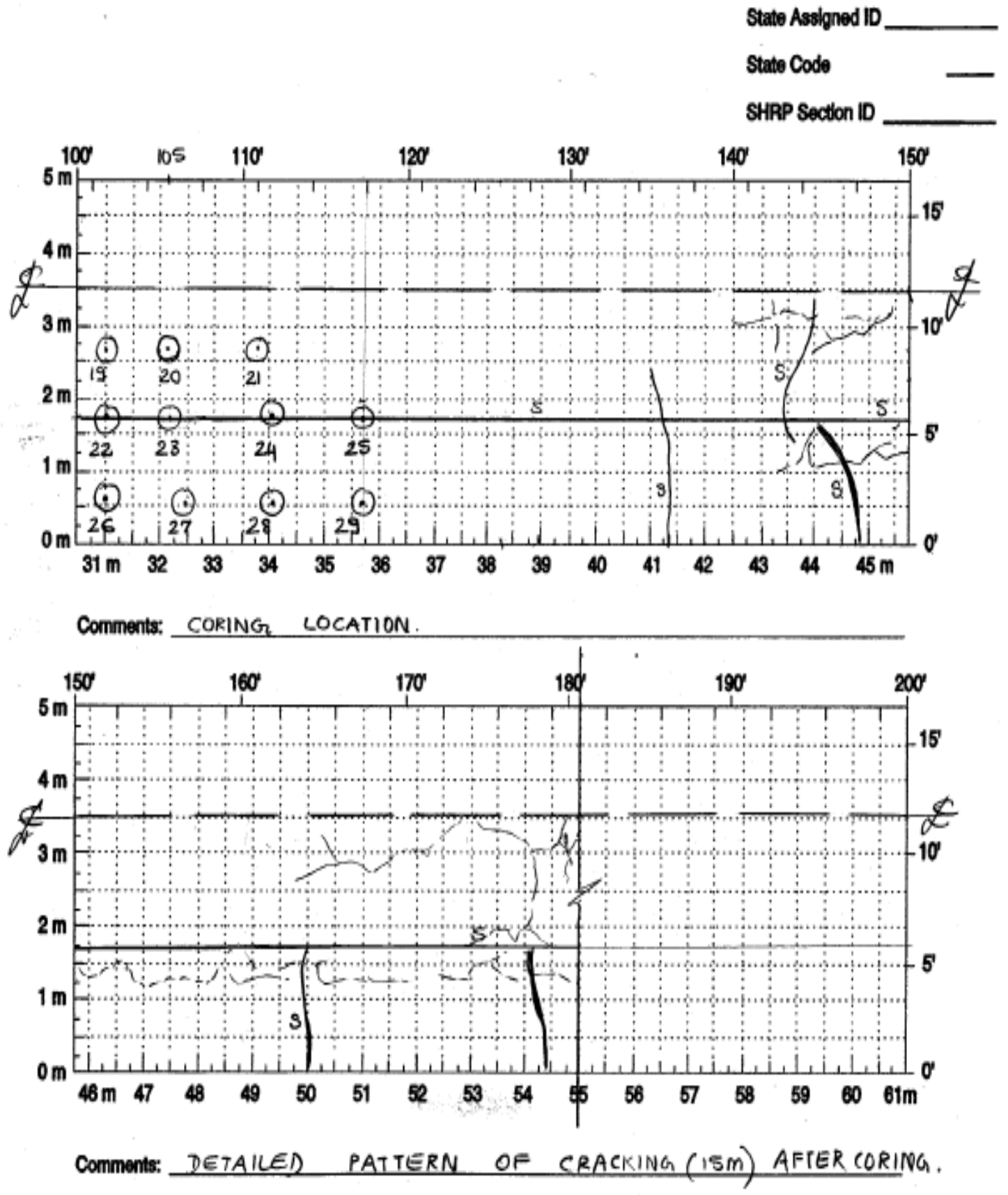

14 cores were obtained from location 2 of Site 1: I-65 North of Lafayette. 


\section{Site 2: I-65 Near Indianapolis}

Location 1:

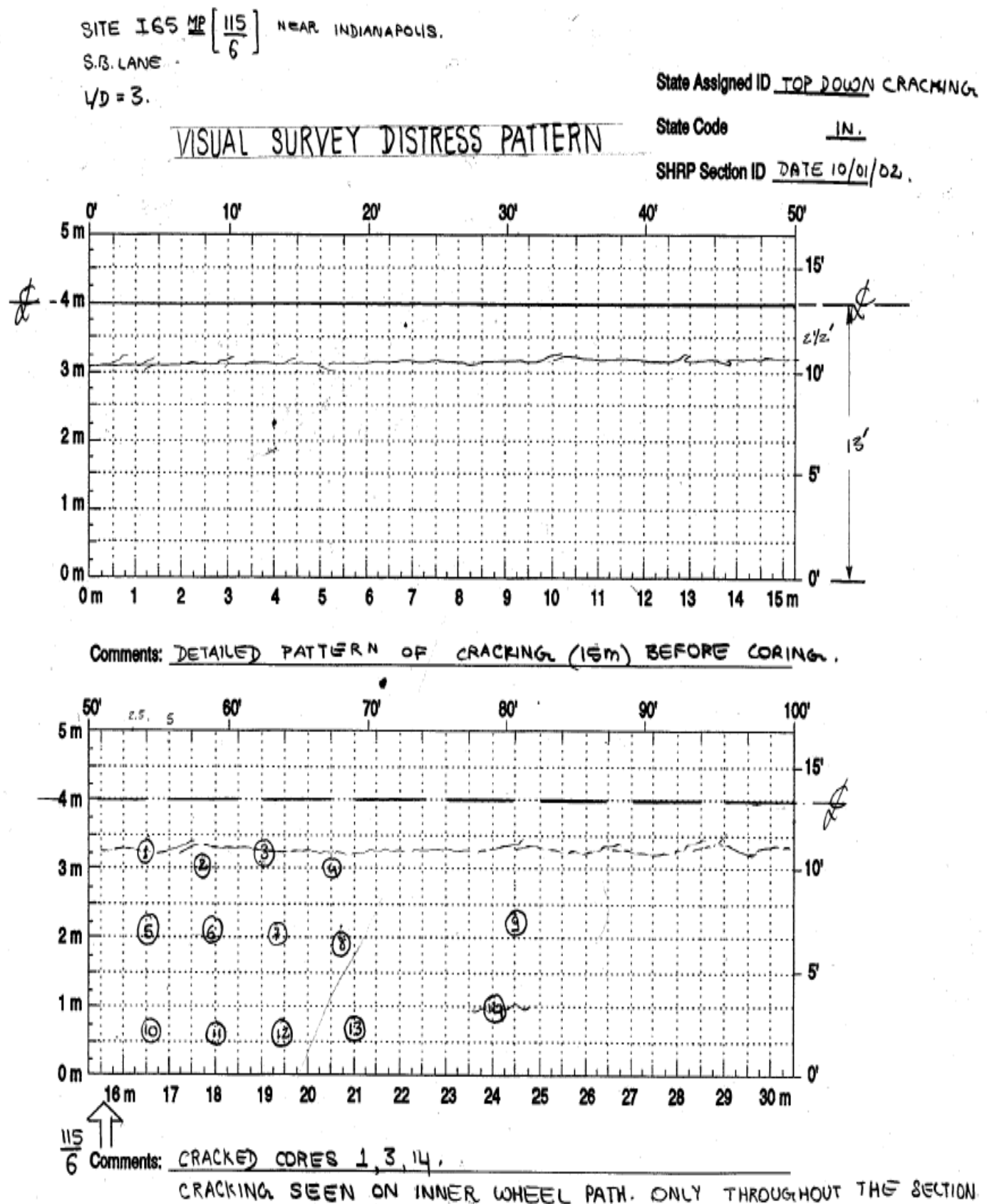

(15)

(16) SHOULDER.

16 cores were obtained from location 1 of Site 2: I-65 Near Indianapolis. 
Location 2:
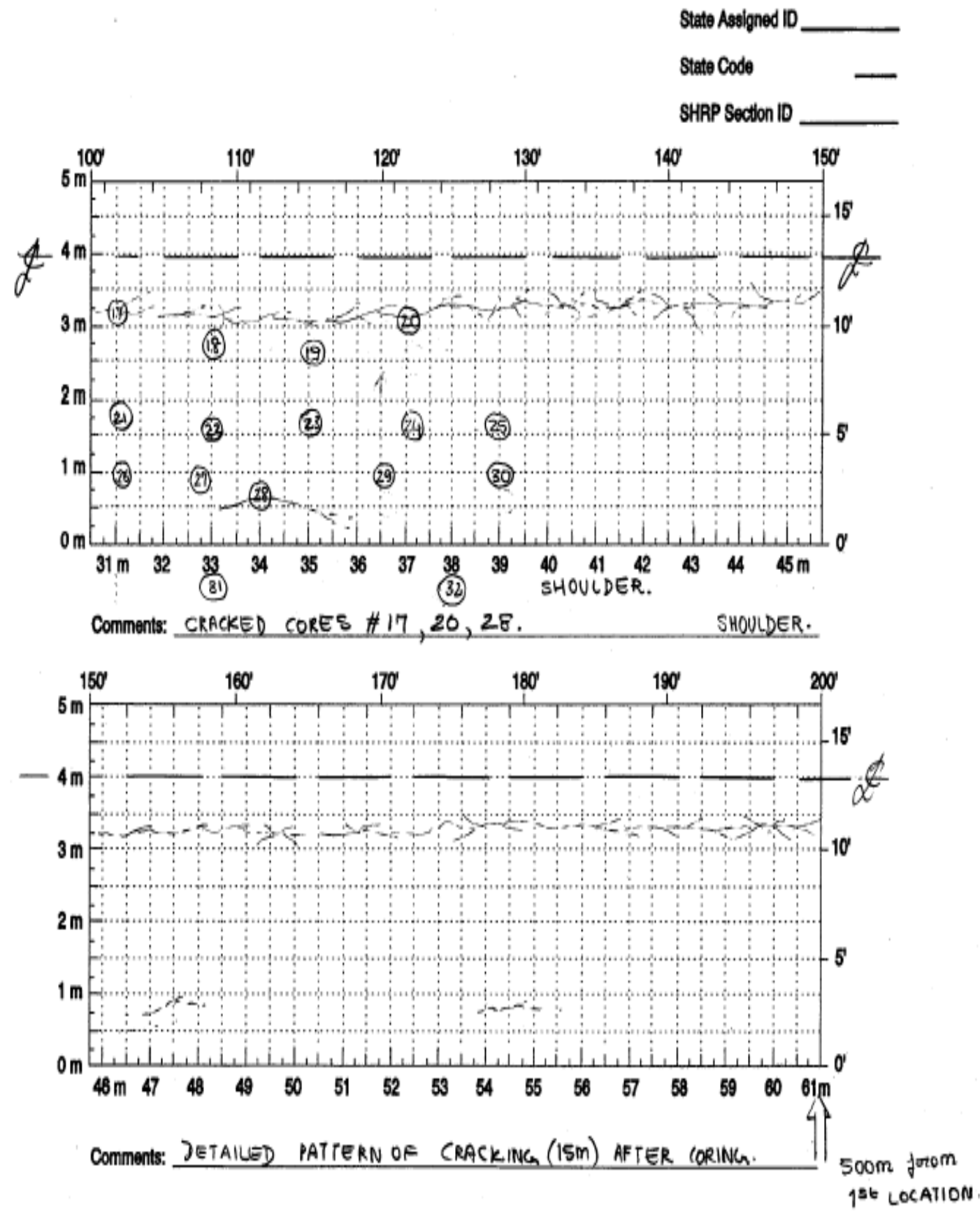

16 cores were obtained from location 2 of Site 2: I-65 Near Indianapolis. 


\section{Site 3: SR 421 Madison}

Location 1:

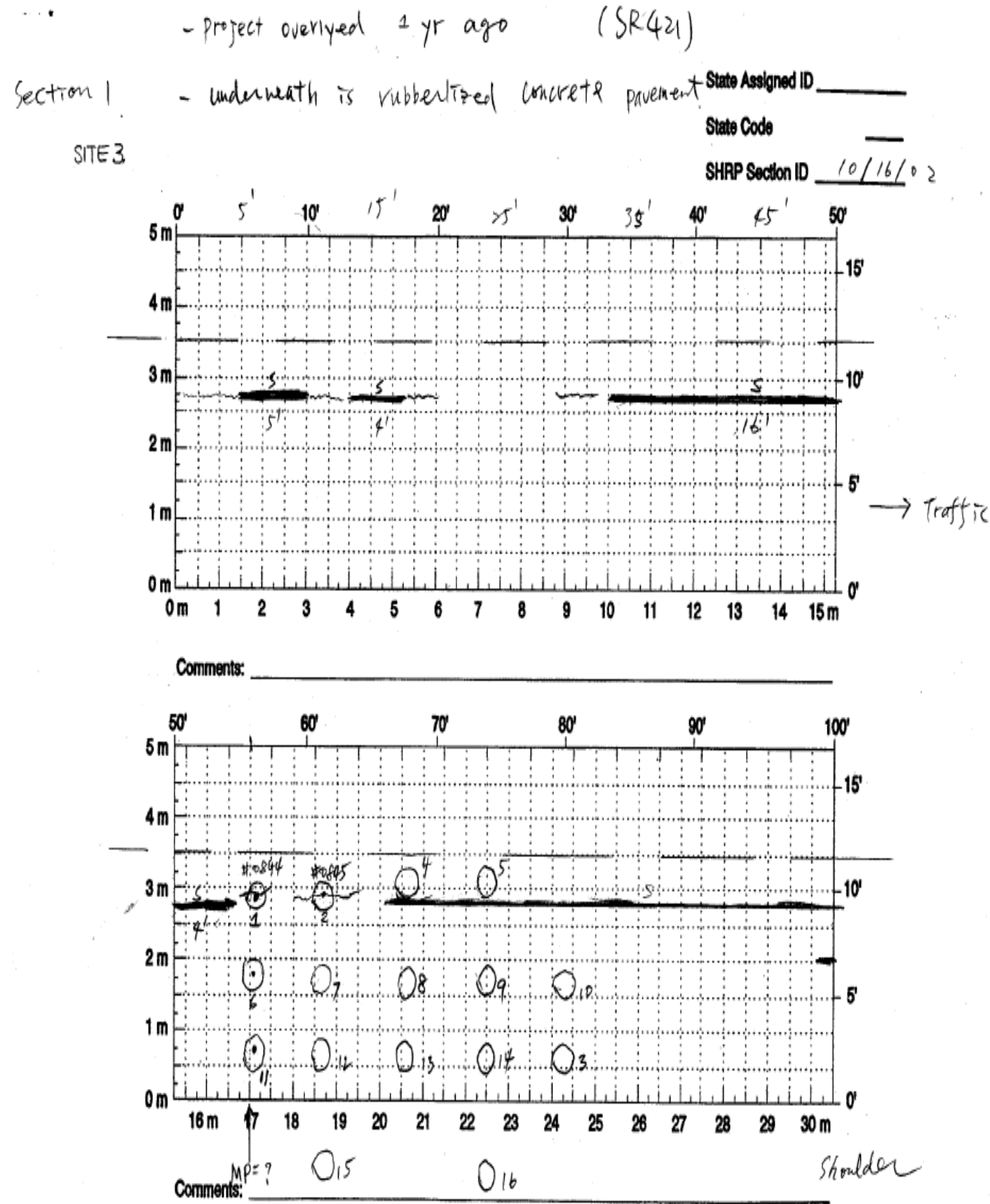

16 cores were obtained from location 1 of Site 3: US 421 Madison. 
Location 2:
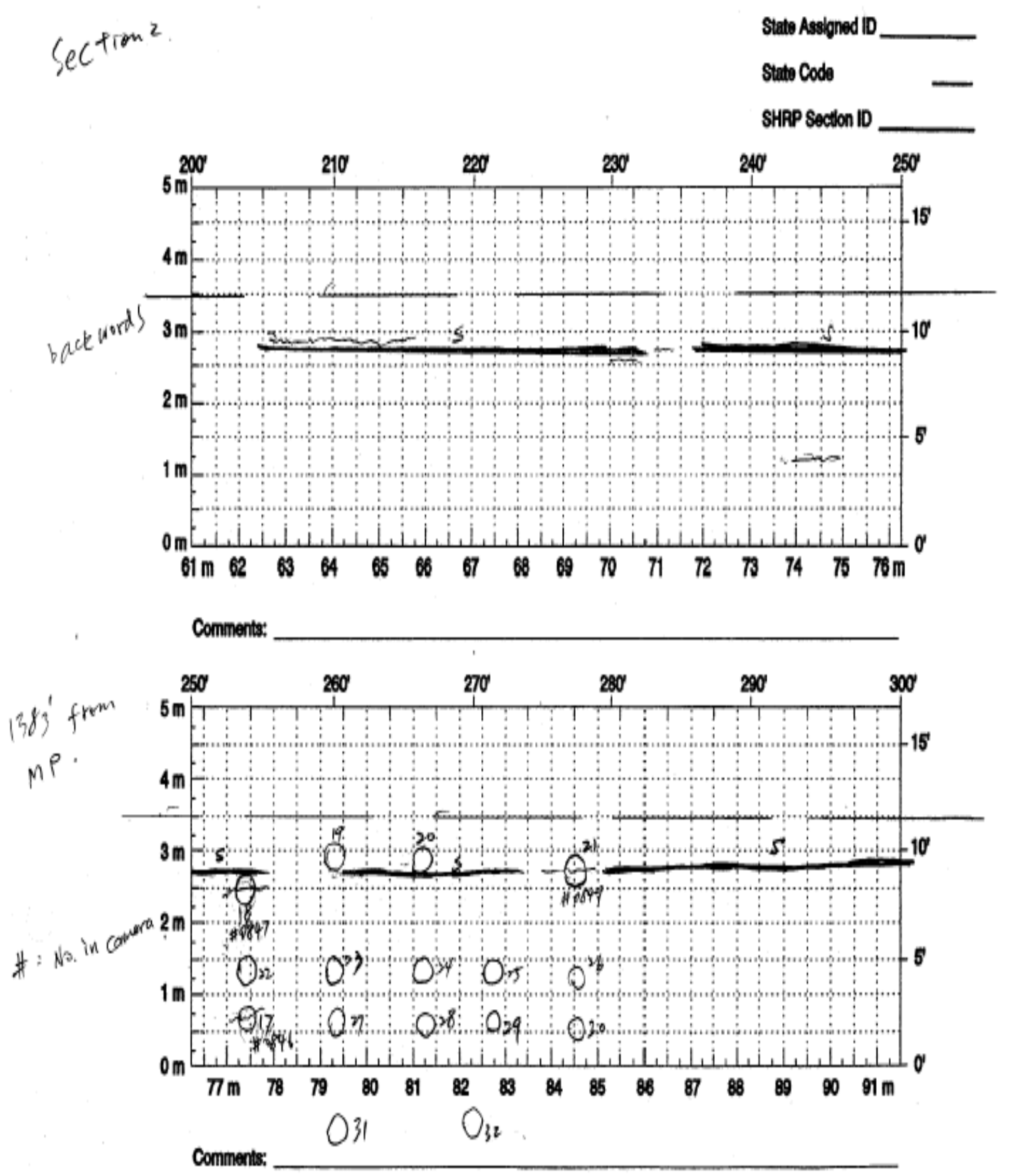

16 cores were obtained from location 2 of Site 3: US 421 Madison. 


\section{APPENDIX B PAVEMENT MANAGEMENT SYSTEM -DISTESS RATINGS}

\begin{tabular}{|c|c|c|}
\hline \multicolumn{3}{|c|}{ COMPOSITE OR FLEXIBLE DISTRESS RATING } \\
\hline RATING & $0=\mathrm{NONE} 1=\mathrm{LOW}$ & $0=\mathrm{NONE} 1=\mathrm{FEW}$ \\
\hline & $2=$ MODERATE $3=\mathrm{HIGH}$ & $2=$ SEVERAL $3=$ MANY \\
\hline DISTRESS & SEVERITY & EXTENT \\
\hline 1. RAVELING & $\begin{array}{l}\text { 1) Light Agg Loss } \\
\text { 2) Moderate Agg Loss } \\
\text { 3) Severe Agg Loss }\end{array}$ & $\begin{array}{l}\text { 1) Isolated Spots Or Strips } \\
\text { 2) } 1225 \% \text { To } 75 \% \text { Of Area } \\
\text { 3) More Than } 75 \% \text { Of Area }\end{array}$ \\
\hline 2. PATCHING & $\begin{array}{l}\text { 1) Minor Distress, Rides Good } \\
\text { 2) Fair Condition } \\
\text { 3) Deteriorated Or Temp Patch }\end{array}$ & $\begin{array}{l}\text { 1) 1-3 Deteriorated Patches Per } 100^{\prime} \\
\text { 2) 4-6 Deteriorated Patches Per } 100^{\prime} \\
\text { 3) }>6 \text { Patches Per } 100^{\prime}\end{array}$ \\
\hline 3. HOLES & $\begin{array}{l}\text { 1) Palm Sized Or Shallow }(<1 ") \\
\text { 2) Dinner Plate/Moderate Depth } \\
\text { 3) Larger Than \#2 }\end{array}$ & $\begin{array}{l}\text { 1) Isolated, Random Occurrence } \\
\text { 2) Occur In } 10 \% \text { To } 50 \% \text { Of Area } \\
\text { 3) Occur In Over } 50 \% \text { Of Area }\end{array}$ \\
\hline $\begin{array}{l}\text { 4. RANDOM OR } \\
\text { ALLIGATOR } \\
\text { CRACKS }\end{array}$ & $\begin{array}{l}\text { 1) Fine, Mostly Long Crx, No Pattern } \\
\text { 2) Tight Crx, Patterned, Light Spalls } \\
\text { 3) Crx, Spalled, Loose Or Severe }\end{array}$ & $\begin{array}{l}\text { 1) Small Area(S);Total }<50 \text { Lineal Ft } \\
\text { 2) }<25 \% \text { Area (Part Of One Track) } \\
\text { 3) }>25 \% \text { Area }\end{array}$ \\
\hline $\begin{array}{l}\text { 5. TRANSVERSE } \\
\text { AND/OR BLOCK } \\
\text { CRACKS }\end{array}$ & $\begin{array}{l}\text { 1) }<1 / 4 \text { In.; Few Incidental; Sealed } \\
\text { 2) }>1 / 4 \text { In; Small Depressed; Tight } \\
\text { 3) Spalls; Depressed; Many Incidental }\end{array}$ & $\begin{array}{l}\text { 1) Avg. }>=40 \text { Ft Space; }<12 \text { Crx In 500' } \\
\text { 2) 20-40 Ft Space; Blx }=30-60 \mathrm{SFt} / 20^{\prime} \\
\text { Multiple Crxs; Light Spalls }>25 \mathrm{Crxs} \\
\text { Per 500' } \\
\text { 3) Avg. }<20 \mathrm{Ft} \text { Space; Blx Avg. }<30 \\
\text { SFt/20' }\end{array}$ \\
\hline $\begin{array}{l}\text { 6. LONGITUDINAL } \\
\text { JOINTS }\end{array}$ & $\begin{array}{l}\text { 1) }<1 / 4 \text { In. Or Sealed Well } \\
\text { 2) Moderate Random Crxs; Tight } \\
\text { 3) Severe Spalls, Random Crxs, Open }\end{array}$ & $\begin{array}{l}\text { 1) }<50 \% \text { Of Length } \\
\text { 2) } 50 \% \text { To } 90 \% \\
\text { 3) Continuous }\end{array}$ \\
\hline 7. EDGE CRACKING & $\begin{array}{l}\text { 1) Crx Tight; No Raveling Or Breaks } \\
\text { 2) Crx Moderate; Minor Break-Up } \\
\text { 3) Missing Pieces; Severe Crx }\end{array}$ & $\begin{array}{l}\text { 1) }<20 \% \text { Of Length }\left(100^{\prime}\right) \\
\text { 2) } 20 \% \text { To } 50 \% \text { Of Length } \\
\text { 3) }>50 \% \text { Of Length }\end{array}$ \\
\hline $\begin{array}{l}\text { 8. WIDENING } \\
\text { CRACKS }\end{array}$ & $\begin{array}{l}\text { 1) Tight Or Well Sealed, }<1 / \text { I"Width } \\
\text { 2) >1/4"; Lo Severity Random Crx } \\
\text { Small Depressed; Light Spalls } \\
\text { 3) Depressed; Many Random; Spalled }\end{array}$ & $\begin{array}{l}\text { 1) Intermittent; }<25 \% \text { Of Length } \\
\text { 2) } 25 \% \text { To } 75 \% \text { Of Length } \\
\text { 3) Nearly Continuous; }>75 \% \text { Of Length }\end{array}$ \\
\hline 9. PUMPING & \multicolumn{2}{|c|}{ Yes - Pumping Is Evident, (Moving Blocks, Ghost Fines, Mud, Etc.) } \\
\hline & \multicolumn{2}{|c|}{ No - Pumping Is Not Evident } \\
\hline 10. MAINTENANCE & \multicolumn{2}{|c|}{$\begin{array}{l}\text { No- If Preventative Maintenance Is Not Evident (Old Or None Performed) } \\
\text { Yes-If Preventative Maintenance Is Evident (Fresh, Or New) }\end{array}$} \\
\hline & Yes-If Preventative Maintenance Is Evi & nt (Fresh, Or New) \\
\hline
\end{tabular}




\section{APPENDIX B PAVEMENT MANAGEMENT SYSTEM DATA}

\begin{tabular}{|c|c|c|c|c|c|c|c|c|c|c|c|c|c|c|c|c|c|}
\hline \multicolumn{18}{|c|}{ DECREASING DIRECTION } \\
\hline \multicolumn{18}{|c|}{ SITE 1 I_65 MP 223_224 } \\
\hline Road ID & Rd_From & Rd_To & Contract & Elem_ID & IRI & PCR_D & $\begin{array}{l}\text { RUT } \\
\text { AVG }\end{array}$ & $\begin{array}{l}\mathrm{Rt}_{-} \\
\text {Type }\end{array}$ & $\mathrm{ROAD}$ & $\begin{array}{l}\text { Final } \\
\text { Cost }\end{array}$ & $\begin{array}{c}\text { Suf } \\
\text { Type }\end{array}$ & Des_No & Let_Date & $\begin{array}{l}\text { Inve } \\
\text { AADT }\end{array}$ & $\begin{array}{l}\text { Year } \\
\text { AADT }\end{array}$ & $\begin{array}{c}\text { No } \\
\text { Lane }\end{array}$ & $\begin{array}{l}\text { Lane } \\
\text { Mile }\end{array}$ \\
\hline I_65 & 222.86 & 223.44 & R-20369R_I_65 & 2002_I_65_223.0 & 74 & 100 & 0.07 & $\mathrm{I}$ & I_65 & 6965000 & $\mathrm{R}$ & 8719125 & $1 / 12 / 1993$ & 30618 & 2001 & 4 & 2.32 \\
\hline I_65 & 223.44 & 224.44 & R-20369R_I665 & 2002_I_65_224.0 & 58 & 87.5 & 0.1 & $\mathrm{I}$ & I_65 & 6965000 & $\mathrm{R}$ & 8719125 & 1/12/1993 & 30618 & 2001 & 4 & 4 \\
\hline I_65 & 224.44 & 225.44 & R-20369R_I_65 & 2002_I_65_225.0 & 83 & 84 & 0.09 & $\mathrm{I}$ & I_65 & 6965000 & $\mathrm{R}$ & 8719125 & $1 / 12 / 1993$ & 30618 & 2001 & 4 & 4 \\
\hline \multicolumn{5}{|c|}{ AVERAGE } & 71.67 & 90.5 & 0.08667 & & & & & & & & & & \\
\hline \multicolumn{18}{|c|}{ SITE 2 I_65 MP 115.6_118 } \\
\hline Road ID & Rd_From & Rd_To & Contract & Elem_ID & IRI & PCR_D & $\begin{array}{l}\text { RUT } \\
\text { AVG }\end{array}$ & $\begin{array}{l}\mathrm{Rt}_{-} \\
\text {Type }\end{array}$ & ROAD & $\begin{array}{l}\text { Final } \\
\text { Cost }\end{array}$ & $\begin{array}{c}\text { Suf } \\
\text { Type }\end{array}$ & Des_No & Let_Date & ${ }_{\mathrm{T}}^{\text {Inve_AAD }}$ & $\begin{array}{c}\text { Year_AA } \\
\text { DT }\end{array}$ & $\begin{array}{c}\text { No_L } \\
\text { ane }\end{array}$ & $-\begin{array}{c}\text { Lane_M } \\
\text { ile }\end{array}$ \\
\hline I_65 & 115.59 & 115.79 & R-22177_I_65 & 2002_I65_115.0 & 119 & 100 & 0.1 & 1 & I_65 & $1.2 \mathrm{E}+07$ & $\mathrm{~J}$ & 8350370 & $11 / 21 / 1995$ & 106015 & 2001 & 6 & 1.2 \\
\hline 1665 & 115.79 & 115.90 & R-22177_I_65 & 2002_I_65_115.0 & 119 & 100 & 0.1 & $\mathrm{I}$ & I_65 & $1.2 \mathrm{E}+07$ & $\mathrm{~J}$ & 8350370 & $11 / 21 / 1995$ & 101932 & 2001 & 6 & 0.66 \\
\hline I_65 & 115.90 & 116.92 & R-22177_I_65 & 2002_I_65_116.0 & 149 & 100 & 0.04 & 1 & I_65 & $1.2 \mathrm{E}+07$ & $\mathrm{~J}$ & 8350370 & $11 / 21 / 1995$ & 101932 & 2001 & 6 & 6.12 \\
\hline 1665 & 116.92 & 117.47 & R-22177_I_65 & 2002_I_65_117.0 & 94 & 100 & 0.05 & 1 & I_65 & $1.2 \mathrm{E}+07$ & $\mathrm{~J}$ & 8350370 & $11 / 21 / 1995$ & 101932 & 2001 & 6 & 3.3 \\
\hline 1665 & 117.47 & 117.92 & R-22177_I_65 & 2002_I_65_117.0 & 94 & 100 & 0.05 & $\mathrm{I}$ & I_65 & $1.2 \mathrm{E}+07$ & $\mathrm{~J}$ & 8350370 & $11 / 21 / 1995$ & 64541 & 2001 & 4 & 1.8 \\
\hline $1+65$ & 117.92 & 118.16 & R-22177_I_65 & 2002_I_65_118.0 & 89 & 100 & 0.05 & 1 & I_65 & $1.2 \mathrm{E}+07$ & $\mathrm{~J}$ & 8350370 & $11 / 21 / 1995$ & 64541 & 2001 & 4 & 0.96 \\
\hline \multicolumn{5}{|c|}{ AVERAGE } & 110.7 & 100 & 0.065 & & & & & & & & & & \\
\hline \multicolumn{18}{|c|}{ SITE 3 U_421MP 1_3 } \\
\hline Road ID & Rd_From & Rd_To & Contract & Elem_ID & IRI & PCR_D & $\begin{array}{l}\text { RUT } \\
\text { AVG }\end{array}$ & $\begin{array}{l}\text { Rt_- } \\
\text { Type }\end{array}$ & ROAD & $\begin{array}{l}\text { Final } \\
\text { Cost }\end{array}$ & $\begin{array}{c}\text { Suf } \\
\text { Type }\end{array}$ & Des_No & Let_Date & $\operatorname{lnve}_{\mathrm{T}} \mathrm{AAD}$ & $\begin{array}{c}\text { Year_AA } \\
\text { DT }\end{array}$ & $\begin{array}{c}\text { No_L } \\
\text { ane }\end{array}$ & ${ }_{\text {Lane_M }}^{\text {Lile }}$ \\
\hline U_421 & 0.89 & 0.99 & R-24208_U_421 & 2001_U_421_000.0 & 180 & 93 & 0.18 & $u$ & U_421 & 5348000 & $\mathrm{~J}$ & 9300110 & $5 / 18 / 1999$ & 13510 & 2001 & 4 & 0.4 \\
\hline U_421 & 0.99 & 1.00 & R-24208_U_421 & 2001 U_421_000.0 & 180 & 93 & 0.18 & $u$ & U_421 & 5348000 & $\mathrm{~J}$ & 9300110 & $5 / 18 / 1999$ & 13510 & 2001 & 4 & 0.04 \\
\hline U_421 & 1.00 & 1.14 & R-24208_U_421 & 2001_U_421_001.d. & 53 & 100 & 0.09 & $u$ & U_421 & 5348000 & $\mathrm{~J}$ & 9300110 & $5 / 18 / 1999$ & 13510 & 2001 & 4 & 0.56 \\
\hline U_421 & 1.14 & 1.59 & R-24208_U_421 & 2001_U_421_001.0 & 53 & 100 & 0.09 & $U$ & U_421 & 5348000 & $\mathrm{~J}$ & 9300110 & $5 / 18 / 1999$ & 12360 & 2001 & 4 & 1.8 \\
\hline U_421 & 1.59 & 1.92 & R-24208_U_421 & 2001_U_421_001. & 53 & 100 & 0.09 & $U$ & U_421 & 5348000 & $\mathrm{~J}$ & 9300110 & $5 / 18 / 1999$ & 12360 & 2001 & 4 & 1.32 \\
\hline U_421 & 1.92 & 2.00 & R-24208_U_421 & 2001_U_421_001. & 53 & 100 & 0.09 & $U$ & U_421 & 5348000 & $\mathrm{~J}$ & 9300110 & $5 / 18 / 1999$ & 12360 & 2001 & 4 & 0.32 \\
\hline U_421 & 2.00 & 2.94 & R-24208_U_421 & 2001_U_421_002. & 43 & 100 & 0.09 & $U$ & U_421 & 5348000 & $\mathrm{~J}$ & 9300110 & $5 / 18 / 1999$ & 12360 & 2001 & 4 & 3.76 \\
\hline U_421 & 2.94 & 3.00 & R-24208_U_421 & 2001_U_421_002. & 43 & 100 & 0.09 & $U$ & U_421 & 5348000 & $\mathrm{~J}$ & 9300110 & $5 / 18 / 1999$ & 12360 & 2001 & 4 & 0.24 \\
\hline \multicolumn{5}{|c|}{ AVERAGE } & 82.25 & 98.25 & 0.1125 & & & & & & & & & & \\
\hline
\end{tabular}




\begin{tabular}{|c|c|c|c|c|c|c|c|c|c|c|c|c|c|c|c|c|c|}
\hline \multicolumn{18}{|c|}{ INCREASING DIRECTION } \\
\hline \multicolumn{18}{|c|}{ SITE 1 I_65 MP 223_224 } \\
\hline Road ID & Rd_From & Rd_To & Contract & Elem_ID & IRI & PCR_D & $\begin{array}{l}\text { RUT } \\
\text { AVG }\end{array}$ & $\begin{array}{l}\text { Rt_ } \\
\text { Type }\end{array}$ & ROAD & $\begin{array}{l}\text { Final } \\
\text { Cost }\end{array}$ & $\begin{array}{l}\text { Suf } \\
\text { Type }\end{array}$ & Des_No & Let_Date & $\begin{array}{l}\text { Inve } \\
\text { AADT }\end{array}$ & $\begin{array}{l}\text { Year } \\
\text { AADT }\end{array}$ & \begin{tabular}{|c} 
No \\
Lane
\end{tabular} & $\begin{array}{l}\text { Lane } \\
\text { Mile }\end{array}$ \\
\hline I_65 & 222.86 & 223.44 & R-20369R_I_65 & 2002_I_65_223.0 & 68 & 99.5 & 0.15 & 1 & I_65 & 6965000 & $\mathrm{R}$ & 8719125 & $1 / 12 / 1993$ & 30618 & 2001 & 4 & 2.32 \\
\hline I 65 & 223.44 & 224.44 & R-20369R_I_65 & 2002_I_65_224.0 & 62 & 89 & 0.2 & $\mathrm{I}$ & I 65 & 6965000 & $\mathrm{R}$ & 8719125 & $1 / 12 / 1993$ & 30618 & 2001 & 4 & 4 \\
\hline I_65 & 224.44 & 225.44 & R-20369R_I_65 & 2002_I_65_225.0 & 91 & 91.5 & 0.15 & $\mathrm{I}$ & I_65 & 6965000 & $\mathrm{R}$ & 8719125 & $1 / 12 / 1993$ & 30618 & 2001 & 4 & 4 \\
\hline \multicolumn{5}{|c|}{ AVERAGE } & 73.67 & 93.333 & 0.16667 & & & & & & & & & & \\
\hline \multicolumn{18}{|c|}{ SITE 2 I_65 MP 115.6_118 } \\
\hline Road ID & Rd_From & Rd_To & Contract & Elem_ID & IRI & PCR_D & $\begin{array}{l}\text { RUT } \\
\text { AVG }\end{array}$ & $\begin{array}{l}\text { Rt_ } \\
\text { Type }\end{array}$ & ROAD & $\begin{array}{l}\text { Final } \\
\text { Cost }\end{array}$ & $\begin{array}{l}\text { Suf } \\
\text { Type }\end{array}$ & Des_No & Let_Date & $\begin{array}{c}\text { Inve } \\
\text { AADT }\end{array}$ & $\begin{array}{l}\text { Year } \\
\text { AADT }\end{array}$ & \begin{tabular}{|c} 
No \\
Lane
\end{tabular} & $\begin{array}{l}\text { Lane } \\
\text { Mile }\end{array}$ \\
\hline I_65 & 115.59 & 115.79 & R-22177_I65 & 2002_I65_115.0 & 115 & 100 & 0.11 & $\mathrm{I}$ & I_65 & $1.2 \mathrm{E}+07$ & $\mathrm{~J}$ & 8350370 & 11/21/1995 & 106015 & 2001 & 6 & 1.2 \\
\hline I_65 & 115.79 & 115.90 & R-22177_I65 & 2002_I_65_115.0 & 115 & 100 & 0.11 & $\mathrm{I}$ & I_65 & $1.2 \mathrm{E}+07$ & $\mathrm{~J}$ & 8350370 & $11 / 21 / 1995$ & 101932 & 2001 & 6 & 0.66 \\
\hline I_65 & 115.90 & 116.92 & R-22177_I65 & 2002_I_65_116.0 & 128 & 99 & 0.04 & $\mathrm{I}$ & 165 & $1.2 E+07$ & $\mathrm{~J}$ & 8350370 & 11/21/1995 & 101932 & 2001 & 6 & 6.12 \\
\hline 165 & 116.92 & 117.47 & R-22177_I65 & 2002_I_65_117.0 & 108 & 100 & 0.06 & $\mathrm{I}$ & I_65 & $1.2 \mathrm{E}+07$ & $\mathrm{~J}$ & 8350370 & $11 / 21 / 1995$ & 101932 & 2001 & 6 & 3.3 \\
\hline I_65 & 117.47 & 117.92 & R-22177_I_65 & 2002_I_65_117.0 & 108 & 100 & 0.06 & $\mathrm{I}$ & 165 & $1.2 \mathrm{E}+07$ & $\mathrm{~J}$ & 8350370 & 11/21/1995 & 64541 & 2001 & 4 & 1.8 \\
\hline \multicolumn{5}{|c|}{ AVERAGE } & 114.8 & 99.8 & 0.076 & & & & & & & & & & \\
\hline \multicolumn{18}{|c|}{ SITE 3 U_421MP $1 \_3$} \\
\hline Road ID & Rd_From & Rd_To & Contract & Elem_ID & IRI & PCR_D & $\begin{array}{l}\text { RUT } \\
\text { AVG }\end{array}$ & $\begin{array}{l}\text { Rt_ } \\
\text { Type }\end{array}$ & ROAD & $\begin{array}{l}\text { Final } \\
\text { Cost }\end{array}$ & $\begin{array}{l}\text { Suf } \\
\text { Type }\end{array}$ & Des_No & Let_Date & $\begin{array}{c}\text { Inve } \\
\text { AADT }\end{array}$ & $\begin{array}{c}\text { Year } \\
\text { AADT }\end{array}$ & \begin{tabular}{|l} 
No \\
Lane
\end{tabular} & $\begin{array}{l}\text { Lane } \\
\text { Mile }\end{array}$ \\
\hline$\cup \_421$ & 1.00 & 1.14 & R-24208_U_421 & 2001 U_421_001.0 & 58 & 100 & 0.17 & $u$ & $\cup \_421$ & 5348000 & $\mathrm{~J}$ & 9300110 & $5 / 18 / 1999$ & 13510 & 2001 & 4 & 0.56 \\
\hline U_421 & 1.14 & 1.59 & R-24208_U_421 & 2001 U_421_001.0 & 58 & 100 & 0.17 & $u$ & $\cup \_421$ & 5348000 & $\mathrm{~J}$ & 9300110 & $5 / 18 / 1999$ & 12360 & 2001 & 4 & 1.8 \\
\hline U_421 & 1.59 & 1.92 & R-24208_U_421 & 2001_U_421_001.0 & 58 & 100 & 0.17 & $u$ & U_421 & 5348000 & $\mathrm{~J}$ & 9300110 & 5/18/1999 & 12360 & 2001 & 4 & 1.32 \\
\hline U_421 & 1.92 & 2.00 & R-24208_U_421 & 2001_U_421_001.0 & 58 & 100 & 0.17 & $\mathrm{U}$ & U_421 & 5348000 & $\mathrm{~J}$ & 9300110 & 5/18/1999 & 12360 & 2001 & 4 & 0.32 \\
\hline U_421 & 2.00 & 2.94 & R-24208_U_421 & 2001 U_421_002. & 46 & 97 & 0.15 & $u$ & U_421 & 5348000 & $\mathrm{~J}$ & 9300110 & $5 / 18 / 1999$ & 12360 & 2001 & 4 & 3.76 \\
\hline U_421 & 2.94 & 3.00 & R-24208_U_421 & 2001_U_421_002. & 46 & 97 & 0.15 & $\mathrm{U}$ & U_421 & 5348000 & $\mathrm{~J}$ & 9300110 & $5 / 18 / 1999$ & 12360 & 2001 & 4 & 0.24 \\
\hline \multicolumn{5}{|c|}{ AVERAGE } & 54 & 99 & 0.16333 & & & & & & & & & & \\
\hline
\end{tabular}




\section{APPENDIX C CORE LOG IN SHEET AND LABORATORY TEST PLAN}

\begin{tabular}{|c|c|c|c|c|c|c|c|c|c|c|c|c|c|c|c|c|}
\hline $\begin{array}{c}\text { LOCATION } \\
\text { COMMENTS }\end{array}$ & ID & $\begin{array}{r}\text { TOTAL } \\
\text { HEIGHT } \\
\text { INCHES }\end{array}$ & $\begin{array}{c}\text { SURFACE } \\
\text { THICKNESS } \\
\mathrm{mm}\end{array}$ & Gmb PURDUE & $\begin{array}{c}\left|\mathrm{G}^{*}\right| \\
\mathrm{NCSC}\end{array}$ & $\begin{array}{c}\left|E^{*}\right| \\
\text { PURDUE }\end{array}$ & $\begin{array}{c}\mathrm{D}(\mathrm{t}) \\
\mathrm{NCSC}\end{array}$ & $\begin{array}{c}\text { INDIRECT } \\
\text { TENSILE } \\
\text { STRENGTH } \\
\text { NCSC } \\
\end{array}$ & $\begin{array}{r}\text { Gmm } \\
\text { NCSC }\end{array}$ & $\begin{array}{c}\mathrm{Pb} \\
\mathrm{NCSC}\end{array}$ & \begin{tabular}{|} 
BINDER \\
RECOVERY \\
NCSC
\end{tabular} & $\begin{array}{l}\text { GRADATION } \\
\text { NCSC }\end{array}$ & $\begin{array}{l}\text { PEN AT } \\
1 \text { TEMP } \\
\text { NCSC }\end{array}$ & \begin{tabular}{|c|} 
SOFTENING \\
POINT \\
NCSC
\end{tabular} & $\begin{array}{c}\text { DSR AT } \\
5 \text { TEMP. } \\
\text { NCSC }\end{array}$ & $\begin{array}{l}\text { DTT AT } \\
2 \text { TEMP } \\
\text { NCSC }\end{array}$ \\
\hline \multicolumn{17}{|l|}{$\begin{array}{r}1 \\
C R A C K F D\end{array}$} \\
\hline CRACKED & 1 & 11.5 & & \begin{tabular}{|l|} 
NOT TAKEN \\
\end{tabular} & & & & & & & & & & & & \\
\hline CRACKED & 2 & \begin{tabular}{|r|}
12 \\
\end{tabular} & & \begin{tabular}{|l|} 
NOT TAKEN \\
\end{tabular} & & & & & & & & & & & & \\
\hline \multirow[t]{10}{*}{ CRACKED } & 3 & BROKEN & & NOT TAKEN & & & & & & & & & & & & \\
\hline & 4 & 13 & 30.25 & 2.327 & & & ep1 $-20^{\circ}$ & Rep1 $-20^{\circ} \mathrm{C}$ & & & & & $\mathrm{X}$ & $\mathrm{X}$ & $\mathrm{X}$ & $\mathrm{X}$ \\
\hline & 5 & 13 & 31.18 & 2.34 & & & ep2 $-10^{\circ}$ & Rep2 $-10^{\circ} \mathrm{C}$ & & & & & $\mathrm{X}$ & $\mathrm{X}$ & $\mathrm{X}$ & $\mathrm{X}$ \\
\hline & 6 & 9 & 30.99 & 2.34 & & & lep3 $0^{\circ} \mathrm{d}$ & $\begin{array}{ll}\text { Rep3 } & 0^{\circ} \mathrm{C} \\
\end{array}$ & & & & & $\mathrm{X}$ & $\mathrm{X}$ & $\mathrm{X}$ & $\mathrm{X}$ \\
\hline & 7 & 13 & 25.2 & 2.331 & & & & & Rep1 & Rep1 & Rep1 & Rep1 & $\mathrm{X}$ & $\mathrm{X}$ & $\mathrm{X}$ & $\mathrm{X}$ \\
\hline & 8 & 13 & 27.6 & 2.258 & & $\mathrm{X}$ & & & & & & & $\mathrm{X}$ & $\mathrm{X}$ & $\mathrm{X}$ & $\mathrm{X}$ \\
\hline & 9 & 12.5 & 27.4 & 2.278 & & & & & Rep2 & Rep2 & Rep2 & Rep2 & $\mathrm{X}$ & $\mathrm{X}$ & $\mathrm{X}$ & $\mathrm{X}$ \\
\hline & 10 & 13 & 30.82 & 2.279 & & & ep1 $-20^{\circ}$ & Rep1 $-20^{\circ} \mathrm{C}$ & & & & & $\mathrm{X}$ & $\mathrm{X}$ & $\mathrm{X}$ & $\mathrm{X}$ \\
\hline & 11 & 13 & 27.17 & 2.266 & & & & & Rep1 & Rep1 & Rep1 & Rep1 & $\mathrm{X}$ & $\mathrm{X}$ & $\mathrm{X}$ & $\mathrm{X}$ \\
\hline & 12 & 13 & 29.75 & 2.275 & & $\mathrm{X}$ & & & & & & & $\mathrm{X}$ & $\mathrm{X}$ & $\mathrm{X}$ & $\mathrm{X}$ \\
\hline \multirow[t]{2}{*}{ NOT USED } & 13 & 12 & 23.22 & 2.232 & & & & & & & & & & & & \\
\hline & 14 & 12 & 29.11 & 2.368 & & $\mathrm{X}$ & & & & & & & $\mathrm{X}$ & $\mathrm{X}$ & $\mathrm{X}$ & $\mathrm{X}$ \\
\hline NOT USED & 15 & 12 & 27.11 & 2.347 & & & & & & & & & & & & \\
\hline \multicolumn{17}{|l|}{\begin{tabular}{|r|}
2 \\
\end{tabular}} \\
\hline CRACKED & 16 & 12 & & \begin{tabular}{|l|} 
NOT TAKEN \\
\end{tabular} & & & & & & & & & & & & \\
\hline CRACKED & 17 & 9 & & NOT TAKEN & & & & & & & & & & & & \\
\hline \multirow[t]{8}{*}{ CRACKED } & 18 & 14 & & NOT TAKEN & & & & & & & & & & & & \\
\hline & 19 & 10 & 22.08 & 2.314 & & & & & Rep2 & Rep2 & Rep2 & Rep2 & $\mathrm{X}$ & $\mathrm{X}$ & $\mathrm{X}$ & $\mathrm{X}$ \\
\hline & 20 & 13 & 29.26 & 2.314 & & $\mathrm{X}$ & & & & & & & $\mathrm{X}$ & $\mathrm{X}$ & $\mathrm{X}$ & $\mathrm{X}$ \\
\hline & 21 & 10.3 & 36.09 & 2.327 & $\mathrm{X}$ & & & & & & & & $\mathrm{X}$ & $\mathrm{X}$ & $\mathrm{X}$ & $\mathrm{X}$ \\
\hline & 22 & 14 & 32.17 & 2.303 & & & ep2 $-10^{\circ}$ & Rep2 $-10^{\circ} \mathrm{C}$ & & & & & $\mathrm{X}$ & $\mathrm{X}$ & $\mathrm{X}$ & $\mathrm{X}$ \\
\hline & 23 & 13 & 25.02 & 2.292 & & & & & Rep1 & Rep1 & Rep1 & Rep1 & $\mathrm{X}$ & $\mathrm{X}$ & $\mathrm{X}$ & $\mathrm{X}$ \\
\hline & 24 & 10 & 33.66 & 2.291 & $\mathrm{X}$ & & & & & & & & $\mathrm{X}$ & $\mathrm{X}$ & $\mathrm{X}$ & $\mathrm{X}$ \\
\hline & 25 & 12.75 & 29.15 & 2.297 & & $\mathrm{X}$ & & & & & & & $\mathrm{X}$ & $\mathrm{X}$ & $\mathrm{X}$ & $\mathrm{X}$ \\
\hline \multirow[t]{5}{*}{ NOT USED } & 26 & 12 & 24.5 & 2.308 & & & & & & & & & & & & \\
\hline & 27 & 11 & 25.83 & 2.311 & & & & & Rep2 & Rep2 & Rep2 & Rep2 & $\mathrm{X}$ & $\mathrm{X}$ & $\mathrm{X}$ & $\mathrm{X}$ \\
\hline & 28 & 11.5 & 31.31 & 2.331 & & \multicolumn{2}{|c|}{ Rep3 } & Rep3 $\quad 0^{\circ} \mathrm{C}$ & & & & & $\mathrm{X}$ & $\mathrm{X}$ & $\mathrm{X}$ & $\mathrm{X}$ \\
\hline & 29 & 13.5 & 28.7 & 2.318 & & $\mathrm{X}$ & & & & & & & & & & \\
\hline & & & & & & & & & & & & & 1 TEST & 2 TESTS & 2 TESTS & 6 TESTS \\
\hline Total Samples & $23(29)$ & & & & 2 & 6 & 6 & (6) & 6 & (6) & (6) & (6) & 20 & & & \\
\hline Total Mix kg & & & & & 2.4 & 7.2 & 7.2 & $(7.2)$ & 7.2 & $(7.2)$ & $(7.2)$ & $(7.2)$ & 24 & & & \\
\hline $\begin{array}{c}\text { Binder Content } \\
\mathrm{kg}\end{array}$ & & & & & 0.108 & 0.324 & 0.324 & $(0.324)$ & 0.324 & $(0.324)$ & $(0.324)$ & $(0.324)$ & 1.08 & & & \\
\hline Rep1-Replicate 1 & & & & & & & & & & & & & & & & \\
\hline ep2-Replicate 2 & & & & & & & & & & & & & & & & \\
\hline
\end{tabular}


SITE 3- SR 421 MADISON

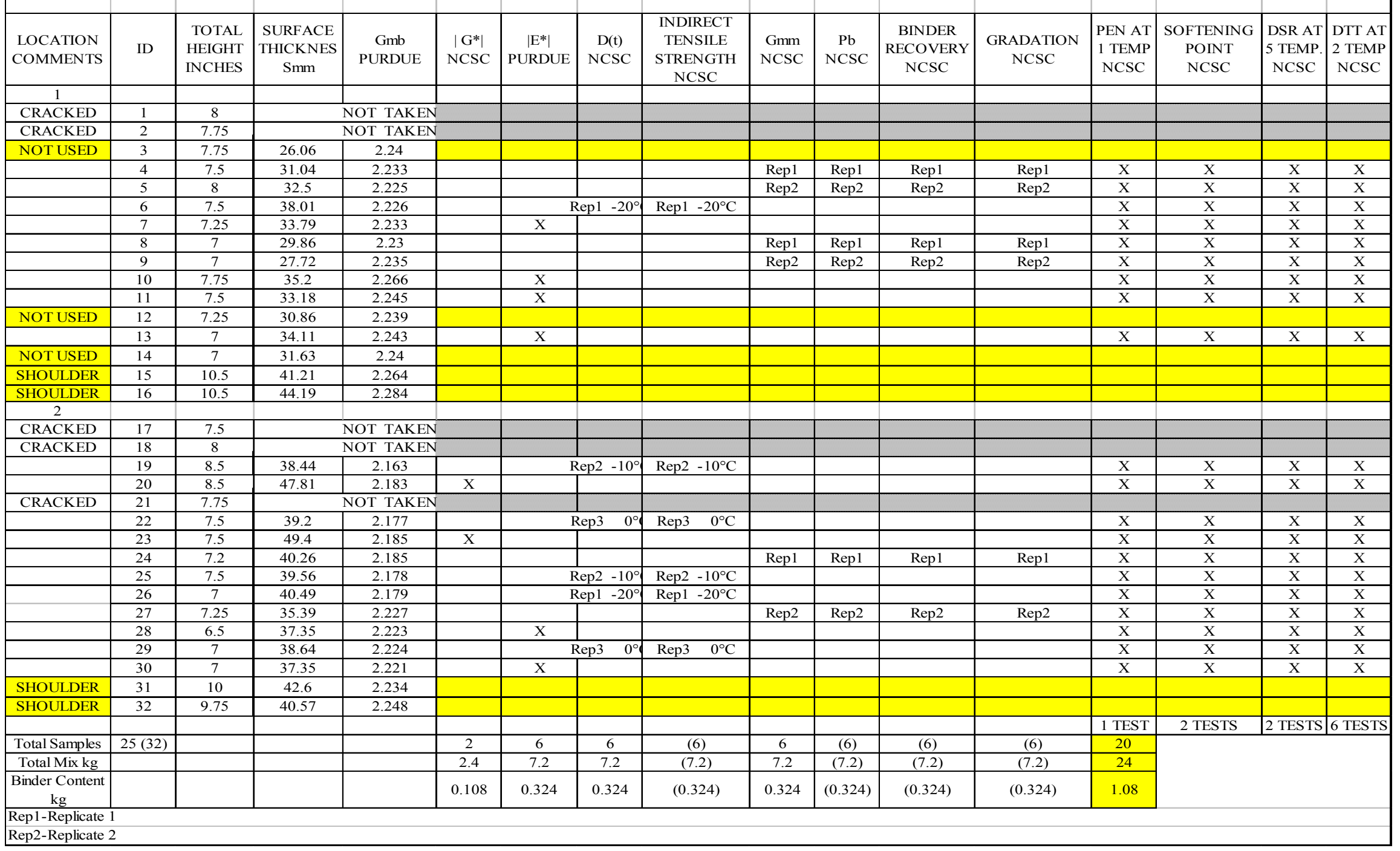




\section{APPENDIX D LABORATORY TEST RESULTS}

\section{PERCENTAGE AIR VOIDS}

\section{Site 1 I-65 North of Lafayette}

\begin{tabular}{|c|c|c|c|c|}
\hline $\begin{array}{c}\text { SAMPLE } \\
\text { ID }\end{array}$ & Gmb PURDUE & Gmm NCSC & $\%$ Air Voids & $\begin{array}{c}\text { Average } \\
\% \text { Air } \\
\text { Voids }\end{array}$ \\
\hline 1 & NOT TAKEN & 2.486 & & \\
\hline 2 & NOT TAKEN & 2.486 & & \\
\hline 3 & NOT TAKEN & 2.486 & & \\
\hline 4 & 2.327 & 2.486 & 6.40 & \multirow{4}{*}{6.10} \\
\hline 5 & 2.340 & 2.486 & 5.87 & \\
\hline 6 & 2.340 & 2.486 & 5.87 & \\
\hline 7 & 2.331 & 2.486 & 6.23 & \\
\hline 8 & 2.258 & 2.486 & 9.17 & \multirow{5}{*}{8.64} \\
\hline 9 & 2.278 & 2.486 & 8.37 & \\
\hline 10 & 2.279 & 2.486 & 8.33 & \\
\hline 11 & 2.266 & 2.486 & 8.85 & \\
\hline 12 & 2.275 & 2.486 & 8.49 & \\
\hline 13 & 2.232 & 2.486 & 10.22 & \multirow{3}{*}{6.85} \\
\hline 14 & 2.368 & 2.486 & 4.75 & \\
\hline 15 & 2.347 & 2.486 & 5.59 & \\
\hline 16 & NOT TAKEN & 2.486 & & \\
\hline 17 & NOT TAKEN & 2.486 & & \\
\hline 18 & NOT TAKEN & 2.486 & & \\
\hline 19 & 2.314 & 2.486 & 6.92 & \multirow{3}{*}{6.74} \\
\hline 20 & 2.314 & 2.486 & 6.92 & \\
\hline 21 & 2.327 & 2.486 & 6.40 & \\
\hline 22 & 2.303 & 2.486 & 7.36 & \multirow{4}{*}{7.65} \\
\hline 23 & 2.292 & 2.486 & 7.80 & \\
\hline 24 & 2.291 & 2.486 & 7.84 & \\
\hline 25 & 2.297 & 2.486 & 7.60 & \\
\hline 26 & 2.308 & 2.486 & 7.16 & \multirow{4}{*}{6.80} \\
\hline 27 & 2.311 & 2.486 & 7.04 & \\
\hline 28 & 2.331 & 2.486 & 6.23 & \\
\hline 29 & 2.318 & 2.486 & 6.76 & \\
\hline
\end{tabular}

where:

\begin{tabular}{|l|l|c|}
\hline & LWP & Left Wheel Path \\
\hline & CENTER & Center \\
\hline & RWP & Right Wheel Path \\
\hline
\end{tabular}


Site 2 I-65 Near Indianapolis

\begin{tabular}{|c|c|c|c|c|}
\hline $\begin{array}{c}\text { SAMPLE } \\
\text { ID }\end{array}$ & Gmb PURDUE & Gmm NCSC & $\%$ Air Voids & $\begin{array}{c}\text { Average } \\
\% \text { Air } \\
\text { Voids }\end{array}$ \\
\hline 1 & NOT TAKEN & 2.502 & & \\
\hline 2 & 2.293 & 2.502 & 8.35 & 8.49 \\
\hline 3 & NOT TAKEN & 2.502 & & \\
\hline 4 & 2.286 & 2.502 & 8.63 & \\
\hline 5 & 2.345 & 2.502 & 6.27 & \multirow{5}{*}{6.35} \\
\hline 6 & 2.328 & 2.502 & 6.95 & \\
\hline 7 & 2.340 & 2.502 & 6.47 & \\
\hline 8 & 2.342 & 2.502 & 6.39 & \\
\hline 9 & 2.360 & 2.502 & 5.68 & \\
\hline 10 & 2.366 & 2.502 & 5.44 & \multirow{4}{*}{6.15} \\
\hline 11 & 2.347 & 2.502 & 6.20 & \\
\hline 12 & 2.342 & 2.502 & 6.39 & \\
\hline 13 & \begin{tabular}{|l|}
2.338 \\
\end{tabular} & 2.502 & 6.55 & \\
\hline 14 & NOT TAKEN & 2.502 & & \\
\hline 15 & 2.257 & 2.502 & 9.79 & \multirow{2}{*}{8.93} \\
\hline 16 & 2.300 & 2.502 & 8.07 & \\
\hline 17 & NOT TAKEN & 2.502 & & \\
\hline 18 & \begin{tabular}{l|l}
2.291 \\
\end{tabular} & 2.502 & 8.43 & \multirow{2}{*}{8.23} \\
\hline 19 & 2.301 & 2.502 & 8.03 & \\
\hline 20 & NOT TAKEN & 2.502 & & \\
\hline 21 & 2.300 & 2.502 & 8.07 & \multirow{5}{*}{8.43} \\
\hline 22 & 2.290 & 2.502 & 8.47 & \\
\hline 23 & 2.298 & 2.502 & 8.15 & \\
\hline 24 & 2.284 & 2.502 & 8.71 & \\
\hline 25 & 2.283 & 2.502 & 8.75 & \\
\hline 26 & 2.300 & 2.502 & 8.07 & \multirow{5}{*}{8.50} \\
\hline 27 & 2.297 & 2.502 & 8.19 & \\
\hline 28 & NOT TAKEN & 2.502 & & \\
\hline 29 & 2.279 & 2.502 & 8.91 & \\
\hline 30 & 2.281 & 2.502 & 8.83 & \\
\hline 31 & 2.275 & 2.502 & 9.07 & \multirow{2}{*}{9.11} \\
\hline 32 & 2.273 & 2.502 & 9.15 & \\
\hline
\end{tabular}

where:

\begin{tabular}{|l|l|c|}
\hline & LWP & Left Wheel Path \\
\hline & CENTER & Center \\
\hline & RWP & Right Wheel Path \\
\hline & SHOULDER & Shoulder \\
\hline
\end{tabular}


Site 3 SR421 Madison

\begin{tabular}{|c|c|c|c|c|}
\hline ID & Gmb PURDUE & Gmm NCSC & $\%$ Air Voids & $\begin{array}{c}\text { Average } \\
\% \text { Air } \\
\text { Voids }\end{array}$ \\
\hline 1 & NOT TA $\triangle E$ TN & - & & \\
\hline 2 & \begin{tabular}{|ll} 
NOT \\
TAKEN
\end{tabular} & - & & \\
\hline 3 & 2.240 & 2.458 & 8.87 & \multirow{3}{*}{9.32} \\
\hline 4 & 2.233 & 2.458 & 9.15 & \\
\hline 5 & 2.225 & 2.458 & 9.48 & \\
\hline 6 & 2.226 & 2.458 & 9.44 & \multirow{5}{*}{8.95} \\
\hline 7 & 2.233 & 2.458 & 9.15 & \\
\hline 8 & 2.230 & 2.458 & 9.28 & \\
\hline 9 & 2.235 & 2.458 & 9.07 & \\
\hline 10 & 2.266 & 2.458 & 7.81 & \\
\hline 11 & 2.245 & 2.458 & 8.67 & \multirow{4}{*}{8.81} \\
\hline 12 & 2.239 & 2.458 & 8.91 & \\
\hline 13 & 2.243 & 2.458 & 8.75 & \\
\hline 14 & 2.240 & 2.458 & 8.87 & \\
\hline 15 & 2.264 & 2.458 & 7.89 & \multirow{2}{*}{7.49} \\
\hline 16 & 2.284 & 2.458 & 7.08 & \\
\hline 17 & \begin{tabular}{|l|} 
NOT TAKEN \\
\end{tabular} & - & & \\
\hline 18 & \begin{tabular}{|l|} 
NOT TAKEN \\
\end{tabular} & - & & \\
\hline 19 & \begin{tabular}{|l|}
2.163 \\
\end{tabular} & 2.458 & 12.00 & \multirow{2}{*}{11.59} \\
\hline 20 & 2.183 & 2.458 & 11.19 & \\
\hline 21 & NOT TAKEN & & & \\
\hline 22 & \begin{tabular}{|l|}
2.177 \\
\end{tabular} & 2.458 & 11.43 & \multirow{5}{*}{11.28} \\
\hline 23 & 2.185 & 2.458 & 11.11 & \\
\hline 24 & 2.185 & 2.458 & 11.11 & \\
\hline 25 & 2.178 & 2.458 & 11.39 & \\
\hline 26 & 2.179 & 2.458 & 11.35 & \\
\hline 27 & 2.227 & 2.458 & 9.40 & \multirow{4}{*}{9.53} \\
\hline 28 & 2.223 & 2.458 & 9.56 & \\
\hline 29 & 2.224 & 2.458 & 9.52 & \\
\hline 30 & 2.221 & 2.458 & 9.64 & \\
\hline 31 & 2.234 & 2.458 & 9.11 & \multirow{2}{*}{8.83} \\
\hline 32 & 2.248 & 2.458 & 8.54 & \\
\hline
\end{tabular}

where:

\begin{tabular}{|c|c|c|}
\hline & LWP & Left Wheel Path \\
\hline & CENTER & Center \\
\hline & RWP & Right Wheel Path \\
\hline & SHOULDER & Shoulder \\
\hline
\end{tabular}


EXTRACTION OF BINDER CONTENT (AASHTO TP 2)

\begin{tabular}{|l|c|c|c|}
\hline REPLICATE & $\begin{array}{l}\text { SITE 1 I-65 } \\
\text { NORTH }\end{array}$ & $\begin{array}{l}\text { SITE2 I-65 } \\
\text { INDIANAPOLIS }\end{array}$ & $\begin{array}{l}\text { SITE3 US-421 } \\
\text { MADISON }\end{array}$ \\
\hline 1 & 4.90 & 5.90 & 6.30 \\
\hline 2 & 5.30 & 6.30 & 6.10 \\
\hline 3 & 5.80 & 5.30 & 6.40 \\
\hline 4 & 5.50 & 6.00 & 6.20 \\
\hline Average & 5.38 & 5.88 & 6.25 \\
\hline Std Dev & 0.38 & 0.42 & 0.13 \\
\hline CV\% & 7.0 & 7.1 & 2.1 \\
\hline
\end{tabular}

GRADATION DATA (AASHTO TP 11, 27)

\begin{tabular}{|c|c|c|c|c|c|c|c|c|c|c|}
\hline \multicolumn{2}{|c|}{ SIZE } & \multicolumn{3}{|c|}{ SITE 1} & \multicolumn{3}{|c|}{ SITE 2} & \multicolumn{3}{|c|}{ SITE 3} \\
\hline inch & $\mathbf{m m}$ & R 1 & Rp 2 & Avg. & R 1 & R 2 & Avg. & R 1 & R 2 & Avg. \\
\hline $3 / 4$ & 19 & 100.0 & 100.0 & 100.0 & 100.0 & 100.0 & 100.0 & 100.0 & 100.0 & 100.0 \\
\hline $1 / 2$ & 12.5 & 96.7 & 100.0 & 98.3 & 100.0 & 100.0 & 100.0 & 100.0 & 100.0 & 100.0 \\
\hline $3 / 8$ & 9.5 & 87.7 & 94.2 & 90.9 & 94.7 & 91.7 & 93.2 & 95.7 & 94.9 & 95.3 \\
\hline$\# 4$ & 4.75 & 51.0 & 61.8 & 56.4 & 63.0 & 56.7 & 59.8 & 66.6 & 63.3 & 64.9 \\
\hline$\# 8$ & 2.36 & 35.5 & 44.9 & 40.2 & 47.4 & 41.7 & 44.6 & 48.1 & 44.3 & 46.2 \\
\hline \#16 & 1.18 & 29.0 & 35.7 & 32.3 & 30.5 & 27.7 & 29.1 & 34.5 & 31.1 & 32.8 \\
\hline \#30 & 0.6 & 23.2 & 27.3 & 25.2 & 20.8 & 19.3 & 20.0 & 20.6 & 18.6 & 19.6 \\
\hline \#50 & 0.3 & 12.3 & 12.3 & 12.3 & 14.6 & 13.4 & 14.0 & 7.8 & 7.3 & 7.6 \\
\hline$\# 100$ & 0.15 & 5.0 & 4.5 & 4.8 & 9.4 & 9.0 & 9.2 & 3.9 & 3.1 & 3.5 \\
\hline \# 200 & 0.075 & 3.1 & 2.7 & 2.9 & 5.8 & 5.8 & 5.8 & 2.9 & 2.0 & 2.5 \\
\hline
\end{tabular}




\section{APPENDIX E DYNAMIC SHEAR RHEOMETER (DSR) TEST}

Site 1 I-65 North of Lafayette

\begin{tabular}{|c|c|c|c|c|c|c|c|c|c|c|c|c|c|c|}
\hline & \multicolumn{2}{|c|}{$15^{\circ} \mathrm{C}$} & \multicolumn{2}{|c|}{$25^{\circ} \mathrm{C}$} & \multicolumn{2}{|c|}{$35^{\circ} \mathrm{C}$} & \multicolumn{2}{|c|}{$40^{\circ} \mathrm{C}$} & \multicolumn{2}{|c|}{$52^{\circ} \mathrm{C}$} & \multicolumn{2}{|c|}{$64^{\circ} \mathrm{C}$} & \multicolumn{2}{|c|}{$76^{\circ} \mathrm{C}$} \\
\hline Freq. Hz & $\delta^{\circ}$ & $\left|G^{*}\right|, \mathrm{Pa}$ & $\delta^{\circ}$ & $\left|G^{*}\right|, \mathrm{Pa}$ & $\delta^{\circ}$ & $\left|G^{\star}\right|, \mathrm{Pa}$ & $\delta^{\circ}$ & $\left|G^{*}\right|, \mathrm{Pa}$ & $\delta^{\circ}$ & $\left|G^{*}\right|, \mathrm{Pa}$ & $\delta^{\circ}$ & $\left|G^{\star}\right|, P a$ & $\delta^{\circ}$ & $\left|G^{\star}\right|, P a$ \\
\hline 0.1 & 43.8 & $7.72 \mathrm{E}+06$ & 55.2 & $1.46 \mathrm{E}+06$ & 64.4 & $2.31 E+05$ & 45.7 & 1.67E+06 & 65.3 & $3.32 E+05$ & 74.6 & $6.34 \mathrm{E}+04$ & 81.1 & $1.47 E+04$ \\
\hline 0.1 & 43 & $8.66 \mathrm{E}+06$ & 54.4 & $1.69 \mathrm{E}+06$ & 63.8 & $2.74 \mathrm{E}+05$ & 47.3 & $1.50 \mathrm{E}+06$ & 65.8 & $2.87 E+05$ & 75.1 & $5.34 \mathrm{E}+04$ & 81.2 & $1.22 \mathrm{E}+04$ \\
\hline 0.2 & 42.1 & $9.59 E+06$ & 53.4 & $1.91 \mathrm{E}+06$ & 63.1 & $3.21 E+05$ & 49 & $1.32 E+06$ & 66.6 & $2.39 \mathrm{E}+05$ & 75.5 & $4.39 E+04$ & 81.4 & $9.65 E+03$ \\
\hline 0.2 & 41.2 & 1.06E+07 & 52.6 & $2.19 \mathrm{E}+06$ & 62.4 & $3.81 E+05$ & 50.8 & $1.16 \mathrm{E}+06$ & 67.3 & $2.02 E+05$ & 75.8 & $3.63 E+04$ & 82 & $7.92 E+03$ \\
\hline 0.3 & 40.5 & $1.18 \mathrm{E}+07$ & 51.9 & $2.50 \mathrm{E}+06$ & 61.7 & $4.42 E+05$ & 52.3 & $1.01 E+06$ & 67.8 & 1.69E+05 & 76.3 & $2.98 \mathrm{E}+04$ & 82.3 & $6.42 E+03$ \\
\hline 0.3 & 40 & 1.31E+07 & 51.3 & $2.86 \mathrm{E}+06$ & 61.1 & $5.21 E+05$ & 53.8 & $8.84 \mathrm{E}+05$ & 68.6 & $1.41 E+05$ & 76.9 & $2.46 \mathrm{E}+04$ & 82.8 & $5.27 E+03$ \\
\hline 0.4 & 39.1 & $1.44 \mathrm{E}+07$ & 50.4 & $3.23 E+06$ & 60.4 & $6.12 \mathrm{E}+05$ & 55.3 & $7.63 \mathrm{E}+05$ & 69.3 & $1.18 \mathrm{E}+05$ & 77.5 & $2.01 E+04$ & 83 & $4.26 E+03$ \\
\hline 0.5 & 38.5 & $1.58 \mathrm{E}+07$ & 49.8 & $3.65 \mathrm{E}+06$ & 59.8 & 7.14E+05 & 56.4 & $6.62 \mathrm{E}+05$ & 70.1 & $9.83 E+04$ & 77.9 & $1.65 \mathrm{E}+04$ & 83.4 & $3.38 E+03$ \\
\hline 0.6 & 37.8 & 1.74E+07 & 49 & $4.13 E+06$ & 59.2 & 8.37E+05 & 58.3 & $5.73 E+05$ & 71 & $8.11 E+04$ & 78.6 & 1.35E+04 & 83.9 & $2.72 E+03$ \\
\hline 0.8 & 37.1 & $1.92 \mathrm{E}+07$ & 48.2 & $4.68 E+06$ & 58.5 & $9.70 \mathrm{E}+05$ & 59.1 & $4.90 \mathrm{E}+05$ & 71.3 & $6.72 E+04$ & 79.1 & $1.10 \mathrm{E}+04$ & 84.1 & $2.17 E+03$ \\
\hline 1.0 & 36.6 & $2.10 \mathrm{E}+07$ & 47.5 & $5.30 \mathrm{E}+06$ & 57.9 & $1.12 \mathrm{E}+06$ & 60.3 & $4.21 E+05$ & 71.7 & $5.58 \mathrm{E}+04$ & 79.7 & 8.97E+03 & 84.6 & $1.74 \mathrm{E}+03$ \\
\hline 1.3 & 35.9 & $2.30 \mathrm{E}+07$ & 46.9 & $5.96 \mathrm{E}+06$ & 57.2 & $1.29 E+06$ & 62.1 & $3.59 \mathrm{E}+05$ & 72.7 & 4.67E+04 & 80.4 & 7.33E+03 & 84.7 & $1.38 \mathrm{E}+03$ \\
\hline 1.6 & 35.3 & $2.51 E+07$ & 46.2 & $6.71 E+06$ & 56.6 & $1.50 \mathrm{E}+06$ & 63.1 & $3.06 \mathrm{E}+05$ & 73.6 & $3.83 E+04$ & 81 & $5.96 \mathrm{E}+03$ & 84.9 & $1.10 \mathrm{E}+03$ \\
\hline 2.0 & 34.8 & $2.73 E+07$ & 45.5 & $7.51 E+06$ & 55.9 & $1.72 E+06$ & 63.6 & $2.60 \mathrm{E}+05$ & 74 & $3.15 E+04$ & 81.4 & $4.83 E+03$ & 85.3 & $8.78 E+02$ \\
\hline 2.5 & 34.2 & $2.98 \mathrm{E}+07$ & 44.9 & $8.40 E+06$ & 55.4 & 1.97E+06 & 64.2 & $2.19 \mathrm{E}+05$ & 74.5 & $2.61 \mathrm{E}+04$ & 81.8 & $3.89 E+03$ & 85.6 & $7.01 E+02$ \\
\hline 3.2 & 33.7 & $3.24 \mathrm{E}+07$ & 44.3 & $9.40 \mathrm{E}+06$ & 54.8 & $2.26 \mathrm{E}+06$ & 70.7 & $1.58 \mathrm{E}+05$ & 75.3 & $2.14 \mathrm{E}+04$ & 82.4 & $3.17 \mathrm{E}+03$ & 86.1 & $5.64 \mathrm{E}+02$ \\
\hline 4.0 & 33.3 & $3.50 \mathrm{E}+07$ & 43.8 & 1.04E+07 & 54.2 & $2.58 E+06$ & 66.1 & 1.44E+05 & 75.9 & 1.78E+04 & 83 & $2.55 E+03$ & 85.8 & $4.56 E+02$ \\
\hline 5.1 & 32.8 & $3.80 \mathrm{E}+07$ & 43.3 & 1.16E+07 & 53.7 & $2.97 E+06$ & 66.5 & $1.21 \mathrm{E}+05$ & 76.8 & $1.48 \mathrm{E}+04$ & 83.7 & $2.07 E+03$ & 86.5 & $3.70 E+02$ \\
\hline 6.4 & 32.5 & $4.09 E+07$ & 42.8 & $1.29 \mathrm{E}+07$ & 53.2 & $3.37 E+06$ & 68 & 1.03E+05 & 77.6 & 1.19E+04 & 84.3 & $1.66 \mathrm{E}+03$ & 86.1 & $2.97 \mathrm{E}+02$ \\
\hline 8.1 & 32.2 & $4.41 E+07$ & 42.5 & 1.42E+07 & 52.8 & $3.83 E+06$ & 68.5 & 8.64E+04 & 78.1 & $9.78 \mathrm{E}+03$ & 84.2 & $1.35 \mathrm{E}+03$ & 87 & $2.37 E+02$ \\
\hline 10.0 & 32.1 & $4.69 \mathrm{E}+07$ & 42.3 & $1.55 \mathrm{E}+07$ & 52.5 & $4.28 E+06$ & 69.5 & $7.38 \mathrm{E}+04$ & 79.1 & 8.07E+03 & 85 & 1.07E+03 & 86.7 & $1.92 E+02$ \\
\hline
\end{tabular}


Site 2 I-65 Loop near Indianapolis

\begin{tabular}{|c|c|c|c|c|c|c|c|c|c|c|c|c|c|c|}
\hline & \multicolumn{2}{|r|}{$15^{\circ} \mathrm{C}$} & \multicolumn{2}{|c|}{$25^{\circ} \mathrm{C}$} & \multicolumn{2}{|c|}{$35^{\circ} \mathrm{C}$} & \multicolumn{2}{|c|}{$40^{\circ} \mathrm{C}$} & \multicolumn{2}{|r|}{$52^{\circ} \mathrm{C}$} & \multicolumn{2}{|r|}{$64^{\circ} \mathrm{C}$} & \multicolumn{2}{|c|}{$76^{\circ} \mathrm{C}$} \\
\hline Freq. $\mathrm{Hz}$ & $\delta^{\circ}$ & $\left|\mathrm{G}^{\star}\right|, \mathrm{Pa}$ & $\delta^{\circ}$ & $\left|\mathrm{G}^{\star}\right|, \mathrm{Pa}$ & $\delta^{\circ}$ & $\left|\mathrm{G}^{*}\right|, \mathrm{Pa}$ & $\delta^{\circ}$ & $\left|\mathrm{G}^{\star}\right|, \mathrm{Pa}$ & $\delta^{\circ}$ & $\left|\mathrm{G}^{\star}\right|, \mathrm{Pa}$ & $\delta^{\circ}$ & $\left|G^{*}\right|, \mathrm{Pa}$ & $\delta^{\circ}$ & $\left|G^{\star}\right|, \mathrm{Pa}$ \\
\hline 0.1 & 52.1 & $5.47 E+06$ & 65.7 & $8.27 E+05$ & 75.5 & $1.10 \mathrm{E}+05$ & 54.5 & $1.43 \mathrm{E}+06$ & 73.8 & $2.57 E+05$ & 82 & 43663 & 85.6 & 9211.4 \\
\hline 0.1 & 50.8 & $6.29 \mathrm{E}+06$ & 64.7 & $9.81 \mathrm{E}+05$ & 74.8 & $1.34 \mathrm{E}+05$ & 56.3 & $1.25 \mathrm{E}+06$ & 74.5 & $2.17 E+05$ & 82.4 & 36178 & 86 & 7558.4 \\
\hline 0.2 & 49.7 & $7.13 \mathrm{E}+06$ & 63.8 & $1.15 \mathrm{E}+06$ & 74 & $1.62 \mathrm{E}+05$ & 58.3 & $1.07 \mathrm{E}+06$ & 75.3 & $1.81 \mathrm{E}+05$ & 82.6 & 29195 & 86.3 & 6014.3 \\
\hline 0.2 & 48.7 & $8.11 E+06$ & 62.6 & $1.36 \mathrm{E}+06$ & 73.3 & $1.97 \mathrm{E}+05$ & 60.1 & $9.20 E+05$ & 75.9 & $1.49 \mathrm{E}+05$ & 83.1 & 23782 & 86.5 & 4849.2 \\
\hline 0.3 & 47.6 & $9.14 \mathrm{E}+06$ & 61.7 & $1.59 \mathrm{E}+06$ & 72.5 & $2.38 \mathrm{E}+05$ & 61.9 & $7.84 \mathrm{E}+05$ & 76.4 & $1.22 \mathrm{E}+05$ & 83.3 & 19012 & 86.8 & 3847.9 \\
\hline 0.3 & 46.5 & $1.04 \mathrm{E}+07$ & 60.8 & 1.87E+06 & 71.8 & $2.85 \mathrm{E}+05$ & 63.6 & $6.67 \mathrm{E}+05$ & 77.1 & $1.01 E+05$ & 83.5 & 15573 & 87.2 & 3102.6 \\
\hline 0.4 & 45.6 & $1.16 \mathrm{E}+07$ & 59.8 & $2.17 \mathrm{E}+06$ & 70.9 & $3.46 \mathrm{E}+05$ & 65.2 & $5.61 E+05$ & 77.8 & $8.24 \mathrm{E}+04$ & 84.3 & 12447 & 87.2 & 2455.8 \\
\hline 0.5 & 44.7 & $1.30 \mathrm{E}+07$ & 58.8 & $2.51 \mathrm{E}+06$ & 70.2 & $4.20 \mathrm{E}+05$ & 66.9 & $4.72 \mathrm{E}+05$ & 78.5 & $6.84 \mathrm{E}+04$ & 84.7 & 10094 & 87.7 & 1953.2 \\
\hline 0.6 & 43.8 & $1.46 \mathrm{E}+07$ & 57.9 & $2.91 \mathrm{E}+06$ & 69.4 & $5.03 \mathrm{E}+05$ & 67.6 & $3.94 \mathrm{E}+05$ & 79.2 & $5.54 \mathrm{E}+04$ & 84.9 & 8061.8 & 87.5 & 1568.4 \\
\hline 0.8 & 42.8 & $1.63 \mathrm{E}+07$ & 56.7 & $3.39 \mathrm{E}+06$ & 68.7 & $5.98 \mathrm{E}+05$ & 69.5 & $3.34 \mathrm{E}+05$ & 79.8 & $4.49 \mathrm{E}+04$ & 85.3 & 6513.5 & 87.7 & 1255.6 \\
\hline 1.0 & 41.9 & $1.81 \mathrm{E}+07$ & 56.1 & $3.91 E+06$ & 67.8 & $7.05 \mathrm{E}+05$ & 70.3 & $2.78 \mathrm{E}+05$ & 80.6 & $3.61 E+04$ & 85.5 & 5160.7 & 87.7 & 1008 \\
\hline 1.3 & 41 & $2.00 \mathrm{E}+07$ & 55 & $4.51 E+06$ & 67.1 & $8.40 \mathrm{E}+05$ & 71.4 & $2.30 \mathrm{E}+05$ & 81.6 & $2.92 \mathrm{E}+04$ & 86.6 & 4157.4 & 88.3 & 801.78 \\
\hline 1.6 & 40.2 & $2.22 \mathrm{E}+07$ & 54.1 & $5.20 \mathrm{E}+06$ & 66.3 & $9.89 \mathrm{E}+05$ & 72.6 & $1.79 \mathrm{E}+05$ & 82.1 & $2.34 \mathrm{E}+04$ & 85.8 & 3294.3 & 88.3 & 638.24 \\
\hline 2.0 & 39.2 & $2.45 \mathrm{E}+07$ & 53.2 & $5.93 \mathrm{E}+06$ & 65.5 & $1.18 \mathrm{E}+06$ & 73.4 & $1.51 \mathrm{E}+05$ & 82.3 & $1.84 \mathrm{E}+04$ & 86.7 & 2655.2 & 88.2 & 504.8 \\
\hline 2.5 & 38.6 & $2.70 \mathrm{E}+07$ & 52.2 & $6.77 \mathrm{E}+06$ & 64.7 & $1.39 \mathrm{E}+06$ & 74.2 & $1.31 \mathrm{E}+05$ & 82.9 & $1.51 E+04$ & 86.9 & 2111.6 & 87.6 & 402.66 \\
\hline 3.2 & 37.8 & $2.97 \mathrm{E}+07$ & 51.3 & $7.76 \mathrm{E}+06$ & 64 & $1.64 \mathrm{E}+06$ & 76 & $1.06 \mathrm{E}+05$ & 83.3 & $1.20 \mathrm{E}+04$ & 87.2 & 1696.7 & 87.7 & 322.85 \\
\hline 4.0 & 37.2 & $3.24 \mathrm{E}+07$ & 50.5 & $8.79 \mathrm{E}+06$ & 63.1 & $1.92 \mathrm{E}+06$ & 75.8 & $8.58 \mathrm{E}+04$ & 84 & $9.46 \mathrm{E}+03$ & 87.7 & 1343.8 & 89.3 & 257.37 \\
\hline 5.1 & 36.5 & $3.56 \mathrm{E}+07$ & 49.7 & $1.00 \mathrm{E}+07$ & 62.3 & $2.26 \mathrm{E}+06$ & 76.8 & $6.97 \mathrm{E}+04$ & 84.2 & $7.74 \mathrm{E}+03$ & 88.2 & 1081 & 88.4 & 202.55 \\
\hline 6.4 & 35.9 & $3.87 \mathrm{E}+07$ & 49 & $1.13 \mathrm{E}+07$ & 61.5 & $2.63 E+06$ & 77.7 & $5.83 E+04$ & 84.4 & $6.26 \mathrm{E}+03$ & 87.9 & 872.54 & 88.1 & 162.23 \\
\hline 8.1 & 35.4 & $4.23 \mathrm{E}+07$ & 48.3 & $1.28 \mathrm{E}+07$ & 60.8 & $3.06 \mathrm{E}+06$ & 79 & $4.72 \mathrm{E}+04$ & 84.9 & $5.02 \mathrm{E}+03$ & 88.2 & 693.19 & 87.3 & 129.39 \\
\hline 10.0 & 35 & $4.56 \mathrm{E}+07$ & 47.8 & $1.42 \mathrm{E}+07$ & 60.2 & $3.51 \mathrm{E}+06$ & 79.4 & $3.91 \mathrm{E}+04$ & 85.3 & $4.09 \mathrm{E}+03$ & 88.1 & 551.22 & 85.7 & 107.74 \\
\hline
\end{tabular}


Site 3 SR 421 Madison

\begin{tabular}{|c|c|c|c|c|c|c|c|c|c|c|c|c|c|c|}
\hline & \multicolumn{2}{|r|}{$15^{\circ} \mathrm{C}$} & \multicolumn{2}{|r|}{$25^{\circ} \mathrm{C}$} & \multicolumn{2}{|c|}{$35^{\circ} \mathrm{C}$} & \multicolumn{2}{|r|}{$40^{\circ} \mathrm{C}$} & \multicolumn{2}{|r|}{$52^{\circ} \mathrm{C}$} & \multicolumn{2}{|c|}{$64^{\circ} \mathrm{C}$} & \multicolumn{2}{|r|}{$76^{\circ} \mathrm{C}$} \\
\hline Freq. Hz & $\delta^{\circ}$ & $\left|G^{\star}\right|, \mathrm{Pa}$ & $\delta^{\circ}$ & $\left|G^{\star}\right|, \mathrm{Pa}$ & $\delta^{\circ}$ & $\left|G^{*}\right|, P a$ & $\delta^{\circ}$ & $\left|G^{*}\right|, \mathrm{Pa}$ & $\delta^{\circ}$ & $\left|G^{\star}\right|, \mathrm{Pa}$ & $\delta^{\circ}$ & $\left|G^{*}\right|, P a$ & $\delta^{\circ}$ & $\left|G^{*}\right|, P a$ \\
\hline 0.1 & 50.1 & $6.45 E+06$ & 60 & 1.07E+06 & 65.2 & $1.88 \mathrm{E}+05$ & 54.7 & $7.19 \mathrm{E}+05$ & 65.9 & $3.17 \mathrm{E}+05$ & 73.9 & $6.97 \mathrm{E}+04$ & 79.3 & $1.60 \mathrm{E}+04$ \\
\hline 0.1 & 3.9 & & 59.3 & & 66.5 & & 53.1 & 1.06E+06 & 66.4 & $2.75 \mathrm{E}+05$ & 74.2 & $5.90 \mathrm{E}+04$ & 79.5 & 1.33E+04 \\
\hline 0.2 & 3.3 & +06 & 8.6 & $=06$ & 65 & & 56.2 & & 67 & & 74.5 & & 79.9 & \\
\hline 0.2 & 7.5 & & 58 & +06 & 65.8 & $=05$ & 55.9 & $56 \mathrm{E}+05$ & 67.6 & $1.96 \mathrm{E}+05$ & 74.9 & $4.08 \mathrm{E}+04$ & 30.3 & +03 \\
\hline 0. & 6.7 & & 57.3 & & 64.9 & +05 & 55.2 & $8.29 \mathrm{E}+05$ & 68.2 & $1.64 \mathrm{E}+05$ & 75.3 & $3.32 \mathrm{E}+04$ & 80.8 & $E+03$ \\
\hline 0. & 5.7 & & 6.9 & & 64.1 & & 56 & $7.44 \mathrm{E}+05$ & 68.7 & $1.38 \mathrm{E}+05$ & 75.8 & $2.73 E+04$ & 81.2 & $E+03$ \\
\hline 0.4 & & & 61 & & 63.6 & & 57.5 & $6.44 \mathrm{E}+05$ & 69.3 & $1.16 \mathrm{E}+05$ & 76.3 & $5 E+04$ & 81.5 & $8 \mathrm{E}+03$ \\
\hline & 4.3 & & 5.2 & +06 & 63.6 & & 58.9 & 05 & 70 & $E+04$ & 76.8 & $3 \mathrm{E}+04$ & 82.1 & $5 \mathrm{E}+03$ \\
\hline & .5 & & 4.8 & +06 & 63.3 & & 60 & $4.74 \mathrm{E}+05$ & 70.6 & $8.07 \mathrm{E}+04$ & 77.3 & $1.53 \mathrm{E}+04$ & 82.3 & $4 \mathrm{E}+03$ \\
\hline 0.8 & 2.8 & & 54.1 & +06 & 62.7 & +05 & 61.1 & $4.05 \mathrm{E}+05$ & 71.1 & $6.74 \mathrm{E}+04$ & 77.9 & $4 \mathrm{E}+04$ & 82.8 & $\mathrm{E}+03$ \\
\hline 1.0 & .9 & & 3.3 & +06 & 62.1 & & 62.2 & $E+05$ & 71.8 & $5.62 \mathrm{E}+04$ & 78.6 & $2 \mathrm{E}+04$ & 83.2 & $7 \mathrm{E}+03$ \\
\hline 1.3 & .2 & -07 & 52.6 & & 61.6 & & 63.2 & $E+05$ & 72.4 & $4.67 E+04$ & 79.1 & $9 \mathrm{E}+03$ & 83.8 & $1.58 \mathrm{E}+03$ \\
\hline 1.6 & .4 & & & & & & 64.1 & $2.50 \mathrm{E}+05$ & 73 & $3.87 \mathrm{E}+04$ & 79.6 & $5 \mathrm{E}+03$ & 84.6 & $1.27 \mathrm{E}+03$ \\
\hline & .6 & & & & & & 65.1 & $2.11 \mathrm{E}+05$ & 73.6 & $3.21 E+04$ & 80.3 & $5.44 \mathrm{E}+03$ & 84.3 & $1.02 \mathrm{E}+03$ \\
\hline 2.5 & & & 50.5 & +06 & 60.1 & +06 & 65.3 & $1.79 \mathrm{E}+05$ & 74.3 & $2.66 \mathrm{E}+04$ & 80.8 & $4.48 \mathrm{E}+03$ & 85.4 & $8.28 \mathrm{E}+02$ \\
\hline 3.2 & 3.3 & & 49.8 & $89 \mathrm{E}+06$ & 59.5 & $3 \mathrm{E}+06$ & 66.2 & $1.50 \mathrm{E}+05$ & 75 & $2.20 \mathrm{E}+04$ & 81.4 & $3.62 \mathrm{E}+03$ & 85.9 & $6.55 \mathrm{E}+02$ \\
\hline 4.0 & 7.6 & +07 & 49.2 & $.00 \mathrm{E}+07$ & 59.1 & $E+06$ & 66.5 & $1.27 \mathrm{E}+05$ & 75.5 & $1.83 \mathrm{E}+04$ & 82 & $2.96 \mathrm{E}+03$ & 85.6 & $5.28 \mathrm{E}+02$ \\
\hline 5.1 & .1 & +07 & 48.6 & $E+07$ & 58.6 & +06 & 68.2 & 1.07E+05 & 76.1 & $1.52 E+04$ & 82.8 & $2.42 \mathrm{E}+03$ & 86.1 & $4.25 E+02$ \\
\hline 6.4 & .6 & & & $1.28 \mathrm{E}+07$ & 58.2 & & 69.1 & $9.08 \mathrm{E}+04$ & 77 & $1.25 \mathrm{E}+04$ & 83.3 & $1.94 \mathrm{E}+03$ & 86 & $3.38 E+02$ \\
\hline & 36.1 & & & $1.44 \mathrm{E}+07$ & 57.6 & & 70 & $7.56 \mathrm{E}+04$ & 77.3 & $1.02 \mathrm{E}+04$ & 83.5 & $1.56 \mathrm{E}+03$ & 85.8 & $2.68 \mathrm{E}+02$ \\
\hline 10.0 & 35.8 & $5.25 \mathrm{E}+07$ & 47.2 & $1.60 \mathrm{E}+07$ & 57.3 & $4.27 \mathrm{E}+06$ & 70 & $6.27 \mathrm{E}+04$ & 78.4 & $8.33 E+03$ & 84 & $1.25 \mathrm{E}+03$ & 85.4 & $2.18 \mathrm{E}+02$ \\
\hline
\end{tabular}




\section{APPENDIX F DIRECT TENSION TEST (DTT) RESULTS}

\section{SITE 1: Temperatures $-12 \mathrm{C}$ and $-18 \mathrm{C}$}

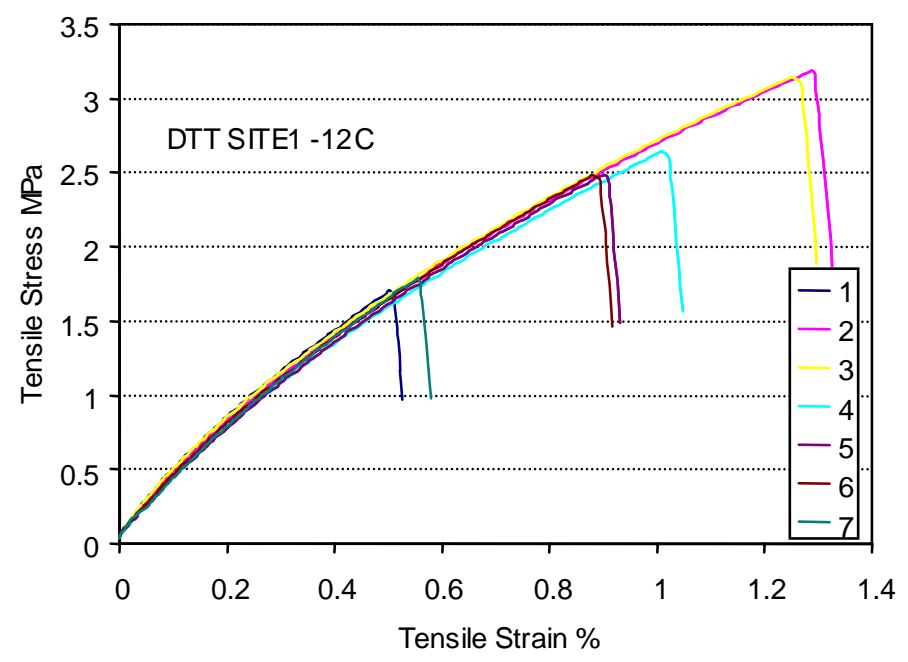

\begin{tabular}{|c|c|c|}
\hline \multicolumn{3}{|c|}{ SITE 1 I-65 North } \\
\hline $\begin{array}{c}\text { ID at } \\
\text { Temp } \\
-12 C\end{array}$ & $\begin{array}{c}\text { Failure } \\
\text { Stress } \\
\mathrm{MPa}\end{array}$ & $\begin{array}{c}\text { Failure } \\
\text { strain } \%\end{array}$ \\
\hline 1 & 1.703294 & 0.502797 \\
\hline 2 & 3.187621 & 1.287613 \\
\hline 3 & 3.147023 & 1.252174 \\
\hline 4 & 2.645618 & 1.010377 \\
\hline 5 & 2.490269 & 0.901994 \\
\hline 6 & 2.490352 & 0.881179 \\
\hline 7 & 1.79721 & 0.555919 \\
\hline Mean & 2.494484 & 0.913151 \\
\hline
\end{tabular}

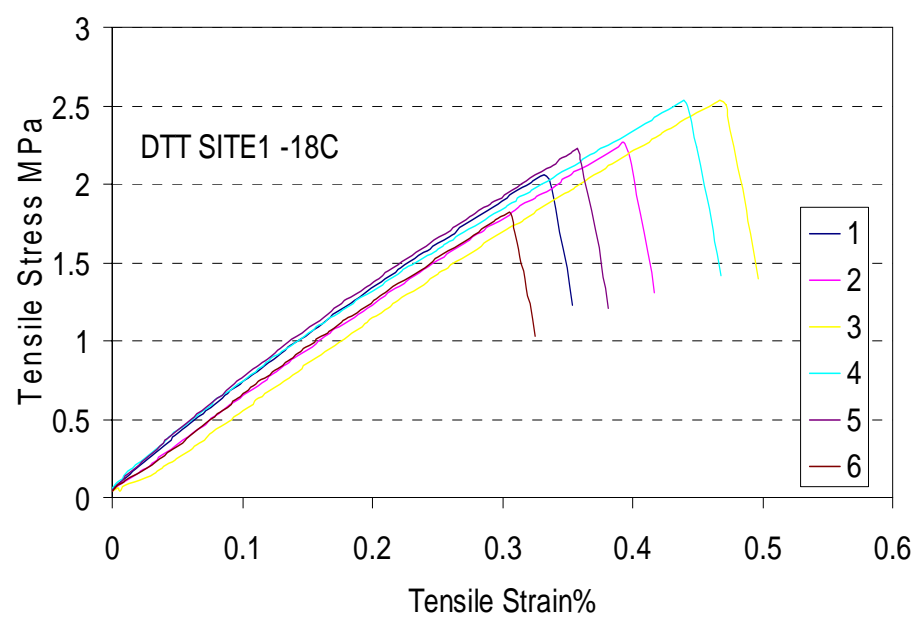

\begin{tabular}{|c|c|c|}
\hline \multicolumn{3}{|c|}{ SITE 1 1 -65 North } \\
\hline $\begin{array}{c}\text { ID at } \\
\text { Temp } \\
-18 C\end{array}$ & $\begin{array}{c}\text { Failure } \\
\text { Stress } \\
\mathrm{MPa}\end{array}$ & $\begin{array}{l}\text { Failure } \\
\text { strain\% }\end{array}$ \\
\hline 1 & 2.059681 & 0.33165 \\
\hline 2 & 2.262697 & 0.393433 \\
\hline 3 & 2.537155 & 0.466703 \\
\hline 4 & 2.533204 & 0.439791 \\
\hline 5 & 2.225107 & 0.357509 \\
\hline 6 & 1.822014 & 0.305531 \\
\hline Mean & 2.239976 & 0.382436 \\
\hline
\end{tabular}


SITE 2 Temperatures -6C, $-12 \mathrm{C},-18 \mathrm{C}$

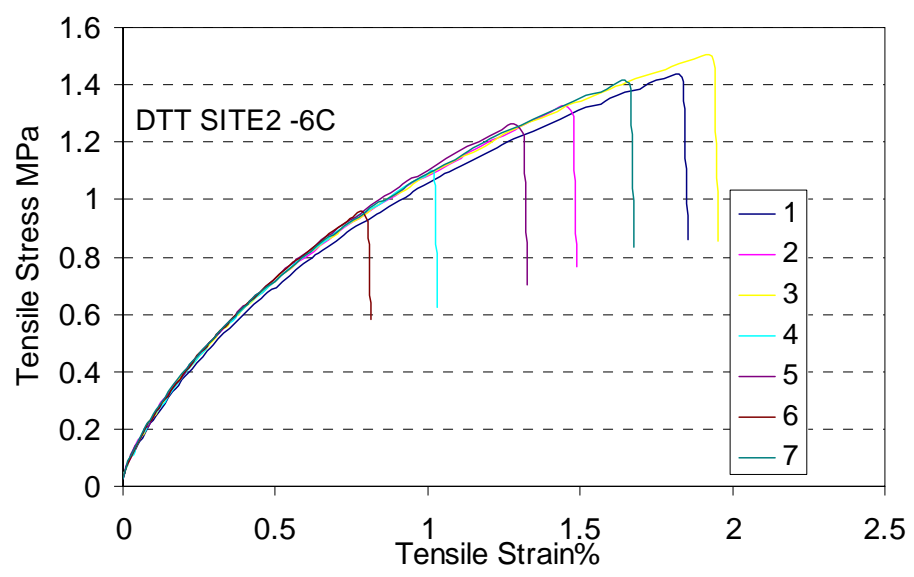

\begin{tabular}{|c|c|c|}
\hline \multicolumn{3}{|c|}{ SITE2 1-65 Near Indianapolis } \\
\hline $\begin{array}{c}\text { ID at } \\
\text { Temp } \\
-6 \mathrm{C}\end{array}$ & $\begin{array}{c}\text { Failure } \\
\text { Stress } \\
\mathrm{MPa}\end{array}$ & $\begin{array}{c}\text { Failure } \\
\text { strain\% }\end{array}$ \\
\hline 1 & 1.435298 & 1.825386 \\
\hline 2 & 1.325078 & 1.450567 \\
\hline 3 & 1.504072 & 1.921219 \\
\hline 4 & 1.103136 & 1.017019 \\
\hline 5 & 1.263794 & 1.283285 \\
\hline 6 & 0.961639 & 0.785552 \\
\hline 7 & 1.415897 & 1.647857 \\
\hline Mean & 1.286988 & 1.418698 \\
\hline
\end{tabular}

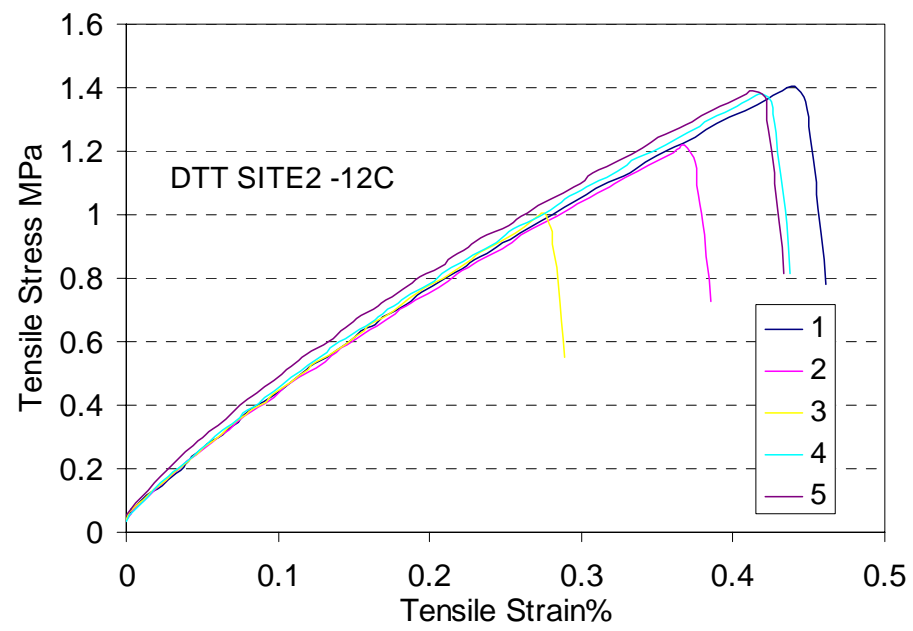

\begin{tabular}{|c|c|c|}
\hline \multicolumn{3}{|c|}{ SITE 2 I-65 Near Indianapolis } \\
\hline $\begin{array}{c}\text { ID at } \\
\text { Temp } \\
-12 C\end{array}$ & $\begin{array}{c}\text { Failure } \\
\text { Stress } \\
\mathrm{MPa}\end{array}$ & $\begin{array}{c}\text { Failure } \\
\text { strain \% }\end{array}$ \\
\hline 1 & 1.407077 & 0.440505 \\
\hline 2 & 1.217456 & 0.368083 \\
\hline 3 & 1.003811 & 0.275518 \\
\hline 4 & 1.382099 & 0.419399 \\
\hline 5 & 1.39263 & 0.413386 \\
\hline Mean & 1.280615 & 0.383378 \\
\hline
\end{tabular}

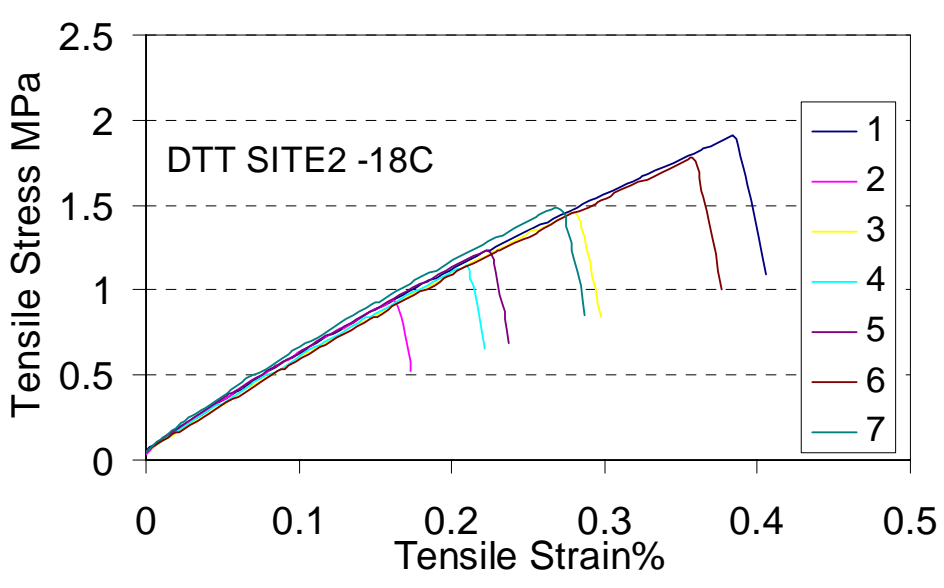

\begin{tabular}{|c|c|c|}
\hline \multicolumn{3}{|c|}{ SITE2 I-65 Near Indianapolis } \\
\hline $\begin{array}{c}\text { ID at } \\
\text { Temp } \\
-18 C\end{array}$ & $\begin{array}{c}\text { Failure } \\
\text { Stress } \\
\text { MPa }\end{array}$ & $\begin{array}{c}\text { Failure } \\
\text { strain \% }\end{array}$ \\
\hline 1 & 1.910702 & 0.384306 \\
\hline 2 & 0.94328 & 0.162486 \\
\hline 3 & 1.46094 & 0.280168 \\
\hline 4 & 1.150818 & 0.209945 \\
\hline 5 & 1.236903 & 0.222403 \\
\hline 6 & 1.776509 & 0.357244 \\
\hline 7 & 1.489895 & 0.268611 \\
\hline Mean & 1.42415 & 0.269309 \\
\hline
\end{tabular}


SITE 3 Temperatures -6C, $-12 \mathrm{C}$

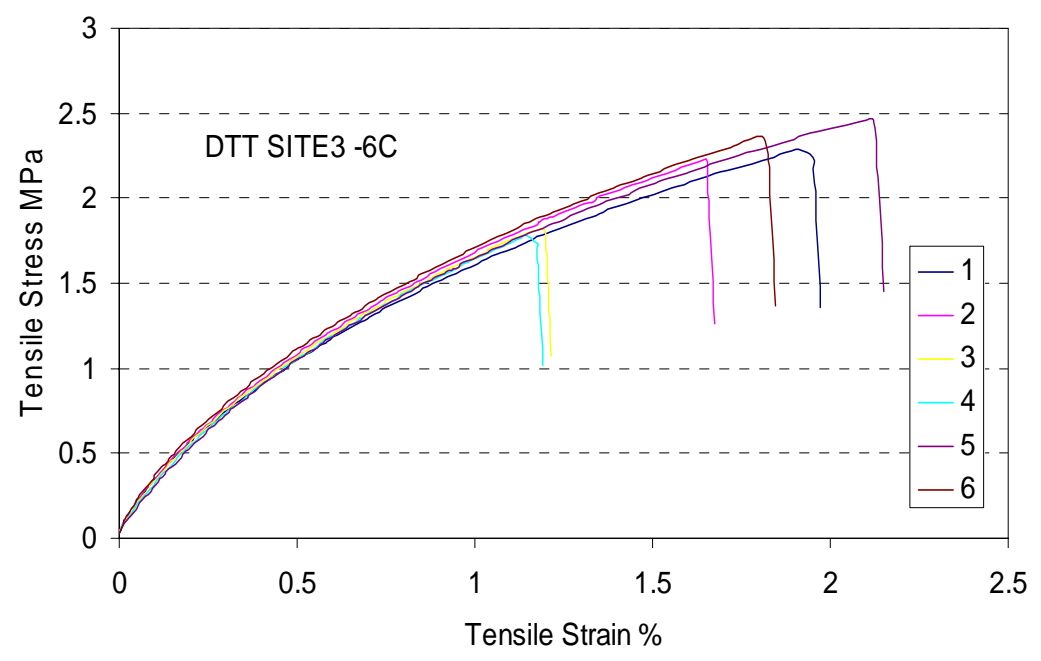

\begin{tabular}{|c|c|c|}
\hline \multicolumn{3}{|c|}{ SITE 3 US 421 Madison } \\
\hline $\begin{array}{c}\text { ID at } \\
\text { Temp } \\
-6 \mathrm{C}\end{array}$ & $\begin{array}{c}\text { Failure } \\
\text { Stress } \\
\mathrm{MPa}\end{array}$ & $\begin{array}{c}\text { Failure } \\
\text { strain \% }\end{array}$ \\
\hline 1 & 2.285131 & 1.910515 \\
\hline 2 & 2.229543 & 1.649013 \\
\hline 3 & 1.825678 & 1.185909 \\
\hline 4 & 1.781526 & 1.143525 \\
\hline 5 & 2.470648 & 2.116252 \\
\hline 6 & 2.361202 & 1.807163 \\
\hline Mean & 2.158955 & 1.635396 \\
\hline
\end{tabular}

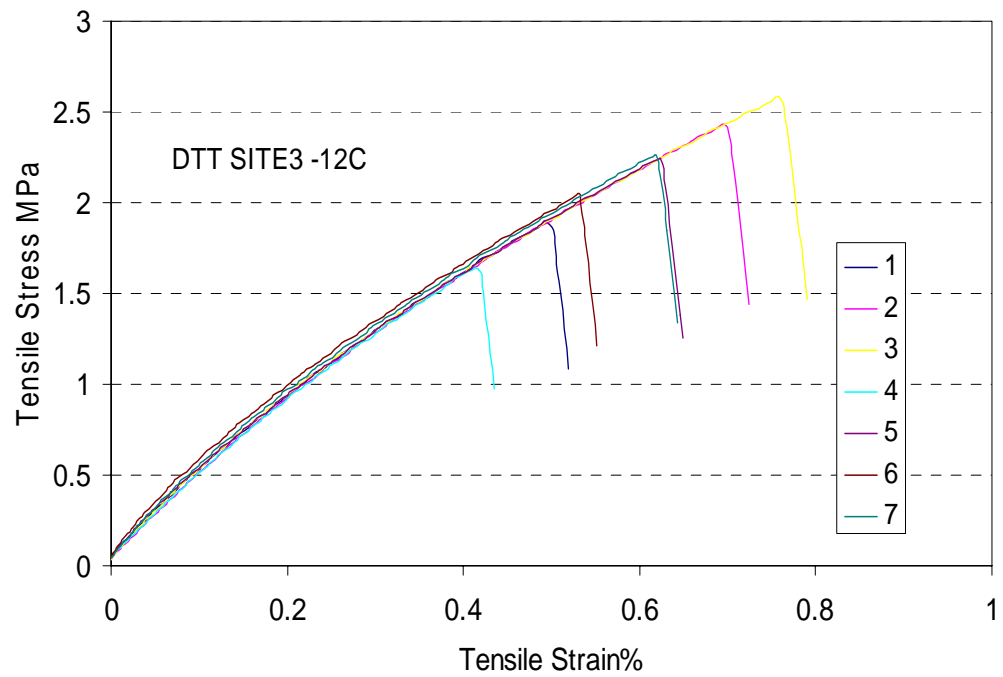

\begin{tabular}{|c|c|c|}
\hline \multicolumn{3}{|c|}{ SITE 3 US421 Madison } \\
\hline $\begin{array}{c}\text { ID at } \\
\text { Temp } \\
-12 \text { C }\end{array}$ & $\begin{array}{c}\text { Failure } \\
\text { Stress } \\
\text { MPa }\end{array}$ & $\begin{array}{c}\text { Failure } \\
\text { strain \% }\end{array}$ \\
\hline 1 & 1.895401 & 0.492446 \\
\hline 2 & 2.431826 & 0.696413 \\
\hline 3 & 2.581209 & 0.756 \\
\hline 4 & 1.643681 & 0.413199 \\
\hline 5 & 2.248731 & 0.622951 \\
\hline 6 & 2.049198 & 0.531916 \\
\hline 7 & 2.266441 & 0.618468 \\
\hline Mean & 2.159498 & 0.590199 \\
\hline
\end{tabular}




\section{APPENDIX G SST SHEAR FREQUENCY SWEEP TEST RESULTS}

SITE 1: I-65 North of Lafayette

\begin{tabular}{|c|c|c|c|c|c|c|c|c|c|c|}
\hline & \multicolumn{2}{|c|}{$4^{\circ} \mathrm{C}$} & \multicolumn{2}{c|}{$10^{\circ} \mathrm{C}$} & \multicolumn{2}{c|}{$20^{\circ} \mathrm{C}$} & \multicolumn{2}{|c|}{$40^{\circ} \mathrm{C}$} & \multicolumn{2}{|c|}{$55^{\circ} \mathrm{C}$} \\
\hline Freq. $\mathrm{Hz}$ & $\delta^{\circ}$ & $\left|\mathrm{G}^{\star}\right|, \mathrm{psi}$ & $\delta^{\circ}$ & $\left|\mathrm{G}^{\star}\right|, \mathrm{psi}$ & $\delta^{\circ}$ & $\mid \mathrm{G}^{*}, \mathrm{psi}$ & $\delta^{\circ}$ & $\left|\mathrm{G}^{\star}\right|, \mathrm{psi}$ & $\delta^{\circ}$ & $\left|\mathrm{G}^{\star}\right|, \mathrm{psi}$ \\
\hline 10.0 & 10.48 & 724,741 & 13.25 & 595,315 & 16.74 & 407,709 & 40.50 & 107,257 & 56.48 & 22,796 \\
\hline 5.0 & 8.44 & 672,737 & 10.40 & 584,442 & 16.64 & 359,649 & 41.38 & 80,366 & 56.17 & 15,674 \\
\hline 2.0 & 7.83 & 628,966 & 10.13 & 533,659 & 17.98 & 307,964 & 43.77 & 53,696 & 52.39 & 9,600 \\
\hline 1.0 & 8.18 & 593,639 & 10.97 & 497,431 & 19.11 & 270,712 & 45.45 & 38,466 & 50.39 & 6,818 \\
\hline 0.5 & 9.00 & 559,966 & 12.31 & 454,695 & 20.92 & 233,436 & 46.69 & 27,402 & 44.81 & 4,910 \\
\hline 0.2 & 9.86 & 506,277 & 13.88 & 399,016 & 24.20 & 188,688 & 47.25 & 17,193 & 42.05 & 3,718 \\
\hline 0.1 & 11.36 & 467,858 & 15.30 & 358,439 & 25.94 & 157,593 & 46.21 & 12,560 & 37.67 & 2,896 \\
\hline 0.1 & 12.79 & 430,027 & 17.65 & 318,891 & 28.44 & 129,586 & 45.30 & 8,673 & 32.07 & 2,203 \\
\hline 0.0 & 14.53 & 375,715 & 19.79 & 267,113 & 32.19 & 97,115 & 42.26 & 5,577 & 20.70 & 2,274 \\
\hline 0.0 & 15.85 & 340,502 & 22.57 & 230,749 & 35.58 & 74,691 & 40.06 & 4,384 & 33.28 & 1,799 \\
\hline
\end{tabular}

Site 2 I-65 Loop near Indianapolis

\begin{tabular}{|c|c|c|c|c|c|c|c|c|c|c|}
\hline & \multicolumn{2}{|c|}{$4^{\circ} \mathrm{C}$} & \multicolumn{2}{c|}{$10^{\circ} \mathrm{C}$} & \multicolumn{2}{c|}{$20^{\circ} \mathrm{C}$} & \multicolumn{2}{c|}{$40^{\circ} \mathrm{C}$} & \multicolumn{3}{|c|}{$55^{\circ} \mathrm{C}$} \\
\hline Freq. $\mathrm{Hz}$ & $\delta^{\circ}$ & $\left|\mathrm{G}^{\star}\right|, \mathrm{psi}$ & $\delta^{\circ}$ & $\left|\mathrm{G}^{\star}\right|, \mathrm{psi}$ & $\delta^{\circ}$ & $\left|\mathrm{G}^{\star}\right|, \mathrm{psi}$ & $\delta^{\circ}$ & $\mid \mathrm{G}^{\star}, \mathrm{psi}$ & $\delta^{\circ}$ & $\left|\mathrm{G}^{\star}\right|, \mathrm{psi}$ \\
\hline 10.0 & 14.59 & 435,557 & 13.20 & 565,666 & 16.78 & 417,768 & 36.47 & 128,729 & 53.50 & 29,214 \\
\hline 5.0 & 13.03 & 397,557 & 11.38 & 500,808 & 16.17 & 364,422 & 37.06 & 101,815 & 53.20 & 21,302 \\
\hline 2.0 & 13.94 & 365,362 & 10.45 & 466,784 & 16.91 & 315,189 & 39.73 & 72,612 & 51.12 & 13,682 \\
\hline 1.0 & 13.42 & 340,389 & 10.96 & 434,096 & 18.58 & 275,303 & 41.46 & 54,848 & 46.99 & 9,885 \\
\hline 0.5 & 13.03 & 318,603 & 11.83 & 405,033 & 20.04 & 240,363 & 41.87 & 40,489 & 43.66 & 7,438 \\
\hline 0.2 & 13.51 & 291,933 & 13.46 & 356,753 & 22.80 & 196,178 & 41.63 & 27,662 & 38.82 & 5,377 \\
\hline 0.1 & 13.89 & 273,537 & 14.83 & 320,474 & 24.94 & 164,752 & 40.65 & 20,493 & 26.31 & 3,711 \\
\hline 0.1 & 15.28 & 254,097 & 16.66 & 286,045 & 26.59 & 136,356 & 37.97 & 16,171 & 27.70 & 3,717 \\
\hline 0.0 & 16.31 & 234,206 & 19.55 & 239,716 & 31.26 & 102,306 & 37.34 & 10,810 & 29.13 & 3,325 \\
\hline 0.0 & 17.93 & 220,674 & 22.26 & 203,255 & 33.84 & 78,877 & 35.12 & 8,668 & 20.16 & 2,002 \\
\hline
\end{tabular}

Site 3 SR 421 Madison

\begin{tabular}{|c|c|c|c|c|c|c|c|c|c|c|}
\hline & \multicolumn{2}{|c|}{$4^{\circ} \mathrm{C}$} & \multicolumn{2}{c|}{$10^{\circ} \mathrm{C}$} & \multicolumn{2}{c|}{$20^{\circ} \mathrm{C}$} & \multicolumn{2}{c|}{$40^{\circ} \mathrm{C}$} & \multicolumn{2}{c|}{$55^{\circ} \mathrm{C}$} \\
\hline Freq. $\mathrm{Hz}$ & $\delta^{\circ}$ & $\left|\mathrm{G}^{*}\right|, \mathrm{psi}$ & $\delta^{\circ}$ & $\left|\mathrm{G}^{*}\right|, \mathrm{psi}$ & $\delta^{\circ}$ & $\left|\mathrm{G}^{*}\right|, \mathrm{psi}$ & $\delta^{\circ}$ & $\left|\mathrm{G}^{*}\right|, \mathrm{psi}$ & $\delta^{\circ}$ & $\left|\mathrm{G}^{\star}\right|, \mathrm{psi}$ \\
\hline 10.0 & 16.37 & 689,877 & & & 18.22 & 410,118 & 39.73 & 117,006 & 61.55 & 17,031 \\
\hline 5.0 & 13.43 & 626,917 & & 17.10 & 365,835 & 41.68 & 91,748 & 59.52 & 12,158 \\
\hline 2.0 & 11.74 & 575,704 & & & 17.84 & 312,822 & 45.38 & 64,468 & 60.49 & 7,377 \\
\hline 1.0 & 11.45 & 543,231 & & & 19.73 & 274,874 & 48.92 & 46,224 & 57.05 & 5,091 \\
\hline 0.5 & 11.93 & 509,581 & & 21.87 & 242,152 & 51.67 & 32,515 & 57.79 & 3,460 \\
\hline 0.2 & 13.41 & 463,449 & & & 25.29 & 197,403 & 51.97 & 21,051 & 55.95 & 2,374 \\
\hline 0.1 & 14.67 & 425,805 & & 28.01 & 165,699 & 51.53 & 15,140 & 47.26 & 1,550 \\
\hline 0.1 & 16.58 & 385,473 & & 31.48 & 136,119 & 51.12 & 10,786 & 45.28 & 1,176 \\
\hline 0.0 & 18.79 & 333,039 & & & 36.23 & 101,518 & 50.91 & 7,106 & 41.37 & 1,217 \\
\hline 0.0 & 20.86 & 291,964 & & & 39.85 & 77,924 & 47.41 & 4,899 & 41.66 & 903 \\
\hline
\end{tabular}

